
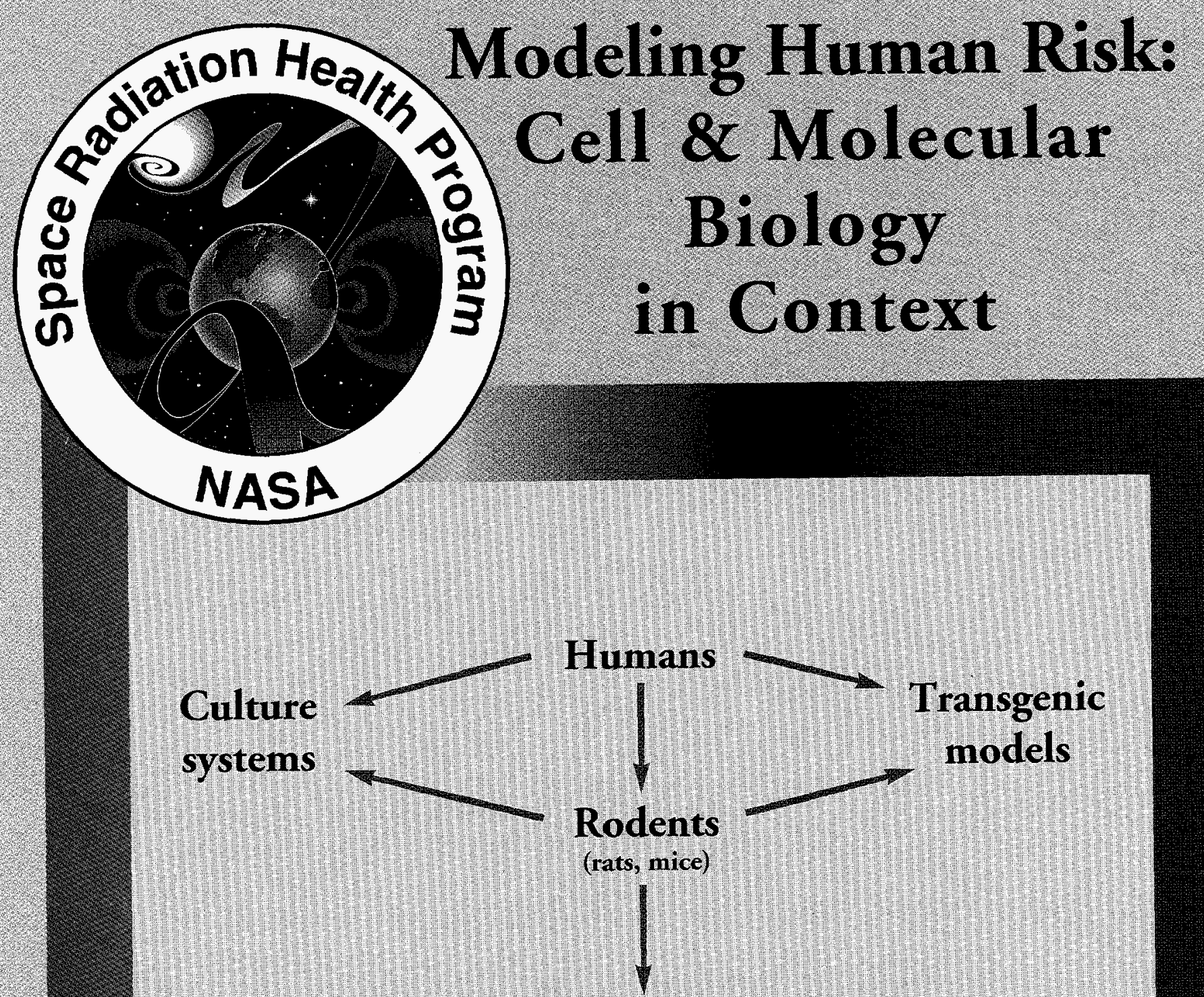

Invertebrates

(nematodes, insects)

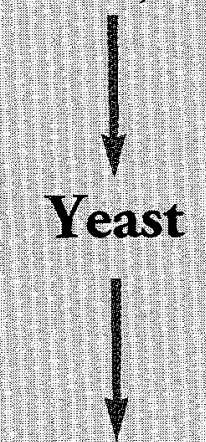

Bacteria

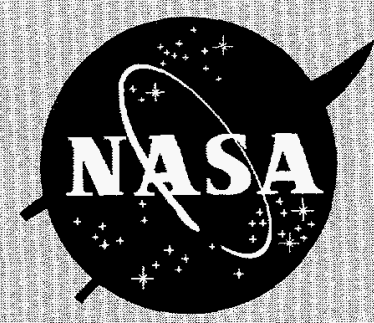




\section{DISCLAIMER}

This document was prepared as an account of work sponsored by the United States Government. While this document is believed to contain correct information, neither the United States Government nor any agency thereof, nor The Regents of the University of California, nor any of their employees, makes any warranty, express or implied, or assumes any legal responsibility for the accuracy, completeness, or usefulness of any information, apparatus, product, or process disclosed, or represents that its use would not infringe privately owned rights. Reference herein to any specific commercial product, process, or service by its trade name, trademark, manufacturer, or otherwise, does not necessarily constitute or imply its endorsement, recommendation, or favoring by the United States Government or any agency thereof, or The Regents of the University of California. The views and opinions of authors expressed herein do not necessarily state or reflect those of the United States Government or any agency thereof, or The Regents of the University of California.

Available to DOE and DOE Contractors

from the Office of Scientific and Technical Information

P.O. Box 62, Oak Ridge, TN 3783 I

Prices available from (615) 576-8401

Available to the public from the

National Technical Information Service

U.S. Department of Commerce

5285 Port Royal Road, Springfield, VA 22161

Ernest Orlando Lawrence Berkeley National Laboratory is an equal opportunity employer.

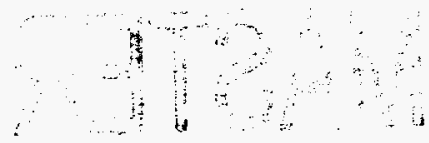




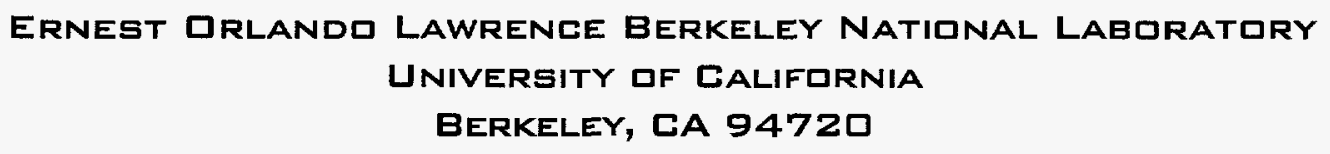

\title{
Modeling Human Risk: Cell \& Molecular Biology in Context
}

\author{
Select Panel Members
}

Mina J. Bissell, Ph.D. (Chair)

Huber R. Warner, Ph.D. (Executive Secretary)

Susan M. Berget, Ph.D.

R. J. M. Fry, M.D.

Philip C. Hanawalt, Ph.D.

Michael Kastan, M.D., Ph.D.

Arthur Kornberg, M.D.

Louise Lutze-Mann, Ph.D.

Kenneth A. Souza, M.A.

Robert Ullich, Ph.D.

Jan Vijg, Ph.D.

Aloke Chatterjee, Ph.D. (ex officio)

\author{
Berkeley Lab \\ Berkeley Lab \\ Baylor College of Medicine \\ Oak Ridge National Laboratory \\ Stanford University \\ Johns Hopkins University \\ Stanford University \\ University of California, SF \\ NASA-Ames Research Center \\ Univ. of Texas, Medical Branch \\ Beth Israel Hospital, Harvard Univ. \\ Berkeley Lab
}

Awarded to Lawrence Berkeley National Laboratory (LBNL) by the Life Sciences Division, Office of Space Sciences and Applications, National Astronautical and Space Administration (NASA)

NASA Order No. W-18,265

Report Number: LBNL-40278

June 1997 
Individuals other than Panel Members who have contributed written material or figures to this report:

Barcellos-Hoff, Mary Helen; Berkeley Lab

Callahan, Paul; NASA - Ames Research Center

Campisi, Judith; Berkeley Lab

Curtis, Stan; Fred Hutchison Cancer Research Center

Joseph, James; Tufts University

Metting, Noelle; Pacific Northwest National Laboratory

Rabin, Bernard; University of Maryland, Baltimore County

Other individuals consulted:

Blakely, Eleanor; Berkeley Lab

Brennan, Kathleen; Berkeley Lab

Budinger, Thomas; Berkeley Lab

Carney, John; University of Kentucky and Centaur Pharmaceuticals

Castro, Joseph; Berkeley Lab

Cooper, Priscilla; Berkeley Lab

Cox, Ann; USAF School of Aerospace Medicine

Garriga, Gian; University of California, Berkeley

Glickman, Barry; University of British Columbia

Goodenough, Ursula; Washington University

Kennedy, Ann; University of Pennsylvania

Kronenberg, Amy; Berkeley Lab

Nelson, Gregory; Loma Linda

Ness, Suzanne; California Biomedical Research Association

Schild, David; Berkeley Lab

Schwarz, Richard; Berkeley Lab

Terazaghi-Howe, Margaret; ORNL

The expert technical assistance of Cathy Sage, Sreela Sen, and David Gilbert at Berkeley Lab is also gratefully acknowledged. 


\section{DISCLAMMER}

Portions of this document may be illegible in electronic image products. Images are produced from the best available original document. 



\section{TABLE OF CONTENTS}

\section{STATEMENT OF WORK}

1

II. EXECUTIVE SUMMARY …………………………………………... 2

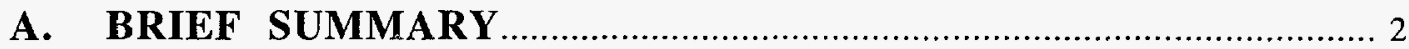

B. CONCLUSIONS DRAWN FROM EXISTING LITERATURE ........... 2

C. QUESTIONS ADDRESSED BY THE PANEL ....................................

D. SUMMARY OF PANEL RECOMMENDATIONS ...............................4

III. INTRODUCTION.

IV. BACKGROUND: RADIATION AND ITS BIOLOGICAL

DAMAGE

A. RADIATION QUALITY IN SPACE

1. NATURE OF RADIATION ENVIRONMENT IN LOW EARTH ORBIT

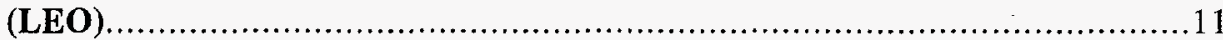

2. NATURE OF RADIATION ENVIRONMENT IN OUTER SPACE........ 11

3. SOLAR PARTICLE EVENTS ...................................................... 14

4. NUCLEAR HITS FROM GCR DURING TRAVEL IN OUTER

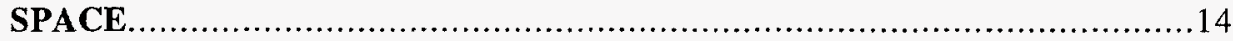

5. PHYSICAL CHARACTERIZATION: DISTINCTION BETWEEN

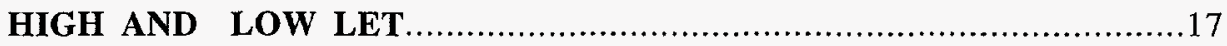

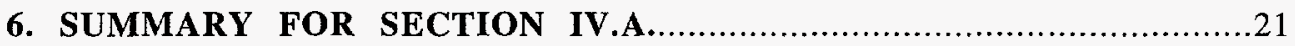

B. CELLULAR AND TISSUE RESPONSE TO RADIATION

DAMAGE

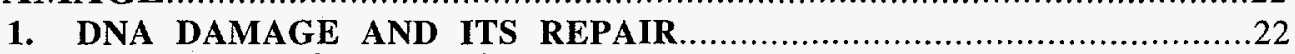

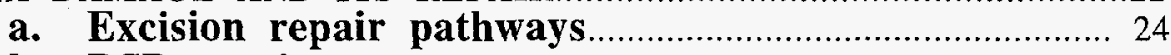

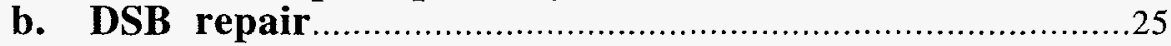

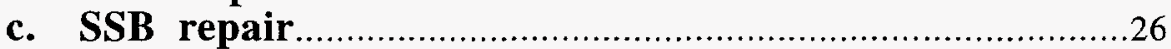

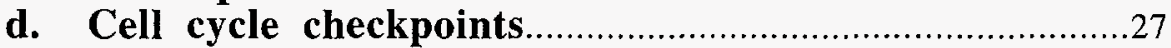

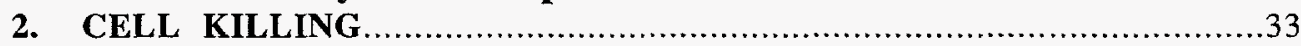

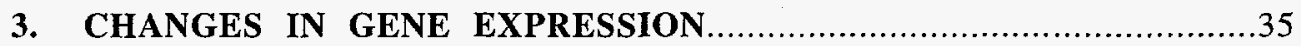

4. TISSUE DAMAGE: THE IMPORTANCE OF THE

MICROENVIRONMENT.....

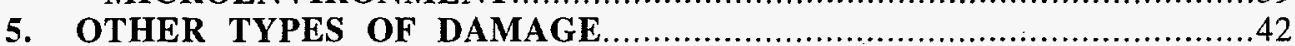

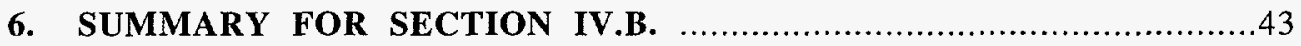

C. HEALTH EFFECTS ASSOCIATED WITH RADIATION DAMAGE44

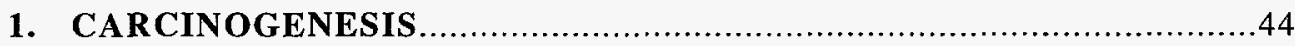

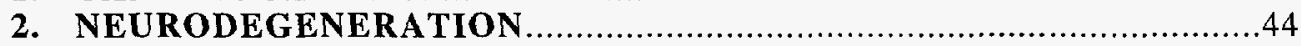

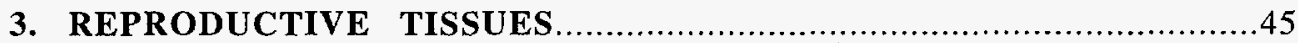

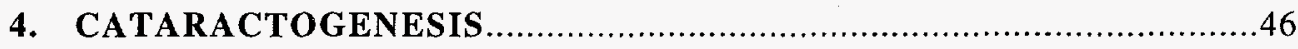

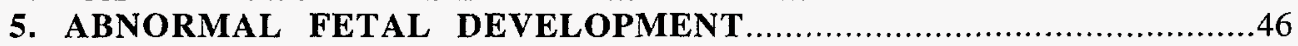

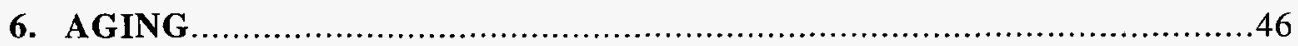

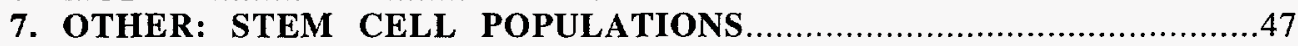

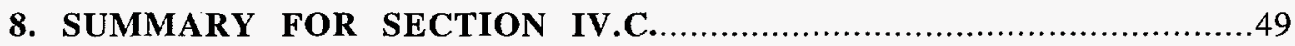

D. MODEL SYSTEMS FOR STUDYING RADIATION DAMAGE .........50

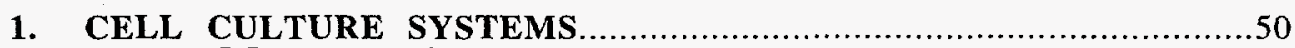

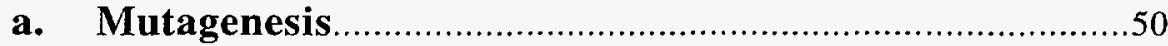

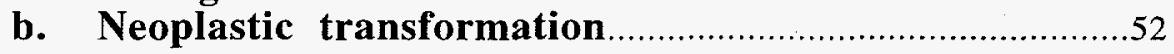




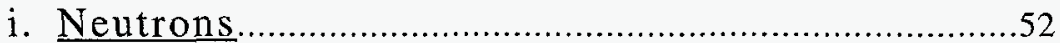

ii. Alpha particles ..........................................................52

c. Cell killing................................................................53

d. Changes in chromatin formation....................................54

e. Remodelling of the microenvironment .......................... 54

f. Single cell irradiation with helium ions ...................................57

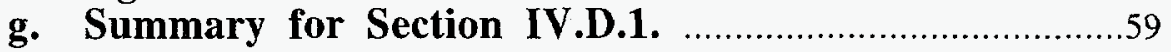

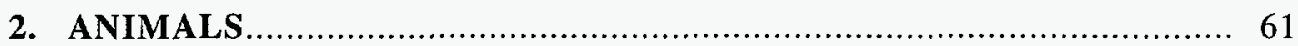

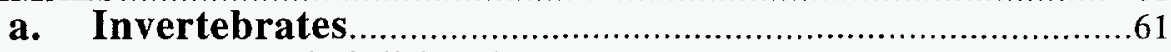

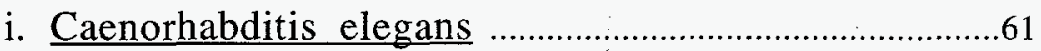

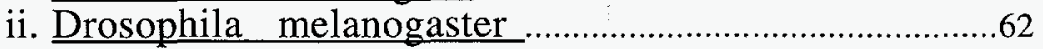

b. Rodents

i. Radiation-induced cell death in vivo...............................63

. Ceramide-induced apoptosis....................................63

. Differential sensitivity to radiation..............................63

ii. Carcinogenesis.

- Lifetime exposure of mice to low-LET radiation.

. Comparison of oncogenic potential of electron and Ar particle irradiation in rats.................64

. The Harderian gland as a model for radiation-induced carcinogenesis.............................64

. Exposure of rats to radon ........................................64

. Effect of electron radiation on oncogene expression in rodents.............................................65

. Influence of LET on carcinogenesis .......................65

iii. Neurobiological damage.

- Substantia nigra cell loss.

- Role of TGF- $\beta 1$ in radiation-induced neuronal death

Alterations in cell signalling in the substantia nigra.

. Conditioned taste aversion.......................................72

. Radiation aging parallels............................................73

. Damage to photoreceptors......................................74

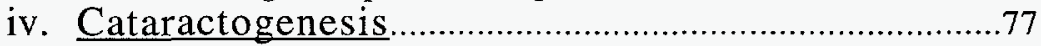

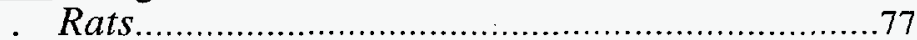

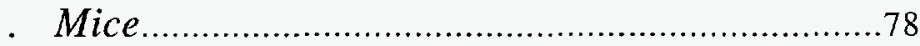

. Rabbits........................................................ 78

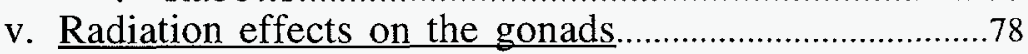

. Low-LET irradiation of male animals ..........................78

. High-LET irradiation of male animals......................79

. Irradiation of female animals ...................................79

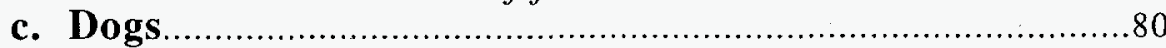

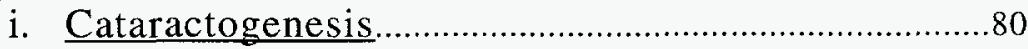

ii. Carcinogenesis induced by irradiation with $\alpha$-particles.....80

iii. Life shortening induced by continuous irradiation

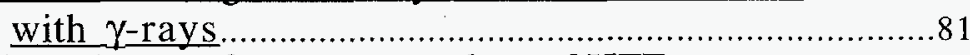

iv. CNS damage from an acute dose of HZE particles.....

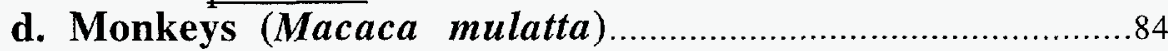




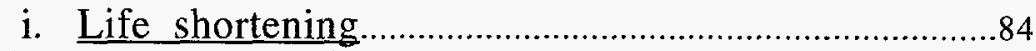

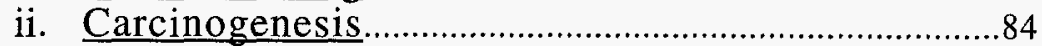

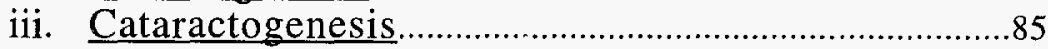

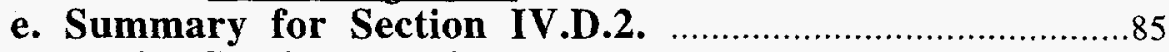

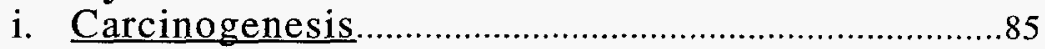

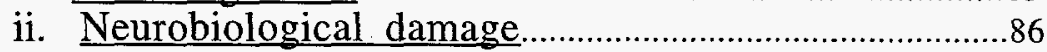

iii. Cell killing in vivo...........................................................

iv. Cataractogenesis ...............................................................

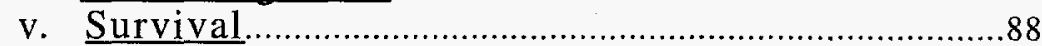

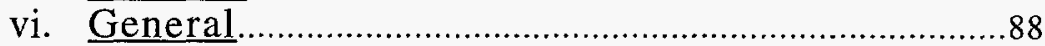

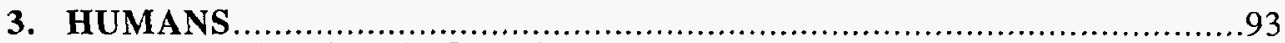

a. Radiation-induced mutagenesis .........................................93

i. Minisatellite mutations in humans induced by radiation from the Chernobyl accident ...............................93

ii. Chromosome aberrations in Chernobyl clean-up workers ..................................................................93

iii. HPRT mutations in Russian cosmonauts...........................93

b. Radiation-induced Cancer …………………………..............94

i. Survivors of atomic bomb blasts in Japan in

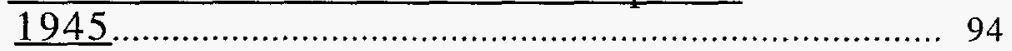

ii. Leukemia after in utero exposure to radiation from Chernobyl.

iii. Thyroid cancers in children living near Chernobyl......

iv. Radon-induced cancer.......................................................101

v. Cancer therapy and induction of second tumors ...............101

c. Human genetic syndromes with increased radiation sensitivity....

d. Neurobiological damage.......................................................103

e. Radiation-induced damage to the gonads....................... 103

f. Cataractogenesis................................................................ 107

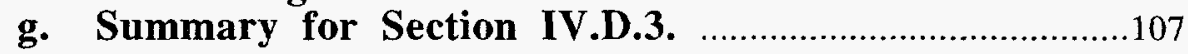

V. CRITICAL MARKERS OF PHYSIOLOGICAL RESPONSE

TO RADIATION-INDUCED DAMAGE ....................................109

A. GENERAL CRITERIA RELATED TO TUMOR INCIDENCE ..........109

1. MUTAGENESIS FREQUENCY ………………................................109

a. General: Using transgenic mouse models for mutation detection.

b. Specific genes....................................................................110

2. GENOMIC INSTABILITY .............................................................111

a. Detection of cytogenetic aberrations using chromosome painting.

b. Unstable sequences..................................................................112

i. Minisatellite repeats.........................................................112

ii. Triplet repeats............................................................... 113

iii. Telomeres ....................................................................113

iv. Mitochondrial DNA deletions...........................................113

c. Detection of genomic instability by PCR ………….........114

i. Inter-locus V-J recombination........................................114

ii. Chr 14-chr 18 translocation ................................................115

3. UNREPAIRED DNA DAMAGE................................................115

4. PERCENTAGE OF CELLS IN S PHASE.....................................116

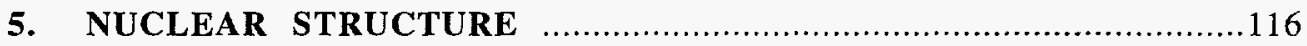

6. CHANGES IN GENE EXPRESSION............................................... 117 
a. Differential display.

b. Microarray probes for mRNA ….....................................117

c. 2-Dimensional (2-D) protein gels................................118

d. Specific proteins........................................................118

e. Green fluorescent protein...........................................119

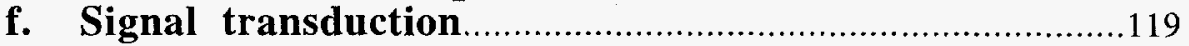

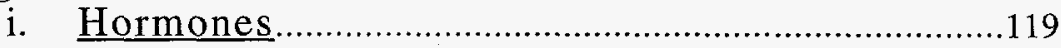

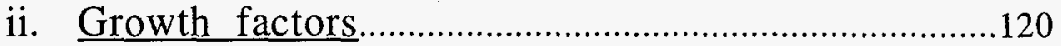

iii. Extracellular Matrix (ECM) .........................................120

g. Serial analysis of gene expression (SAGE) ...............120

7. ALTERATIONS IN ECM/TISSUE STRUCTURE........................... 120

8. CELL DEATH BY APOPTOSIS ................................................. 121

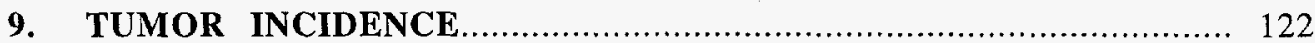

a. Mice hemizygous for tumor suppression genes............122

b. Tissue-specific tumor induction....................................122

c. Synergy between $\boldsymbol{c}-\boldsymbol{m y} \boldsymbol{c}$ and $\boldsymbol{b} \boldsymbol{c l}-\mathbf{2}$ in tumor induction 123

d. Mice deficient in DNA repair.....................................123

B. GENERAL CRITERIA RELATED TO NEUROBIOLOGICAL

DEFICITS

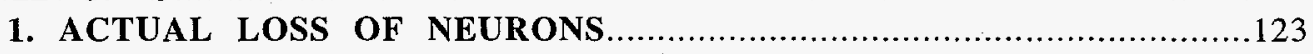

2. BRAIN IMAGING TECHNIQUES (PET, MRI, MRS) ..........................124

3. CONDITIONED TASTE AVERSION BEHAVIOR ...............................124

4. SPECIFIC ENZYME LOSS ......................................................... 125

C. OTHER LATE EFEECTS

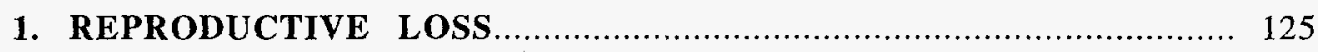

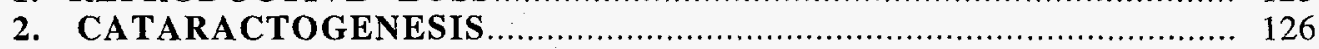

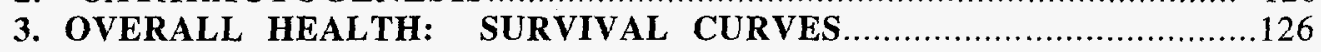

VI. CRITICAL QUESTIONS

A. CAN RESULTS WITH LOW-LET RADIATION BE

EXTRAPOLATED TO HIGH-LET RADIATION?

B. CAN EFFECTS WITH HIGH DOSES BE EXTRAPOLATED

TO LOW DOSE?

C. IS THERE SYNERGY BETWEEN RADIATION

AND MICROGRAVITY?

D. IS THERE SYNERGY BETWEEN DIFFERENT TYPES OF RADIATION?.

E. WHAT IS THE BASIS FOR TISSUE SPECIFICITY?

G. CAN ANIMAL RESULTS BE EXTRAPOLATED TO HUMANS?

VII. PANEL RECOMMENDATIONS

A. THE NECESSITY OF USING ANIMALS ……………...................145

B . OTHER RECOMMENDATIONS.

1. ETHICAL USE OF ANIMALS IN SPACE RESEARCH. 


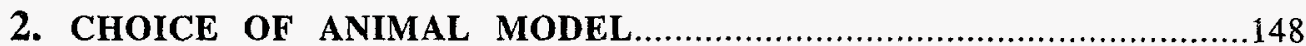

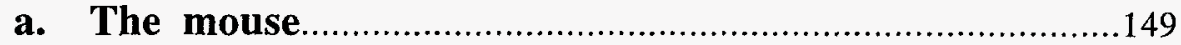

i. Selection of mouse strain...............................................150

ii. Transgenic (TG) and knockout (KO) mice .....................151 Generation of transgenic and

knockout mice

iii. Concerns about the use of transgenic and knockout mouse models.

3. OPTIMIZATION OF THE USE OF ANIMALS...............................158

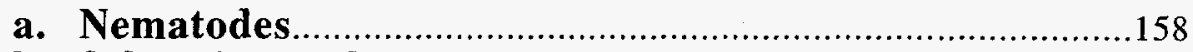

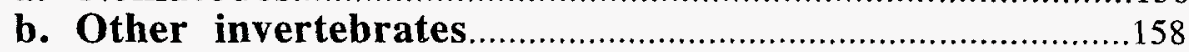

c. Interspecies comparison: relevance to human risk.........159

d. Modeling with functional culture systems.......................162

e. The need for interdisciplinary research.........................166

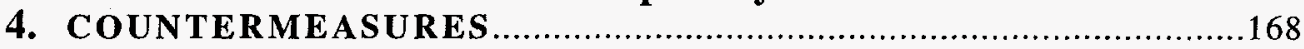

a. Radioprotectants.................................................. 168

b. Measuring inter-individual differences in susceptibility................................................................ 171

i. Gene testing......................................................... 172

ii. Phenotypic testing: DNA repair ........................................173

iii. Inter-species differences..................................................174

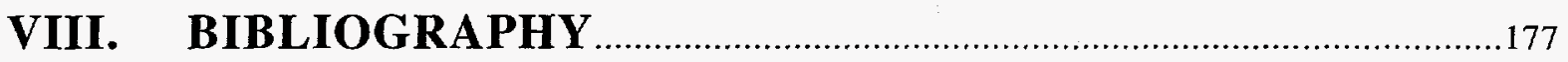

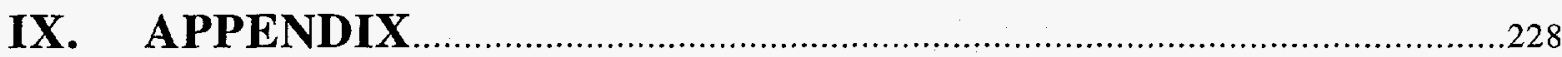

A. BIOLOGICAL TISSUES AVAILABLE FROM PREVIOUS

SPACE FLIGHTS .....................................................................230

1. BIOLOGICAL TISSUES AVAILABLE FROM SPACE-FLOWN

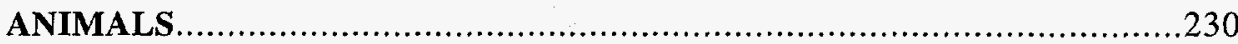

2. POTENTIAL ANIMALS FLOWN PRIOR TO A HYPOTHETICAL 2016 MANNED MARS MISSION................................................234

3. BIOLOGICAL TISSUES AVAILABLE FROM ASTRONAUTS ...........234

B. CELL SIGNALLING THROUGH G PROTEINS .............................22

C. CHEMICAL CARCINOGENICITY STUDIES IN RODENTS ...........236

D. SOURCES OF TRANSGENIC AND KNOCKOUT MICE.................239

E. USE OF RADIOPROTECTANTS TO REDUCE DAMAGE DUE

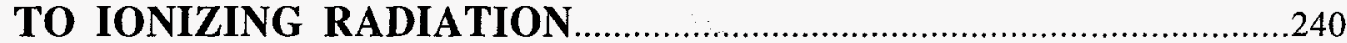

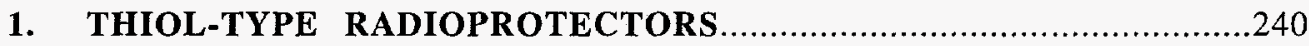

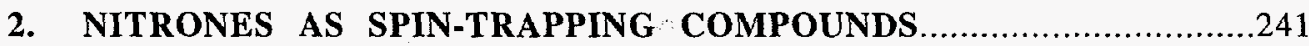

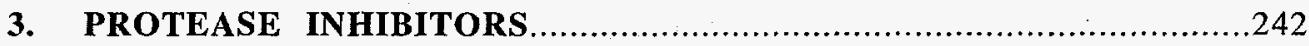

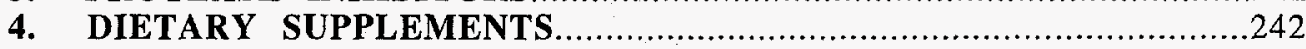

X. BIOSKETCHES OF PANEL MEMBERS ……………………..............

LIST OF TABLES 
Section IV

1

3

4

5

6

7

8

9

10

11

12

13

14

15

\section{Section V}

1

2

Section VII
Sources of radiation

Estimates of hits per cell nucleus due to GCR on a

3-year Mars mission

Radiation-induced DNA damage.

Enzymes involved in repair of radiation-induced

damage in human cells.

Human DNA repair genes implicated in sensitivity to

ionizing radiation

Examples of changes in gene expression induced by ionizing radiation

Radiation-induced changes in the microenvironment

Cancer induction in rats by electrons and Ar particles

Summary of radiation-induced neurobiological deficits in rats

Effect of dose on life span of beagles continuously

irradiated with $\gamma$-rays....

Effect of dose fractionation...

Radiation-induced effects at low doses.

Cancer in atomic bomb survivors

Human breast cancer susceptibility genes

Survival of cells of the human testis exposed to X-rays.

Summary of biological endpoints for studies in humans........127-128

Summary of biological endpoints for studies in model systems129-130

Selected examples of animal studies with relevance to understanding human biology 146

Selected examples of transgenic mouse models useful for modelling human biology.

Selected examples of gene knockout mouse models useful for modelling human pathology

Cell culture models for studying human biology

Amelioration of neurodegenerative processes by nerve growth factors..................................................... 170

Selected examples of genes mutated in a variety of human cancers 
TABLE NO.

Section IX

$1 \mathrm{a}$

$1 b$

$1 \mathrm{c}$
TABLE

PAGE

Biological tissues available from previous space flights

SLS-2 Unassigned Biospecimens...................................232

Pare.03 Unassigned Biospecimens..................................233

Potential animal specimens available from future flights.............235 


\section{LIST OF FIGURES}

FIGURE NO.

TITLE

PAGE

Section IV

1

Representative track segments of $600 \mathrm{MeV} / \mathrm{n}, \mathrm{He}, \mathrm{Ne}$, and $\mathrm{Fe}$ particles.

2

Typical damage clusters in DNA induced by low-LET and very high-LET irradiation

3

Pathways of radiation-induced DNA

damage and repair

4

Tracks of damage induced by $\alpha$-particles in

HeLa cells.

Radiation-induced loss of tyrosine hydroxylase in the substantia nigra in rats.

Section VII

1

Interspecies comparison for establishing relevance to human risk

2

A new paradigm for cancer biology

3

Model for estimating human risk from

experiments in animals and cultured cell systems.

Section IX 


\section{GLOSSARY AND ABBREVIATIONS}

\section{$\underline{\text { Radiobiological and space terms }}$}

\begin{tabular}{|c|c|}
\hline DREF & dose-rate effectiveness factor \\
\hline GCR & galactic cosmic rays \\
\hline GEO & geosynchronous earth orbit \\
\hline Gy & $\begin{array}{l}\text { gray, a measure of absorbed radiation dose; } 1 \mathrm{~Gy}=100 \mathrm{rads}= \\
1 \mathrm{~J} / \mathrm{Kg}\end{array}$ \\
\hline HZE & high charge, high energy particle \\
\hline LEO & low earth orbit \\
\hline LET & linear energy transfer \\
\hline $\mathrm{Q}$ & $\begin{array}{l}\text { quality factor; indicates the relative effectiveness of } \\
\text { radiation compared to } X \text {-rays or } \gamma \text {-rays }\end{array}$ \\
\hline RBE & $\begin{array}{l}\text { relative biological effectiveness (a dimensionless term; } \\
\text { varies as a function of radiation quality, dose, dose rate, } \\
\text { and endpoint) }\end{array}$ \\
\hline SPE & solar particle event \\
\hline Sv & $\begin{array}{l}\text { sievert, a measure of dose equivalence } \\
\mathrm{Sv}=\mathrm{Q} \times \text { Dose (in Gy) }\end{array}$ \\
\hline WL & $\begin{array}{l}\text { working level; } \mathrm{WL} \text { is the concentration of short-lived } \\
\text { radon progeny producing } 1.3 \times 10^{5} \mathrm{MeV} \text { of potential } \alpha \text { - } \\
\text { energy in } 1 \text { liter of air }\end{array}$ \\
\hline $\begin{array}{l}\text { WLM } \\
\mathrm{Z}\end{array}$ & $\begin{array}{l}\text { exposure equivalent to } 170 \mathrm{hr} \text {. at } 1 \mathrm{WL} \\
\text { atomic number/charge of an } \mathrm{HZE} \text { particle }\end{array}$ \\
\hline
\end{tabular}

\section{$\underline{\text { Non-radiobiological terms }}$}

$A T M$

$B R C A$

CNS

DSB

ECM

HPRT

MRI

NF-KB

PCR

PET

SSB

TGF ataxia telangiectasia (mutated) gene in humans

breast cancer gene ( 1 or 2 )

central nervous system

double strand breaks (in DNA)

extracellular matrix

hypoxanthine-quanine phosphoribosyl transferase gene

magnetic resonance imaging

nuclear factor - kappa B

polymerase chain reaction

positron emission tomography

single strand breaks (in DNA)

transforming growth factor 



\section{STATEMENT OF WORK}

NASA Order No. W-18,265 was awarded to the Lawrence Berkeley National Laboratory (LBNL) by the Life Sciences Division, Office of Space Sciences and Applications, National Astronautical and Space Administration (NASA) in FY1995 to "evaluate the extent to which experiments with animal models are essential for the development of new and more accurate predictions of the risks associated with exposure to HZE particles." The purpose of this evaluation is to provide the basis for a research agenda to be developed and implemented well before a mission to Mars which is currently anticipated to occur sometime between 2015 and 2020. This will be accomplished by a Select Panel, to be chaired by Mina J. Bissell, Director, Life Sciences Division, LBNL. The Panel will issue a written report by the end of 1996 . The actual statement of work follows:

\section{NSCORT (RADIATION HEALTH) SUPPLEMENTAL STATEMENT OF WORK}

(January 1, 1996 - December 31, 1996)

Animal Experimentation at the Frontiers of Molecular, Cellular and Tissue Radiobiology

A Select Panel to evaluate the extent to which experiments with animal models are essential for the development of new and more accurate predictions of risks associated with exposure to HZE particles. The Select Panel will make recommendations to the NASA Space Radiation Health Program, based on their evaluation, which will be essential for the development of research strategies and the development of countermeasures to radiation injury to humans in space. The Select Panel will evaluate the existing information on the use of animal models and will establish correlations with existing or projected data on human models. The Panel will then evaluate the need for additional experimentation including the use of human genes in transgenic models. If indeed it is determined that new animal experimentation is necessary, the panel will probe how to use the minimum number of animals for the maximum amount of information. Such information, in conjunction with existing theoretical and experimental framework of NSCORT, could lead to significant predictions at minimum cost, time and number of required animals. 


\section{EXECUTIVE SUMMARY}

\section{A. BRIEF SUMMARY}

In space missions beyond the protection of the terrestrial magnetosphere, astronauts may face unique health hazards from ionizing radiation. The level of radiation in space is significantly higher than on Earth and consists of particles, some of which cause more marked effects than $X$ or gamma rays. The radiation environment in deep space consists of galactic cosmic rays (GCR), about $85 \%$ protons, $13 \%$ helium ions and $1 \%$ heavier ions, called High- $Z$ and High-Energy (HZE) particles, and to a much lesser extent solar particle emission. Sporadic solar particle events, especially during solar maximum, nevertheless increase the level of radiation markedly and consist of $90-95 \%$ protons, $5-10 \%$ helium ions and $0.1 \%$ heavier nuclei. Shielding against the energetic heavy nuclei such as iron and very high-energy protons that produce secondary radiation as a result of interactions with the shielding and the human body is a complex problem. An understanding of the health risks associated with the effects of the radiation, in particular the HZE particles, is central for the design of optimal shielding and planning by NASA for a long-term presence of humans in space.

This report focuses on the extent to which animals are required to assess health risks to humans exposed to radiation in space.

The Panel was unanimous in recognizing that (1) our current knowledge of health effects of exposure to galactic radiation during travel in outer space is extremely inadequate, (2) neither existing in vitro and culture models nor theoretical and computational biology can substitute for in vivo studies, and (3) animal experimentation which would take advantage of the state of the art cell and molecular biology techniques is most emphatically needed. The Panel thus recommends that thoughtful animal experimentation should be pursued selectively, but decisively, as outlined in this report.

\section{B. CONCLUSIONS DRAWN FROM THE EXISTING LITERATURE}

As a first step in its deliberations, the Panel reviewed the current literature, as well as a number of reports that were relevant to the task. The Panel concluded that:

- When the level of radiation is high, it can cause certain health effects. These include cancers such as leukemia and breast cancer, and damage to organs such as the brain, the gonads and the eye. While there are considerable data on the effects of low-LET radiation such as $X$ and gamma rays, there are no adequate data on human health effects of protons, neutrons 
and, in particular, HZE particles. The Panel, therefore, paid special attention to the health effects of HZE particles.

- Cultured cells in conjunction with theoretical and computational analysis have been used extensively to characterize the changes caused by $x$ rays and gamma rays on DNA damage, mutations, chromosome aberrations and the repair pathways. The rates at which these pathways operate and their manner of regulation have not been adequately examined for HZE particles.

- The microenvironment is an extremely important factor in determining biological outcomes in response to all forms of environmental stress, including ionizing radiation. While there is much more information about radiation damage to DNA, additional data are necessary on damage to cellular proteins and extracellular matrix components. The latter is now known to have profound consequences for individual cellular responses.

- All model systems have assets and limitations. Agents such as radiation that damage cells can, in overview, be seen to have a general mechanism of action, but as the focus narrows, the exact mechanisms can be specific to the specific organism, the tissue, the cell type, the exact developmental window, etc. Model systems -- rodent cell cultures as surrogates for human cell cultures, or mice and other animals as surrogates for humans -- at best can test only some aspects of radiation damage and can give us insight into how radiation causes specific damage, but we cannot completely rule out potential intrinsic differences with humans.

- It is very difficult to generate cancerous cells of human origin in culture. Even if it were possible to transform these cells, the task of extrapolating the mechanisms of neoplasia from rodent and/or human cells to human organs in vivo remains a challenge. There are no accepted methods of doing so at present.

- $\quad$ Scientific and technological advances in molecular and cell biology in the past decade provide a rich variety of approaches which can be used to evaluate outcomes of radiation-induced damage in both humans and animals. These are summarized in Section V. As new advances are made and become available through ongoing biological research, it is important to update these approaches.

\section{QUESTIONS ADDRESSED BY THE PANEL}

Before the Panel could reach a conclusion on the need for animal experimentation, several important questions that have relevance to estimation of human risk due to galactic radiation were discussed in detail. The Panel has suggested some solutions to a number of these questions 
Others require additional research to clarify the health effects and to validate the model systems used.

- Given that the data already accumulated on the effects of low-LET radiation cannot easily be extrapolated to the effects of high-LET radiation what experiments must be conducted with protons and HZE particles to define the relevant outcomes for humans?

- Can effects obtained with high doses or high dose rates be used to predict effects at the protracted low doses encountered in outer space?

- What strategies can be developed to extrapolate results obtained with animals to humans, thus providing satisfactory estimates of human risk?

- What are the reasons for the marked variation in radiation sensitivity between tissue types and different individuals? What biochemical factors account for the tissue-specific differences? What is the basis of individual susceptibility? Could animal models be used to address and understand these differences?

\section{SUMMARY OF PANEL RECOMMENDATIONS}

- The Panel unequivocally endorses the ethical, informed, and optimal use of animals. Indeed, the Panel concludes that animal experimentation is absolutely necessary to assess the health effects in humans from exposure to HZE particles. To ignore the systemic effects resulting from the interactions of different cell types and tissues would ignore the most likely health problems. Simple models are best for defining the general outline of the mechanisms, but in evaluating health risks, it is essential that these studies be combined with experiments conducted on the whole organism.

- The Panel recognizes that the mouse has particular advantages as a model system -- (small, mammalian, inbred, advanced knowledge of genetics, relatively cost-effective, etc.) -- for studying radiation-induced damage. However, other species and systems should be considered (as discussed in detail in the report) where a model has clear experimental advantages for answering a specific question. Because HZE particles can damage cells in a variety of ways, different model systems will be required to understand the underlying mechanisms of action and potential health effects. For instance, to observe infrequent specific gene mutations requires a large number of targets. In this case, the use of cultured cells from mouse and human as well as bacteria would be advantageous. To study chromosomal damage and long term consequences, the fruit fly ( $D$. melanogaster) and nematodes ( $C$ elegans) would be useful because of their short generation time and well-characterized genetic profile. To observe changes in specific tissues, the mouse would be advantageous because it is mammalian, has a complex organizational 
structure similar to humans, has a well-characterized genetic profile and is relatively inexpensive to study.

- Genetically engineered mice can be used to elucidate the mechanisms of radiation-induced cancer and neurodegenerative damage. This will in turn provide the data required for modeling of the response to radiation, such as dose-response relationships and dose-rate effects, which are central to assessing risk.

- The Panel emphasizes the need to develop and verify methods for extrapolating the results obtained from experimental animals to humans as discussed in the report. To best mimic the in vivo situation, functional, organ-specific culture models of both mice and humans that retain tissue specificity need to be employed.

- Many effects of radiation become apparent months or even years after the exposure. For instance, low-LET radiation can cause fibrosis, cancer, and cataracts as late effects, and remodeling of the extracellular matrix and mutations as early effects. Therefore, in studies of high-LET radiation, longitudinal studies to distinguish early and late health effects are desirable.

- During space flight, it is likely that a cell hit by a HZE particle would have been hit recently by a proton or helium ion. The question of whether multiple hits pose a significant increase in health hazard would require further study.

- Given the dramatic increase in cancer incidence with the increasing age of the individual, age should become an important variable in all radiological studies. Because astronauts are expected to be in the middle third of their life span, the animal models used should be aged accordingly. Indeed, research into response to HZE radiation of young and old animals and their cells would appear timely, and the Panel recommends inclusion of age as an important variable in appropriate experiments.

- Because so little data are available on radiation-induced neurological damage or neuronal loss in humans, and because of the singular characteristics of energy deposition by HZE particles, the impact of HZE particles on individual neurons and neuronal networks in model organisms must be studied to determine whether neurodegeneration in humans as a result of travel in outer space could be a concern. Such studies in lower organisms and model vertebrates need to be analyzed for relevance to humans using stepwise and comparative analysis, as discussed in Section VII of the report.

- Attention should be given to developing effective radioprotectant strategies against the biological consequences of high-LET radiation. Such 
radioprotectants may include antioxidants for limiting the spread of damage to cells not initially hit.

- A variety of markers of radiation-induced damage in blood cells (lymphocytes and erythrocytes) have been identified (Table V.1). The relationship between the markers that are experimentally accessible and the status of damage in organs and tissues needs to be established, first in animal models and then in humans. However, it should be recognized that this relationship may vary from individual to individual.

- As the genes that determine the responses to ionizing radiation become identified and cloned, it is essential that the radiation-sensitivity of animals that are homo- or heterozygous for these genes be determined. Studies of polymorphism in these same genes may provide important additional information as to individual susceptibility, an increasingly important area of research. Technology is now available to evaluate individual genetic differences in susceptibility to radiation for several genes such as BRCA1,ATM, and others. Molecular epidemiologic studies are needed to better relate polymorphisms at these and other loci to individual susceptibility.

- Computational biological techniques need to be employed together with specific experimental systems to unravel the mechanisms that give rise to the higher order complexities of radiation damage and repair.

- Non-invasive imaging technologies combined with improved molecular markers should be used in humans who have had to be exposed to high HZE particles for various reasons (e.g. in studies of cancer patients treated with helium, neon, silicon or argon ions) to learn more about the consequences of such exposures.

Radiation is an important hazard faced by astronauts on a Mars mission While the long term, low level exposure to a mixture of low and high LET radiation is difficult to duplicate in ground-based experiments, sending a sufficient number of animals into space to achieve a statistically significant incidence rate is simply impractical. If at all possible, such an approach should be restricted to a carefully selected number of critical experiments for validation of ground-based models and observation of possible interactions with other risks in space. In any case, an ambitious program needs to be put in place to better understand the functional and mechanistic differences between low and high LET radiation in ground-based experimentation Because of the exquisite complexity of mammalian systems, strategies need to be developed to encourage different groups and disciplines using various model systems to interact, share data and design experiments with relevance to humans as a central criterion. Research institutions capable of launching 
interdisciplinary programs to address this need should be specifically recruited to participate in this program. 


\section{INTRODUCTION}

It is anticipated that early in the next century manned missions into outer space will occur, with a mission to Mars scheduled between 2015 and 2020. However, before such missions can be undertaken, a realistic estimation of the potential risks to the flight crews is required. One of the uncertainties remaining in this risk estimation is that posed by the effects of exposure to the radiation environment of outer space. Although the composition of this environment is fairly well understood, the biological effects arising from exposure to it are not. The reasons for this are three-fold:

1. A small but highly significant component of the radiation spectrum in outer space consists of highly charged, high energy (HZE) particles which are not routinely experienced on earth, and for which there are insufficient data on biological effects;

2. Most studies on the biological effects of radiation to date have been high-dose, high dose-rate, whereas in space, with the exception of solar particle events, radiation exposures will be low-dose, low dose-rate;

3. Although it has been established that the virtual absence of gravity in space has a profound effect on human physiology, it is not clear whether these effects will act synergistically with those of radiation exposure.

Traditionally, adverse effects of various types of radiation on humans have been investigated in animal models, mostly rodents. Early studies of this kind were greatly accelerated by the Manhattan project, which made us acutely aware of the dangers of ionizing radiation of various energies. In view of (a) the already extensive literature on radiation effects in animals and (b) the recent emergence of sophisticated genetic analysis and manipulation technology, the question has arisen as to the necessity of still using animals in the conventional way in firmly establishing radiation risk in outer space. As such, the basic question addressed in this report is whether or not additional animal experimentation is necessary to reliably estimate the risk of exposure to HZE particles and, if yes, how the cost, time and animal number can be minimized by aggressively exploiting the technology base of modern day experimental biology and genetics.

This report first aims at providing a solid background of available scientific literature on what is known about radiation effects in general and HZE effects in particular. Careful attention is paid to recently emerged insights into the nature of the damage inflicted, the various cellular response pathways and the possibilities to analyze and manipulate such pathways to create the superior model systems that might be necessary to obtain a full understanding of the adverse health effects that could be the result of radiation exposure. After drawing the more general conclusion that some further animal experimentation cannot be avoided, the body of the existing literature is then analyzed to transform the original basic question into a series of operational criteria regarding the research that still needs to be done. 
The report is closed by a series of recommendations, including the establishment of a panel of biological endpoints that may be used to assess the nature of damage using a repertoire of model systems and modern analytical tools. An extensive bibliography and series of appendices serve to reference the report.

A somewhat similar report, titled Cellular and Molecular Research to Reduce Uncertainties in Estimates of Health Effects from Low-Level Radiation was issued in 1990 by the U. S. Nuclear Regulatory Commission (Elkind et al., 1990). That report was deemed to be timely then because of the recent discovery and characterization of oncogenes, the development of the techniques of recombinant DNA, and the progress which had been made in the characterization of the genetic basis of some human cancers. However, that report focussed only on mutagenesis and cancer induction, and overemphasized the use of cell culture systems, rather than tissues and intact animals.

Another recent effort to develop better risk estimates for radiation-induced cancer was a workshop sponsored by the Office of Health and Environmental Research, DOE and Columbia University. In their report (Arnheim et al., 1993), these workshop participants recommended a variety of cellular and animal studies including: 1) the use of model transformation systems based on non-immortalized human cells; 2) the use of transgenic mice to investigate the effects of tumor suppressor gene deficiency; 3) the use of repair-deficient animals to assess increased tumor susceptibility; 4) studies of rodents that are constitutionally heterozygous for mutations in tumor suppressor genes; and 5) studies to determine why rodents ard humans differ in terms of genomic instability. While many of these recommendations are valid for radiation exposures in outer space, that report did not place significant emphasis on the inclusion of HZE particles in the research agenda, or on the concerns associated with possible neurobiological damage.

Finally, a very complementary report titled Radiation Hazards to crews of Interplanetary Missions. Biological Issues and Research Strategies, was recently issued by the Space Studies Board of the National Research Council. That report concluded that of the known late effects, cancer is the most important, but suggested that the CNS is also at risk. That report addressed three issues not covered in detail by this report, namely: (1) shielding for crew protection, (2) severe limits on the availability of radiation particle types and energies for HZE particle research, and (3) timelines for addressing the priority research questions.

This current report takes a broad biological approach, and emphasizes the concepts that neurobiological endpoints are also important and that DNA is not the only major radiation target. It is already clear that the radiation environment in deep space (protons and HZE particles) increases the risk of 
cancer, although the probability of such an outcome is not known. In contrast, the risk of damage in the human central nervous system is less certain both qualitatively and quantitatively, and both must be addressed. Furthermore, this report also adds the concept of the use of genetically modified animal models, and has placed an overriding emphasis on relevance of model systems (including questioning the use of nonimmortalized human cells if grown under non-physiological conditions) to human risk. Finally, we argue that the extreme tissue specificity of radiation damage is proof enough of the importance of studying damage in the physiological context of the tissue. 


\section{BACKGROUND: RADIATION AND ITS BIOLOGICAL DAMAGE}

\section{A. RADIATION QUALITY IN SPACE}

To understand the radiation threat to astronauts in either earth orbit or during travel in outer space, it is first necessary to characterize the nature of this radiation. Earlier space flights both in earth orbit, and to the moon, have provided considerable data on the sources of radiation in outer space. These data are qualitatively summarized in Table IV.1. In 1989 the National Council on Radiation Protection and Measurements (NCRP) published report no. 98 titled "Guidelines on radiation received in space activities" (NCRP, 1989). This NCRP report discussed more quantitative aspects of what was known in 1989, some of which is summarized below. An update of this report will appear in 1997.

\section{NATURE OF RADIATION ENVIRONMENT IN LOW EARTH ORBIT (LEO)}

The total dose per day behind $1 \mathrm{~g} / \mathrm{cm}^{2} \mathrm{Al}$ shielding is about $1.1 \mathrm{mSv}$, or approximately equivalent to that received per year on earth. Thus, travel in earth orbit subjects space travelers to at least 300 times more radiation than experienced on earth. The actual exposure in LEO varies with altitude and inclination of the orbit, as well as shielding available from the spacecraft. A major part of the radiation comes from the inner trapped radiation belt, which consists mainly of protons.

\section{NATURE OF RADIATION ENVIRONMENT IN OUTER SPACE}

Galactic cosmic rays (GCR) are the major radiation source in outer space, and these are composed of $\mathrm{H}(85 \%), \mathrm{He}(13 \%)$, and HZE particles $(1 \%)$. The relative abundance and ionizing power of the even numbered HZE particles in GCR is shown in the Appendix, Figure IX.1. Although the fluence of HZE particles in GCR is low, the high charge of these particles makes them particularly damaging. Because of its relative abundance and charge of +26 , $\mathrm{Fe}$ is a major concern among the various HZE particles encountered. Although $\mathrm{C}, \mathrm{O}, \mathrm{B}, \mathrm{Li}, \mathrm{N}$ and Be particles are less highly charged, their abundance indicates they must also be considered (Table IV.2.).

Some knowledge about exposure to HZE particles in outer space has already been gained, as the HZE dose rate during the Apollo 17 flight was calculated to be $0.12 \mu \mathrm{Gy}$ per hour (Bücker and Horneck, 1975), or about 1.05 mGy per year for HZE particle irradiation. Ignoring solar particle events, the total dose of radiation during a 3-year mission is about $0.3 \mathrm{~Gy}$, mostly due to protons. Robbins (in press) has estimated that during a mission to Mars annual 
exposure from GCR would be between $0.15 \mathrm{~Sv} / \mathrm{yr}$. at solar maximum and 0.58 $\mathrm{Sv} / \mathrm{yr}$. at solar minimum; thus, he estimates the total mission dose equivalent would be between 0.45 and $1.75 \mathrm{~Sv}$, or about 0.2 to $0.9 \mathrm{~Gy}$ (excluding SPE). 
TABLE IV.1

SOURCES OF RADIATION*

\begin{tabular}{|c|c|c|c|}
\hline Type & Description & Location & $\begin{array}{l}\text { Secondary } \\
\text { Radiation }\end{array}$ \\
\hline Trapped & Low LET(1) & 3-12 E(r) (2) & Bremsstrahlung \\
\hline \multirow[t]{3}{*}{ Electrons } & Large temporal variations & $\mathrm{I}(\max ) 3.5 \mathrm{E}(\mathrm{r})$ & Penetrating \\
\hline & Not very penetrating & $\mathrm{GEO}(3)$ & Low LET \\
\hline & Low dose rate & & \\
\hline Trapped & Ranges from low to high LET & $\operatorname{LEO}(4)$ & Neutrons \\
\hline \multirow{2}{*}{ Protons } & Penetrating & & High LET \\
\hline & Low dose rate & & \\
\hline Solar & Mostly protons & Outside Earth's & Neutrons \\
\hline Particle & Lesser amounts of heavier ions & magnetic field-- & Nuclear fragments \\
\hline \multirow{4}{*}{ Events } & Occurs sporadically & polar orbit & High LET \\
\hline & Occasional events of extremely & GEO & Penetrating \\
\hline & high intensity & Moon & \\
\hline & & $\begin{array}{l}\text { Interplanetary } \\
\text { space }\end{array}$ & \\
\hline \multirow{6}{*}{$\begin{array}{l}\text { Galactic } \\
\text { Cosmic } \\
\text { Rays }\end{array}$} & Protons, $\mathrm{He}$, heavier ions & Outside Earth's & Neutrons \\
\hline & (especially Fe) & magnetic field -- & Nuclear fragments \\
\hline & Very penetrating, high LET & polar orbit & High LET \\
\hline & Low dose rate, isotropic & GEO & Penetrating \\
\hline & & Moon & \\
\hline & & $\begin{array}{l}\text { Interplanetary } \\
\text { space }\end{array}$ & \\
\hline
\end{tabular}

(1) LET: linear energy transfer (expressed as $\mathrm{keV}$ per $\mu \mathrm{m}$ ) -- a measure of the amount of energy depos per unit track length as radiation interacts with matter; for a given radiation dose, biological effects : strongly dependent on the LET of the radiation

(2) $\mathrm{E}(\mathrm{r})$ : Earth radius, equal to $6,000 \mathrm{~km}$

(3) GEO: Geosynchronous Earth orbit

(4) LEO: Low-Earth orbit

*Taken from Exploring the Living Universe: A Strategy for Space Life Sciences, A report of the NASA Life Sciences Strategy Planning Study Committee (June, 1988). 


\section{SOLAR PARTICLE EVENTS}

Also important is the radiation due to solar particle events (SPE), and exposure to these SPE is potentially life-threatening. Although the relative abundance of particles associated with these solar particle events is similar to that of GCR, the timing of, and amount of exposure to, SPE is sporadic and unpredictable. This problem is not easily dealt with, and NCRP Report No. 98 merely states that "in a long duration mission to Mars, the likelihood of an $\mathrm{SPE}$ is considerable and special design features will be requir ad to protect crew members." Robbins (in press) has estimated that SPE exposure may contribute about another $0.3 \mathrm{~Sv} / \mathrm{yr}$., or almost $1 \mathrm{~Sv}$ on a 3-yr. Mars mission, although the exposure rate due to an SPE could increase 100- to 1000-fold during brief intervals, i.e., several days? Thus, SPE exposure could double the annual estimated dose of GCR.

\section{NUCLEAR HITS FROM GCR DURING TRAVEL IN OUTER SPACE}

Total exposure to ionizing radiation in terms of hits per cell nucleus during a 3-year mission to Mars has been estimated by Curtis and Letaw (1989), and are summarized in Table IV.2. These authors attempted to model the impact of GCR on humans shielded by aluminum as in modern spacecrafts, by assuming the nuclear target was at the center of a $4 \mathrm{~g} / \mathrm{cm}^{2}$ aluminum spherical shell within which there is a $30 \mathrm{~g} / \mathrm{cm}^{2}$ diameter spherical water phantom containing the target nucleus. Assuming an average cross-sectional area of $100 \mu \mathrm{m}^{2}$ for the nuclei in human cells, these authors estimated that roughly one third of these nuclei will be hit by at least one HZE particle in the range $10 \leq Z \leq 28$ during a three year mission in outer space, and that all nuclei will be hit by at least one HZE particle in the range $3 \leq Z \leq 9$. Table IV.2 shows the individual contribution of each HZE particle within these ranges. Because of its high charge, an Fe particle can be expected to make a major contribution to the damage caused by HZE particles, in spite of its relatively low "hit" frequency per any given cell nucleus, i.e., once every 100 years. Assuming the human body contains about $10^{14}$ cells, and that all cells are at the same shielding thickness $\left(5 \mathrm{~g} / \mathrm{cm}^{2}\right.$ deep in a $30 \mathrm{~g} / \mathrm{cm}^{2}$ sphere), at least $3 \mathrm{x}$ $10^{12}$ cell nuclei would be hit by an Fe particle during the mission. It is also worth noting again that nearly every nucleus will be hit by either a $\mathrm{C}$ or $\mathrm{O}$ particle during the mission, as well as by a B, Li, N, Be or F particle.

The low particle fluence of HZE particles means that the likelihood of a cell being hit by two or more heavy particles within a short time interval is very low. In principle, this would seem to indicate that dose rate effects, which can be attributed to energy deposition by multiple particles, are not likely to be significant. However, several factors have a bearing on such an argument. These include questions about energy deposition by multiple delta rays traversing a cell, the length of time during which a cell "remembers" the passage of a previous particle, and the extent to which communication 
between different cells hit at closely spaced times can affect the biological outcome of the radiation interaction.

Every nucleus will also be hit by a proton once every three days, and an $\alpha$ particle once every 30 days. Finally, the actual nuclear hit frequency for any given cell will depend on the size of its nucleus.

More recently, detailed calculations have been made for galactic cosmic ray hit frequencies specifically to cells of the central nervous system using the CAM (computerized anatomical man) model (Curtis et al., in press). As an example, for a point within the brain near the hippocampus (the Nucleus Basalis of Meynert) and the thalamus, either $2 \%$ or $13 \%$ of the cells, respectively, would be hit by at least one Fe particle on a three-year mission to Mars at solar minimum inside the pressurized vessel of a typical spacecraft (1 $\mathrm{g} / \mathrm{cm}^{2}$ aluminum shielding) depending on the cross section of the sensitive area assumed $\left(60\right.$ or $\left.470 \mu \mathrm{m}^{2}\right)$. Eight $\%$ or $46 \%$, respectively, would be hit by at least one particle with $Z \geq 15$ for the same conditions. An additional $4 \mathrm{~g} / \mathrm{cm}^{2}$ aluminum shielding to account for equipment that might be present in the vehicle made little difference in these numbers. 
TABLE IV.2

\section{ESTIMATES OF HITS PER CELL NUCLEUS DUE TO GCR ON A 3-YEAR MARS MISSION}

\begin{tabular}{llll} 
Element & $\begin{array}{l}\text { Atomic } \\
\text { Number }\end{array}$ & $\begin{array}{l}\text { Total Hits } \\
\text { per Nucleus }\end{array}$ & $\begin{array}{l}\% \text { Total } \\
\text { Nuclei Hit }\end{array}$ \\
\hline
\end{tabular}

Particles with $\mathrm{Z} \leq 9$

$\begin{array}{llcc}\mathrm{H} & 1 & 400 & 100 \\ \mathrm{He} & 2 & 36 & 100 \\ \mathrm{C} & 6 & 0.60 & 60 \\ \mathrm{O} & 8 & 0.50 & 50 \\ \mathrm{~B} & 5 & 0.30 & 30 \\ \mathrm{Z} & 3 & 0.24 & 24 \\ \mathrm{BV} & 7 & 0.18 & 18 \\ \mathrm{Be} & 4 & 0.12 & 12 \\ \mathrm{H} & 9 & 0.024 & 2.4\end{array}$

HEE Particles: $10 \leq \mathrm{Z} \leq 28$

$\begin{array}{cllc}\mathrm{Mg} & 12 & 0.10 & 10 \\ \mathrm{Ne} & 10 & 0.08 & 8.0 \\ \mathrm{Si} & 14 & 0.07 & 7.0 \\ \mathrm{Fe} & 26 & 0.03 & 3.0 \\ \mathrm{Na} & 11 & 0.024 & 2.4 \\ \mathrm{Al} & 13 & 0.016 & 1.6 \\ \mathrm{~S} & 16 & 0.012 & 1.2 \\ \mathrm{Ca} & 20 & 0.009 & 0.9 \\ \mathrm{Ar}, \mathrm{Ti} & 18,22 & 0.007 \text { (each) } & 1.4 \\ \mathrm{P}, \mathrm{K}, \mathrm{Cr}, \mathrm{Mn} & 15,19,24,25 & 0.005 \text { (each) } & 2.0 \\ \mathrm{Cl}, \mathrm{Sc}, \mathrm{V} & 17,21,23 & 0.004(\text { each) } & 1.2 \\ \mathrm{Co}, \mathrm{Ni} & 27,28 & 0.001(\text { each) } & 0.2\end{array}$

*Estimates are derived from calculations of Curtis and Letaw (1989), assuming the average size of a nucleus is $100 \mu \mathrm{m}^{2}$ and aluminum shielding of $4 \mathrm{~g} / \mathrm{cm}^{2}$. These estimates include some nuclei that may be hit more than once. 


\section{PHYSICAL CHARACTERIZATION: DISTINCTION BETWEEN HIGH AND LOW LET}

LET in radiation biology refers to linear energy transfer and is generally used to characterize the efficiency with which an energetic charged particle transfers energy to a medium. It is defined as the amount of energy transferred by a charged particle to the molecules of a medium for every unit distance it penetrates. In the process, the particle loses energy progressively and if the medium is thick enough, it can lose all its energy and come to a complete stop. For all charged particles, the LET increases as they lose speed.

Low-LET refers to the rate of energy transfer with low efficiency. High-energy electrons and the electrons that are generated by ${ }^{60} \mathrm{Co} \gamma$-rays and X-rays are generally characterized as low-LET radiation. Protons in galactic cosmic rays are also called low-LET radiation. HZE particles with atomic number $\geq 2$ are generally referred to as high-LET radiation because of their greater efficiency in energy transfer. The LET of a particle varies as the square of its charge, $Z$ (also the atomic number), and varies inversely as the square of the speed with which it moves through a medium. For example, at the same speed, a proton $(Z=1)$ has a lower-LET value than neon $(Z=10)$ by a factor of 100 . An Fe particle $(Z=26)$ will have a higher LET-value by a factor of 6.8 compared to a Ne particle of the same speed. Similarly, the LET-value of a slower proton is about four times greater than another proton with a speed about twice that of the slow moving one. A very high energy proton or an electron can have a LET-value of $0.2 \mathrm{keV} / \mu \mathrm{m}$, and that of an energetic iron particle can be 175 $\mathrm{keV} / \mu \mathrm{m}$, or even higher for a lower speed particle. A stopping iron particle can deposit energy at the rate of $1,000 \mathrm{keV} / \mu \mathrm{m}$ which is considered very highLET. It is known that radiation-induced biological damage increases with LET, up to a maximum LET of about 100. To understand the reason for such a relationship, one has to understand the associated mechanisms at the molecular, cellular and tissue level of organization.

There are many examples in experimental radiobiology where the LET does not uniquely determine the extent of biological damage in a qualitative manner. For example, for the same LET value, two different charged particles can have different cell killing effects, or can have different mutation or transformation frequencies. To understand these differences and the overall biological effects of HZE particles, it is important to consider the track structure, which describes the microscopic pattern of energy deposition. The track structures of low-LET charged particles are qualitatively very different from those of high-LET particles, and these differences are considered to be the reason of the greater biological effectiveness of HZE particles.

In Figure IV.1 a two-dimensional view of different LET tracks is presented for $600 \mathrm{MeV} / \mathrm{n} \mathrm{He}$, Ne and Fe particles. The corresponding LET values are 1.03 $\mathrm{keV} / \mu \mathrm{m}$ for $\mathrm{He}, 25.9 \mathrm{keV} / \mu \mathrm{m}$ for $\mathrm{Ne}$ and $175 \mathrm{keV} / \mu \mathrm{m}$ for Fe. As mentioned 
earlier, these values vary approximately as the square of the respective charges of the particles because their respective speed is the same. These tracks are formed in a very short time $\left(10^{-15} \mathrm{sec}\right)$, and hence can only be estimated theoretically. These calculations were done in liquid water which can be considered as tissue-equivalent from the point of view of gross energy transfer because a living cell contains $80 \%$ of water by volume. In the figure each solid dot represents an energy transfer event. In the case of a low-LET particle (e.g. a high energy $\alpha$-particle) the energy deposition events are quite infrequent, and hence the chemistry and biochemistry events that follow subsequent to energy deposition events are isolated from each other, leading to infrequent or isolated damage sites on a DNA molecule. On the contrary, in the case of a high-LET particle (e.g. Fe particle), the energy deposition events are very frequent as seen by the density of solid dots (Metting et al., 1988). Such high density events lead to highly clustered damage sites on a DNA molecule (Holley and Chatterjee, 1996; also see Figure IV.2). The neon track is an intermediate LET case. However, even in this case, it is possible to have clusters of damages. Because of this fundamental difference between low-LET and high-LET particles, it is unlikely that biological effects due to low-LET radiation cannot be extrapolated to high-LET radiation. A discussion of the difficulties of extrapolation from low-LET to high-LET is addressed later in Section VI.A. 

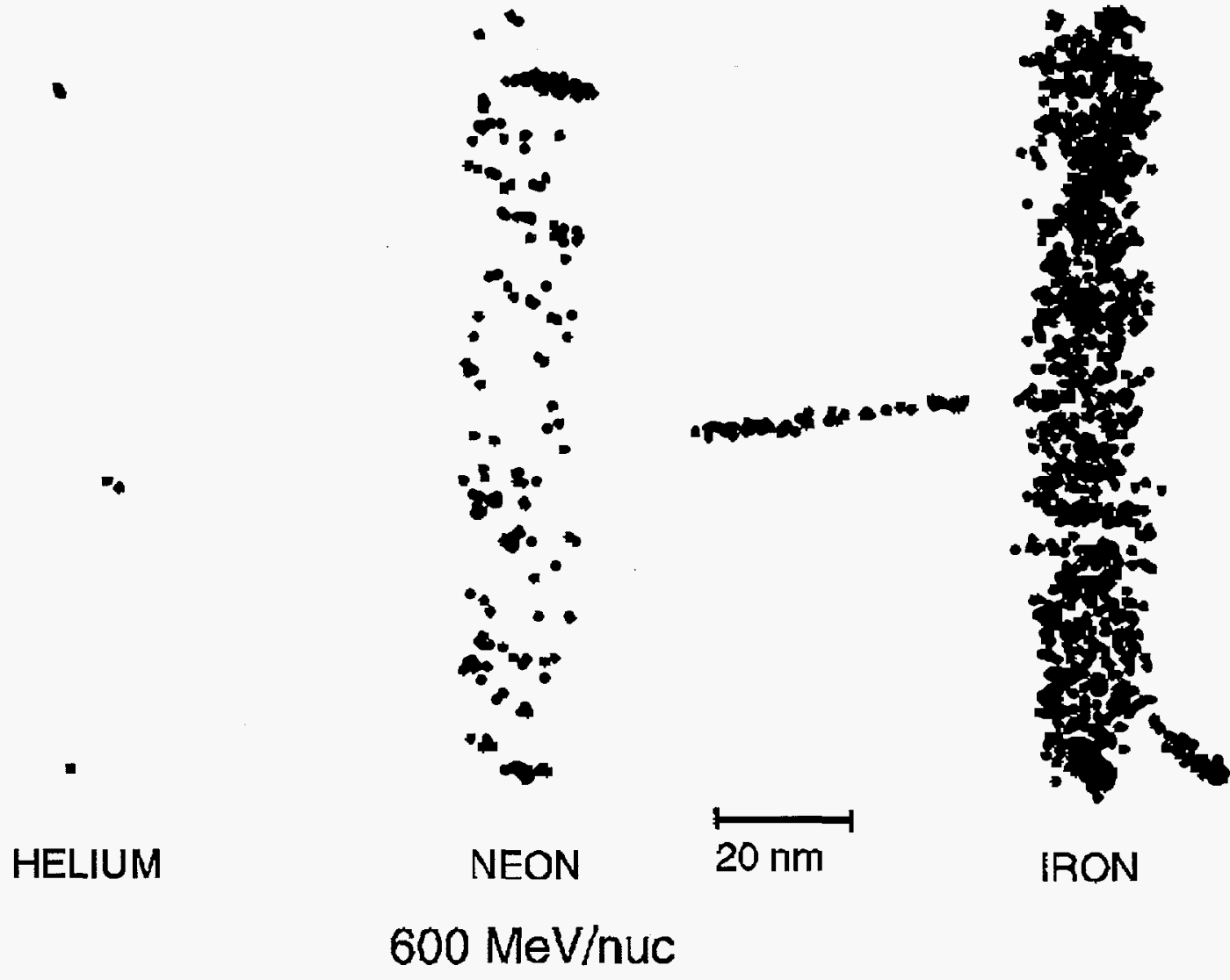

IRON

Figure IV.1: Representative track segments of $600 \mathrm{MeV} / \mathrm{n} \mathrm{He}, \mathrm{Ne}$ and Fe particles. 
$2500 \mathrm{keV} / \mu \mathrm{m} \mathrm{Fe}$

ssssssssss Cossssss

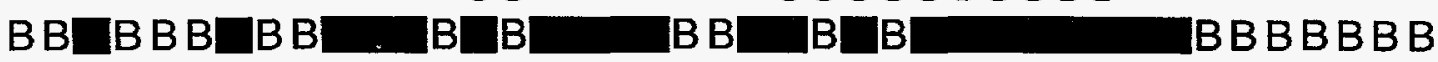
$\mathrm{BBBBB} B \mathrm{~B} \sim \mathrm{B} \square \mathrm{B} \square \mathrm{B} \square \mathrm{B} \square \mathrm{B} \square \mathrm{B} \square \mathrm{B} \square \mathrm{B} \square \mathrm{BBBB}$ ssssssśOSSSSSOSOSOSCOOSCOOOSOSOSSSSSS

$1 \mathrm{keV} / \mu \mathrm{m} \mathrm{He}$

SSSSSSSSSSSSSSSSSSOOSSSSSSSSSSSSSS BвBвBвBBBBBBBBBBB BBBBBBBBBBBBBBBBBBBBBBB BBBBBBBBBBBBBBBBBBBBBBBBBBBBB BBBBBBBBBBB SSSSSSSSSSSSSSSSSSSSSSSSSOSSSSSSSSSSSSS

Figure IV.2: Typical damage clusters in DNA induced by low-LET and very high-LET irradiation. 


\section{SUMMARY FOR SECTION IV.A.}

- The radiation exposure to be experienced during a trip to Mars has been estimated to be about:

$\begin{array}{lrll} & \text { Dose } & & \text { Hits per nucleus } \\ & & & \\ \text { Protons } & 50 \mu \mathrm{Gy} / \text { day } & & 0.4 \mathrm{hits} / \text { day } \\ \alpha \text {-particles } & 35 \mu \mathrm{Gy} / \text { day } & & 0.04 \mathrm{hits} / \text { day } \\ \text { HZE particles }(3 \leq \mathrm{Z} \leq 28) & 3 \mu \mathrm{Gy} / \text { day } & & 0.003 \mathrm{hits} / \text { day }\end{array}$

- These estimates suggest that only very rarely will a given nucleus be traversed by more than one HZE particle per day. However, they also indicate that there is a high probability that a nucleus hit by an HZE particle will also be hit by another particle, most likely a proton, within that same day. Thus, it is important to understand what synergistic effects can be expected from such multiple hits.

- Because of the fundamental physical differences between low-LET and high-LET radiation, it is unlikely that biological effects due to low-LET radiation can be reliably extrapolated to high-LET radiation. The major difference is the density of energy disposition in biological material.

- The above daily doses will be increased many-fold for a short period of time during an SPE.

\section{Review references:}

Kiefer J, Schenk-Meuser K, Kost M. 1996. Radiation Biology. In: Biological and Material Research in Space. D Moore, P Bie, H Oser, (Eds.), SpringerVerlag, New York, pp. 300-367.

NCRP. 1989. Guidance on Radiation Received in Space Activities, NCRP Report No. 98, National Council on Radiation Protection and Measurements, Bethesda, MD.

Schimmerling W. 1992. Radiobiological problems in space: An overview. Radiat. Environ. Biophys. 31: 197-203. 


\section{B. CELLULAR AND TISSUE RESPONSE TO RADIATION DAMAGE}

Since the discovery of $X$-rays and radioactivity by Roentgen and the Curies in the late nineteenth century, it has become abundantly clear that radiation can damage living tissue severely, causing cancer, and even rapid death if a large enough dose is received in a short period of time. However, low dose continuous radiation also induces pathological change, albeit at a much slower rate. Thus, considerable research has been done to understand how radiation damages cells and cellular components, and how this damage either is repaired or leads to pathological change in tissues. The best characterized early radiation-induced effects are DNA damage, cell killing and changes in gene expression, and the purpose of this section is to provide an overview of what is currently known. While some of these studies at the molecular, cellular and tissue level have been carried out with heavy ions, the great majority of our knowledge of the biological effects of ionizing radiation is based on studies using low-LET radiation. Thus, it is important throughout to distinguish between results obtained with low-LET and high-LET radiation, because of their widely differing physical characteristics as discussed above in Section IV.A.5.

The cellular molecules of most concern with regard to radiation damage are not only DNA, but also lipids containing unsaturated fatty acids, and proteins. Ionizing radiation damages a molecule such as DNA in at least two distinct ways, the most frequent of which is the generation of reactive oxygen species through the radiolysis of water. These reactive species can damage any organic molecule (such as DNA) with which they come in contact. The other mechanism is by interaction of the particle with the DNA, thereby directly damaging the base and sugar moieties (Becker et al., 1996), and possibly even breaking the sugar-phosphate backbone. These so-called "primary" events have been reviewed by Ward (1988).

\section{DNA DAMAGE AND ITS REPAIR}

Cells are under continuous onslaught not only from environmental stress such as radiation and toxic chemicals, but also internal metabolic stress, e.g., reactive oxygen species such as superoxide anion $\left(\mathrm{O}_{2}^{-}\right)$, hydrogen peroxide $\left(\mathrm{H}_{2} \mathrm{O}_{2}\right)$, and hydroxyl radical $(\cdot \mathrm{OH})$, produced as byproducts of cellular, particularly mitochondrial, metabolism. Thus, very robust DNA repair systems have evolved to deal with DNA damage. These repair systems include nucleotide and base excision repair (Sancar, 1994; Hanawalt, 1994), mismatch repair (Modrich, 1994), and double strand break repair (for references see Table IV.3. - IV.5.). 
Much of the early work on radiation damage has focussed on DNA because of its unique role in storing and replicating the genetic information in the cell. The kinds of damage inflicted on DNA are summarized in Figure IV. 3 and Table IV.3, along with several review references. Base damage by low-LET radiation occurs mainly through the generation of reactive species by the radiolysis of water, but most cells contain robust systems to repair such damage with high fidelity. During this process of repair, transient singlestrand DNA breaks (SSB) are generated as intermediates in the repair pathway.

Double-stranded breaks (DSB) can be generated from clusters of oxidized bases induced by high doses of low-LET radiation (i.e. many damaged sites close together). High-LET radiation can also generate clusters of base damage, or can produce both SSB and DSB directly, i.e., independently without base damage (Ward, 1985). DSB are two orders of magnitude less likely to be produced by ionizing radiation than are single base modifications (Cooper et al., 1996), but they are particularly lethal. Thus, the primary events due to ionizing radiation, in order of abundance, are thought to be: base damage $>$ SSB $>>$ DSB.

A single-base lesion in the DNA induced by isolated free radical attack usually neither kills cells nor leads to mutagenesis in mammals. This suggests that base excision repair, the pathway primarily responsible for the repair of oxidatively damaged bases (reviewed by Wallace, 1988), is both rapid and faithful. Consistent with this, Moran and Ebisuzaki (1987) showed that essentially all DNA strand breaks in the surviving HeLa cells, after irradiation with sufficient ${ }^{137} \mathrm{Cs} \gamma$-rays to kill $70 \%$ of the cells, were repaired within 30 minutes after irradiation, although they did not evaluate the fidelity of this repair. However, thymine radicals formed in DNA as a result of gammairradiation of cells have been shown to react with tyrosine moieties in proteins, in which case repair of the resulting protein-DNA crosslink may not be possible.

All of these phenomena could cause mutations and/or cell killing if the damage is so extensive as to overwhelm the DNA repair systems. The failure to repair DSB quicky and accurately is thought to lead to a variety of DNA rearrangements such as fragmentation and deletions, and a variety of chromosome aberrations (Morgan et al., 1996). Thus, the repairability of DNA damage is a critical issue with regard to whether ionizing radiation induces genomic instability and substantial changes in the genetic information. Our current knowledge about what we know about mechanisms of DNA repair is summarized below. Persistent and extensive damage is also thought to induce programmed cell death, although the exact mechanism of this induction is not known (see Section IV.B.2. below). 


\section{a. Excision repair pathways}

DNA repair systems include DNA damage reversal, DNA excision repair, DNA mismatch repair and DNA recombinational repair. DNA damage reversal systems are photoreactivation, involving the separation of UVinduced pyrimidine dimers by a photolyase, and alkyl damage reversal by alkyl group acceptor proteins. DNA excision repair can be subdivided into two major variants: nucleotide excision repair (NER) and base excision repair (BER) (Sancar, 1994; 1995). NER is used to excise so-called bulky DNA adducts as part of an oligonucleotide. However, other forms of DNA damage, such as oxidative DNA damage, are also repaired by means of NER (Huang et al., 1994; Hanawalt, 1994).

NER is coupled to transcription in two ways. First, basal transcription and NER share components in the form of transcription factor TFIIH, two helicases which are identical to ERCC3/XPB (3'-5') and ERCC2/XPD (5'-3') (Schaeffer et al., 1993; 1994; Frejter et al., 1992). ERCC and XP refer to genes required for repair of UV-induced damage (Lehmann et al., 1994; Cleaver, 1968); these genes are called $E R C C$ for excision repair cross-complementing and $X P$ for xeroderma pigmentosum. Second, a dedicated subpathway of NER acts on lesions in the transcribed strands of expressed genes when those lesions block transcription (Bohr et al., 1985; Hanawalt, 1994). For some lesions this results in preferential repair of the transcribed strand, a feature that is lost in Cockayne's syndrome.

It is unlikely that the nucleotide excision repair pathway plays a major role in repairing DNA damaged by ionizing radiation; unless something resembling a bulky adduct is formed, it probably does not. One exception is the XPG protein which is required for transcription-coupled repair of both $X$-ray- and HZE particle-induced base damage (Cooper et al., 1997), but none of the other XP gene products is known to be required for repair of damage induced by ionizing radiation. The XPF protein is an endonuclease homologous to ERCC4 (Sijbers et al., 1996), and complexes with ERCC1 to produce an endonuclease activity which is active on UV-damaged DNA; it is not known whether it also plays a role in repair of ionizing radiation-induced damage.

Base excision repair (BER) is the main system for removing small base damages, including oxidative DNA lesions (Wallace, 1994). In this respect it may be somewhat more relevant for heavy ion-induced DNA damage than NER. In contrast to NER, BER employs DNA lesion-specific glycosylases to recognize and bind to the damaged site, and remove the base. The resulting abasic site is cleaved to remove the 5'-deoxyribose phosphate and the onenucleotide gap is closed by DNA polymerase $\beta$ and sealed by DNA ligase (Wallace, 1994; Sancar, 1994). Defects in BER have been shown to result in hypersensitivity to both alkylating agents and ionizing radiation (Wallace, 
1994). Table IV.4 summarizes some of the enzymology thought to be required for base excision repair.

Other activities which play roles in DNA excision repair pathways, depending on the pathway and the exact nature of the DNA damage, include damage recognition proteins, helicases, DNA polymerases $\delta$ and $\varepsilon$, replication factors, phosphatases (if phosphate is on $3^{\prime}$ terminus of the nick), transcription factors, and DNA binding proteins (Sancar, 1994; Hanawalt, 1994). For example, it has recently been suggested that a gene mutated in subjects with Werner's syndrome, a premature aging syndrome, may code for a helicase activity (Yu et al., 1996); such subjects are prone to genomic instability. Individuals with Bloom's syndrome, a DNA repair deficiency syndrome, also lack an apparent helicase activity (Ellis et al., 1995).

The function of DNA mismatch repair (MMR) systems is to monitor the newly synthesized DNA strand for incorrect or mismatched bases which are removed and replaced by the correct equivalents (Modrich, 1994). In this process the correct strand is recognized on the basis of methylation signals. Heritable mutations in a MMR gene lead to a so-called mutator phenotype, that is, a very high susceptibility of the cell or organism to mutations (Loeb, 1994). An example is the characteristic microsatellite instability in patients with hereditary nonpolyposis colorectal cancer (HNPCC), a disease caused by germline mutations in MMR genes (Fishel et al., 1994; Papadopoulos et al, 1994). To some extent, DNA excision repair and MMR overlap. MMR is not only involved in the repair of mismatch bases, but also in the repair of chemical damage to DNA, processing of recombination in intermediates, etc. (Modrich, 1994; Afzal et al., 1995). Recent evidence indicates that mutations in MMR genes selectively abolish transcription-coupled repair of UV-induced lesions in Escherichia coli and human-derived MMR-deficient cell lines (Mellon et al., 1996).

\section{b. DSB Repair}

The most relevant repair system for heavy ion-induced DNA damage is DSB repair; heavy ions as well as other forms of ionizing radiation and hydroxyl radicals induce DSB. In mammalian cells DSB are thought to be repaired by a form of illegitimate recombination which shares enzymatic activities used in $\mathrm{V}(\mathrm{D}) \mathrm{J}$ recombination, the mechanism by which variability is generated in genes encoding immunoglobulins and T-cell receptors (Taccioli and Alt, 1995; $\mathrm{Chu}$, 1996) The rejoining reaction in $\mathrm{V}(\mathrm{D}) \mathrm{J}$ recombination does not require homology in the recombining DNA, but short stretches of homology are used if present. Several genes involved in both $V(D) J$ recombination and DSB repair have been cloned (Table IV.5.). Several ionizing radiation-sensitive rodent cell mutants, defective in DSB rejoining, have been shown to be defective in components of DNA-dependent protein kinase, an abundant nuclear protein in human cells, which is also required for $V(D) J$ 
recombination. They also exhibit defects in the rejoining steps in V(D)J recombination. Errors in this process, which can also catalyse recombination between sequences not normally involved in Ig or TCR gene rearrangements, may lead to the radiation-induced recombinations that cause cell transformation or cell death.

The genes identified so far as candidates for repair of ionizing radiationinduced damage to DNA are listed in Table IV.5. Thompson and Jeggo (1995) have recently catalogued the human genes as $\underline{X}$-ray repair crosscomplementing (XRCC) genes because of their ability to substitute for rodent genes required for repair of X-ray-induced damage. Unfortunately, exact biochemical functions have not yet been established for most of the XRCC genes, except the XRCC7 gene which codes for the DNA-dependent protein kinase (Kirchgessner et al., 1995). This enzyme interacts with the Ku70 (XRCC6) and Ku80 (XRCC5) proteins which form a complex and bind to the ends of DSB in DNA. Just as the exact activities of most of these XRCC gene products are unknown, the actual enzymatic pathways(s) for repair of DSB in mammalian DNA is unknown at this time. However, a reasonable model for how this might be accomplished in mammalian cells has been outlined by Chu (1996). In yeast, DSB repair occurs largely through homologous recombination (Game, 1993; Shinohara and Ogawa, 1995). The partial homology of some of the human XRCC genes with the yeast rad genes (Table IX.5), suggests overlap between gene products involved in DSB repair in yeast and mammalian cells.

One possible variable in repairability of damage involving DSB is whether the damage occurs in nucleosomal DNA or in linker DNA. Löbrich et al. (1995) have reported that most of the correct rejoining occurs within the first 2 hours following X-irradiation of cultured human fibroblasts, whereas incorrect rejoining occurs primarily between 2 and 20 hours. By 20 hours after irradiation essentially all of the double-strand ends were rejoined, and $70 \%$ of these were correctly joined. In this result, correct refers to the rejoining of pieces from a single chromosome, but does not imply that no bases have been lost or added. It is tempting to hypothesize that DSB which are held together by histones can be rapidly and correctly joined, whereas DSB in linker DNA are more likely to join incorrectly leading to translocations. This hypothesis, even if correct, does not shed light on the actual joining mechanism.

\section{c. SSB repair}

Repair of SSB may be trivial because of the need to accomplish this in almost all repair and replication pathways. SSB with $3^{\prime}$ hydroxyl and $5^{\prime}$ phosphoryl ends can thus be readily repaired by DNA ligase alone. Thus, while some "tailoring" of radiation-induced nicks in DNA by phosphatases, kinases and exonucleases may be required before ligation can occur, the enzymatic machinery for gap-filling and ligation is normally present. Tailoring of nicks 
may use the same enzymes involved in base excision repair. For a discussion of these pathways see Warner (1983).

\section{d. Cell cycle checkpoints}

In order to become permanent, a DNA lesion must be fixed in the genome of a cell in the form of a mutation, that is, a heritable alteration that can be corrected only by elimination of the cell. Genetic stability is controlled by a number of interrelated and overlapping cellular functions, the most important of which are the various DNA replication, repair and recombination pathways. A major component of cellular defense against DNA damage are cell cycle checkpoints, that is, monitoring systems for DNA damage that temporarily halt transcription and/or replication until the lesions are repaired (Carr, 1996). Two important examples of cell cycle checkpoints are the tumor suppressor genes $p 53$ and ATM. The $p 53$ gene is thought to be activated by DNA damage, and to subsequently induce the p21 cdk inhibitor, which mediates growth arrest (Hartwell and Kastan, 1994). The p53 gene product is also considered to play a key part in apoptosis pathways (Lowe et al., 1993). When inactivated, as is the case in many tumors, the organism loses an important mechanism for eliminating unwanted cells, and regulating cell cycle progression

Inactivation of the ATM gene product causes the recessive disease ataxia telangiectasia, which is characterized by greatly elevated cancer risk, hypersensitivity to ionizing radiation and failure to show normal damageinduced cell cycle arrest (Meyn, 1995a). The ATM protein might be an upstream component of a radiation-induced signal transduction pathway which is activated by DNA damage and involves the recruitment of p53 (Savitsky et al., 1995a), and perhaps other checkpoint proteins (Carr, 1996). The ATM protein shares the phoshoinositide 3-kinase (PI-3 kinase) domain with several large proteins in yeast, Drosophila, and mammals (Keith and Schreiber, 1995), including the catalytic subunit of DNA-dependent protein kinase (Hartley et al., 1995). There is also significant homology between ATM and the yeast cell cycle checkpoint gene, mec1, which mediates transcription in response to DNA damage (Kiser and Weinert, 1996). Upon exposure to X-rays or radiomimetic drugs, cells from AT patients exhibit high rates of p53dependent apoptosis (Meyn et al., 1994). No information exists at this point about heavy ion-induced DNA damage and the ATM/p53 response.

\section{Review references:}

Friedberg EC, Meira LB, Cheo DL. 1997. Database of mouse strains carrying targeted mutations in genes affecting cellular responses to DNA damage. Mutat. Res. (In press). 
Morgan WF, Day JP, Kaplan MI, et al. 1996. Genomic instability induced by ionizing radiation. Radiat. Res. 146: 247-258.

Wallace SS. 1994. DNA damages processed by base excision repair: biological consequences. Int. J. Radiat. Biol. 66: 579-589.

Ward JF. 1988. DNA damage produced by ionizing radiation in mammalian cells: Identities, mechanisms of formation, and repairability. Prog. Nucleic Acid Res. Mol. Biol. 35: 95-125. 


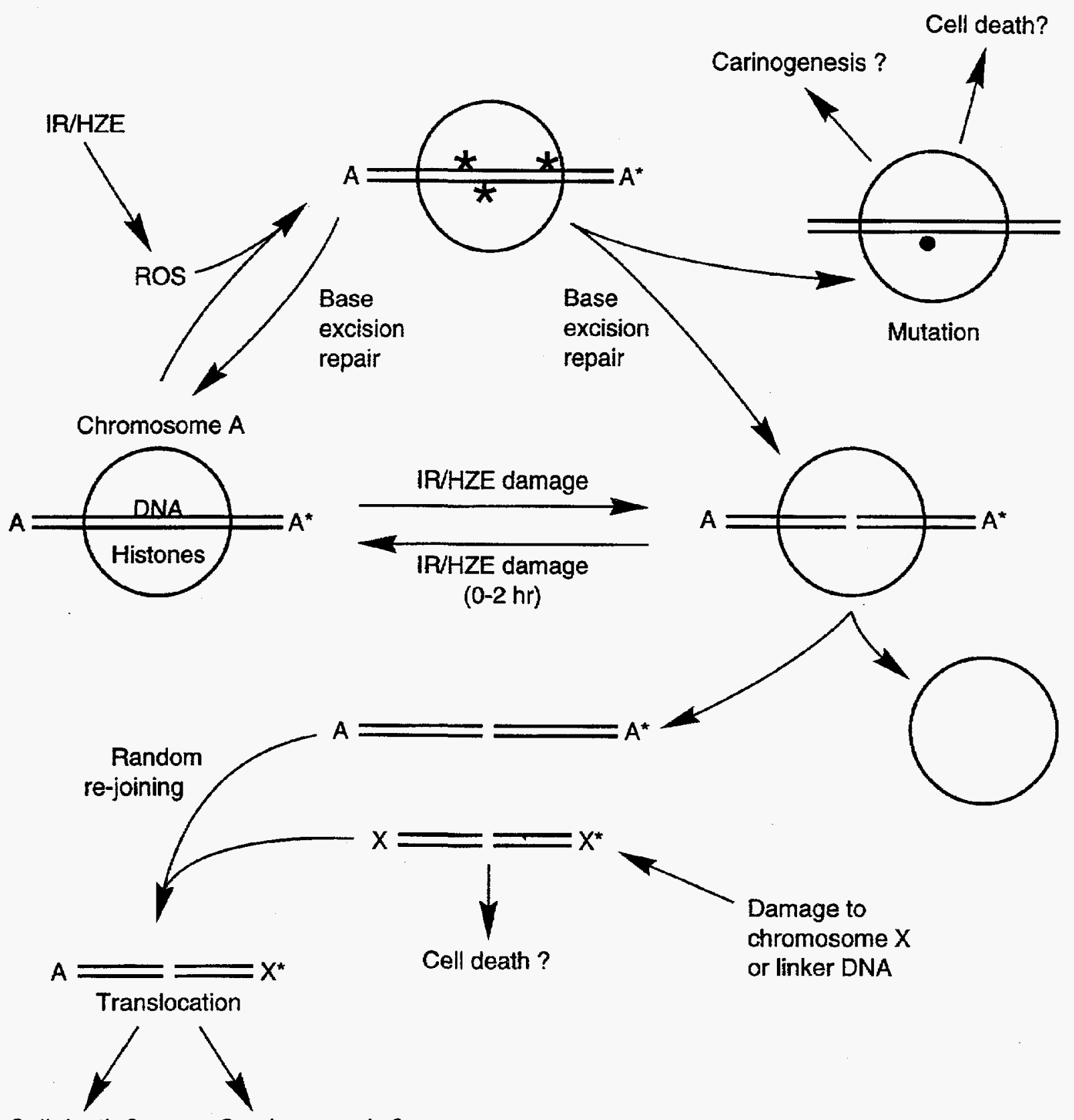

Cell death ? Carcinogenesis ?

Figure IV.3. PATHWAYS OF RADIATION-INDUCED DNA DAMAGE AND REPAIR $\mathrm{IR}=$ ionizing radiation

HZE $=$ high charge, high energy particles

ROS $=$ reactive oxygen species

$\star=$ base damaged by ROS

- = mutated base 
TABLE IV.3

\section{RADIATION-INDUCED DNA DAMAGE}

\begin{tabular}{|c|c|c|c|}
\hline Damage & Effect* & Repairability & References \\
\hline $\begin{array}{l}\text { Altered bases } \\
\text { in DNA }\end{array}$ & primary & easily repaired & Ward, 1995 \\
\hline $\begin{array}{l}\text { Single-strand } \\
\text { breaks in DNA }\end{array}$ & $\begin{array}{l}\text { primary and } \\
\text { secondary }\end{array}$ & $\begin{array}{l}\text { usually easily } \\
\text { repaired }\end{array}$ & Ward, 1985 \\
\hline $\begin{array}{l}\text { Double-strand } \\
\text { breaks in DNA }\end{array}$ & $\begin{array}{l}\text { primary and } \\
\text { secondary }\end{array}$ & $\begin{array}{l}\text { usually not all } \\
\text { accurately repaired }\end{array}$ & $\begin{array}{l}\text { Löbrich et al., } 1995 \\
\text { Ikpeme et al., } 1995 \\
\text { Taucher-Scholz et al., } \\
1995\end{array}$ \\
\hline DNA fragmentation & $\begin{array}{l}\text { primary and } \\
\text { secondary }\end{array}$ & $\begin{array}{l}\text { results from } \\
\text { inability to repair } \\
\text { primary damage }\end{array}$ & $\begin{array}{l}\text { Holley and Chatterjee } \\
\text { 1996; Rydberg, } 1996\end{array}$ \\
\hline DNA deletions & secondary & $\begin{array}{l}\text { results from } \\
\text { inability to repair } \\
\text { primary damage }\end{array}$ & Kronenberg et al., 1995 \\
\hline $\begin{array}{l}\text { Chromosomal } \\
\text { rearrangements }\end{array}$ & secondary & $\begin{array}{l}\text { results from } \\
\text { inability to repair } \\
\text { primary damage }\end{array}$ & $\begin{array}{l}\text { Nagasawa and } \\
\text { Little, } 1981 \\
\text { Morgan et al., } 1996\end{array}$ \\
\hline $\begin{array}{l}\text { Protein-DNA } \\
\text { crosslinking }\end{array}$ & secondary & not repaired? & Olinski et al., 1992 \\
\hline
\end{tabular}

*primary refers to immediate and direct effects; secondary refers to effects that are a consequence of processing of the initial damage. 
TABLE IV.4

\section{ENZYMES INVOLVED IN REPAIR OF RADIATION-INDUCED \\ DAMAGE IN HUMAN CELLS}

\section{Damage}

1. Non-bulky base modifications in DNA, e.g. 8-hydroxyguanine (base excision repair)

\section{Enzyme}

Specific DNA glycosylases

$\mathrm{AP}$ endonuclease

DNA

deoxyribophosphospho-

diesterase

DNA polymerase $\beta$

DNA ligase

DNA ligase (assuming there are appropriate $3^{\prime}$ and $5^{\prime}$ termini)

XRCC gene products?

Multicatalytic protease

Phoospholipase A2?

Acyl transferase?

\section{Activity}

Remove damaged base and create an AP site*
Cleave DNA at AP site (on 5 ' side of lesion?)

Excise 5' deoxyribose phosphate group

Replace missing nucleotide(s)

Re-seal the ss-break
2. Single-strand breaks (SSB)

3. Double-strand breaks (DSB)

4. Protein oxidation

5. Lipid peroxidation
Re-seal the ss-break See Table IX.5

* Refers to apurinic or apyrimidinic site

References: Wallace, 1988; Wallace, 1994; Price and Lindahl, 1991; Warner, 1983; Weindruch et al., 1993 


\section{TABLE IV.5 HUMAN DNA REPAIR GENES IMPLICATED \\ IN SENSITIVITY TO IONIZING RADIATION}

Gene

$X R C C 1$

XRCC2 , XRCC3 distant homologs of yeast rad51; involved in

$\mathrm{XRCC}^{*}$

$\mathrm{XRCC}^{*}$

$\mathrm{XRCC}^{*}$

$\mathrm{XRCC7^{* }}$

XRCC8

XRCC9 recombinational repair and crosslink repair

Activity/Function Of Gene Product

complexes with DNA ligase III

distant homolog of yeast rad1 and XPF; may be an endonuclease involved in nucleotide excision repair? same as XR-1

Ku80; complexes with Ku70 and binds to dsDNA ends; activates DNA-PK $\mathrm{CS}$

Ku70; complexes to Ku80 and binds to ds DNA ends; activates DNA-PK $\mathrm{CS}_{\mathrm{C}}$; no cell line deficient in this gene has yet been isolated

DNA-dependent protein kinase (DNA-PK $\mathrm{cs})$; deficient in $\mathrm{V}(\mathrm{D}) \mathrm{J}$ recombination

?

correct mitomycin C sensitivity; involved in crosslink repair

${ }^{*}$ Genes also involved in V(D)J recombination

References: Thompson and Jeggo, 1995; Kirchgessner et al., 1995; Jeggo et al., 1995; Chu, 1996. 


\section{CELL KILLING}

Cell death in biological systems can be separated into two distinct forms: necrosis and programmed death or apoptosis (Kerr et al., 1972; Arends et al., 1994; Columbano, 1995). Necrosis results from massive cell injury, and often is accompanied by inflammation. This is more likely to occur when the dose to the cell or tissue is very high. Apoptosis is a more subtle process, and until recently it was generally assumed to be a biological process whose major function is to destroy unwanted cells during development. This perception began to change as roles emerged for apoptosis in the negative selection of thymocytes and lymphocytes (Nagata and Golstein, 1995) and as a balancing factor in maintaining proliferative homeostasis (Thompson, 1995; Williams, 1991). It is now believed that when cells become extensively damaged, apoptosis may become either a preferred or essential alternative to repair. This may be particularly important when using irradiation and drugs to damage and ultimately destroy cancer cells.

Homeostasis in many mammalian tissues may be a state of unstable equilibrium, with cells poised to either proliferate or die depending on the balance of factors impacting them. Most, if not all, of the cell death machinery may be present at all times, but whether it actually is used depends on a variety of both extracellular and intracellular signals. During apoptosis the cell activates this intrinsic suicide mechanism (Fraser and Evan, 1996), which fairly quickly kills the cell and disposes of the debris. Apoptosis is induced by a wide variety of stimuli such as oncoproteins, growth factors, metalloproteases, tumor necrosis factor, antibodies, ionizing radiation, DNA damage, etc. (Reed, 1994). This is particularly true in lymphocytes which have a "differentiated program" to die in response to certain signals (Nagata and Golstein, 1995).

The actual enzymatic machinery used in apoptotic death is becoming increasingly understood; this was greatly facilitated by the genetic analysis employed by Horwitz and others in Caenorhabditis elegans (summarized in Ellis et al., 1991). The process involves activation of pre-existing proteases to effect cleavage of specific proteins such as poly (ADP-ribose) polymerase (Tewari et al., 1995), and actin (Kayalar et al., 1996). An endonuclease(s) is activated to degrade the nuclear DNA into double-stranded fragments which give the appearance of a "ladder" when separated by gel electrophoresis. The expression of c-fos and c-jun protooncogenes also appears to be required for apoptosis in some cells (Colotta et al., 1992).

The mechanism by which ionizing radiation induces apoptosis is not known with any certainty, but until recently it was assumed the process might be initiated by a direct hit at the level of nuclear DNA. However, ionizing radiation, like other forms of environmental stress, induces a variety of biochemical responses and the actual trigger could be any one of a number of lesions such as an oxidized protein or lipid, a disrupted membrane, or altered 
DNA structure. For example, irradiation has been shown to induce increases in the activity of protein kinase C (Woloschak et al., 1990), a DNA binding protein (Teale et al., 1992) and a variety of transcription factors (Sherman et al., 1990; Brach et al., 1991; Weichselbaum et al., 1991).

Recently, more specific insights have been achieved in this fast developing field. The p53 gene product is known to be essential for radiation-induced apoptosis in thymocytes (Lowe et al., 1993), and probably other tissues such as liver, kidney, brain, skin and the myocardium (Santana et al., 1996); however, it may not be required in breast cells. It has also been shown that Bruton's tyrosine kinase is required for the radiation-induced apoptosis of lymphoma $B$ cells (Uckun et al., 1996), indicating that this protein kinase is involved in transduction of the signal, at least in B lymphocytes. Finally, a role for the transcription factor nuclear factor-Kappa B (NF-KB) in a fibrosarcoma cell line has now been established. (Wang et al., 1996a) have shown that the activation of NF-KB by ionizing radiation, as well as by tumor necrosis factor or chemotherapeutic agents, protects cells from apoptosis, apparently because NF$\mathrm{KB}$ plays a role in inducing anti-apoptotic genes. Thus, manipulation of IKB, an inhibitor of NF-KB, could affect the balance between the positive and negative intracellular factors regulating apoptosis.

Haimovitz-Friedman et al. (1994b) have shown that irradiation by ${ }^{137} \mathrm{Cs} \gamma$-rays induces apoptosis of bovine aortic endothelial cells by activating acid sphingomyelinase, which then generates ceramide, a known inducer of apoptosis. Comparable levels of ceramide can even be induced by irradiating cell-free membranes, suggesting that DNA damage need play no role in this process. This observation does not preclude a separate DNA damagedependent initiating event as well. Verheif et al. (1996) have shown that a wide variety of environmental stresses, including ionizing radiation, induce significant increases in intracellular ceramide levels in a dose-dependent manner, which is followed by apoptosis several hours later, suggesting that a common apoptotic pathway can be induced by different stimuli. In fact, in Drosophila, an ICE-protease appears to be required for induction of both apoptosis and ceramide production (Pronk et al., 1996).

The impact of such cell death may be different for dividing and non-dividing cells. In tissues that can regenerate by proliferation of nearby undamaged cells, e.g., the liver, direct cell killing may pose no special problem, and the effects of heavy ions, while quantitatively different, may not be qualitatively different than those induced by low-LET irradiation. In contrast, cell killing is liable to have a much larger impact on tissues containing a large number of non-proliferating cells, such as the central nervous system (CNS), where neuron-linked pathways may be disrupted.

There are also negative regulators of apoptosis in mammalian cells, the best known of which is bcl-2. The $b c l-2$ gene was originally identified as an 
oncogene because over-expression of this gene down-regulates apoptosis, and leads to altered growth (Williams, 1991). Whether or not a cell undergoes apoptosis, therefore depends both on the nature and extent of the damage inflicted, and on the status of the regulatory factors such as the bcl-2 protein.

\section{Review references:}

Barinaga M. 1996. Forging a path to cell death. Science 273: 735-737; Life-death balance within the cell. Science 274: 724 .

Canman CE, Kastan MB. 1995. Induction of apoptosis by tumor suppressor genes and oncogenes. Seminars Cancer Biol. 6: 17-25.

Reed JC. 1994. Bcl-2 and the regulation of programmed cell death. J. Cell Biol. 124: 1-6.

Wyllie AH. 1995. The genetic regulation of apoptosis. Curr. Opin. Genetics Develop. 5: 97-104.

Yuan J. 1996. Evolutionary conservation of a genetic pathway of programmed cell death. J. Cell. Biochem. 60: 4-11.

\section{CHANGES IN GENE EXPRESSION}

Radiation may alter the pattern of gene expression in such a way that cellular response to stimuli is also altered. Recent studies have demonstrated effects on intracellular signalling pathways, second messengers, and cell surface receptors. These factors determine whether a cell lives or dies, or gains neoplastic potential. In addition, radiation-induced gene expression may have extracellular ramifications such as induction of cytokines and growth factors, and alteration in extracellular matrix components. Such changes may also influence the response of other cells in the tissue, including transient residents like inflammatory cells and macrophages that may not have been irradiated themselves. Complex paracrine and endocrine cytokine cascades have been implicated in the generation of late effects following radiotherapuetic exposures (Anscher et al., 1995). Interpreting the pattern of gene expression observed in cell cultures of a single cell type in terms of its relevance to tissue response is likely to be stymied by lack of appropriate context, as the pattern of gene expression may depend on the cell type, transformation status, and context. Changes in gene expression can both affect the response of cells to radiation exposure, and influence how cells respond to subsequent stimuli. 
How cells sense radiation exposure is an area of active research. While it has been proposed that DNA damage is the trigger for changes in gene expression, it is also clear that other targets, such as the cell membrane, and even individual proteins, are important. Intracellular signalling, as well as additional events at the cell membrane, transduce signals to the nucleus in a coordinated, rapid and global mechanism of cellular response. Many transcription factor proteins are activated by pertinent signals via conformational change due to biochemical alterations such as phosphorylation, metal binding, or oxidation. Radiation exposure can cause dissociation of transcription factors from their inhibitor proteins (Brach et al., 1991; Hallahan et al., 1993a; Zhan et al., 1993), and the mRNA for these transcription factors may then rapidly increase through autoactivation of a self-binding site in the promoter that is secondary to protein activation.

Cells are well-equipped to detect reactive oxygen species, which appear to be critical in a variety of tissue responses, including physiological events like inflammation, ischemia/reperfusion, and aging, and this may well be the fundamental stimulus in terms of radiation-induced gene expression. Transcription factor proteins contain redox-sensitive regions that affect their ability to bind to DNA sequences and thereby regulate gene expression. A specific example is $p 53$, a tumor suppressor gene that encodes a nuclear phosphoprotein that can bind to DNA and negatively regulate gene expression. p53 is induced by ionizing radiation (Zhan et al., 1993) and was recently shown to be redox-sensitive (Hainaut and Milner, 1993). Oxidation disrupts p53 conformation and DNA binding, whereas reduction favors folding into the active conformation. NF-KB, OxyR and fos-jun transcription factors exhibit similar traits. Proteins that contain redox-sensitive elements perform a sensor function, and when such proteins are also part of a signal transduction pathway, they have the potential to amplify and elicit a concerted program of response.

Boothman et al. $(1989,1993)$ identified a set of unique radiation-induced transcripts and proteins that are elevated in cultured melanoma cells and fibroblasts soon after exposure to relatively low doses $(<6 \mathrm{~Gy})$ of $\mathrm{X}$-irradiation, but the identity and function of these proteins are not known. These, and some of the other changes in gene expression induced by ionizing radiation discussed above, are summarized in Table IV.6.

\section{Review references:}

Hallahan DE, Haimovitz-Friedman A, Kufe DW, et al. 1993b. The role of cytokines in radiation oncology. In: Important Advances in Oncology, VT DeVita, S Hellman, SA Rosenberg, (Eds.), JB Lippincott Co., Philadelphia, pp. 71-80. 
Massague' J. 1996. TGF $\beta$ signalling: receptors, transducers and Mad proteins. Cell 85: 947-950. 
TABLE IV.6

\section{EXAMPLES OF CHANGES IN GENE EXPRESSION INDUCED BY IONIZING RADIATION}

\section{Class of Proteins}

Transcription Factors

Protein Kinases

Growth Factors

Proto-oncogenes

Other proteins
Examples

c-jun, junB, c-fos

DNA-binding protein

p53

protein kinase $\mathrm{C}$

basic fibroblast growth factor (bFGF)

transforming growth factor- $\beta 1$ (TGF- $\beta 1$ )

epidermal growth factor (EGF)

interleukins

tumor necrosis factor $\alpha$ $(\mathrm{TNF}-\alpha)$

$c-s r c$ and $c-H a-r a s$

X-ray-induced proteins

extracellular matrix proteins

tissue-type plasminogen activator
References

Sherman et al., 1990

Mertz et al., 1992

Hallahan et al., 1993a

Teale et al., 1992

Singh et al., 1990

Zhan et al., 1993

Hainut and Milner, 1993

Woloschak et al., 1990

Kim et al., 1992

Haimovitz-Friedman et al., 1991

Finkelstein et al., 1994

Langberg et al., 1994

Barcellos-Hoff, 1993

Barcellos-Hoff et al., 1994

Schmidt-Ullrich et al., 1996

Hong et al., 1995

Chiang and McBride, 1991

Anderson and Woloschak, 1992

Boothman et al., $1989 ; 1993$.

Finkelstein et al., 1994

Boothman et al., 1991

Fukunaga et al., 1992 
The expression of damage in tissue is modulated by biological parameters that are poorly understood. Delineating the molecular events following radiation exposure in vivo is complicated by the presence of many cell types per tissue, and by the interactions among them. Thus, cultured cells have been employed to elucidate cellular responses to radiation. However, we now know that such cell culture models, while offering well-defined conditions, fall short in many traditional systems of recreating appropriate environments for physiological function and response.

The potential impact of microenvironments on radiation response (and vice versa) has gained credence as more detail is gained in our understanding of how homeostasis is maintained through a web of soluble growth factors and hormones, insoluble extracellular matrix components, and cell surface receptors that communicate signals to individual cells as well as between cells. For example, radiation-induced basic fibroblast growth-factor was initially thought to stimulate repair of potentially lethal damage via an autocrine loop in endothelial cells (Haimovitz-Friedman et al., 1991). However, it has recently been shown that the change in cell survival in the presence of bFGF is due to protein kinase $\mathrm{C}$ induction (Haimovitz-Friedman et al., 1994a), which prevents apoptosis initiated by ceramide production originating at the cell membrane (Haimovitz-Friedman, et al., 1994b). Preliminary studies have shown that exogenous bFGF protects endothelial cells against apoptosis and inhibits radiation-induced tissue damage in the lung (Fuks et al., 1994). These data suggest that radiation-induced cell killing is more complex than previously believed, and that there are alternatives to DNA damage as the critical event.

Gene expression in irradiated tissues can now be explored at the molecular level using immunohistochemistry and in situ hybridization to localize expression, and neutralizing antibodies, antisense RNA or peptide delivery, and genetically engineered animals to demonstrate functional relationships between events. It is important to emphasize the need to address questions wherever possible at the tissue level, or at least in cell culture systems where the 3-dimensional structure, polarity and cell-cell interactions are maintained, and the influence of the microenvironment is retained. Studies in 3-dimensional culture clearly demonstrate that the the pattern of gene expression is dramatically different from that in 2-dimensional culture (Adams and Watt, 1993; Roskelley et al., 1995; for a clear demonstration of changes in transcription factors when hepatocytes are cultured on a basement membrane, see Rana et al., 1994). In addition, rules applicable to stromal cells can't be generalized to epithelial cells, for example, when antibodies have been used to demonstrate how irradiation alters the structure and function of tissues, a complex pattern emerges. Table IV.7 lists some of the changes induced by $\gamma$-rays and Fe particles. These observations suggest that high-LET 
radiation is much more likely to damage the components of basement membrane, e.g., laminin, than is low-LET radiation, whereas stromal components such as collagen III, are affected by both.

\section{Review reference:}

Adams JC, Watt FM. 1993. Regulation of development and differentiation by the extracellular matris. Development 117: 1183-1198.

Askenas J, Muschler J, Bissell M. 1996. The extracellular matrix in epithelial biology: Shared molecules and common themes in distant phyla. Develop. Biol. 180: 433-444.

Rana B, Mischoulon D, Xie Y, et al. 1994. Cell-extracellular matrix interactions can regulate the switch between growth and differentiation in rat hepatocytes: reciprocal expression of $\mathrm{C} / \mathrm{EBP} \alpha$ and immediate-early growth response transcription factors. Molec. Cell. Biol. 14: 5858-5869.

Roskelley CD, Srebow A, Bissell MJ. 1995. A hierarchy of extracellular matrixmediated signalling regulates tissue-specific gene expression. Curr. Opin. Cell Biol. 7: 736-747. 
TABLE IV.7

RADIATION-INDUCED CHANGES IN THE MICROENVIRONMENT

$\begin{array}{llll}\begin{array}{l}\text { Component of } \\ \text { Microenvironment* }\end{array} & \begin{array}{l}\text { Source of } \\ \text { Radiation }\end{array} & \begin{array}{l}\text { Timing } \\ \text { of Effect }\end{array} & \begin{array}{l}\text { Biological } \\ \text { Effect }\end{array} \\ \text { TGF- } \beta 1 & \gamma \text {-rays } & 1 \text { hour-7 days } & \begin{array}{l}\text { Rapid activation, } \\ \text { predominately stromal }\end{array} \\ & \text { Fe } & 12 \text { hour-14 days } & \begin{array}{l}\text { Delayed activation, } \\ \text { predominately } \\ \text { epithelial }\end{array} \\ \text { Collagen I } & \gamma \text {-rays } & 1 \text { day } & \begin{array}{l}\text { Down regulation } \\ \text { No change }\end{array} \\ \text { Collagen III } & \text { Fe } & -- & \begin{array}{l}\text { Up-regulation } \\ \text { Up-regulation, delayed }\end{array} \\ \text { Tenascin } & \gamma \text {-rays } & 1-3 \text { days } & \begin{array}{l}\text { Up-regulation } \\ \text { Fe }\end{array} \\ \text { Fibronectin } & \gamma \text {-rays } & 1 \text { days } & \text { Up-regulation, delayed } \\ & \text { Fe } & 5-9 \text { days } & \text { No change } \\ \text { Collagen IV } & \gamma \text {-rays } & - & \text { No change } \\ & \text { Fe } & -- & \text { No change } \\ \text { Laminin } & \gamma \text {-rays } & -- & \text { No change } \\ & \text { Fe } & -- & \text { No change } \\ & \gamma \text {-rays } & -- & \text { Disrupted }\end{array}$

* Mouse mammary gland was used for all of these experiments

References: Barcellos-Hoff, 1993; Barcellos-Hoff et al., 1994; Ehrhart et al., 1996. 


\section{OTHER TYPES OF DAMAGE}

Radiation-induced oxidative stress may modify membrane structure and function; this could be particularly relevant in the neurons. Lipid peroxidation is the most frequent outcome of free radical attack on lipids, and the subsequent breakdown of these peroxides generates a variety of aldehydic compounds such as malondialdehyde and 4-hydroxy nonenal. These aldehydes frequently react with the amino groups of proteins, thus altering their structure and function. These altered proteins also inhibit the protease(s) involved in degradation of oxidized proteins (Friguet et. al., 1994). The impact of direct oxidative damage to proteins in irradiated cells is not understood, but it is reasonable to assume it too is not negligible.

\section{Review references:}

Stark G. 1991. The effect of ionizing radiation on lipid membranes. Biochim. Biophys. Acta 1071: 103-122

Stadtman ER. 1992. Protein oxidation and aging. Science 257: 1220-1224. 


\section{SUMMARY FOR SECTION IV.B.}

- The best documented radiation-induced early biological effect is DNA damage, which has the potential to induce mutagenesis, carcinogenesis and cell death. The primary lesions, in order of their frequency of induction, are base damage $>$ single strand breaks $>$ double strand breaks, although these measurable endpoints are not independent of each other. Robust repair systems are in place to repair single base alterations, but it is unlikely that DSB are repaired with high fidelity.

- Radiation can induce cell death by several different mechanisms. Death may occur by apoptosis either through the activation of acid sphingomyelinase at the membrane, or as a result of extensive DNA damage. However, it is not known by what mechanism the signal is transduced from the damaged DNA to the cell death machinery. Another mechanism could be by necrosis if the DNA or membrane is damaged so badly that its functional integrity is lost. It is not known how sensitive neurons are to killing by HZE particles in vivo, and model systems are needed to address this question.

- Changes in gene expression occur following irradiation due to multiple causes, including alterations in DNA structure and sequence, an increase in oxidative stress, and changes in the microenvironment that have been documented to alter gene expression.

- Radiation can also damage other biological molecules such as proteins, lipids, and carbohydrates, but very little is known about the impact of such radiation-induced damage on cell function. One likely outcome is activation of molecules which sense the level of oxidative stress in a cell, such as TGF- $\beta 1$ and NF-KB. This area needs to be looked at more critically, and in depth.

- The impact of radiation on the structure and function of extracellular matrix, and its role in regulating the 3-dimensional organization of cells in a tissue, is a new but important area of research, which requires extensive further study. 
IV.C.

HEALTH EFFECTS ASSOCIATED WITH RADIATION

DAMAGE

Little is known about the biological effects of long term exposure to radiation in outer space. Only a few astronauts have been exposed to such radiation during the short duration Apollo missions to the moon. Thus, predictions of adverse health effects derive from earth-based experiments which poorly simulate either the radiation exposure encountered in outer space or the effects, if any, of microgravity. Nevertheless, those who have considered this issue in the past have concluded that long term risks are primarily carcinogenesis, cataractogenesis, abnormal fetal development, and loss of CNS and peripheral neurons. Radiation-induced damage may also accelerate processes associated with aging.

\section{CARCINOGENESIS}

While a large body of evidence supports the concept that accumulated genetic changes underlie the development of cancer (Kinzler and Vogelstein, 1996a), single altered genes can markedly increase predisposition to particular cancers. Radiation, a well-documented inducer of cancer, can play a role in both. The tumor types most likely to occur following therapeutic irradiation exposure are leukemias, soft tissue sarcomas, thyroid malignancies, breast carcinomas and certain brain tumors (astrocytomas, glioblastomas).

It has been generally assumed that radiation-induced cancer is primarily due to damage to the DNA, and the experimental evidence so far points to either 1) mutations that arise from base damage, e.g. oxidation of thymine and guanine, followed by proliferation of cells containing the mutated gene, or 2) DNA strand breaks which can result in chromosome rearrangements such as deletions, insertions, translocations, or actual chromosome loss. If a mutation either inactivates a tumor suppressor gene or activates an oncogene, the cell is now vulnerable to subsequent insults, including subsequent irradiation, which may eventually lead to cancer. Regardless of the mechanism, it is clear that long term exposure to radiation, even at low doses, increases the risk of carcinogenesis. This is thought to be possibly due to genomic instability which is a major outcome of radiation-induced damage ( Tlsty et al., 1995; Morgan et al., 1996). Morgan et al., (1996) have summarized several biological events which may lead to late-appearing effects, and they postulate that cryptic damage in the form of dicentric chromosomes may emerge at any time as a result of successive cycles of dicentric bridge breakagerejoining which may generate new karotypic rearrangements, some of which will be carcinogenic.

\section{NEURODEGENERATION}

Terminally differentiated cells such as neurons do not become cancerous due 
to radiation, but they may be vulnerable to outright killing by HZE particles. The effects of an HZE particle that may traverse about 1,000 cells per $\mathrm{cm}$., depositing a large amount of energy into the neurons traversed, and affecting neighboring cells, are likely to be quite different from those caused by low-LET radiation. Once killed, these cells are not regenerated in the human brain. Loss of neurons due to radiation damage might mimic one or more of the late-onset neurodegenerative diseases such as Alzheimer's disease, Parkinson's disease, amyotrophic lateral sclerosis or Huntington's disease. Evidence of neuronal apoptosis in humans with Alzheimer's disease has been reported by Anderson et al. (1996), and neurons are subject to apoptosis in vitro upon withdrawal of growth factors (Martin et al., 1992; Estus et al., 1994). Thus, there is concern that humans exposed to radiation in outer space for several years could eventually develop symptoms characteristic of one or more of these neurodegenerative diseases.

\section{REPRODUCTIVE TISSUES}

Estimates of the risk of impaired fertility and permanent sterility, as a result of exposure to low-LET radiation, can be made with reasonable confidence based on human experience. The area of uncertainty is whether, and by how much, protracted exposures are more or less damaging to the reproductive tissues than are single doses. There are few data for the effects of high-LET radiation on the human gonad, and relatively little is known about the effects of HZE particles in experimental animals. Countermeasures to radiation damage have not been assessed in terms of protection against loss of fertility, apart from shielding of the gonads from irradiation during diagnostic or therapeutic procedures.

Two types of cells are found in the seminiferous tubules: 1) Sertoli cells which are resistant to low-LET radiation, and 2) spermatogenia consisting of cells in the various stages of differentiation and the stem cells from which they arise. All the proliferative cells are radiosensitive, and in mice the $D_{0}$ (the final slope of the survival curve) for the clonogenic cells, which are assumed to be the stem cells, is about 1.7, and the $\mathrm{D}_{\mathrm{q}}$ (a measure of the width of the survival curve) is about $2.7 \mathrm{~Gy}$, indicating the capability for repair.

There is a third important population of cells, the Leydig cells, which are interstitial and the source of testosterone and other hormones. These cells are relatively radioresistant and thus, although exposure to radiation may cause a decrease in fertility, reduction in libido has not been reported. However, changes in the levels of both LH and FSH have been reported, suggesting some dysfunction of the Leydig cells after radiation therapy (Kinsella, 1989). The most important effect of radiation on the testis is the temporary reduction in fertility, which may occur with doses as low as 0.15 $\mathrm{Sv}$, and sterility that may be permanent with doses of 5 to $6 \mathrm{~Gy}$. 
The ovarian oocytes are found in the Graafian follicles and are irreplaceable. The number of follicles, about 400,000 , is maximal shortly after birth, but at any time in the adult there are immature, maturing, and mature follicles. While there is a considerable excess of follicles for the release of ova during the reproductive period, radiation-induced loss will cause reduced fertility, or even sterility. The oocytes vary in radiosensitivity, depending on the stage of development. The granulosa cells are radiosensitive, in contrast to the connective tissue of the ovary. Thus, the ovary is a radiosensitive organ and temporary sterility can result from doses in the 1.5-6.5 Gy range.

The endometrial lining of the female reproductive tract is also sensitive to ionizing radiation. Female rhesus monkeys exposed to whole body irradiation with single-energy protons, mixed-energy protons, $\mathrm{X}$-rays and electrons had incidence rates for endometrosis of $54 \%, 73 \%, 71 \%$, and $57 \%$, compared to an incidence rate of $26 \%$ for non-irradiated monkeys (Fanton and Golden, 1991).

\section{CATARACTOGENESIS}

At least two components of the eye, the lens and the retina, are particularly sensitive to radiation. Cataract formation is one of the near inevitable consequences of aging, but the process is hastened by radiation. It is not yet clear whether this results from the consequences of cell killing; DNA damage to the mitotically active epithelial cells; direct oxidation of the lens proteins, particularly crystallin which results in loss of transparency; or effects on the microenvironment, particularly the basement membrane. It is highly likely that the mechanism would be dependent on the dose, and at high doses a combination of all four of these factors would be operative.

\section{ABNORMAL FETAL DEVELOPMENT}

Mutations induced by radiation could also affect fetal development. While this would be a factor in colonization in outer space, it should not be a factor on a 3-year mission to Mars, and will thus not be further addressed in this report.

\section{AGING}

Whereas the exact molecular mechanisms of aging remain to be elucidated, it is generally agreed that aging and age-related pathology are due to both genetic and environmental factors. One of these environmental factors is thought to be oxidative damage due to low level, but continuous oxidative stress. Thus, radiation, which also elevates the level of oxidative stress, is potentially capable of perceptibly increasing the rate of aging of susceptible tissues in astronauts during a Mars mission. 
Bone marrow stem cell depletion is a late effect occurring in response to acute high doses of radiation, and could possibly be a concern during prolonged travel in outer space, particularly following exposure to an SPE. A more subtle threat would be the slow loss of stem cells due to HZE-particleinduced damage which could compromise tissue renewal much later in life. Thus, some attention should be given to the relative susceptibility of stem cells to HZE particles by following loss of colony forming units in bone marrow of irridated animals.

\section{Review references:}

Ainsworth EJ. 1986. Early and late mammalian responses to heavy charged particles. Adv. Space Res. 6: 153-165.

Blakely EA, Fry RJM. 1995. Radiation protection in space. Radiat. Environ. Biophys. 34:129-131.

Brenner DJ, Medvedovsky C, Huang Y, et al. 1991. Accelerated heavy particles and the lens. VI. RBE studies at low doses. Radiat. Res. 128: 73-81.

Kinzler KW, Vogelstein B. 1996a. Lessons from hereditary colorectal cancer. Cell 87: 159-170.

Meistrich ML, van Beek ME. 1990. Radiation sensitivity of the human testis. Adv. Radiat. Biol. 14: 227-268.

Morgan WF, Day JP, Kaplan MI, et al. 1996. Genomic instability induced by ionizing radiation. Radiat. Res. 146: 247-258.

NCRP. 1989. Guidance on Radiation Received in Space Activities, NCRP Report No. 98. National Council on Radiation Protection and Measurements, Bethesda, MD. pp. 85-105 (effects of radiation on the eye) and pp. 105-122 (radiation carcinogenesis).

NCRP. 1990. The Relative Biological Effectiveness of Radiations of Different Quality, NCRP Report No. 104. National Council on Radiation Protection and Measurements, Bethesda, MD, pp. 106-151.

Tlsty TD, Briot A, Gualberto A, et al. 1995. Genomic instability and cancer. Mutat. Res. 337: 1-7. 
Vainio H, Cardis E. (1992). Estimating human cancer risk from the results of animal experiments: relationship between mechanism and dose-rate and dose. Am. J. Indust. Med. 21: 5-14.

Warner HR, Starke-Reed P. (In press). Oxidative stress and aging. In: Oxygen, Gene Expression and Cellular Function, D. Massaro, L Clerch, (Eds.), Marcel Dekker, Inc., NY. 


\section{SUMMARY FOR SECTION IV.C}

It is quite clear that research on radiation damage covers a broad segment of biology. Indeed, it covers many of the outstanding problems in biology. As such, to know how to proceed in space exploration would require an in-depth analysis of our current knowledge in the above areas as they relate to human physiology. This is not a mean task and must integrate the existing knowledge in radiation biology with our basic understanding of mechanisms in molecular, cellular and tissue biology, and how these result in pathological outcomes.

- Exposure to radiation, especially high-LET radiation is clearly mutagenic, and mutagenesis is an accepted risk factor for cancer, especially in conjunction with genomic instability.

- An important area which deserves considerable attention before committing to a manned mission to Mars is the impact of HZE particle radiation on individual neurons and neural networks in vivo.

- While it has been documented that radiation induces cataractogenesis, it is felt that this is now a correctable problem, so the long term health risk in astronauts is relatively minimal compared to other health risks.

- Radiation affects the reproductive organs, but this would also appear to have minimal impact on a manned mission to Mars, except for the possible reduction in sperm production.

- Some aspects of aging are similar to radiation-induced effects. A common feature of the two is increased oxidative stress, but there is insufficient evidence to establish that this is a causal link.

- It is not known whether stem cells are more or less sensitive to HZE particles, compared to other cell types. If they are more sensitive this could cause significant wide-ranging difficulties related to tissue renewal later in life. 


\section{IV.D. MODEL SYSTEMS FOR STUDYING RADIATION DAMAGE}

The uncertainty about the health effects of galactic cosmic radiation in humans derives from a lack of knowledge about damage resulting from HZE particle irradiation. There are a number of reasons: earth-bound exposure to these particles is very low, there is a lack of clearly defined endpoints to use in measuring damage, and most importantly, it is not possible to use human subjects for research. Thus, model systems are required as surrogates for humans. These model systems include cultures of both human and animal cells; invertebrate models such as yeast, nematodes, and insects; and vertebrates such as rodents, dogs and non-human primates. The following sections will document but not exhaustively review the current state of knowledge gained using these model systems.

\section{CELL CULTURE SYSTEMS}

Cell lines from both animals and humans have been used in a wide variety of experiments to obtain information on biological damage due to radiation, and repair of that damage. Unfortunately, few studies have been performed with primary cell cultures, or with cells grown in a relevant physiological microenvironment. Therefore, the results obtained are primarily from immortalized cells grown under non-physiological conditions, and cannot adequately simulate the events occurring in vivo. In addition, to measure in vivo rates of reactions, one needs to use either relevant model organisms or non-invasive techniques in humans.

\section{a. Mutagenesis}

Much of the data available are based on mutations in the hypoxanthineguanine phosphoribosyl transferase (HPRT) gene, often in fibroblasts, because a positive selection system for hprt mutants has been developed (see Section V.A.1.b.). Studies have been performed both in rodent cell lines (e.g. Chinese hamster V79 cells), and in cultured human fibroblasts, and results obtained indicate that there is an optimum for both cell killing and hprt mutation induction at an LET of about $100 \mathrm{keV} / \mu \mathrm{m}$ (Cox et al., 1977; Hei et al., 1986b). Using Ar, Fe and La particles, Tsuboi et al. (1992) demonstrated a strong negative correlation between mutagenicity of the hprt gene and LET in the range of LET from 150 to 920; a similar relationship was found between LET and cell killing. Many of the hprt mutations induced by particle irradiation are accompanied by chromosomal aberrations, in contrast to mutations induced by $\mathrm{X}$-rays, suggesting that these particles induce more unrepairable damage in the DNA than do X-rays.

Zhu et al. (1996b) have done a detailed analysis of mutations induced by $\gamma$-rays and low energy light ions in a hybrid $\mathrm{CHO}$ cell line designated $\mathrm{A}_{\mathrm{L}}$. This cell line carries a single copy of human chromosome 11 which carries the marker 
gene S1; none of the genes on this human chromosome is essential for survival of the $\mathrm{CHO}$ cell line except genes in the telomeric region near 11p15. Using $150 \mathrm{keV} / \mu \mathrm{m} \alpha$-particles, these investigators showed that the mutation frequency at the S1 locus was 30-60 times higher than the frequency at the hprt locus, which is on the $\mathrm{X}$-chromosome. They also showed that radiationinduced mutations, and especially deletions, in the hprt gene were frequently observed, and that deletion size was dependent on both LET and dose. Similar results were observed at the S1 locus. These authors concluded that high-LET radiation induces predominately multilocus mutations, and that the increasing dose increases the probability of interaction between two independent radiation tracks.

When Fe particles were used to induce mutations in this hybrid cell, large deletions were also commonly observed by Kronenberg et al. (1995). These deletions range up to several tens of million basepairs. The frequency of mutations in the marker gene (S1) on the hybrid chromosome was about 50fold higher than mutations in the hprt gene. These results suggest further that hprt mutagenesis is a good model only for determining relative incidence of large deletion induction, because extensive linkage analysis of hprt-detective mutants arising from exposure to either $\mathrm{X}$-rays or low fluences of HZE particles demonstrates an inability to recover deletions that extend farther than 1.3 Mbp telomeric to hprt (Nelson et al., 1995; 1996). The hprt gene may lie near a gene essential for survival, which is then deleted along with the hprt gene in larger deletions, thereby causing loss of viability. Another conclusion is that HZE particle-induced mutagenesis may increase carcinogenic risk through deletion of regions carrying tumor suppressor genes.

Mutations have also been quantified for the autosomal heterozygous thymidine kinase $(t k)$ locus in human lymphoblasts. These data suggested that there is an LET-dependence for the induction of mutations that peaks at about $60 \mathrm{keV} / \mu \mathrm{m}$, and then declines. The molecular basis for the decline in mutant recovery at the highest LETs is unknown, but may be a reflection of a poor survival of cells with large deletions.

Molecular studies on the nature of mutations induced by $\alpha$-particles have demonstrated that large deletions predominate (Aghamohammadi et al., 1992; Chen et al., 1992; Lutze et al., 1992; Metting et al., 1992; Schwartz et al, 1994; Jostes et al., 1994, 1996; Bao et al., 1995). The extent of these deletions appears to be dictated primarily by the target gene being examined and the flanking essential regions. For example, deletion size is restricted at the hemizygous hprt locus, but not at the heterozygous $t k$ locus (Evans et al., 1994; Chaudhry et al., 1996). This would imply that it is more likely that ionizing radiation will cause cancer through the loss of tumor suppressor genes than by the activation of oncogenes, although stable translocations induced by ionizing radiation could be responsible for moving oncogenes 
into locations where they would be expressed. As we come to a greater understanding of the neoplastic process, it is likely that by studying the molecular spectra of ionizing radiation-induced mutations it will be possible to determine the likelihood that a single track of high-LET radiation would be capable of producing the changes necessary to induce neoplasia.

These studies of mutagenesis and induction of chromosome aberrations suggest possible qualitative as well as quantitative differences between highand low-LET radiations, and different particle types of the same LET that need to be examined further for their applicability to cancer risks (Kronenberg, 1995; Kadhim et al., 1992). The observation that high-LET radiation can induce genomic instability, i.e., the induction of delayed radiation damage leading to expression of damage in the progeny of surviving irradiated cells, is relevant to the situation to which astronauts are exposed in outer space.

\section{b. Neoplastic transformation.}

i. Neutrons: Data obtained prior to 1990 have been summarized in NCRP No. 104 (1990). These data have shown that neutrons are more effective at inducing neoplastic transformation of hamster embryo cells than are X-rays up to doses of about $1 \mathrm{~Gy}$ (Hall et al., 1982). A very similar result was reported by Han and Elkind (1979) using $\mathrm{C}_{3} \mathrm{H} / 10 \mathrm{~T} 1 / 2$ cells, a rodent cell line. Fractionation of the dose increased the transformation frequency per surviving cell in the case of neutrons, but reduced it in the case of ${ }^{60} \mathrm{CO} \gamma$-rays (Elkind et al., 1984), but this effect with neutrons has not been universally observed (Miller et al., 1988). The transformation frequency per surviving cell also increased with increasing LET at constant dose (Hei et al., 1988a).

ii. Alpha particles: Studies with human bronchial epithelial cells in vitro have shown that immortalized cells can be transformed to the neoplastic state by doses as low as 0.3 Gy of $\alpha$-particle irradiation (Hei et al., 1994). Transformation efficiency in $\mathrm{C}_{3} \mathrm{H} 10 \mathrm{~T} 1 / 2$ cells is dependent on the LET of the inducing radiation, and increases with the LET to a maximum between 70-100 $\mathrm{keV} / \mu \mathrm{m}$ (Miller et al., 1995). It has also been shown that the inverse dose rate effect occurs for cellular transformation, although it was dependent on the LET of the inducing radiation, and was found only for LETs between 40 and $120 \mathrm{keV} / \mu \mathrm{m}$, and in cycling cells (Miller et al., 1993). The latter implies that the effect may be induced only at a sensitive stage in the cell cycle.

The value of in vitro assays as predictors of tumorigenic potential was shown to be questionable in a study which examined the induction of cytogenic damage in different strains of animals that had previously been shown to have differential sensitivities to radon-induced lung cancers. No correlation between cytogenic damage, as measured by the induction of micronuclei, and the animals' susceptibility to tumor induction was found (Khan et al., 1995). This suggests that the use of in vitro assays may have limited value in risk 
estimation, although they may have value in the determination of the mechanisms of the tumorogenic process. This was shown very clearly in the elegant studies that first demonstrated the process of radiation-induced genomic instability. Kadhim et al., $(1992,1994)$ showed the induction of nonclonal chromosomal aberrations in clonal descendants of hematopoietic stem cells after low-dose, $\alpha$-particle exposure of human and murine bone marrow cells. This is evidence for the induction by high-LET radiation of a transmissible genomic instability, which at the doses used in these experiments, produces a variety of aberrations in the clonal descendants, and implies that the effect of a dose of ionizing radiation may be far higher than would be predicted from the inducing dose alone. These authors also reported that this effect was not induced by low-LET irradiation, and suggested this could be a property of high-LET irradiation only. The possibility that the effects of low doses of ionizing radiation may be more extensive than previously expected was also demonstrated by a study on the induction of sister chromatid exchanges (SCEs) with $0.31 \mathrm{mGy}$ of $238 \mathrm{Pu}$ which induced elevated SCEs in $30 \%$ of the cells, although it was estimated that only $1 \%$ of the cell nuclei were traversed by an $\alpha$-particle (Nagasawa and Little, 1992). Similar studies on the induction of the tumor suppressor gene, $p 53$, in $\alpha$-irradiated cells have also shown that p53 levels were elevated in more cells than could have been traversed by an $\alpha$-particle (Hickman et al., 1994).

\section{c. Cell killing}

That ionizing irradiation can kill cultured cells is well known. Killing with charged particles is often an exponential function of dose, although the survival curve with $\gamma$-rays may have a shoulder before exponential killing begins (Zhu et al., 1996b). Using $\gamma$-rays and small particles, these authors showed that killing efficiency generally increased with LET: $\gamma$-rays $<$ protons $(10 \mathrm{keV} / \mu \mathrm{m})<\alpha$-particles $(90 \mathrm{keV} / \mu \mathrm{m})$ (although $150 \mathrm{keV} / \mu \mathrm{m} \alpha$-particles were less efficient than the $90 \mathrm{keV} / \mu \mathrm{m} \alpha$-particles). Kronenberg et al. (1995) have estimated that in an experiment where $94 \%$ of human TK6 lymphoblasts were hit with at least one Fe particle, with an average of 2.7 traversals per cell, $87 \%$ of the cells were killed. Exactly what kills the cells is not so clear, but it is likely that apoptosis plays a role in some of these deaths (see Section IV.B.2.). These results suggest that the observed mutations are mainly from cells hit only once, because few cells sustaining multiple hits survive. Tsuboi et al. (1992) also estimated that only a few hits (2-3) per nucleus by Fe particles in human skin fibroblasts are sufficient to kill the cell. These conclusions, when combined with the calculations shown in Table IV.2, emphasize the importance of determining whether a similar level of vulnerability to HZE particles exists in vivo.

Xia et al. (1995) compared two human lymphoblast cell lines which were isolated from a single donor, but varied substantially in their sensitivity to ionizing radiation. The resistant strain, WTK1, expresses an excess of p53 
protein, but the protein had been altered by mutation. X-ray-induced apoptosis was delayed by several days in this strain compared to the wild type, whereas apoptosis induced by growth factor deprivation retained normal kinetics. The mutant strain is also more sensitive to radiation-induced mutation. These results suggest that cell killing due to radiation, but not growth factor-deprivation, is p53-dependent in these cells.

Kronenberg et al. (personal communication) using these same cells have demonstrated that WTK1 cells are more susceptible than their wild type p53 counterparts to both $\mathrm{Fe}$ - and proton-induced mutations. The increase in susceptibility is $25-40 \mathrm{x}$ more evident for the $t k$ locus, but only $2 \mathrm{x}$ more evident for the hprt locus. More recently, experiments in lymphoblasts differing only in expression of $b c l-2$ or $b c l-X_{L}$ demonstrated that suppression of apoptosis limits the expression of X-ray-induced mutations in cells with a wild type $p 53$ gene (Cherbonnel-Lasserre, et al., 1996).

\section{d. Changes in chromatin conformation}

A sensitive assay for low doses of radiation is the method of anomalous viscosity time dependence (AVTD) which correlates with changes in the conformation of chromatin and the cooperative interactions between DNA and DNA-binding proteins. The changes can cause subsequent changes in gene expression. A dose of $0.5 \mathrm{cGy}{ }^{137} \mathrm{Cs} \gamma$-rays reduces the viscosity peaks for human fibroblasts, mouse splenocytes and rat thymocytes (Belyaev and Harms-Ringdahl, 1996). This reduction was observed for doses of $\gamma$-rays up to 4 cGy. For doses in the range of 10-50 cGy the viscosity is increased by irradiation, and the inflection dose corresponding to the change from a decrease to an increase in AVTD extrapolates to 3-4 cGy. The increase in AVTD is dose-dependent, and exposure to $1 \mathrm{cGy}$ corresponds to about one single-stranded break per chromosome, and these breaks are readily repaired during incubation of cells at $37^{\circ} \mathrm{C}$.

\section{e. Remodelling of the Microenvironment}

Because cells exist in complex microenvironments that mediate phenotype and cell interactions in vivo, it is preferable and necessary to study cells within that context. The microenvironment includes both the insoluble extracellular matrix (ECM) and soluble cytokines that modulate cellular response to stimuli, which in turn may modify the microenvironment. While the radiation response of tissues has been well-described in terms of morphological parameters, pathophysiological manifestations and clinical consequences, such as tumor suppression and radiogenic fibrosis, the molecular mechanisms underlying these events are not yet well understood. Many of these effects have been attributed to DNA damage and its consequences such as cell death, but recent evidence suggests that additional processes initiated by radiation exposure are important. Altered 
microenvironment gene expression in irradiated tissues may result in changes in the phenotype of the cells that reside therein. These changes affect the cellular response to subsequent stimuli such as repeated irradiation or physiological challenge.

The microenvironment instructs individual cells how to interact with each other, and is an important conduit for information in normal physiological processes. Conversely, disruption of the microenvironment can promote cancer (Sympson et al., 1995; Z. Werb and M. Bissell, personal communication). In terms of tissue effects, radiation-induced changes in the cellular microenvironment could have a persistent influence on tissue structure and cellular function, differentiation and neoplastic potential. Whereas previous biochemical studies had demonstrated that doses of more than 5 Gy induced changes in ECM at periods of a month or more, analysis using immunolocalization in irradiated mammary gland demonstrates rapid (within $24 \mathrm{hrs)}$ global and dynamic microenvironment remodeling after doses of 5 Gy (Barcellos-Hoff, 1993). As a tissue mechanism contributing to carcinogenesis, the irradiated microenvironment may be differentially affected by radiation quality. Recent studies by Ehrhart et al. (1996) have demonstrated rapid and global remodeling of the microenvironment in irradiated murine mammary gland, and have identified characteristics of the HZE-irradiated remodeling that are distinct from those following sparsely ionizing radiation (Table IV.7). The data demonstrate that HZE particles can elicit specific microenvironmental modifications not observed after $\gamma$ radiation, and the authors postulate that these changes contribute to the functional and carcinogenic cellular effects of HZE exposure. In particular, irradiation with $600 \mathrm{MeV}$ Fe particles induced changes in the basement membrane, which is an important mediator of epithelial integrity (Section IV.B.4.). The rapid onset of this remodeling and its global nature suggest that further research may lead to new strategies for manipulating acute radiation effects during space flight and, possibly, subsequent events such as carcinogenesis.

The basement membrane normally serves as a barrier between stromal and epithelial cells, but cancerous cells destroy it in order to invade underlying tissue and metastasize. Radiation-induced changes in basement membrane integrity might thus promote neoplastic progression induced by Fe particle irradiation. Basement membrane discontinuities are characteristic of carcinoma in situ, whereas the basement membrane is lost in invasive carcinoma. Increased degradation of basement membrane by transformed cells is exacerbated by inability to either resynthesize or lay down a basement membrane (Liotta et al., 1983; Petersen et al., 1992). Chemical or geneticallyengineered disruption of the extracellular matrix in mammary gland is conducive to the expression and progression of mammary tumors (Lewko et al., 1981; Sympson et al., 1995; Lochter et al., 1997). Furthermore, the production of transin, a protease that degrades basement membranes by 
radiation-induced benign skin papillomas, correlates with a high rate of conversion to malignancy as compared to chemically-induced tumors (Bowden et al., 1990). Radiation-induced changes in microenvironment may thus act both as an initiator and a promoter of carcinogenesis.

TGF- $\beta 1$ may mediate certain aspects of this ECM remodeling (Barcellos-Hoff, 1996). TGF- $\beta 1$ is increased during the acute post-irradiation period in mammary gland, small intestine and lung (Barcellos-Hoff, 1993; Langberg et al., 1994; Finkelstein et al., 1994). TGF- $\beta 1$ normally exists in a latent form that is bound to ECM, and requires activation to induce biological action. Recent studies with sparsely ionizing $\gamma$-irradiation indicate that radiation exposure at doses from $10 \mathrm{cGy}$ to $5 \mathrm{~Gy}$ leads to TGF- $\beta 1$ activation within an hour, and persists for at least 7 days (Ehrhart $e$ al., submitted). The timing of TGF- $\beta 1$ activation and the localization are different in Fe-irradiated tissue compared to ${ }^{60} \mathrm{Co} \gamma$-irradiated tissue. The earliest evidence of TGF- $\beta 1$ activation after irradiation with $0.8 \mathrm{~Gy} 600 \mathrm{MeV}$ Fe particles is at $24 \mathrm{hr}$, is predominantly epithelial, and persists at least 14 days. Using $1 \mathrm{GeV}$ Fe particle whole body irradiation, a dose response has shown that activation is detected at doses of $10 \mathrm{cGy}$ and above (Barcellos-Hoff and Ehrhart, personal communication).

Activation of TGF- $\beta 1$ by radiation can have carcinogenic effects in a tissue already compromised by aberrant expression of other genes. For example, when grown in collagen gels, both normal and ras-transformed mammary epithelial cells form organ-like structures in which the cells maintain their epithelial characteristics (Oft et al., 1996). The addition of TGF- $\beta 1$ to the rastransformed cells renders them invasive and resistant to growth inhibition by TGF- $\beta 1$; similar synergistic effects are observed in vivo. Addition of TGF- $\beta 1$ to normal cells simply results in growth arrest.

Yang et al., (1995) have conducted experiments that indicate that $\gamma$-irradiation of the fetus damages the developing hemopoietic microenvironment rather than the hemopoietic progenitor cells. Hemopoiesis is the product of two components: the hemopoietic tissue and the regulatory stromal microenvironment in which it resides. Mice irradiated in utero exhibit deficient hemopoiesis for at least 6 months after birth. The irradiated offspring show a persistent microenvironment deficit as evidenced by $70 \%$ fewer stromal progenitors and the failure to support transplanted unirradiated hemopoietic progenitor cells. These authors have recently suggested that the RBE for alpha particle exposure is 100-350 when this endpoint is used, which contrasts greatly to values $(2-20)$ obtained by direct irradiation of stem cells (Jiang et al., 1994). Thus, it is clear that the RBEs observed depend heavily on the biological system and endpoint chosen. Such complex interplay between stroma and parenchyma argues that it may be important to determine the RBE for long-term effects in vivo. 
In summary, experiments in irradiated murine mammary gland have demonstrated that radiation-induced microenvironment remodeling is: 1) rapid, global and dynamic over a period of at least 14 days, 2) sensitive to low doses (10 cGy), and 3) sensitive to radiation quality effects. To date few studies have focused on the character or consequences of the irradiated microenvironment. However, preliminary studies in murine mammary gland also suggest that irradiating the stroma has a more profound effect on the character of the developing mammary epithelium than irradiating the epithelium (Barcellos-Hoff, 1996).

\section{f. Single cell irradiation with helium ions}

Noelle Metting (personal communication.) has synchronized HeLa S3 cell cultures and has irradiated these cells, one at a time, with energetic helium ions that approximated alpha particles. After a two-hour incubation the cells were fixed and the cellular DNA was probed by enzymatic addition of fluorescin-labelled dNTP's to 3'-termini. The cells were then viewed by confocal laser scanning microscopy to detect the location of the fluorescinlabelled nucleotides. The results are shown in Figure IV.4. There is a clear and distinct difference in the labelling of irradiated and unirradiated cells in these experiments. The irradiated cells are labelled in discreet, columnar foci, when viewed from the top (upper left picture) or from the side (lower left picture), in a cell irradiated with three particles. In contrast, labelling in the control cell is diffuse and spread across most of the cell nucleus. These data are consistent with evidence that during the two-hour incubation, repair endonucleases are recruited to these sites of highly localized DNA damage. These pictures suggest a novel method to visualize early events in the process of DNA repair in mammalian cells.

However, as mentioned above, both the fact that these cells are malignant and that they are single cells, and thus completely devoid of microenvironmental regulation, must be taken into consideration before general conclusions can be drawn about repair in vivo. While it is possible that such a fundamental process as repair of DNA damage may be independent of cell-cell and cell-ECM interactions, and whether cells are normal or malignant, this cannot be assumed a priori, and must be demonstrated experimentally. 


\section{Irratiatici}

Cinntrol

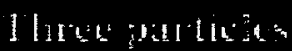

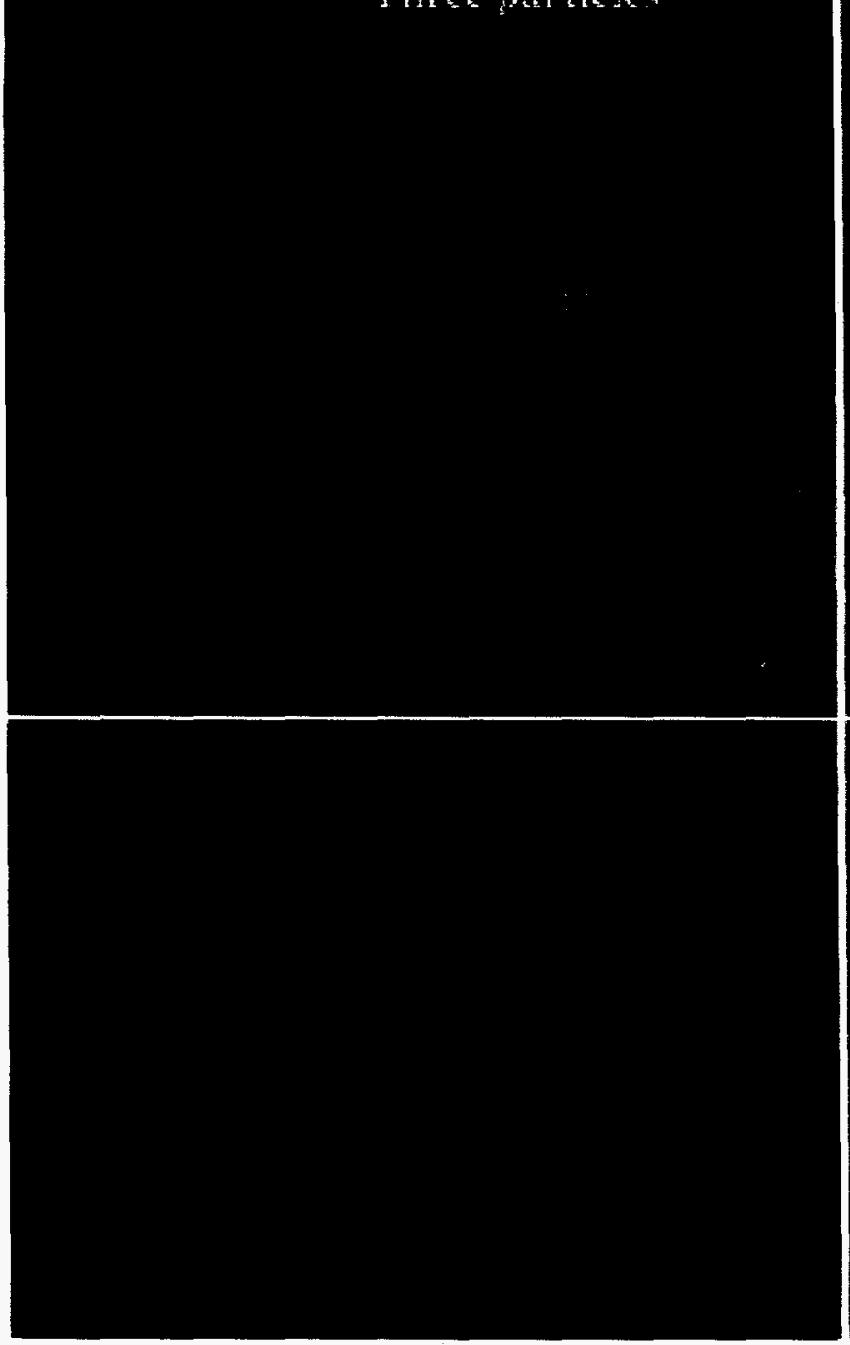

Figure IV.4: Tracks of damage induced by helium ions in HeLa cells. The cells on the left were irradiated by 3 particles, and the 3'-termini of DNA were labelled by incubating the cells with fluorescein-labelled dNTPs. In the upper figure the cells are viewed from the top; in the lower figures, from the side. Photographs provided by Noelle Metting (Pacific Northwest National Laboratory). 


\section{g. Summary for Section IV.D.1.}

Results from studies with cultured cells have been most useful for elucidating molecular mechanisms and biochemical pathways. However, while rates of reactions and pathways can be determined in cellular systems, this information will only be useful in predicting human risk in outer space if appropriate strategies can be established to extrapolate these results to the level of the whole organism.

- HZE particles are clearly mutagenic, carcinogenic and can induce cell death. They are roughly 10 times more potent per Gy than are low-LET forms of radiation, such as $\gamma$-rays.

- When human lymphoblasts are traversed by an average of $2.7 \mathrm{Fe}$ particles per cell, $87 \%$ of the cells are killed; Poisson distribution calculations indicate that $94 \%$ of the cells are actually hit. These results suggest that mutations arise primarily from cells hit only once, and that multiple hits by Fe particles (as few as 2?) usually kill cells, although some cells are probably killed by traversal by a single Fe particle.

- HZE particles induce a significant number of double-strand breaks, many of which cannot be faithfully repaired. Two of the consequences of these breaks are DNA deletions and chromosome rearrangements.

- Studies of mutagenesis at different loci have demonstrated that the mutant frequency and spectra are strongly influenced by the size and location of the target gene being studied. Very large deletions $(\geq 3 \mathrm{Mb})$ are not recovered at the hrpt locus because of the high probability of deleting a nearby essential gene. In systems where the target gene has an autosomal location, higher mutation frequencies and larger deletions can be recovered. Factors such as these have to be carefully considered if results obtained with low-LET radiation are to be extrapolated to those expected for high-LET radiation, where it is anticipated a greater proportion of large deletions will be induced.

- Irradiation of cells in an inappropriate microenvironment can lead to erroneous conclusions about the behavior of irradiated cells in tissues. Irradiation of tissues leads to activation of TGF- $\beta 1$ which resides within the ECM, and rapid and global remodelling of the microenvironment. HZEirradiation elicits microenvironmental effects which are distinct from those observed following low-LET ionizing radiation (Table IV.7).

- Existing studies of radiation-induced genomic instability indicate that there may be qualitative as well as quantitative differences between high- and lowLET radiations and different particle types of the same LET. These differences 
need to be examined further for their applicability to health risks during space travel.

- Theoretical modelling and additional experiments with cell culture systems may be necessary to predict the existence of synergistic effects from a combination of particles of both low- and high-LET.

Review references.

Blakely EA. 1992. Cell inactivation by heavy charged particles. Radiat. Environ. Biophys. 31: 181-196.

NCRP. 1990. The Relative Biological Effectiveness of Radiations of Different Quality, NCRP Report No. 104. National Council on Radiation Protection and Measurements, Bethesda, MD, pp. 49-74. 


\section{a. Invertebrates}

i. Caenorhabditis elegans: The nematode Caenorhabditis elegans (C. elegans) has been suggested as a model system for space biology studies by Johnson and Nelson (1991). C. elegans possesses several characteristics which make it ideal for genetic studies in general; it is a small transparent selffertilizing hermaphrodite with a fixed number of cells: 959 in the adult hermaphrodite, and 1031 in the adult male (Sulston et al., 1983). Its entire developmental history is known, and it is sensitive to a variety of chemical and physical agents, including radiation (Nelson et al., 1992). Several mutants sensitive to radiation have been isolated and partially characterized by Hartman and Herman (1982), and the entire sequence of the 6 chromosomes which comprise the genome will soon be known.

Autosomal recessive lethal mutations were induced in $C$. elegans by both low-LET radiation $\{\alpha$-particles $(1.8 \mathrm{keV} / \mu \mathrm{m})>$ protons $(0.55)>\gamma$-rays $(0.3)\}$ and high-LET particle radiation $\{\mathrm{Ar}(199)>\mathrm{Nb}(520)>\mathrm{Ar}(100)>\mathrm{Si}(45)>\mathrm{Ne}(27)\}$ in a linear response fashion (Nelson et al., 1989). In these experiments the inactivation cross-sections were two orders of magnitude less than the cross section of the gamete nucleus indicating that at least several hits per nucleus are required to produce a mutation. Deletion mutations in the unc 22 gene, a gene for a muscle protein, were much more frequent after irradiation with $\mathrm{Ne}, \mathrm{Fe}$ or neutron particles, than they were after irradiation with $\gamma$-rays or protons. Thus, the pattern of radiation-induced mutations in nematodes is similar to that observed using animal cells in culture (Section IV.D.1.a.). When irradiations were performed in the absence of oxygen, the mutation frequencies were reduced by about $50 \%$, suggesting that at least $50 \%$ of the mutations were due to a direct hit on the DNA target, rather than mediated by reactive oxygen species.

Nematodes were flown on the IML-1 Spacelab mission, but the length of this mission was not provided (Nelson et al., 1994). The influences of repair capability and microgravity on mutation frequency were investigated by maintaining the nematodes at either $4^{\circ} \mathrm{C}$ (non-permissive temperature) or $22^{\circ} \mathrm{C}$ (permissive temperature), and by placing some nematodes in a $1 \mathrm{xg}$ centrifuge at $22^{\circ} \mathrm{C}$ during space flight. The preliminary results from this flight include: 1) space flight increased the overall mutation frequency 8-fold over the spontaneous rate observed in ground-based controls; 2) mutants associated with specific tracks in detectors were often characterized by chromosomal rearrangements; 3 ) dose exposures received during the flight were in the range of $0.8 \mathrm{mGy}$ to $1.1 \mathrm{mGy}$; and 4) there was not a significant difference in mutation rates between nematodes maintained at $1 \times \mathrm{xg}$ versus the microgravity of the Spacelab. 
When the radiation-sensitive ( $\mathrm{rad}$ ) mutants isolated by Hartman and Herman (1982) were exposed to $\gamma$-rays from ${ }^{60} \mathrm{Co}$, only rad 2 was found to be hypermutable. The mutability of rad2 was not tested for its response to HZE particles. However, irradiation also induced formation of nucleoplasmic bridges during development which is thought to be due to chromosomal rearrangements. Such bridges were induced by both $\gamma$-rays and HZE particles. Both $\gamma$-rays and neutrons induced more nucleoplasmic bridge formation in rad2 and rad7 mutants, whereas $\gamma$-rays only increased bridge formation in rad2 (Nelson et al., 1992). Thus, C. elegans has a repair pathway for ionizing radiation, and the rad2 gene product is involved in this pathway.

Although the above data indicate that $C$. elegans can be used to relate radiation damage to mutagenesis, its greatest potential may be in studying radiation-induced cell killing, particularly of neurons. Not only have all of the neuronal cells been identified in the adult, but also the cells which they activate (White et al., 1986). Although the loss of any given neuron due to HZE particle-induced damage could presumably be determined by electron microscopy, such a procedure would not lend itself well to mass screening of such events. Instead, functional tests are needed so that mutants can be screened in a light microscope.

At least two approaches seem feasible. One of these is suggested by the work of Chalfie et al. (1994), who have used the gene for green fluorescent protein linked to the mec7 promoter. Mec7, the gene for $\beta$-tubulin, is abundantly expressed in the six mechanosensitive neurons; thus, these neurons also express the green fluorescent protein, and the loss of this expression would indicate either disruption of gene expression in a given neuron, or actual loss of the neuron. The other approach is suggested by the work of Avery and Horvitz (1989), who have shown that a single neuron, M4, is necessary and sufficient for isthmus peristalsis. If the M4 neuron is killed, the nematode can no longer perform peristalsis, but pumping is maintained. These are but two examples of approaches which could be developed as model systems to study neuron killing in response to HZE particle irradiation.

ii. Drosophila melanogaster: Fruit flies were exposed to HZE particles by D'Amelia et al. (1984) to determine what structural changes might occur in the central nervous system. These flies were exposed to either Ar particles $(6$ $\times 10^{4}$ to $8 \times 10^{7}$ particles $\left./ \mathrm{cm}^{2}\right)$ or $\mathrm{Kr}$ particles $\left(5.8 \times 10^{3}\right.$ to $2.2 \times 10^{6}$ particles $/ \mathrm{cm}$ ). Anatomical changes such as fragmented membranes, swelling of neuronal cytoplasm, and increases in glial lamellae were observed at fluences as low as one hit per 100 cell bodies. Thus, it is clear that even low fluences of these HZE particles can induce significant structural damage. In parallel experiments by these authors using mice, structural changes were also induced by Ar particles at doses as low as $0.05 \mathrm{~Gy}$. In a separate experiment D'Amelio et al. (1982) showed that a dose of $\mathrm{Kr}$ particles as low as $0.042 \mathrm{~Gy}$ induced morphological changes in fruit fly brains. 


\section{b. Rodents}

i. Radiation-induced cell death.

Ceramide-induced apoptosis:. New insights into the acid sphingomyelinase-dependent apoptotic pathway (discussed in Section IV.B.2.) are now possible because of the availability of knockout mice deficient in acid sphingomyelinase (Santana et al., 1996). Radiation of these mice with up to $30 \mathrm{~Gy}{ }^{137} \mathrm{Cs} \gamma$-rays failed to induce either an increase in ceramide in the lungs of these mice, or apoptosis. In contrast, radiation-induced apoptosis in the spleen and thymus, while reduced, was significant in the knockout mice compared to the control animals. Comparison with $p 53$ knockout mice indicated that acid sphingomyelinase-mediated apoptosis and p53-mediated apoptosis are likely distinct and independent. This suggests that apoptosis in these tissues is at least partially independent of sphingomyelinase, and dependent on p53. Santana et al. (1996) suggest that radiation-induced sphingomyelinase-dependent apoptosis is membrane-based, while p53dependent apoptosis may be related to DNA damage. The sphingomyelinasedeficient mice are born without apparent developmental defects, as is the case for p53-deficient mice (Kemp et al., 1994), suggesting that developmental apoptosis is distinct from both of these mechanisms. How radiation activates sphingomyelinase is unknown. Pharmacologic manipulation of sphingomyelinase activity could potentially be used to modulate radiationinduced apoptosis.

Differential sensitivity to radiation. Jurásková and Kozubek (1996) used continuous irradiation of $\mathrm{C} 57 \mathrm{Bl} \times \mathrm{BALB} / \mathrm{c} \mathrm{F} 1$ mice with ${ }^{60} \mathrm{Co} \gamma$-rays to compare the effect of the radiation on LS/BL lymphosarcoma cells and hematopoietic stem cells. The mice received $10 \mathrm{cGy}$ per hour for periods of up to 152 weeks. The tumor cells growing in the peritoneal cavity of these mice tolerated the radiation and survived very well, whereas the stem cells were killed at a rate of about $90 \%$ every 3 days. These results demonstrate the relative sensitivity of stem cells (compared to the tumor cells) to continuous $\gamma$-radiation at a dose as low as $10 \mathrm{cGy}$ per hour.

\section{ii. Carcinogenesis}

Lifetime exposure of mice to low level $\beta$-radiation. Ootsuyama and Tanooka (1993) have exposed virgin female ICR/CRI mice to a $90 \mathrm{Sr}-90 \mathrm{Y}$ disk three times a week throughout the lifetime of the mice, starting at 7 weeks of age. Radiation doses varied from 0.5 to 11.8 Gy per exposure on the back of the mouse. At dose exposures of $2.5 \mathrm{~Gy}$ or more, all mice developed skin and bone tumors by about 500 days of age. In contrast, no mice receiving a dose exposure of 0.5 Gy developed tumors. This exposure, while not altering the maximum life span, did reduce the mean life span by about $10 \%$. Thus, 
tumorigenicity at high doses cannot be extrapolated to low dose exposures under the experimental conditions used in this experiment.

Comparison of oncogenic potential of electron and Ar particle irradiation in rats. Burns et al. (1993) have determined the tumor incidence in Sprague-Dawley CD rats exposed at 1 month of age to either $1.8 \mathrm{MeV}$ electrons or $640 \mathrm{MeV} /$ nucleon Ar particles. In each case, $8 \mathrm{~cm}^{2}$ of folded skin was irradiated by a single dose of radiation, and tumor incidence was determined at the age of 1 year. The data from this experiment are shown in Table IV.8. It is clear that the Ar particles are many times (about ten) more effective at inducing cancer than are the electrons at the same dose. These investigators also demonstrated that fractionation of a $19.5 \mathrm{~Gy}$ dose of electrons into $3 \times 6.5$ Gy doses reduced the cancer incidence by 10-fold; fractionation into $5 \times 3.9$ doses eliminated the cancer incidence due to electrons altogether. These results also illustrate that predictions of effects at low dose cannot be made from data obtained at high rates dose given at a high dose rate.

The Harderian gland as a model for radiation-induced carcinogenesis. The Harderian gland system in rodents has been proposed as a model for carcinogenesis induced by HZE particles (Fry et al., 1985; Alpen et al., 1993; Alpen et al., 1994). While it is true that humans do not possess such a gland, these studies are still useful because there are few models for radiationinduced epithelial cancers. Alpen et al. (1993) reported that tumor induction in mice 16 months after irradiation is directly proportional to doses up to at least 3 Gy for both $\alpha$-particles and ${ }^{60} \mathrm{Co} \gamma$-rays, with the $\alpha$-particles being about $50 \%$ more effective. Tumor induction in mice was about 10 -fold greater for Fe particles than for $\alpha$-particles or $\gamma$-rays. These and related data are summarized in Table IV.8, and indicate that tumor induction is directly related to LET up to an LET of about 200. If a Fe dose is delivered as $6 \times 0.07 \mathrm{~Gy}$ doses at 2-week intervals instead of a single 0.4 Gy dose, the tumor prevalence is increased from 0.29 to 0.43 (Alpen et al., 1994), in contrast to results with low-LET irradiation, where dose fractionation usually causes a decrease in tumor induction. The authors hypothesize that this enhancement by dose fractionation will be observed only with particles of very high LET (see Table IV.11). A major question is whether enhancement by fractionation of low doses would also be observed.

Exposure of rats to radon. One finding from studies on irradiation of rats with radon ( $\alpha$-particles) is that protraction of the dose causes an increase in the effect. While this has significant implications for the effects of exposure in the space radiation environment where exposure to high LET radiation occurs at a low rate, it should be noted that the inverse dose rate effect is not independent of the dose. It was shown that if rats were exposed to 320 WLM of radon at exposure rates that differed by an order of magnitude (100 WL vs. $1000 \mathrm{WL}$ ), the tumor incidence was higher by a factor of 2-3 at the 
lower dose rate (Cross et al., 1984). However, in another study where the cumulative dose was only 25 WLM, protraction of the exposure over 18 months produced no significant increase in tumor incidence over controls, whereas the same dose delivered over 4-6 months produced a statistically significant increase (2-3\%) (Chameaud et al., 1985). These differences are considered to be due to the fact that at very low doses it is extremely unlikely that a cell will ever be traversed by more than one particle. Where the possibility for multiple hits is vanishingly small, there is no expectation that a dose-rate effect can occur. Extrapolation of data to the space radiation environment will require the determination of whether the effects of HZE particles at low doses are in fact enhanced by dose fractionation, and whether both the dose and dose rate of this radiation in space fall within the required parameters to induce this response.

Effect of electron radiation on oncogene expression in rodents. Carcinogenesis in rodents can often be correlated with amplification of oncogene expression. Jin et al. (1992) have shown that expression of both the $c$-myc and $\mathrm{V}$-Ha-ras oncogenes are amplified in skin tumors in rats irradiated at 1 month of age by either 10 or $20 \mathrm{~Gy}$ of $0.8 \mathrm{MeV}$ electrons. This group (Garte et al., 1990) also demonstrated that radiation-induced $c-m y c$ amplification occurred in rat skin carcinomas, but not sarcomas, and that amplification of $c-m y c$ increased with increasing time in given tumors, suggesting that $c-m y c$ amplification might be a result, rather than a cause of, the radiation-induced carcinogenesis. In contrast to electron radiation, $\mathrm{Ne}$ particles at $45 \mathrm{keV} / \mu \mathrm{m}$ induce very little c-myc amplification (Felber et al., 1992).

Influence of LET on carcinogenesis. Data for tumor induction following proton irradiation are available for only a few tumor types following acute exposures. The limited dose response data which can be obtained from these studies suggest similarities with those after $\gamma$-ray irradiation (Yochmowitz et al., 1985; Clapp et al., 1974; Burns et al., 1989). Only one study has found evidence to support an RBE of greater than one. Additional support for the similarity of proton effects with low-LET radiations comes from the work of Burns et al., (1975) who reported a nonlinear dose response for rat skin tumor induction similar to that after exposure to electrons, and a reduction of the carcinogenic effects of protons with fractionation. The dose responses for protons, $\gamma$-rays, and $\mathrm{X}$-rays tend to be linear/quadratic, and there is clear evidence for repair of DNA damage induced by low-LET radiation. While most data tend to support the view that risks for high energy protons will be similar to those for low-LET radiations, additional studies of protons in the range of energies relevant to those encountered in space would strengthen this conclusion considerably. The purpose of such experiments would be to determine whether biological effects of these higher energy protons are qualitatively similar to those of low-LET 
radiations, and to determine whether repair of proton-induced DNA damage can be observed. Protons are the major component of GCR (Section IV.A.2).

Information on tumor induction following exposure to heavy ions is limited. The experiments conducted by Burns et al. (1993) on skin tumor induction in rats following argon irradiation provide evidence of a fairly linear dose response for tumor induction with this high-LET radiation, and support the expectation of a relatively high RBE. However, because of the dominance of the quadratic nature of the low-LET dose response, the data do not allow for the estimation of an RBE that could be used in the determination of an appropriate quality factor. To do this requires information on the relationship between LET and RBE for tumor induction. The only such systematic study of RBE and LET relationships for tumor induction were conducted for the Harderian gland in mice, as discussed above. The data show a rise in RBE with LET which peaks at an RBE of 30 in the 100-200 $\mathrm{keV} / \mu \mathrm{m}$ range (Alpen et al., 1994). Importantly, there was no clear cut evidence of a decrease in RBE at LETs up to about $400 \mathrm{keV} / \mu \mathrm{m}$ as predicted by LET-biophysical models, and which has been observed for cell killing and mutation. Because the quality factor-versus-LET relationships adopted by ICRP (1991) incorporate a decrease at LETs greater than $100 \mathrm{keV} / \mu \mathrm{m}$, these Harderian gland data suggest possible important discrepancies which need to be explored with other tumor-induction models. Studies of Harderian gland tumorigenesis also suggest that the RBE values for fission spectrum neutrons are similar to those for $100-200 \mathrm{keV} / \mu \mathrm{m}$ heavy ions (NCRP, 1990). If this is the case, there are dose-response and dose-rate data for the induction of several tumors in mice after neutron irradiation which could possibly be used in support of establishing a reliable quality factor for heavy ions in this energy range. 
TABLE IV.8

CANCER INDUCTION IN RODENTS

Cancer Induction in Rats by Electrons and Ar particles

$\underline{\text { Skin cancer yields per } 100 \text { rats }}$

DOSE

\begin{tabular}{ccc}
$(\mathrm{Gy})$ & Electrons & Ar parti \\
\hline & & \\
Control & 0.0 & 0.0 \\
0.5 & -- & 3.8 \\
1.6 & -- & 10.7 \\
3.2 & -- & 13.3 \\
$5.0 ; 4.8$ & 2.7 & 44.2 \\
6.3 & -- & 59.2 \\
$9.8 ; 9.5$ & 22.4 & 148 \\
13.7 & 25.0 & -- \\
19.2 & 108 & -- \\
26.9 & 237 & --
\end{tabular}

Adapted from Burns et al. (1993)

Dose Required for 30\% Harderian Gland Tumor Induction in Mice Ion/Particle Energy $(\mathrm{MeV})$ $\operatorname{LET}(\mathrm{keV} / \mu \mathrm{m})$ Dose (Gy)

${ }^{60} \mathrm{Co} \gamma$-rays

Protons

$\alpha$-particles

$\mathrm{Ne}$

$\mathrm{Fe}$

$\mathrm{Fe}$

$\mathrm{Nb}$
250

228

670

600

350

600
0.23

0.4

1.6

25

193

253

464
3.0

1.6

2.0

0.8

0.2

0.3

0.25

Adapted from Alpen et al. (1993) 


\section{iii. Neurobiological damage:}

Whereas such factors as weightlessness, genetic aberrations, increased risk of cancer, etc., have been addressed extensively during previous orbital missions, the potential health hazards of extended spaceflights with respect to brain and behavior have not been examined to any great extent (NCRP, 1989). The central nervous system (CNS) was considered to be a radio-resistant tissue in the past because neurons are post-mitotic in the adult. However, the neuroglia (Chauser et al., 1977) and the vascular endothelium (Rheinhold, 1980) are affected by radiation and, therefore, secondary effects on the grey matter of the brain and spinal cord can occur. These effects will occur with all types of radiation, but the deposition of energy and the characteristics of the damage from traversal of contiguous cells by densely ionizing particles are very different from those observed after low-LET radiation. Therefore, differences in the probability of damage to the brain from high-LET radiation compared to low-LET radiation is expected.

In the case of low-LET radiation in the human, necrosis of the brain can occur after large doses, such as $70 \mathrm{~Gy}$ received in fractionation regimens for cancer therapy (Kramer et al., 1972). The tolerance dose for the brain is considered to be about 55 Gy fractionated over about six weeks. Tolerance doses for the spinal cord are lower, and morphological changes are found after a dose of 40 Gy given in fractions in the human (Kramer et al., 1977), and after considerably lower total doses in experimental animals (see UNSCEAR, 1982 for references).

The studies of the effects of HZE particles (e.g. Fe) on the rodent brain, the information generated in cell culture systems about the mechanisms of DNA damage caused by HZE particles and its repair (Sections IV.B.1), and the fact that on a long duration deep space mission a large number of neurons will be traversed (Table IV.2), all suggest a potential for HZE particles to alter brain function and behavior. The concern is whether or not there is a significant risk for clinically important late effects in the brain and other neuronal tissues. The use of computerized tomography (CT) and magnetic resonance imaging (MRI) have increased the ability to detect radiation-induced changes, in particular, cortical atrophy, and positron emission tomography (PET) makes it possible to investigate function as well (Section V.B.2). Research on the neurobiological effects of the higher $\mathrm{Z}$ particles indicate that relatively low doses can cause alterations in rodents. Some of these are discussed below, and are summarized in Table IV.9.

Given the more recent findings of damage to the microenvironment (Section IV.B.4.), it is possible that some of the following radiation-induced effects are 
due to extensive damage to the extracellular matrix. This in turn could cause the profound disturbance in neuronal functions discussed below.

Substantia nigra cell loss. One of the more striking changes produced by $0.1-1.0 \mathrm{~Gy}$ of $600 \mathrm{MeV}$ Fe particle irradiation are profound losses in tyrosine hydroxylase immunoreactivity in the substantia nigra (Madi Gupta, personal communication; also see Figure IV.5; these losses approach 60-80\%). Significant decreases in cell numbers in this brain region resemble the losses seen in Parkinson's disease, where profound motor behavioral deficits have been observed. Unfortunately, further examinations of the extent and specificity of this cell loss have been hampered by limited access to Fe particlegenerating facilities.

Philpott et al. (1985) have shown that mice given brief exposure to low doses of Ar particles showed time-dependent reductions in performance of a wire suspension task, a measure of muscle strength. More recently, Joseph et al. (1992) have shown similar effects on the wire suspension task in animals exposed to low doses of either $600 \mathrm{MeV}$ or $1 \mathrm{GeV} / \mathrm{n}$ Fe particle irradiation. Thus, one might postulate that either delayed or immediate radiationinduced motor deficits might occur on or following a Mars expedition.

The precise central loci of such deficits are still unknown. However, studies in non-irradiated organisms suggest that the nigrostriatal system may be important in mediating these effects. The striatum (the end terminus of this system) is one of the basic central processing areas involved in mediating motor behavior. This structure appears to control a variety of motor responses ranging from the simple, e.g., balance and coordination, (Bernheimer et al., 1973), to the complex, e.g., the ordering and sequencing of intricate behavioral patterns directed by exteroceptive stimuli (Cools et al., 1984). Thus, Fe particle irradiation produces at least two types of effects in the nigrostriatal system which could ultimately be expressed as decrements in motor behavior, namely cell loss and deficits in signal transduction in the striatum. 

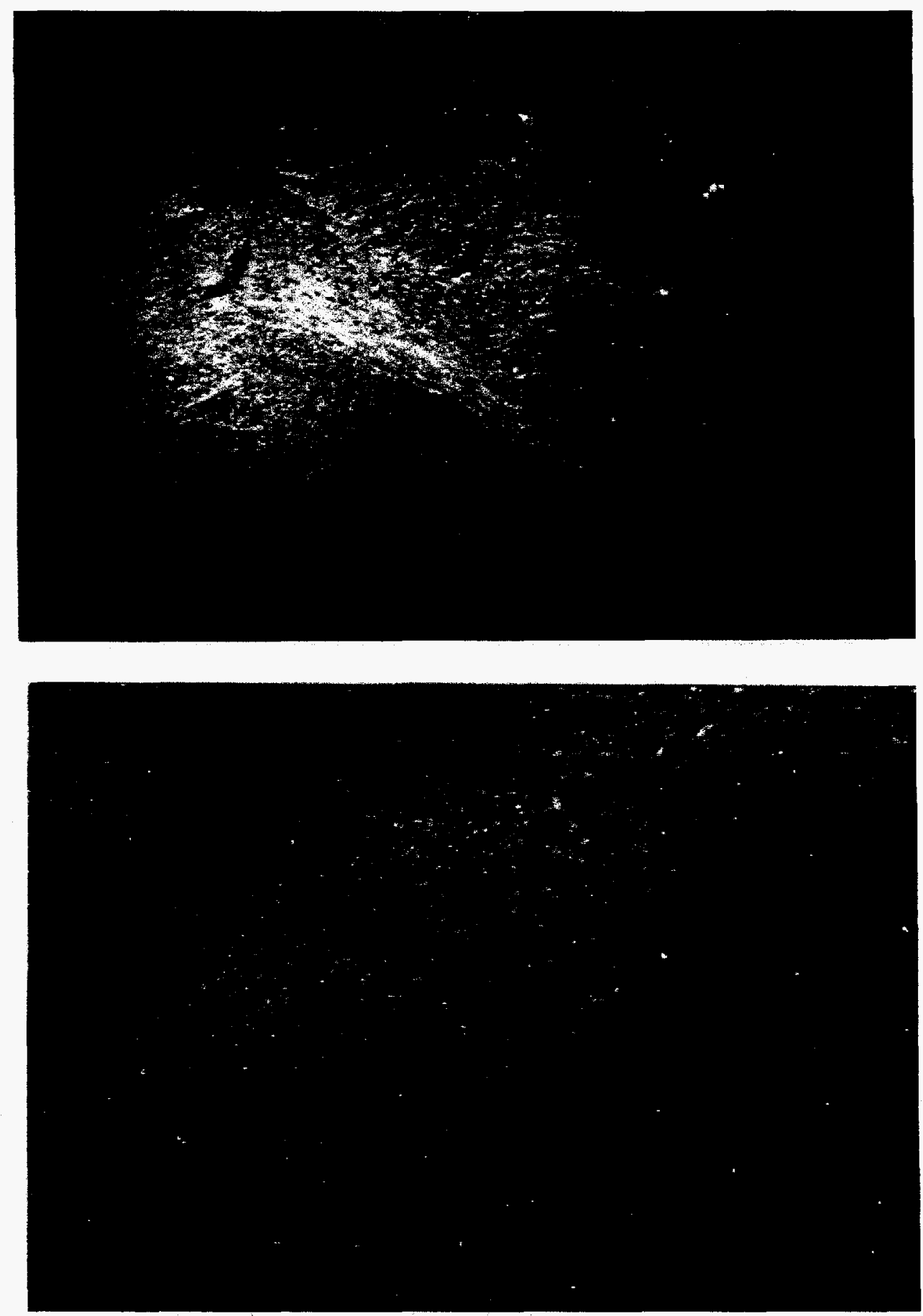

Figure IV.5: Radiation-induced loss of tyrosine hydroxylase in the substantia nigra in rats. Top - unirradiated control; Bottom - irradiated with 0.5 Gy Fe particles. Photograph taken by Madi Gupta (University of Kentucky) and provided by James Joseph (Tufts University) 
Based on studies using 2-5 Gy doses of $\gamma$-radiation exposure, glial cell cultures show perturbations of oligodendroglia cell proliferation that are postulated to occur in radiosensitive progenitor and immature glial cells. The results reported by Vrdoliak et al. (1992) show that radiation-induced apoptotic cell death is exhibited by mature oligodendrocytes, but not by either immature oligodendrocytes or by their progenitors, suggesting that differentiated cells are immediately lost from the population whereas immature or multipotent cells are repressed by other mechanisms. Importantly, TGF- $\beta 1$ is critical to both processes. Apoptosis is an orchestrated response to inappropriate stimuli (Evans, 1993). Thus, if TGF- $\beta 1$ is activated during injury or tissue remodeling, then a differentiated cell, which has limited ability, if any, to proliferate and thus contribute to repair or remodeling, may be stimulated to undergo apoptosis to make way for new cells. During this process it would not benefit immature cells to proliferate and differentiate only to die, which may explain why TGF- $\beta 1$ activation in irradiated CNS could be considered to be a beneficial process following exposure to either an acute radiation dose or low fluence events. Thus, the same signal, i.e. TGF- $\beta 1$, represses early lineages (McKinnon et al., 1993).

Alterations in cell signalling in the substantia nigra. Neurotransmitters and other ligands relay transfer messages through receptors such as the muscarinic receptors. These receptors are linked to signal-transducing guanine regulatory binding proteins, the $G$ proteins (see reviews by Ali and Agrawal, 1994; Axelrod, et al., 1988; Birnbaumer, 1991; Raymond, 1995; Rens-Domiano and Hamm, 1995), which are linked to specific second messengers that further convey the signals to other neurons, and to subsequent targets (for discussion of signal transduction pathways, see Sections V.A.6.f. and IX.B).

Joseph et al., (1992) have shown that superfused striatal slices obtained from young ( 3 month) rats exposed to low doses (0.1 Gy-1 Gy) of Fe particle irradiation $(600 \mathrm{MeV}$ or $1 \mathrm{GeV})$ exhibited reductions in the ability of oxotremorine, a potent muscarinic agonist, to enhance $\mathrm{K}^{+}$- evoked release of dopamine ( $\left.\mathrm{K}^{+}-\mathrm{ERDA}\right)$. These animals had previously exhibited motor behavioral decrements. These alterations are similar to those seen in aged animals, and these $\mathrm{K}^{+}$-ERDA decrements were evident for as long as 180 days after irradiation. Subsequent experiments indicated that in addition to these declines, there were reductions in carbachol-stimulated 1,4,5 inositol triphosphate (IP3) activity, the primary second messenger in this pathway (Joseph et al., 1993), and carbachol-stimulated low $\mathrm{K}_{\mathrm{m}}$ GTPase activity (Villalobos-Molina et al., 1994), an indicator of receptor-G protein coupling/uncoupling. 
Conditioned taste aversion. Rabin et al. $(1989,1991)$ have used the conditioned taste aversion (CTA) paradigm with rats to evaluate the behavioral toxicity of several types of radiation. The CTA measures the avoidance of a normally preferred food which has been associated with toxic consequences to the organism. As such, it is a standard design for evaluating behavioral toxicity (Riley and Tuck, 1985). The effect of radiation in CTA induction is considered to be both directly on the brain, but also on some target in the gastrointestinal tract, possibly the enterochromaffin cells. In general, the CTA induced by different types of radiation parallels radiation LET. The least toxic effects on behavior were observed following exposure to ${ }^{60} \mathrm{Co} \gamma$-rays, electrons and protons $(155 \mathrm{MeV} / \mathrm{n})$, and the heavy particles which have LETs ranging from $0.2 \mathrm{keV} / \mu \mathrm{m}$ to $85 \mathrm{keV} / \mu \mathrm{m}$. Exposure to $600 \mathrm{MeV} \mathrm{Fe}$ particles $(\mathrm{LET} \approx 189 \mathrm{keV} / \mu \mathrm{m})$ is significantly more effective in producing a CTA than any other tested radiation type.

Although fewer types of radiation have been tested using a second paradigm, similar results are obtained when emesis (vomiting) in ferrets is used as the measure of behavioral toxicity (Rabin et al., 1992). For all types of radiation, increasing the dose of radiation produced a corresponding increase in the percentage of animals that vomited. The most effective types of radiation were fission spectrum neutrons and $\mathrm{Fe}$ particles which had the lowest threshold for initiating a response and for producing response in all of the animals. The low LET types of radiation, $\gamma$-rays, electrons and protons, were significantly less effective in producing emesis and/or retching.

Previous research (Rabin et al. 1983; 1989) has established that the acquisition of a radiation-induced CTA following exposure to either ${ }^{60} \mathrm{Co} \gamma$-rays or to Fe particles is dependent upon the integrity of the area postrema (AP), the chemoreceptive trigger zone for emesis (Borison, 1974). The AP is a highly vascularized circumventricular organ which is characterized by a weak bloodbrain barrier. This observation is consistent with the hypothesis that the behavioral toxicity following exposure are mediated by the effects of irradiation on the peripheral nervous system, and that the mechanisms underlying the acquisition of a CTA following exposure to ${ }^{60} \mathrm{Co} \gamma$-rays and $\mathrm{Fe}$ particle radiation are the same.

Joseph et al. $(1992,1993)$ observed that whole body exposure to low doses of $\mathrm{Fe}$ particles induced changes in dopaminergic function. This suggests that such exposures may also affect a range of dopamine-mediated behaviors, such as the amphetamine-induced CTA. Previous research established that disrupting the functioning of the dopaminergic system by injection of the dopamine antagonist haloperidol, or treatment with the neurotoxin 6hydroxydopamine, which produces widespread destruction of dopaminergic nerve terminals throughout the brain, will prevent the acquisition of an amphetamine-induced CTA. In contrast, exposing rats to Fe particles should 
have no effect on the acquisition of lithium chloride-induced CTA, which is not mediated by the dopaminergic system.

To evaluate this hypothesis, rats were exposed to low doses (0.1-1 Gy) of 600 $\mathrm{MeV} /$ nucleon $\mathrm{Fe}$ particles. Irradiation disrupted the acquisition of a CTA produced by injection of amphetamine, which depends upon the integrity of the dopaminergic system, but had no effect on lithium chloride-induced CTA learning. These results are consistent with the hypothesis that the disruption of amphetamine-induced CTA learning by exposure to low doses of $56 \mathrm{Fe}$ particles is due to a direct effect on dopaminergic mechanisms in the central nervous system.

Thus, radiation of rats with iron particles affects both the peripheral and central nervous systems. Furthermore, because dopamine is involved in the mediation of a range of behaviors related to motivation, reinforcement, and learning, the observation that exposure to heavy particles can affect one dopamine-mediated behavior raises concern about the possible effects of such exposure on other dopamine-mediated behaviors. A similar disruption of amphetamine-induced CTA learning was not observed following exposure of up to $5 \mathrm{~Gy}$ of fission spectrum neutrons or up to $9 \mathrm{~Gy}$ of ${ }^{60} \mathrm{Co} \gamma$-rays. Apparently at these doses there is simply a non-selective disruption of all CTA learning produced by both amphetamine and lithium chloride, possibly resulting from the general toxicity of high-dose irradiation.

Radiation-aging parallels. The results described above with respect to signal transduction in young rats are very similar to those seen as a function of aging. Investigations carried out using superfused slices from old and young animals indicated that there were reductions in oxotremorineenhanced $\mathrm{K}^{+}$-ERDA in the old animals, indicating that these muscarinic receptors are showing deficits in signal transduction that are contributing to their loss of sensitivity (Joseph et al., 1988a, Joseph and Roth, 1991; Roth et al., 1995). These deficits include reduced IP3 formation following stimulation, and a reduction in $\mathrm{IP}_{3} \mathrm{Ca}^{2+}$ mobilization efficiency from cortical microsomes of old rats (Burnett et al., 1990).

Just as seen with radiation, studies have indicated that whenever the ligandmuscarinic subtype 1 receptor (mAChR)-G protein interfaces are "bypassed", the age-related decrements in signal transduction are reduced, suggesting that the deficits occur early in the process (Joseph et al., 1988b). Investigations have also shown that there are age-related reductions in muscarinic agoniststimulated GTPase activity from hippocampus and striatum (Yamagami et al., 1992).

In summary, it appears that with respect to signal transduction there are similar losses in sensitivity in muscarinic receptors induced by both aging and 
radiation. These deficits may have their origin within the membranes in which these receptors are contained. Alterations in the microenvironments, created by a decreased ability to respond to oxidative stress that has been observed in aging (Joseph et al., 1996), or oxidative stress induced by radiation, can have profound effects on receptor function. Because these receptors are important in mediating both cognitive and motor functions, these changes could be expressed as behavioral deficits which could have critical results on a 3-year mission in outer space. It is critical, then, to examine the effects of HZE particles in middle-aged or older animals in order to determine agingradiation interactions on microenvironments, membranes, and subsequent signal transductions.

Damage to photoreceptors. Krebs et al. (1990) have exposed the eyes of Columbia-Sherman albino rats to 0.1 and 2.5 Gy Fe particles at an LET of 195 $\mathrm{keV} / \mu \mathrm{m}$. The retinas were then examined at various times up to 186 days after irradiation. Radiation with $2.5 \mathrm{~Gy}$ induced losses of photoreceptor cells = bipolar cells > pigment epithelial cells, which reached a maximum loss of about $25 \%$ for photoreceptor and bipolar cells by 15 days after irradiation. No subsequent cell loss occurred during the next 170 days. In contrast, the maximum loss of pigment epithelial cells was only $15 \%$, and by 186 days after irradiation the cell number returned to normal. Irradiation with $0.1 \mathrm{~Gy}$ had negligible effects on the number of any of these cell types.

The evidence from studies by Williams and Lett (1994) on rabbit retinal cells, considered to be a surrogate for neurons in the CNS, indicate that acute irradiation with either argon or iron particles can kill these cells. The LETs used in these experiments were about 90 and $220 \mathrm{keV} / \mu \mathrm{m}$ for argon and iron, respectively, and the NZW rabbits were about 2 months old at the start of the experiment. The kinetics of cell loss were dependent upon the dose of particles used. For argon, no immediate loss was observed with doses $\leq 4 \mathrm{~Gy}$, but by 3 years after irradiation about $10-15 \%$ of the retinal cells had been lost following this dose. Doses $\geq 5$ Gy resulted in early cell loss within 2-3 months, with less subsequent loss over the next 3 years. Similar effects were observed with iron particles, except that the early loss threshold dose was 1-2 Gy, and subsequent loss with increasing age was greater than that observed with argon. These authors estimated that the photoreceptor cell losses were about $1.7 \%$ and $2.5 \%$ per Gy for argon and iron, respectively.

Lett et al. (1987) have also exposed excised retinas from NZW rabbits to X-rays, neon particles, and argon particles, at doses varying from 9 to $260 \mathrm{~Gy}$, depending on the type of radiation. DNA strand breaks were then evaluated by alkaline sucrose gradients. The results indicate that these ionizing radiations do damage DNA in these isolated retinas, and underline the importance of investigating the late effects on DNA and repair in neurons, especially now that new techniques can detect DNA damage, its nature, and repair with greater sensitivity than previously (Rydberg et al., 1994; Löbrich et 
al., 1994; Sutherland et al., 1996). The current quantitative assessment of both early and late loss of neurons as a function of dose and LET is inadequate for the task of estimating risks.

These radiation-induced neurobiological changes discussed in this section are summarized in Table IV.9. These results indicate that radiation-induced neurobiological alterations during travel in outer space might be important, especially at older ages, and that it will be necessary to determine whether the dose of HZE particles encountered in outer space is sufficient to produce significant damage of this kind in humans, which could manifest itself either during the flight or later in life.

\section{Review references:}

Laramore GE. 1991. Injury to central nervous system after high LET radiation. In: Radiation Injury to the Nervous System. PH Gutin, SA Leibel, GE Sheline, (Eds.), Raven Press, New York, pp. 341-360.

Rodriguez A, Levy RP, Fabrikant JI. 1991. Experimental central nervous system injury after charged particle irradiation. In: Radiation Injury to the Nervous System. PH Gutin, SA Leibel, GE Sheline, (Eds.), Raven Press, New York, pp. 149-181. 
TABLE IV.9

\section{SUMMARY OF RADIATION-INDUCED NEUROBIOLOGICAL DEFICITS IN RATS}

Radiation
Source

${ }^{60}$ Co $\gamma$-rays, electrons, protons, HZE particles

Fe particles

Ar, Fe particles

Fe particles

Fe particles

Fe particles

Ar, Fe particles

\section{Neurobiological Change} Observed

Conditioned taste aversion (CTA)

Reduced amphetamine-induced CTA

Reduced "hang time"

Loss of tyrosine hydroxylase antigen in the substantia nigra

Reduced oxotremorine-dependent $\mathrm{K}^{+}$- evoked release of dopamine

Reduced muscarinic subtype 1 receptors

Early cell killing and accelerated loss of cells with age Implication Reference

triatal and nigral cell loss

loss of neurons in the substantia nigra

deficits in signal transduction

deficits in signal transduction

loss of photoreceptor cells
Rabin et al., 1989; 1991

Joseph et al., 1992; 1993

Philpott et al., 1985

Jim Jospeh

(personal commun.)

Joseph et al., 1992

Joseph et al., 1988a

Krebs et al., 1990;

Williams and Lett, 1994 
iv. Cataractogenesis:

At least two components of the eye are particularly sensitive to radiation: the lens and the retina. Effects of irradiation of a lens are heterogeneous, because of the heterogeneity of the lens itself. The lens contains both mitotically active and enucleated cells. It is not known whether cataracts are caused by damage to the peripheral mitotically active epithelial cells, or the central amitotic cells, or both. Cataract formation is one of the near inevitable consequences of aging, but the process is hastened by irradiation. NCRP Report No. 98 (1989) has summarized data on induction of cataracts by irradiation, and concluded the following: 1) radiosensitivity varies significantly (at least 10-fold) among animal species, roughly in inverse relationship to size and maximum life span; 2) a single exposure to $X$-rays is more damaging than fractionated doses of the same total dose in mice, but little benefit was observed from fractionated doses using Ar particles; and 3) there is no qualitative difference between induction of cataracts by HZE particles and other kinds of radiations.

Rats. When male Fischer-344 rats were exposed to a single $2 \mathrm{~Gy}$ dose of $55 \mathrm{MeV}$ protons at 10 weeks of age, no cataracts were seen until about 18 months of age in either the irradiated or control animals (Cox et al., 1993). From 18 months on, cataracts increased substantially in both the irradiated and control animals, and the difference between them appears to be insignificant. Average life span was reduced in the irradiated animals by about $10 \%$, but there was no difference in maximum life span.

A recent study using neutrons provides a somewhat different picture. In this study the eyes of one-month old Columbia-Sherman albino rats were irradiated with $440 \mathrm{keV}$ neutrons at doses of 2, 10, 50 and $250 \mathrm{mGy}$, delivered either as an acute dose, or fractionated into 4 equal doses separated by 3 hrs (Worgul et al., 1996). These animals were then periodically examined for cataracts for the next 2 years. A separate set of animals was given acute doses of $250 \mathrm{kVp} \mathrm{X}$-rays over a range of 0.5 to $10 \mathrm{~Gy}$. The results from these studies include: 1) the relative biological effectiveness of the neutrons increased with decreasing dose; 2 ) dose fractionation increased cataractogenesis at the highest dose of neutrons ( $250 \mathrm{mGy})$; 3 ) there was evidence of clinically significant changes at doses as low as 2 mGy, even though these authors estimated that less than $5 \%$ of the cells were irradiated at this dose. Finally, these authors concluded that these results with neutrons in rats were quite consistent with results obtained earlier with humans exposed to atomic bomb blasts in Japan, rats exposed to argon and iron particles, and mice and rabbits exposed to argon particles. These summary results imply that cataract incidence due to the low doses of high LET radiation experienced in outer space (see Section IV.A.2.) 
could be more substantial than might be predicted from results of acute high dose experiments. 
Mice. Female $\mathrm{B}_{6} \mathrm{CF}_{1}$ mice at about 3 months of age were exposed to a single dose of protons or $\mathrm{Ne}, \mathrm{Fe}, \mathrm{Nb}$, or La particles and then examined 64 weeks later for a variety of cataract-related cellular endpoints, such as nuclear fragmentation, micronucleation, and meridional row disorganization (Tao et al., 1993a). Damage increased with both increasing dose and LET, although LET effects usually peaked or plateaued at an LET of about 200. Whether these pathological changes are causal events in the development of cataracts remains to be shown.

Rabbits. New Zealand white (NZW) rabbits at 8-10 weeks of age were exposed to a single dose of $\mathrm{Fe}$ particles and then the cataract index was followed for 6 years (Lett et al., 1991). No cataracts were observed in control animals, or animals irradiated with $0.5 \mathrm{~Gy} \mathrm{Fe}$ particles, and only slight increases beginning at about 5 years were observed with a dose of $1 \mathrm{~Gy}$. In animals irradiated with 2 and 5 Gy, there was an immediate increase in the cataract index following irradiation, the magnitude of which was roughly proportional to the dose. The cataract index then began to rise slowly at 3.7 and 0.5 year after irradiation, for the 2 and 5 Gy doses, respectively. These results suggest there may be two distinct mechanisms for Fe particle-induced cataract in rabbits. The first could be due to direct damage to the lens proteins by generation of reactive oxygen species by the Fe particle. The second is a delayed response, the mechanism of which is obscure.

\section{v. Radiation effects on the gonads}

Low-LET irradiation of male animals. Rodents have been the major model system for the study of radiation effects of spermatogonial cells. The requisite for understanding the radiation response of the testis is an understanding of the development of sperm, from the stem cell population, through terminal differentiation stages (Oakberg, 1956; 1971). The full cycle of spermatogenesis in rats takes about 6 weeks, compared to 10 weeks in humans. With differentiation through spermatocyte stages to spermatozoa, the resistance to irradiation increases. The stem cells are somewhat more resistant than the most sensitive differentiating spermatogonia. Recovery of spermatogenesis has been reported in mice after single doses of 6 and $10 \mathrm{~Gy}$ of low-LET radiation, doses at which mutations were noted (Russell, 1951; Russell and Russell, 1954).

Doses of $\mathrm{X}$-rays and ${ }^{60} \mathrm{Co} \gamma$-rays that have been reported to cause sterility in other experimental animals range from 4-5 Gy in rats (Shaver, 1953; Erickson, 1976) to $9.5 \mathrm{~Gy}$ in rabbits. It is often stated that the response of the testis to multiple fractionated or protracted low dose-rate exposures differs from that of other tissues because the effect of such exposures may be equal to or even greater than it is with single doses. However, maintenance of the germline in mice irradiated with a total dose of $15 \mathrm{~Gy}{ }^{60} \mathrm{Co} \gamma$-rays from daily doses up to 0.03 Gy/day was reported by Stadler and Gowen (1964); they found no 
reduction in reproductive capacity. The claim of the greater effectiveness of fractionated irradiation in decreasing spermatogenesis stems from the study of dogs by Casarett and Eddy (1968), who found that 0.03 Gy per day for a total dose of $3.75 \mathrm{~Gy}$ of $\mathrm{X}$-rays caused a more severe depression of spermatogenesis than a single dose of $3.75 \mathrm{~Gy}$. When the total dose was increased to $4.75 \mathrm{~Gy}$, the aspermia was permanent. The capability for repair and recovery is indicated by the finding that when the daily dose was reduced to $0.0012 \mathrm{~Gy}$, even continuous irradiation from 22 months of age onward caused no detectable reduction in the sperm count.

High-LET irradiation of male animals. The RBE of neutrons compared to $X$-rays range from 2.5 to 3.2 depending on the neutron energy. Loss of testis weight as a function of dose has been used to assay the effect of neutrons (Hornsey et al., 1977) and of HZE particles. Using this assay, Alpen and Powers-Risius (1981) determined the RBE of ${ }^{60} \mathrm{Co} \gamma$-rays, $\alpha$-particles, helium, carbon, neon, and argon particles. The highest RBE was about 2.2 with a beam of about $100 \mathrm{keV} / \mu \mathrm{m}$.

Irradiation of female animals. The primordial oocyte is more sensitive to radiation than are later stages of maturation in the mouse. The relationship of radiosensitivity to the stage of maturation is not consistent among species, and there are significant species-dependent differences in radiosensitivity of the ovary itself. In mice, a dose of $1 \mathrm{~Gy}$ of $\mathrm{X}$-rays can cause permanent sterility (Rugh and Wolff, 1957), but in the monkey a dose of about $20 \mathrm{~Gy}$ is required. The female germ line is maintained in mice irradiated with a daily dose of $0.03 \mathrm{~Gy}$, even when the accumulated dose reaches 15 Gy (Stadler and Gowen, 1964). The ovary in the adult is less radiosensitive than the testis, but the opposite is the case for the fetal gonads.

\section{c. Dogs \\ i. $\quad$ Cataractogenesis}

Beagles at 10 weeks of age received whole body irradiation with $0.83 \mathrm{~Gy}$ of ${ }^{60} \mathrm{Co} \gamma$-rays, and lens opacification was determined yearly (Cox et al., 1993). No significant increase in cataract index was seen in either control or experimental subjects until 10 years of age. At this time, the cataract index began to rise in both groups, and there was no difference between the two groups until 14 years of age, when the cataract index in the few irradiated dogs remaining began to increase slightly faster than it did in the control animals.

\section{ii. Carcinogenesis induced by irradiation with $\alpha$-particles}

Beagles were exposed to $\alpha$-particles through injection of ${ }^{224} \mathrm{Ra}$ either as a single dose, or fractionated into 10 or 50 weekly doses over a range of total doses to bone of 0.1 Gy to 3 Gy (Muggenburg et al., 1996). The results indicate 
that 1) an $\alpha$-particle dose delivered as a single dose resulted in fewer tumors than seen after a protracted dose; 2) hematological dyscrasia was more severe after an acute dose than a protracted dose; 3) the results with these dogs roughly mimic what was already known about induction of bone, breast and kidney tumors in humans, except that bone tumors were 40-50 times more frequent in dogs. Significant life span shortening was seen at $3 \mathrm{~Gy}$ for all three dose protocols, and also for $1 \mathrm{~Gy}$ when fractionated over 50 weeks; no significant life span shortening was seen at 0.3 or $0.1 \mathrm{~Gy}$.

\section{iii. Life shortening induced by continuous irradiation with $\gamma$-rays}

To simulate the effects of protracted low dose rates in humans, Carnes and Fritz (1993) irradiated beagles continuously with ${ }^{60} \mathrm{Co} \gamma$-rays at doses varying from 3 to $540 \mathrm{mGy}$ per day. The ages of first exposure (AFE) varied from $400-$ 709 days, with irradiation beginning in most dogs in the age range of 400-600 days. Dogs were then analysed depending on whether they died of acute causes (such as bone marrow damage), died with tumors, or died of a pathology not related to neoplasia.

All animals receiving at least $262.5 \mathrm{mGy}$ per day died an acute death, usually less than one year following AFE. No animals receiving $\leq 18.8 \mathrm{mGy}$ per day died an acute death. The survival data obtained for non-acute deaths are summarized in Table IV.10. These data provide clear evidence that continuous exposure to as little as $7.5 \mathrm{mGy} \gamma$-rays per day has life-shortening effects in dogs; slight effects are also seen at $3.0 \mathrm{mGy}$ per day. Statistical analysis of these data indicated that once a dog survived long enough to get cancer, death depended only on accumulated dose, whereas both accumulated dose and dose rate were important in non-tumor deaths.

\section{iv. $\quad$ CNS damage from an acute dose of HZE particles}

It is known that the human brain suffers ancillary damage during radiation therapy for brain tumors (DiChiro et al., 1988). Magnetic resonance imaging (MRI) and positron emission tomography (PET) have been used on humans to evaluate this damage (Dooms et al., 1986; Doyle et al., 1987; see also Section V.B.2.). However, because it is not possible to carry out well-controlled longitudinal studies in humans, dogs have been used as a model for studying CNS effects in humans. The canine brains are sufficiently large to permit study of small structures with current conventional medical imaging techniques. Thus, the canine brain has been widely researched and has been found to be an adequate model for studying brain structures known to be involved in aging and a variety of neurologic disorders. The studies of Fike et al. $(1984 ; 1988)$ demonstrated that at least two processes may be involved in the development of neurological damage following irradiation, one that is rapid, and one that is a slower and more degenerative process. 
Using a total of 15 beagles, Brennan et al., (1993) induced necrosis and edema by hemi-brain irradiation with single doses of $13 \mathrm{~Gy}$ or more neon or helium particles. The PET and MRIs scans remained relatively normal until several weeks before death at 20-30 weeks post-irradiation. In contrast, animals receiving 7.5-11 Gy remained normal for at least 3 years, at which time they were sacrificed for histopathological studies. The unanswered question is whether metabolic changes may occur late in life after these lower doses.

These same investigators have recently started a second study using 6 beagles (4 experimental, 2 controls). All animals were given an acute, but uniform dose of $\mathrm{Fe}$ particle irradiation over the CNS equivalent to an average of 3 particles per cell nucleus. PET and MRI scans were done on all animals prior to irradiation. Follow-up analyses will include non-invasive PET, MRI and MRS scans to evaluate changes in neuroanatomy and neurochemistry in the CNS. MRI and PET scans done during the first $31 / 2$ years following irradiation have indicated no anatomical or metabolic abnormalities in these dogs so far (Thomas Budinger and Kathleen Brennan, personal communication). 
TABLE IV.10

\section{EFFECTS OF DOSE ON LIFE SPAN OF BEAGLES CONTINUOUSLY IRRADIATED WITH $\gamma$-RAYS}

\begin{tabular}{cll} 
& \multicolumn{2}{l}{ Age of death at 50\% survival } \\
$\begin{array}{c}\text { Dose } \\
(\mathrm{mGy} / \text { day })\end{array}$ & $\begin{array}{l}\text { Tumor-related } \\
\text { death (days) }\end{array}$ & $\begin{array}{c}\text { Other late } \\
\text { death (days) }\end{array}$ \\
\hline & & \\
0.0 & 5100 & 5200 \\
3.0 & 5000 & 4900 \\
37.5 & 2500 & 3100 \\
75.0 & 1500 & 1000
\end{tabular}

Average remaining life span after initiation of exposure*

$\begin{array}{lc}\begin{array}{l}\text { Tumor-related } \\ \text { death (days) }\end{array} & \begin{array}{l}\text { Other } \\ \text { death }\end{array} \\ & \\ 4120 & 3518 \\ 3822 & 3500 \\ 3500 & 3160 \\ 2772 & 2809\end{array}$

$* \mathrm{AFE}=400$ days for all animals

Adapted from Carnes and Fritz (1993) 


\section{d. Monkeys (Macaca mulatta)}

During the period 1964-1969, the United States Air Force and NASA irradiated almost 2,000 rhesus monkeys with protons, high energy electrons, or X-rays to determine the effects of a single dose, total body surface exposure on mortality, carcinogenesis, endometriosis and cataractogenesis (Wood, 1991; Fanton and Golden, 1991; Lett et al., 1991). The animals varied in age from 18 months to 3 years old, and have been followed periodically ever since. Dose protocols were varied to include both low $(0.26-2.8 \mathrm{~Gy})$ and high $(3.6-8.0 \mathrm{~Gy})$ doses, and low $(32-55 \mathrm{MeV})$ and high $(138-2300 \mathrm{MeV})$ energy protons.

\section{i. Life shortening}

Although not all the monkeys have yet died, the data accumulated after 25 years indicate that while the low energy - high dose protons have an immediate negative effect on survival, the high energy - low dose survival curve does not differ from that of control monkeys for about the first 10 years post-irradiation. Between 10 and 20 years these curves diverge, but by 20 years post-irradiation there are only small differences in mortality between unirradiated animals, low energy-low dose, and high energy-low dose irradiated animals. In contrast, the monkeys receiving a high dose survived less well throughout the post-irradiation period, regardless of the energy of protons used.

\section{ii. Carcinogenesis}

Male monkeys were significantly more likely to develop cancer due to proton irradiation than were female monkeys, and this difference was apparent within the first 1 to 2 years after irradiation (Wood, 1991). Non-leukemic cancers were the most significant cause of early death in male monkeys, although the monkeys exposed to low energy protons were particularly sensitive to glioblastomas. Death was much more likely to be due to cancer following doses in the range of $3.0-8.0 \mathrm{~Gy}$, than in the range $0.25-2.8 \mathrm{~Gy}$, ignoring energy differences. These data differ from atomic bomb survivor data in two ways: 1) the male bias toward early cancer, and 2) relative scarcity of leukemia in the monkeys. Wood (1991) addressed the first discrepancy by suggesting the possibility that many of the high risk female monkeys succumbed first to endometriosis, leaving a more cancer-resistant female population.

The incidence of endometriosis was increased substantially by all forms of irradiation employed (Fanton and Golden, 1991). Compared to an incidence of $26 \%$ in unirradiated females, $53 \%$ of irradiated animals developed endometriosis. Incidence levels varied from $54 \%$ for single-energy protons, to $57 \%$ for electrons, and $71 \%$ for $\mathrm{X}$-rays. 


\section{iii. Cataractogenesis}

Lett et al. (1991) have done an extensive study of cataractogenesis using the USAF/NASA monkeys, as well as a variety of other species (Cox et al., 1993) Of all the species they have studied, monkeys and rabbits demonstrated the most significant difference between controls and irradiated subjects. At doses of $2.5 \mathrm{~Gy}$ or less of protons (whole body radiation at an age of 2 years) there was no increase in cataract index until about 20 years after irradiation. At that time the cataract index of the controls began to increase slightly, but it began to increase rapidly in the irradiated animals. The age at which this increase occurred was inversely related to the dose but not the energy of the protons.

\section{e. Summary for Section IV.D.2}

There are many variables which affect the risk of an individual or a strain to radiation-induced carcinogenesis, and these must be taken into account when evaluating the results of different experiments. These include, but are not limited to, age and nutritional status of the experimental subjects, genotype of the strain, and tissue being studied. These factors make it difficult to generalize results from individual experiments to all members of a species. Thus, the following "bullets" must be considered with this caution in mind.

\section{i. Carcinogenesis}

- HZE particles such as Ar are about ten times more likely per Gy to induce cancer in rats than are electrons; particles such as $\mathrm{Fe}$ and $\mathrm{Nb}$ are about ten and five times more likely to induce Harderian gland tumors in mice than are ${ }^{60} \mathrm{Co} \gamma$-rays and protons, respectively (Table IV.8). The Harderian gland model which predicts a linear log-log plot of LET vs. cancer risk coefficient should be tested with other tumor induction models.

- Even though mice are highly susceptible to tumors, when exposed to $0.5 \mathrm{~Gy}$ $\beta$-radiation three times a week they do not show an increased rate of skin or bone tumor incidence compared to control animals. They also have a survival curve quite similar to that of unirradiated animals. In contrast, when the dose is increased to $0.75 \mathrm{~Gy}$, some tumors begin to appear about 800 days, and an increase to $1 \mathrm{~Gy}$ markedly decreases the time of appearance of the first tumors (500 days), and increases the tumor incidence. However, these data cannot be interpreted to mean that exposure to low doses of high-LET radiation will not be carcinogenic.

- Internal irradiation of beagles with 1 or $3 \mathrm{~Gy}$ of $\alpha$-particles from $224 \mathrm{Ra}$ resulted in more bone tumors when the dose was fractionated into 50 doses given over 50 weeks than it did when given as a single dose. The risk of developing a bone tumor was 40-50 times higher in these dogs than has been reported for humans. 
- The data available for radiation-induced carcinogenesis in monkeys is limited to protons. Proton irradiation induced more cancer in male than female monkeys, and leukemias were relatively rare. Both of these results are contrary to the human atom bomb data. It is not known whether these differences are due to the different quality of the radiation, or to biological differences between monkeys and humans, but these questions are relevant because protons constitute $87 \%$ of the GCR.

- An important role for p53-dependent apoptosis in preventing radiationinduced cancer in mice is suggested by experiments with p53 knockout mice. When p53 is absent apoptosis is suppressed (at least in thymocytes), and carcinogenesis increases substantially. This result is consistent with the observation that humans with only one normal copy of the p53 gene (LiFraumeni syndrome) become cancer-prone with the loss of the normal copy of the gene (Malkin et al., 1990).

\section{ii. Neurobiological damage.}

- The experiments with conditioned taste response in rats indicate that both peripheral and central nervous systems are disrupted by low dose radiation, but the CNS effect is observed only after irradiation with HZE particles. Thus, the effects of exposure to low doses of HZE particles on behavior mediated by the dopaminergic system, as might occur on long duration missions outside the magnetosphere, cannot be modelled using low-LET radiations. In contrast, for behaviors mediated by the effects of the radiation on peripheral systems it may be possible to extrapolate from the results obtained with low-LET radiation.

- Numerous studies with rats have suggested that radiation may modify membrane transport mechanisms being activated by oxygen free radicals or by responding to increased lipid peroxides (Stark, 1991). Stark also pointed out that certain free radicals are able to gain access to the interior of the membrane and react with the lipid matrix, membrane-bound proteins, G proteins, or membrane-containing neurotransmitter receptors such as $\mathrm{mAChR}$. Lipid peroxidation can alter membrane structure and function (Schroeder, 1984), because membrane properties are strongly influenced by lipid composition and membrane fluidity, suggesting a similarity between radiation and aging effects. Aging-related changes include increased lipid peroxidation, cholesterol/phospholipid ratios, sphingomyelin content and rigidity. It is almost certain that most of those chosen for long-term spaceflights will be middle-aged or approaching middle age. Thus, HZE particle irradiation in outer space would be impinging upon brain areas that are already experiencing the effects of aging, and these effects may be additive or synergistic. This would be particularly crucial in individuals already genetically disposed to an age-related neurodegenerative disorder such as Alzheimer's disease. Major 
questions are whether radiation in outer space is sufficient to accelerate agerelated neurodegeneration, and whether such acceleration would be missioncompromising, or delayed until the return to earth, were it to occur.

- The experiments with regard to estimated risk of brain damage in dogs due to HZE particles are inconclusive. The brain irradiation experiments are compromised by the fact that a total of only 15 dogs was employed, and the endpoints chosen might not detect subtle but important changes such as those detected in experiments with rats. For these reasons, concluding that there is a threshold for neurological damage in dogs of $11 \mathrm{~Gy}$ for an acute dose of $\mathrm{Ne}$ or $\alpha$-particles is premature.

- A model system for directly relating neuron damage to irradiation dose is the nematode $C$. elegans, because the nematode nervous system has been extremely well characterized. The function of most neurons is now understood, and the functional integrity of individual neurons can be evaluated by use of cell-specific expression of genes such as the gene for green fluorescent protein (Section V.A.6.e.). Strategies to relate results with this system to mammals with their complex brain structure need to be developed.

\section{iii. Cell killing in vivo.}

- Irradiation of mice with up to $30 \mathrm{~Gy}{ }^{137} \mathrm{Cs} \gamma$-rays induces apoptosis of cells in the lungs, spleen and thymus. However, when mice deficient in acid sphingomyelinase activity are irradiated, apoptosis of lung cells does not occur. This indicates not only that apoptosis in the lung depends on the production of ceramide, but that radiation-induced apoptosis is initiated by different mechanisms in various tissues.

- Continuous irradiation of mice with 2.4 Gy per day ${ }^{60}$ Co $\gamma$-rays killed hemopoietic stem cells at a rate of about $90 \%$ every 3 days, while lymphosarcoma cells growing in the peritoneal cavity tolerated this dose. These results illustrate the widely varying vulnerability of different cell types to radiation-induced apoptosis, and are quite relevant to the problems encountered with radiation therapy for tumors in humans.

iv. Cataractogenesis

The observation that of the models tested, the monkey gives a significant radiation-induced response compared to controls at fairly low doses of protons, suggests that the monkey would be a good animal model for estimating low dose effects due to protons in humans. However, for experimentation on HZE particle-induced damage, rabbits may also be a reasonable model. The results reported for dogs using $\gamma$-rays are inconclusive. Although the rat has been used extensively to study radiation-induced cataractogenesis, the sharp spontaneous increase in cataract index in 
unirradiated rats beginning at 15-20 months of age compromises the use of the rat as an animal model for evaluating cataracts induced by low doses of radiation. Because it is now possible to correct cataracts surgically, research in this area is not considered to have as high a priority as those where remediation is not yet available.

\section{v. $\quad$ Survival}

Many experiments that have been done with animals relate organismal survival to radiation exposure, but the most useful animal studies are those using low dose-rate protocols, especially if the dose has been highly fractionated. Some results from such studies using low-LET forms of radiation include:

- A single dose total body irradiation of monkeys with protons had life shortening effects at all combinations of low vs. high dose, and low vs. high energy. The least impact was seen with low dose (0.26 - 2.8 Gy) and low energy (32- $55 \mathrm{MeV}$ ) protons.

- Continuous irradiations of beagles with ${ }^{60} \mathrm{Co} \gamma$-rays beginning at about one year of age have shown that radiation doses less than $3 \mathrm{mGy}$ per day have little if any impact on life span, irrespective of the cause of death. This dose is an order of magnitude larger than the exposure to low-LET radiation by protons anticipated during outer space travel.

Because facilities are not available, it has not been possible to design experiments to evaluate the effect of low dose-highly fractionated HZE particle irradiation on survival in any animal model system, nor is this situation likely to change in the near future. Thus, survival, even if it were a desirable endpoint, does not appear to be a feasible experimental approach for studying the impact of HZE particles in a moderate or long-lived animal model without a suitable dedicated facility. Survival studies also provide little or no information about mechanisms, and require fairly large numbers of animals.

\section{vi. General}

- Because the radiation exposure during space travel is continuous and low dose, rather than acute, it is particularly important to understand whether and how results from single dose experiments can be extrapolated to infinitely fractionated exposure. The results summarized in Table IV.11 indicate that fractionation of low-LET radiation dose usually reduces the radiation-induced effects, whereas fractionation of a high-LET radiation dose increases most radiation-induced endpoints. However, they also support the idea that if the dose rate is low enough, even high-LETcontinuous irradiation may not induce a significant pathological effect. 
- This leads to an important question: How low does an exposure have to be before it no longer induces an outcome detectable above background? The results summarized in Table IV.12 suggest that we have insufficient data of this kind, even in animals. Most studies have used large doses in order to obtain measurable and significant effects. Animal models with enhanced vulnerability to radiation would allow us to extend our ability to measure effects due to low levels of radiation. Genetically engineered animals (mainly mice) can be useful here if methods can be developed to extrapolate results first from these mice to normal mice, and then to humans.

- Most data support the view that risks for high energy protons will be similar to those for low-LET radiations, but studies of protons are needed in the range of energies relevant to those in space because $85 \%$ of the particle radiation in space is protons.

- An important question is how to determine risk from doses that at the level of concern, i.e., during travel in outer space, are so low that large numbers of animals must be used to obtain statistically significant results. The current approach of extrapolating from data obtained at high doses using some model for dose-response relationships is clearly equivocal. The potential of using genetically engineered mice with enhanced vulnerability to very low doses of radiation must be assessed. However, the use of such animals requires the development of methods for the reliable extrapolation of the results to normal mice and humans. 
TABLE IV.11

EFFECT OF DOSE FRACTIONATION

\begin{tabular}{|c|c|c|c|c|c|c|}
\hline SPECLES/STRAIN & RADIATION & LET & $\begin{array}{l}\text { DOSE } \\
\text { PROTOCOL }\end{array}$ & ENDPOINT & $\begin{array}{l}\text { EFEECT OF } \\
\text { ERACTIONATION }\end{array}$ & REFERENCE \\
\hline \multirow[t]{2}{*}{$\begin{array}{l}\mathrm{C}_{3} \mathrm{H} 10 \mathrm{~T} 1 / 2 \text { cells } \\
\text { in culture }\end{array}$} & $\boldsymbol{\gamma}$-rays & & $\begin{array}{ll}1 & \text { Gy/min vs. } \\
1 \mathrm{mGy} / \mathrm{min}\end{array}$ & transformation & reduce frequency & Elkind et al., 1984 \\
\hline & neutrons & & $\begin{array}{l}380 \mathrm{mGy} / \mathrm{min} \text { vs. } \\
0.86 \mathrm{mGy} / \mathrm{min}\end{array}$ & transformation & increase frequency & \\
\hline $\begin{array}{l}\text { Rats: - } \\
\text { Sprague-Dawley }\end{array}$ & electrons & & $\begin{array}{l}19.5 \text { Gy vs. } \\
3 \times 6.5 \text { Gy or } \\
5 \times 3.9 \text { Gy } \\
(1 \text { day intervals) }\end{array}$ & skin tumors & $\begin{array}{l}\text { reduce frequency } \\
\text { reduce frequency }\end{array}$ & $\begin{array}{l}\text { Burns } \\
\text { et al., } 1993\end{array}$ \\
\hline $\begin{array}{l}\text { Mice: } \\
\text { B6CF } 1 / A n 1\end{array}$ & Fe particles & 193 & $\begin{array}{l}0.4 \text { Gy vs. } \\
6 \text { x } 0.07 \text { Gy } \\
(3 \text { hr. intervals })\end{array}$ & $\begin{array}{l}\text { Harderian gland } \\
\text { tumor frequency }\end{array}$ & $\begin{array}{l}\text { increase tumor } \\
\text { frequency } 1.5 \mathrm{x}\end{array}$ & $\begin{array}{l}\text { Alpen } \\
\text { et al., } 1994\end{array}$ \\
\hline $\begin{array}{l}\text { Rats: - } \\
\text { Columbia-Sherman }\end{array}$ & neutrons & 440 & $\begin{array}{l}0.25 \text { Gy vs. } \\
4 \text { x } 0.0625 \text { Gy } \\
(3 \text { hr. intervals })\end{array}$ & cataractogenesis & increase rate & $\begin{array}{l}\text { Worgul } \\
\text { et al., } 1996\end{array}$ \\
\hline Dogs: beagles & $\begin{array}{l}224 \text { Ra-injected } \\
\text { ( } \alpha \text {-particles) }\end{array}$ & & $\begin{array}{l}3 \text { Gy vs. } \\
50 \times 0.06 \text { Gy } \\
(1 \quad \text { wk intervals })\end{array}$ & $\begin{array}{l}\text { hematological } \\
\text { dyscrasia } \\
\text { bone tumors } \\
\text { survival }\end{array}$ & $\begin{array}{l}\text { decrease dyscrasia } \\
\text { increase frequency } \\
\text { decrease longevity }\end{array}$ & $\begin{array}{l}\text { Muggenberg } \\
\text { et al., } 1996\end{array}$ \\
\hline Dogs: beagles & X-rays & & $\begin{array}{l}3.75 \text { Gy vs. } \\
125 \times 0.03 \mathrm{~Gy} \\
(1 \text { day intervals })\end{array}$ & spermatogenesis & $\begin{array}{l}\text { decrease } \\
\text { spermatogenesis }\end{array}$ & $\begin{array}{l}\text { Casarett and } \\
\text { Eddy, } 1968\end{array}$ \\
\hline & & & $\begin{array}{l}\text { or } 0.0012 \text { Gy/d. } \\
\text { (continuous) }\end{array}$ & & $\begin{array}{l}\text { no effect on } \\
\text { spermatogenesis }\end{array}$ & \\
\hline
\end{tabular}


TABLE IV.12

RADIATION-INDUCED EFFECTS AT LOW DOSES

\begin{tabular}{|c|c|c|c|c|c|}
\hline \multirow{6}{*}{$\begin{array}{l}\text { Human diploid } \\
\text { fibroblasts (VH-10) }\end{array}$} & RADIATION & ENDPOINT & $\begin{array}{l}\text { HIGHEST DOSE } \\
\text { WITH NO EFFECT }\end{array}$ & $\begin{array}{l}\text { LOWEST DOSE } \\
\text { WITH EFFECT } \\
\end{array}$ & REFERENCE \\
\hline & $\gamma$-rays & $\begin{array}{l}\text { viscosity of cell } \\
\text { lysates }\end{array}$ & 1 mGy? & $5 \mathrm{mGy}$ & $\begin{array}{l}\text { Belyaev and } \\
\text { Harms-Ringdahl, } 1996\end{array}$ \\
\hline & $\gamma$-rays & TGF- $\beta 1$ activation & $?$ & $100 \mathrm{mGy}$ & $\begin{array}{l}\text { Ehrhart } \text { et al. } \\
\text { submitted }\end{array}$ \\
\hline & GCR & mutation frequency & $?$ & $\begin{array}{l}1 \text { mGy-during } \\
10 \text { day flight }\end{array}$ & $\begin{array}{l}\text { Nelson et al., } \\
1994\end{array}$ \\
\hline & $\begin{array}{l}\text { electrons } \\
\text { Ar particles }\end{array}$ & $\begin{array}{l}\text { skin tumors } \\
\text { skin tumors }\end{array}$ & $\begin{array}{c}3900 \mathrm{mGy} \\
?\end{array}$ & $\begin{array}{l}5000 \mathrm{mGy} \\
500 \mathrm{mGy}\end{array}$ & $\begin{array}{l}\text { Burns et al., } \\
1993\end{array}$ \\
\hline & $\begin{array}{l}\alpha \text {-particles } \\
\text { Ne particles } \\
\text { Ar particles }\end{array}$ & $\begin{array}{l}\text { CTA }(10 \% \\
\text { sucrose intake })\end{array}$ & $\begin{array}{ll}500 & \mathrm{mGy} \\
200 & \mathrm{mGy} \\
200 & \mathrm{mGy}\end{array}$ & $\begin{array}{r}1000 \mathrm{mGy} \\
500 \mathrm{mGy} \\
300 \mathrm{mGy}\end{array}$ & Rabin et al., 1991 \\
\hline
\end{tabular}


TABLE IV.12 (CONTINUED)

\begin{tabular}{|c|c|c|c|c|c|}
\hline $\begin{array}{l}\text { Rats: Columbia- } \\
\text { Sherman (albino) }\end{array}$ & Fe particles & $\begin{array}{l}\text { loss of photo- } \\
\text { receptor cells }\end{array}$ & $?$ & $2500 \mathrm{mGy}$ & Krebs et al., 1990 \\
\hline Rabbits: NZW & Fe particles & cataract & $500 \mathrm{mGy}$ & $1000 \mathrm{mGy}$ & Lett et al., 1991 \\
\hline \multicolumn{6}{|c|}{ FRACTIONATED DOSES } \\
\hline Mice: ICR/CRJ & $\beta$-radiation & $\begin{array}{l}\text { tumor } \\
\text { incidence }\end{array}$ & $\begin{array}{l}{ }^{*} 500 \mathrm{mG} / \mathrm{dose} \\
(3 \mathrm{x} / \text { week })\end{array}$ & $\begin{array}{l}1000 \mathrm{mGy} / \text { dose } \\
(3 \times / \text { week })\end{array}$ & $\begin{array}{l}\text { Ootsuyama and } \\
\text { Tanooka, } 1993\end{array}$ \\
\hline Dogs: beagle & $\gamma$-rays & life-shortening & $\begin{array}{l}* 3 \mathrm{mGy} / \mathrm{day} \\
\text { (continuous) }\end{array}$ & $\begin{array}{l}7.5 \mathrm{mGy} / \mathrm{day} \\
\text { (continuous) }\end{array}$ & $\begin{array}{l}\text { Carnes and Fritz, } \\
1993\end{array}$ \\
\hline
\end{tabular}

* at these dose rates a $5-10 \%$ reduction in average life span was observed, but this reduction is not associated with any obvious pathology and it is not clear how statistically significant this difference is. 


\section{a. Radiation-induced mutagenesis}

i. Minisatellite mutations in humans induced by radiation from the Chernobyl accident

Dubrova et al. (1996) have determined the mutation frequency in blood samples from children born in the region around Chernobyl after the accident on 26 April 1986. The sample included only children born between February and September, 1994 to parents who had both lived continuously in the contaminated area around Chernobyl since the time of the accident. Mutations at various minisatellite loci were determined and found to be two times higher than those found in a control population in England. There is general concern about whether the findings are negated by the use of this questionable control population.

The elevated mutation rates correlated with the level of ${ }^{137} \mathrm{Cs}$ surface contamination, suggesting that these putative germline mutations were induced by the elevated levels of ${ }^{137} \mathrm{Cs}$. These investigators also estimated that the total exposure to ${ }^{137} \mathrm{Cs}$ was about $5 \mathrm{mSv}$ per year, while the thyroid exposure to ${ }^{131}$ I was about $0.18-0.19$ Gy per person. These estimates suggest either that the mutations were induced by the acute ${ }^{131}$ I exposure, or the ${ }^{137} \mathrm{Cs}$ exposure was substantially underestimated, the control population used was inappropriate, or low doses of chronic irradiation are more mutagenic than high doses of acute irradiation. In evaluating radiation risk for travel in outer space, it is important to determine whether this latter possibility may be correct.

\section{ii. Chromosome aberrations in Chernobyl clean-up workers}

Soviet citizens who were sent to the Chernobyl site to contain and clean up the contamination were exposed to subacute levels of radiation estimated to be between 5 and 25 cGy. Cytogenic analysis of metaphase lymphocytes for stable aberrations such as translocations and insertions, was performed on control and exposed workers $(n=253)$ by painting chromosomes 1,2 and 4 simultaneously (Ramsey et al. 1996). They found a highly significant difference between these groups indicating a possible effect of the radiation exposure, but noted that age and smoking status also influenced the level of aberrations.

iii. HPRT mutations in Russian cosmonauts. Khaidakov et al. (1997) examined 107 mutant hypoxanthine-guanine phosphoribosyl transferase (HPRT) clones obtained from five Russian cosmonauts who had completed space flights of 7 - 365 days, and been exposed to radiation doses in the range of 4 to $127 \mathrm{mGy}$. The clones were isolated from T-lymphocytes collected one 
to two years following completion of the flight. The mutation frequencies were 2- to 5-fold higher than those observed in healthy, unexposed noncosmonaut subjects, and the mutations included deletions and insertions, as well as point mutations, many of which resulted in mRNA-splicing errors. However, the profile of mutations resembled that observed in unexposed subjects, suggesting that the additional mutations were not caused by irradiation which would be expected to bias the spectrum towards deletions. Furthermore, because pre-flight controls were not available, it is not clear whether the higher mutation frequencies existed before the flight and resulted from occupational hazards or environmental factors related to being a cosmonaut, rather than radiation per se.

\section{b. Radiation-induced cancer.}

\section{i. Survivors of atomic bomb blasts in Japan in 1945}

The risks for cancer development associated with space flight and the uncertainties in these risks have been discussed previously in considerable detail in NCRP report 98 (1989). Whether it is the terrestrial environment or deep space, current understanding of the cancer risk in humans following radiation exposure has as its foundation the epidemiological data from studies of atomic bomb survivors (Kato and Schull, 1982; Kato et al., 1982). The atomic bomb survivor data for solid tumors have been updated by Thompson et al. (1994), and more recently by Pierce et al. (1996).

Studies of other exposed populations, principally medically and occupationally exposed populations, have provided supplementary and supportive data (Boice, 1996). Based on these data, risk estimates after lowLET irradiation for both mortality and cancer incidence have been developed for leukemia and solid tumors in a number of organ sites (ICRP, 1991). The NIH has also published detailed radioepidemiological tables (Rall et al., 1985).

The strongest link between radiation exposure and cancer risks have been found for leukemia (except for chronic lymphocytic), thyroid, and female breast (Table IV.13). Increased risks for these cancers have been consistently observed in exposed populations and considerable data exist on dose response relationships for these cancer types. Other cancers for which there appears to be an increased risk include stomach, liver, colon, lung, ovary, skin, and bladder; the excess relative risk at $1 \mathrm{~Sv}$ for all solid cancers is 0.63 . Tissues for which no increased risk was observed in atomic bomb survivors include oral cavity, pharynx, esophagus, rectum, gall bladder, pancreas, larynx, uterus, prostate and kidney. For low LET radiation, cancers of the bone and connective tissue as well as the uterus and rectum have been found, but only after high dose exposures, in the range of 10-30 Gy. No increased risks for these tumors have been found in studies of populations exposed to low doses. 
The data in Table IV.13 indicate that radiation-induced breast cancer has a uniquely high relative excess risk among solid tumors. Land (1995) has asked whether this increased risk is robust enough to confirm "the possible existence of a radiation-susceptible subgroup," and has concluded that it may be. Genes such as $B R C A 1, B R C A 2$, and $A T M$ (see Table IV.14) might be risk factors in such a subgroup, and a study to evaluate this possibility is underway. Unfortunately, discovery of the BRCA1 and BRCA2 genes has not yet led to an understanding of how the products of these 2 genes work (Kahn, 1966). Land also has used the data of Tokunaga et al. (1994) to calculate the relationship between relative excess risk of breast cancer and dose in Sv, and finds that up to $5 \mathrm{~Sv}$, the relationship is linear with a slope of about unity. In considering only the data for very low exposures i.e., $<0.1 \mathrm{~Sv}$, he further concludes that "an expanded study limited to low dose survivors. . would be expected to yield comparatively little useful information", except perhaps to confirm that a minimum threshold does exist for a one-time exposure to lowLET radiation.

Leukemia appears to be a more likely outcome of high dose radiation exposure, and was the first long term effect noticed in the exposed Japanese population; it is tempting to speculate that the increase in acute lymphocytic leukemia could be due to the relative ease of induction of telomerase in lymphocytes and thymocytes (Weng et al., 1996; Buchkovich and Greider, 1996). The relative risks at $1 \mathrm{~Sv}$ for acute lymphocytic leukemia, chronic myelocytic leukemia, and acute myelogenous leukemia are shown in Table IV.13 (Preston et al., 1994). There was no evidence for excess relative risk for chronic lymphocytic leukemia or adult T-cell leukemia.

Considerably less information is available on populations exposed to high LET radiations (Boice, 1996). Available data for cancer induction after exposure to high-LET radiation is limited to exposures from internal emitters under very special circumstances. As a result, doses are not known with any degree of certainty and increased cancer risks are mainly limited by the distribution patterns for the particular isotopes. These data are of little value for deriving risks associated with external exposure to high-LET radiations which would be encountered in the space environment.

Because current estimates of cancer risks associated with radiation exposure are based mainly on data from the Japanese survivors of the atomic bombings, there are a number of uncertainties in these estimates. First, because this is an ongoing study of a population in which approximately half of the population is still living, estimates are highly dependent upon whether the projection models used to estimate lifetime risks are appropriate. Second, because the radiation exposure in Japan was delivered as an acute high doserate exposure principally of gamma rays, with a relatively minor component of the dose coming from fission neutrons, uncertainty with respect to the 
risks is increased when the radiation is delivered at low dose rates or the total dose is protracted from weeks to months.

Very few data exist for populations exposed at low dose rates or at low doses per fraction. Data from studies of tuberculosis patients treated with multiple fluoroscopies represent the largest study which is available to address fractionation effects. Data from these studies suggest no reduction in risk following fractionated radiation exposures for breast cancer, while for lung cancer a reduction in risk was observed (Boice et al., 1991; Davis et al. 1989). Current risk estimates have incorporated a dose rate effectiveness factor (DREF) which reduces risk estimates for certain neoplasms by a factor of two under conditions of low dose rate or protracted exposure conditions (ICRP, 1991; UNSCEAR, 1993). This DREF is based on current models for mechanisms of radiation carcinogenesis and the results of data derived from experimental studies examining tumor induction in experimental animals, and cellular endpoints in a range of species including human cells. A third area of uncertainty is related to models used to transfer risks in the Japanese population irradiated in 1945, with specific and unique patterns of cancer incidence rates and age-specific mortality rates, to modern Western populations.

A number of biological factors including age, gender, and genetic background are known to influence cancer risks (Boice et al., 1991; Tokunaga et al., 1994; Pierce et al., 1996). The projected excess lifetime risk per Sv for those exposed at age 30 is estimated at 0.14 and 0.10 for females and males, respectively. The risk for those at 50 years of age are about $1 / 3$ of those exposed at the younger ages. The excess lifetime risk for leukemia at $1 \mathrm{~Sv}$ for those exposed at 10 or 30 years of age is estimated to be about 0.008 and 0.015 for females and males, respectively. Exposure at 50 years of age carries a risk of about $2 / 3$ the risk at the younger ages. Risk of thyroid cancer appears to be almost entirely limited to children under the age of 15 (Thompson et al., 1994). Female breast and ovary are known to be sensitive to cancer induction by radiation while in the male, breast cancer, testicular cancer and prostate cancer have not been linked to radiation exposure. Because of the sensitivity of the breast and ovary it is not surprising that females are at an increased risk; however, a recent study has reported higher cancer risks for women even when these two tumors were excluded from the analysis (Boice, 1996; Thompson et al., 1994).

Genetic background also influences cancer risks following radiation exposure. Individuals in families with Li-Fraumeni syndrome appear to be at high risk for developing second cancers following radiation therapy ( $\mathrm{Li}$ et al., 1988). More recently, it has been suggested that individuals heterozygous for ataxia telangiectasia may be at high risk for breast cancer after radiation exposure, but this conclusion has been sharply criticized and, at present is a matter of controversy (Swift et al., 1991; Boice and Miller, 1992). This is discussed in more detail in Section IV.D.3.c. All of these data on biological factors are 
intriguing, but as yet, incomplete. A full understanding of the influence of age, gender and genetic background on cancer susceptibility after exposure to radiation will require substantially more data. 
TABLE IV.13

\section{CANCER IN ATOMIC BOMB SURVIVORS}

\section{Relative Excess Risk of Solid Tumors at $1 \mathrm{~Sv}$ in Atomic Bomb Survivors}

Tissue Relative Excess Risk*

breast

thyroid

urinary bladder

1.02

skin (non-melanoma)

1.00

ovary

0.99

lung

0.95

colon

0.72

all tissues

0.63

liver

0.49

stomach

0.32

control

0.00

Adapted from Thompson et al. (1994)

Relative Excess Risk of Leukemia at $1 \mathrm{~Sv}$ in Atomic Bomb Survivors

Leukemia

acute lymphocytic leukemia chronic myelocytic leukemia acute myelogenous leukemia

chronic lymphocytic leukemia
Relative Excess Risk*

9.1

6.2

3.3

0.0

* Relative excess risk is defined as $(\mathrm{O} / \mathrm{E})-1$, where $\mathrm{O}$ is the number of events observed in the exposed population, and $E$ is the number of the same type of events expected in a population in the absence of an exposure.

Adapted from Preston et al. (1994). 
TABLE IV.14

HUMAN BREAST CANCER SUSCEPTIBILITY GENES

\section{Gene}

$B R C A 1, B R C A 2$

ATM

FHIT (a fragile site on chr. 3)
Phenotype

predisposes to breast cancer

ataxia telangiectasia

genome instability

cell cycle regulation

radiation sensitivity
Reference

Easton et al., 1993

Wooster et al., 1994

Savitsky et al., 1995a; 1995b

Barlow et al., 1996 predisposes to breast, but also colon and lung cancer
Ohta et al., 1996 


\section{ii. Leukemia after in utero exposure to radiation from Chernobyl}

Whereas irradiation by fallout from the Chernobyl accident has not yet been shown to be a risk factor for childhood leukemia, Petridou et al., 1996 reported that exposure in utero did increase the risk of infant leukemia 2-3 fold. This increase was observed in Greek children exposed to an average fallout of $2 \mathrm{mSv}$, suggesting that the fetus is particularly susceptible to ionizing radiation

\section{iii. Thyroid cancers in children living near Chernobyl}

Since 1990 there has been a marked increase in the number of cases of thyroid cancers in children living in Belarus, the Ukraine and the Russian Federation, the countries most contaminated by the Chernobyl nuclear accident. In Belarus, directly to the north of Chernobyl, the number of childhood cancers per year has risen from 2 in 1986 to more than 80 in 1994 (Kazakov et al., 1992), while in the Ukraine there has been a 5-fold increase in the same period (Likhtarev et al., 1995). The predominate type of cancer is papillary carcinoma, with the majority being relatively aggressive tumors that have extensions into the parathyroid tssues. There now appears to be consensus that these childhood cancers can be attributed to the release of radioactive iodine, and in particular ${ }^{131} \mathrm{I}$, following the accident. This is because iodine is concentrated in the thyroid, and the geographical distribution of the cancers closely matches the fallout pattern of this element (Likhtarev et al., 1995).

Although it was anticipated that there would be an increase in tumor frequency following the accident at Chernobyl, the short latency period and the very high incidence of the tumors were unexpected, especially because ${ }^{131} \mathrm{I}$ has been used both in diagnostic and therapeutic medicine without an increase in cancer incidence. The difference has been attributed to age because most patients receiving ${ }^{131}$ I clinically are adolescents and adults, whereas the significant increase in cancers occurring in people exposed in the Chernobyl incident occurred in children aged 15 and 18 years at the time of exposure (Baverstock et al., 1992). The other contributory factors may be the mixture of isotopes released at Chernobyl (132I, 133I and 135I were also released, although these isotopes have half-lives of minutes or hours compared to the 8 day halflife of ${ }^{131} \mathrm{I}$ ) and the environmental conditions in the areas around Chernobyl (Balter, 1995). Also, because iodine is concentrated in the thyroid, and children have smaller organs and drink more milk (which contains iodine) than adults, it has been estimated that the exposed children received doses that on average were three times higher than the adults 


\section{iv. $\quad$ Radon-induced cancer}

Considerable information has already been amassed on the effects of exposure in humans to a high LET radiation source - that of radon gas and its radioactive daughter progeny. Radon is an inert gas produced in the decay series from uranium and thorium. It is an $\alpha$-particle emitter with an emission energy of $5.49 \mathrm{MeV}$, and decays with a half-life of minutes to produce particulate daughters which are themselves radioactive ( $\alpha$-particle emitters). Because of its presence in the domestic environment, studies ranging from the epidemiological to the molecular have been conducted on the effects of exposure to radon. These studies can serve not only as a source of information on the biological effects of exposure to a high LET source, but also as a guide to the type of studies that are most likely to yield information that is pertinent for risk assessment and reduction in humans.

Uranium miners have provided the basis for many epidemiological studies on the effects of exposure to radon on carcinogenesis in humans. The clearest data to come from these studies is that prolonged exposure to the underground mine environment significantly increases the possibility of contracting lung cancer. What has been more difficult to establish unambiguously is that radon alone is a neoplastic agent. This is because the underground mine also contains substances such as arsenic, silica, diesel exhaust and fungal mycotoxins which may have acted as promoters of the carcinogenic effects of radon exposure.

Studies which excluded smokers from the analysis, have shown a 12-fold increase in deaths due to lung cancer (Roscoe et al., 1989). This does not in any way provide sufficient information on the potential risks of radon exposure in the home, where the dose, dose-rates and ambient air qualities are very different from those found in the underground mine. Investigators do agree that exposure to radon in the home, where it has been estimated that the lifetime exposure is less than $1 \mathrm{~Gy}$, can contribute to cancer risk (Hui et al., 1990; James et al., 1995; Jostes, 1996). However, the level of radon remediation required and the extent of risk are still unclear and so it has been considered necessary to conduct experiments in vitro and with animals to determine whether effects found at high doses and dose rates can be extrapolated to the low doses found in the home. However, it is clear that doses of $\alpha$-particles less than $1 \mathrm{~Gy}$, emitted by bone-seeking radionuclides rather than radon, can be linked to induction of bone sarcomas (Mays, 1988).

Sequence analysis of the $p 53$ tumor suppresser gene in lung cancers from uranium miners revealed that mutations had been induced in the gene in 30 - $40 \%$ of the tumors. In one study, it was found that deletions had been induced in 2 of the 9 genes studied; no transversions (characteristic of smoking) were detected (Vahakangas et al., 1992). In another study, of a cohort of 52 heavily exposed uranium miners, it was found that $31 \%$ of 
mutations detected had an AGG to ATG transversion at codon 249 which would suggest a "molecular signature" for $\alpha$-particle radiation (Taylor et al., 1994). However, it appears also possible that these mutations were induced by aflatoxin exposure in the mines from the resident molds; transversions at $G$ nucleotides have been documented as the predominant mutation induced by aflatoxin exposure (Venitt and Biggs, 1994). This indicates that these p53 mutations may not be a direct result of the irradiation. These inconclusive results indicate the need for well-controlled experiments in model systems.

\section{v. Cancer therapy and induction of second tumors}

One treatment for tumors in humans is irradiation with $\mathrm{HZE}$ particles. Second tumors as a result of treatment with $\mathrm{He}$ and $\mathrm{Ne}$ particles resulted in 3 tumors out of 163 patients and 2 tumors out of 92 patients, respectively (Joseph Castro, personal communication). The total mean fractionated dose in each case was 60-70 Gy, indicating that these high doses are carcinogenic at a frequency of about $2 \%$, or several fold greater than what would be expected for low-LET irradiation. However, the few numbers of tumors observed lowers the confidence limits of this estimate.

\section{c. Human genetic syndromes with increased radiation sensitivity}

Li-Fraumeni syndrome and ataxia telangiectasia (AT) are two human genetic syndromes whose phenotypes appear to include increased radiation sensitivity based on experiments carried out with knockout mice and cultured cells from patients. Li-Fraumeni syndrome patients carry one normal and one mutant p53 gene (Li et al., 1988; Malkin et al., 1990). Kemp et al. (1994) have shown that comparable heterozygous $p 53+/-$ mice are radiation-sensitive as shown by decreased latency before tumor induction by ${ }^{60}$ Co $\gamma$-rays. The radiation-induced tumor spectrum also differs from that observed in unirradiated controls. The p53 protein acts as a tumor suppressor in at least two ways; first, p53 arrests DNA replication until DNA repair has been completed, (Kuerbitz et al., 1992), and second, p53 is required for radiation-induced apoptosis, at least in thymocytes (Lowe et al., 1993). Thus, once the normal p53 allele becomes mutated the mouse is prone to mutagenesis because replication is not delayed until repair is complete, and tumorigenesis is more likely because preneoplastic cells are not removed by apoptosis. As a result, $p 53-/-$ cells are more resistant to UV light than are p53+/- cells because the former are unable to die by apoptosis (Ford and Hanawalt, 1995).

The AT syndrome has recently been recapitulated in knockout atm mice, and these mice are very sensitive to ${ }^{137} \mathrm{Cs} \gamma$-rays (Barlow et al., 1996). In the few experiments which have been done, the $\mathrm{atm}^{+} / \mathrm{atm}^{-}$heterozygous mice resemble wild type controls in radiation sensitivity. The actual defect in atmdeficient mice has not yet been elucidated, although experiments with cells 
cultured from AT patients indicate that 1) in AT cells p53 induction after irradiation is delayed, as is induction of gadd45 and $p 21$ (Artuso et al., 1995), 2) double-stranded breaks are not repaired as completely in AT cells as they are in normal cells (Blöcher et al., 1991), and 3) radiation-induced chromosome aberrations are greater in AT cells (Pandita and Hittelman, 1992). The increased chromosomal aberrations are presumably due both to the delay in repairing double-strand breaks, and the delayed induction of $p 53$.

The above results suggest that atm-/-, p53 -/-, or $p 53+/-$ mice can be used to increase sensitivity to irradiation in experiments to determine whether low doses of irradiation can induce significant effects. In fact, Tennant et al. (1995) have proposed the use of $p 53+/-$ mice for identifying potential chemical carcinogens (see Section V.A.9.a.). However, all of the above experiments were done with ${ }^{60} \mathrm{Co}$ and ${ }^{137} \mathrm{Cs} \gamma$-rays, so there is a need to repeat some of these experiments with HZE particles.

\section{d. Neurobiological damage}

There are very few data in humans concerning the neurobiological effects of neutrons, and none for HZE particles. From the clinical data, it is suggested that the RBE for injury to the brain by mid-energy neutrons is about 4-5 (See Laramore (1991) for details and references). There are no data for the effects of protons, neutrons, or HZE particles on the CNS in humans that can be used for estimating the risks of late effects that must be considered in the planning of interplanetary missions and the design of the shielding for the space vehicles. The use of RBEs to estimate the risk of late effects from HZE particles must be questioned because of the distinct differences in the pattern of the deposition of energy. In other words, based on the results obtained in culture systems for cell killing (Section IV.D.1.c.), it seems unlikely that data obtained with low-LET radiation can be extrapolated to high-LET with confidence using a radiation weighting factor. Thus, it is necessary to obtain and use data from experimental animals to assess the effects of HZE particles on the human CNS.

\section{e. Radiation-induced damage to the gonads}

The radiosensitivity of the human testis was first reported about eleven years after the discovery of $\mathrm{X}$-rays. The data on the effects of radiation on the testis come from atomic bomb survivors, radiotherapy patients, investigation of volunteer subjects at state penitentiaries, and to a lesser extent, accident cases. The effects have been reviewed by Meistrich and van Beek (1990). The endpoints of concern are temporary and permanent sterility, which result from the reduction in sperm caused by the killing of the spermatogonia. In the human, the paracrine mechanisms that regulate differentiation are perhaps even more sensitive than the spermatatogonial stem cells, and their 
inactivation is an important aspect of the radiosensitivity (Meistrich and van Beek, 1990).

The response of the various cell types in human volunteers exposed to 1.0 and 6.0 Gy of X-rays is shown in Table IV.15. It can be seen that the Ap and B spermatogonia are the most sensitive, in agreement with findings in experimental animals; these are the mitotic spermatogenia.

Consistent with the kinetics of spermatogenesis, sperm counts do not decrease for 8 weeks after exposure and the nadir in the sperm counts is not reached until 3-8 months after exposure. In mice the decrease in sperm counts occurs more rapidly, consistent with the more rapid maturation cycle.

There appears to be a considerable variability in sensitivity among men. Significant reductions in sperm counts have been reported after a single dose of 0.15 Gy. About 50 percent of men exposed to about 0.4 Gy will show azoospermia, and 90 percent will after $1.0 \mathrm{~Gy}$. The data from accident cases suggest that 50 percent of the men showed azoospermia 1 year after $1.5 \mathrm{~Sv}$. Recovery can take a long time, about one year after single doses of $0.5 \mathrm{~Gy}$. Even up to doses of $6 \mathrm{~Gy}$, recovery may occur but takes two or more years. Permanent sterility probably does not occur until exposure exceeds $6 \mathrm{~Gy}$.

There are not sufficient data for the effects of protons, neutrons, or HZE particles on the human testis. Risk estimates for these radiation qualities will have to be obtained using RBE values determined for appropriate endpoints in experimental animals. Perhaps the most important data that are needed are those for protracted exposures to protons, in particular those of high energy, because of the high proton fluence in GCR.

In the human, the ovary is less sensitive than the testis with regard to loss of fertility. Doses below 1 Gy of low-LET radiation are not likely to have longterm effects on fertility, although temporary infertility may occur for a few months. About 5 percent of women may be sterile for 5 years or more after single doses of $2 \mathrm{~Gy}$ to $6.5 \mathrm{~Gy}$. It is estimated that doses of $6 \mathrm{~Gy}$ to $20 \mathrm{~Gy}$ are required to permanently sterilize 50 percent of women (Lushbaugh and Casarett, 1976). Radiation injury of the ovary is reduced when the exposures are fractionated or protracted, which is an important point because the exposures in deep space are protracted and at a low dose rate.

Neel (1990) has reviewed the cytogenetic data available from the study of the survivors of the atomic bomb blasts in Hiroshima and Nagasaki. These data have failed to demonstrate an effect of parental exposure to radiation on the frequency of sex-chromosomal aneuploids in their children. Furthermore, a variety of other endpoints such as congenital defects, chromosome translocations, malignancies, etc., failed to show a significant difference in frequency between children of exposed and non-exposed parents. Neel 
concluded that: "We are beginning to develop the case for humans being rather less sensitive to the genetic effects of radiation than had been projected by studies on mice ...". However, recent data on the dose-related increase in mutations at minisatellite loci in chilldren born in Belarus after the Chernobyl accident are consistent with the induction of germline mutations by exposure to ionizing radiation (Dubrova et al., 1996). This indicates the need for further studies before firm conclusions can be reached about the effects on reproduction of chronic exposure to ionizing radiation. 
TABLE IV.15

SURVIVAL OF CELLS OF THE HUMAN TESTIS EXPOSED TO X-RAYS

$\%$ cells remaining

Cell type

$1.0 \mathrm{~Gy}^{*} \quad 6.0 \mathrm{~Gy}^{*}$

Spermatogonia

$\mathrm{A}_{\mathrm{d}}{ }^{a}$
$\mathrm{Ap}_{\mathrm{p}}{ }^{b}$
$\mathrm{~B}^{\mathrm{C}}$

Early

Pachytene

Round

Elongated
83

11

1

50

52

1

Spermatocytes

1

53

1

53

Spermatids

53

42

a Ad spermatogonia are considered to be reserve stem cells

$b$ Ap spermatogonia are cycling stem cells

C B spermatogonia are precursors of spermatocytes

*Although the doses are given here in Gy, many of the original reports record the exposures in roentgens so the absorbed doses were probably $5-10 \%$ less than indicated by the values given here in Gy. Survival is 2 weeks after exposure to X-rays.

(Data from Rowley et al., 1974, adapted by Meistrich and van Beek, 1990) 


\section{f. Cataractogenesis}

Schull et al. (1994) have studied the occurrence of cataracts in Hiroshima atomic bomb survivors and found thresholds of $1.1 \mathrm{~Gy}$ and $0.06 \mathrm{~Gy}$ for $\gamma$-rays and neutrons, respectively. Blakely et al. (1994) have taken advantage of a very different man-made experiment, i.e., cataract induced by irradiation of intraocular melanomas by helium ions 4-5 times over a 4-16 day period. Such irradiation is difficult to accomplish without some concomitant partial irradiation of the lens, and the exposure of the lens can be calculated from the geometry of the treatment. Of the 33 patients who had $1-10 \%$ of their lens exposed during the melanoma treatment, $48 \%$ developed mild lens opacity, and $12 \%$ developed significant cataract; only one of the 21 patients with less than $1 \%$ of their lens exposed developed significant cataract. The asymmetric nature of the opacity observed suggests that the damage is localized to the portion of the lens exposed. The patients were followed for up to 13 years, but no correlation between latency of onset of lens opacity and percent of lens exposed was observed. The interpretative value of these preliminary results is limited by the nature of the dose protocol and the asymmetric exposure used, i.e., in outer space travel there will be no localization of exposure, and the exposure will be fairly constant with time. Nonetheless, such data might be useful if it becomes possible to establish an interspecies calibration between radiation-induced cataract in humans and animals.

\section{g. Summary for Section IV.D.3}

- Most human data have come from survivors of the atomic bomb blasts in Japan in 1945. These data indicate that leukemia is the most likely radiationinduced cancer in response to an acute high dose of low-LET radiation. The tissues at highest risk for solid tumors are breast, thyroid, bladder, ovary and lung. Comparable knowledge about high-LET radiation is not available.

- Exposure to the fallout from the Chernobyl accident has been linked with varying degrees of confidence to the following outcomes: 1) increased minisatellite mutations in children born to exposed parents, 2) increased chromosomal aberrations in lymphocytes from clean-up workers, 3) leukemia in exposed Greek children, and 4) increased thyroid cancer in Belarusian children. These effects are assumed to be due primarily to $\gamma$ radiation from ${ }^{137} \mathrm{Cs}$ and various isotopes of I, particularly ${ }^{131} \mathrm{I}$. These results provide further epidemiological evidence that low level, continuous $\gamma$ irradiation of humans is carcinogenic.

- The few results available on Russian cosmonauts have not yet provided evidence to suggest that space travel in low Earth orbit is either mutagenic or carcinogenic. 
- Two human syndromes, Li-Fraumeni and ataxia telangiectasia, are characterized by radiation sensitivity. These experiments of nature have been reproduced in transgenic mice, and these mice can provide opportunities to study radiation-induced damage at very low doses because of the increased radiation sensitivity of these two animal models.

- There are very few data on radiation-induced neurobiological damage or neuron killing in vivo in humans.

- Radiation-induced damage due to HZE particles must be modelled by experiments in animals and/or cultured cells under physiological conditions because of the paucity of data available and the impossibility of doing experiments on human subjects.

\section{Review references:}

Boice JD Jr., 1996. Risk estimates for radiation exposures. In: Health Effects of Exposure to Low-Level Ionizing Radiation. WR Hendee, FM Edwards, (Eds.), Institute of Physics Publishing, Philadelphia, pp. 237-268.

Schull WJ, Weiss KM. 1992. Radiation carcinogenesis in humans. Adv. Radiat. Biol. 16: 215-258. 


\section{CRITICAL MARKERS OF PHYSIOLOGICAL RESPONSE TO RADIATION-INDUCED DAMAGE}

Taking the Background Section into account, in this section the Panel has provided a number of approaches which could be used to evaluate the impact of HZE particle irradiation on biological parameters primarily relevant to carcinogenesis and CNS damage in animal model systems. The usefulness of these techniques will clearly depend on the research question being asked in any particular experiment, but it is clear that at this point in our knowledge no single measurement is sufficient to predict risk. Thus, a multi-faceted approach is recommended. The advantages and disadvantages of these techniques are briefly summarized in Tables V.1 and V.2. It is also assumed that new and more powerful techniques will become available in the next few years which will make it possible to measure more subtle consequences of exposure which cannot currently be addressed adequately.

An overview of a recent symposium on toxicity testing has been published by MacGregor et al. (1995). These authors reviewed a wide variety of new molecular endpoints and methods for routine toxicity testing. The methods and endpoints discussed included damage-inducible genes, hybridization probes for detection of chromosomal damage, detection of mutations, single cell electrophoresis to detect DNA damage and cell death, and application of accelerator mass spectrometry. Many of these techniques are also relevant to the task of assessing radiation damage, and some specific examples are included in the following discussion.

\section{A. GENERAL CRITERIA RELATED TO TUMOR INCIDENCE}

\section{MUTAGENESIS FREQUENCY}

\section{a. General: Using transgenic mouse models for mutation detection}

It has long been generally accepted that mutagenesis and carcinogenesis are closely linked, but it is also clear from many experiments that if there is such a link it is not linear, and there is no one-to-one correlation. Nevertheless, this linkage provides the conceptual basis for the bacteria-based Ames test for mutagens (Ames et al., 1973). It would be useful to have a similarly sensitive assay for mutagenesis in animals in vivo. In 1989 and 1991, the first transgenic animal models for studying mutations in vivo were reported (Gossen et al., 1989; Kohler et al., 1991). These models were based on multiple integrated copies of a bacteriophage lambda vector containing the bacterial reporter genes lacZ or lacI. The first animal models to be routinely used for this purpose were the Muta Mouse and Big Blue transgenic mice carrying lambda phage-based probes for mutagenesis (Morrison and Ashby, 1994). It has been shown that although the spontaneous mutation frequency at the 
transgene loci are higher than those at an endogenous locus such as hprt, the induced mutation frequencies are not significantly different (Skopek et al., 1995; Tao et al, 1993b). This may be due in part to the inability to detect deletion mutants in these transgenic systems (Lee et al., 1994; Douglas et al., 1994, Winegar et al., 1994; Katoh et al., 1994). Hence, they are less suitable for studying radiation effects, particularly those due to HZE particles.

A recently developed system, based on an integrated lacZ-containing pUR288 plasmid, is more efficient and can detect a broad spectrum of mutations (Gossen et al., 1995a; Martus et al., 1995; Boerrigter et al., 1995; Dollé et al., 1996; Vijg and Douglas, 1996; Boerrigter and Vijg, 1997). Several transgenic lines with the plasmid cluster located on different chromosomes are available. At least one of them is characterized by a much higher mutant frequency. The occurrence of such lines has been described before (Gossen et al., 1991; Leach et al., 1996), and are indicative of unstable regions in the mammalian genome. The details of how to use these techniques have been published by Vijg and Douglas (1996).

Using this assay, Dolle et al. (1996) demonstrated that the average spontaneous mutation frequency in four different mouse organs (spleen, kidney, liver, lung) varied from 4 to $7 \times 10^{-5}$, compared to about $1 \times 10^{-5}$ in Escherichia coli. These mutations included both point mutations and size changes. Single treatment with the mutagenic agent ethylnitrosourea (ENU) at $100 \mathrm{mg}$ and $250 \mathrm{mg}$ ENU per $\mathrm{Kg}$ body weight induced 7- and 14-fold increases in the mutation frequencies, respectively. Because the mutated genes can be rescued by positive selection (millions of transformants can be obtained per experiment), and the mutations are caused by a wide range of mutagenic agents (Boerrigter et al., 1995), this transgenic plasmid model should provide a desirable system for detecting mutation rates in vivo due to radiation damage. For example, Gossen et al. (1991) demonstrated that in one of the mouse "mutator lines" the integration site for the transgene involved the pseudoautosomal region of the X-chromosome, which is known to be (meiotically) unstable in the human too. Preliminary results indicate that with the plasmid model, iron particle-induced large deletion mutations can be detected, and that there are tissue-specific differences in the frequency of induced mutations. (L. Lutze-Mann/J. Vijg, unpublished).

\section{b. Specific genes}

Albertini et al., (1993) have suggested several genes useful for assessing somatic cell mutations in humans. These include the genes for hemoglobin $\beta$ chain, glycophorin A, hypoxanthine-guanine phosphoribosyl transferase (HPRT), and HLA. Mutation frequencies can be determined for the first two in erythrocytes, and for the latter two in T-lymphocytes. Hprt gene mutation is a very useful assay system, because cells carry only one functional copy and positive selection of mutant cells is possible using resistance to 6-thioguanine 
(Albertini et al., 1988). They have shown that the mutation frequency of the human hprt gene due to high dose, low-LET ionizing radiation is in the range $1-5 \times 10^{-6} / \mathrm{cGy}$. The mutation frequency determined in atomic bomb survivors was only $7.5 \times 10^{-9} / \mathrm{cGy}$ (Hakoda et al., 1988), but this result may not be reliable because it was determined a very long time after exposure, and because dose estimates for the survival cannot be determined exactly. A major disadvantage of the hprt mutation frequency assay is that the hprt gene is located near an essential gene on the X-chromosome of mice and humans (Kronenberg et al., 1995), so that an assay requiring cell proliferation before selection will result in loss of many mutant cells if this essential gene is also damaged or deleted. Thus, the hprt mutation frequency may be substantially underestimated when the damage is induced by high-LET particles such as Fe nuclei.

The glycophorin A (GPA) locus has also been used to evaluate mutation frequencies in atomic bomb survivors (Kyoizumi et al., 1996). Mutations in this gene can be detected by flow cytometry of erythrocytes. Briefly, erythrocytes are exposed to anti-GPA monoclonal antibodies against one of the two alleles (M and N) of GPA. These antibodies are labeled either with fluorescin or biotin; binding of biotin antibodies is monitored by subsequent labeling with streptavidin-conjugated phycoerythrin. By using the appropriate mixtures of antibodies, hemizygous NX, homozygous NN and heterozygous $\mathrm{MN}$ forms can all be distinguished from each other; the same is true for MX, MM and MN.

The minimum detectable radiation dose was $0.24 \mathrm{~Sv}$, and the doubling radiation dose was $1.24 \mathrm{~Sv}$. This doubling dose of GPA mutant frequency is similar to that of solid cancer incidence in A-bomb survivors suggesting that GPA mutation frequency may reflect cancer risk in a population exposed to low-LET radiation; whether a similar relationship exists for high-LET radiation is not known. The mutation frequencies measured in this study resulted from an acute exposure and the frequencies measured in each individual have been stable over the 5 years the study has been in progress. It is assumed this assay should also be useful for studies on humans exposed to chronic, low-level radiation.

\section{GENOMIC INSTABILITY}

\section{a. Detection of cytogenetic aberrations using chromosome painting}

A linkage between chromosomal rearrangements and cancer induction has already been established in a variety of systems (Tsujimoto et al., 1984; Liu et al., 1994). Using probes for specific chromosomes, Ramsey et al. (1995) have demonstrated the ability to detect stable aberrations (translocations and insertions) in human lymphocyte chromosomes by a technique known as chromosome painting. They found that the frequency of these aberrations is 
dependent upon at least five variables: age, smoking, airborne carcinogens, previous major illness and dietary factors. Of these, age was clearly the most important, accounting for as much as $70 \%$ of the variation. The method has also been used to quantitate radiation-induced genomic instability (Tucker et al., 1993). Recent improvements now permit all 24 human chromosomes to be uniquely painted in a single experiment (Speicher et al., 1996; Schröck et al., 1996); experimental details are described in the two cited papers.

The assay is very sensitive, as aberration frequencies measured using probes for chromosomes 1,2 and 4 in 40 year old males are in the range of $0.2-1.5$ per 100 cells. By age 80 , frequencies as high as 6 per 100 cells are seen. In a preliminary experiment, J. Tucker and L. Lutze-Mann (personal communication) have shown that exposure of mice to $1 \mathrm{~Gy}$ of Fe particles initially increases the number of chromosomal rearrangements by as much as 50 per 100 cells. However, with time this number falls to about 10 per 100 cells, suggesting either that cell death may be occurring in some of the damaged cells, or that mutant cells are at a selective disadvantage. The utility of this assay is enhanced by the fact that it is relatively non-invasive, and can be done longitudinally so that each subject can serve as its own preirradiation control. Also, it can be used to compare different species, and can be used on cultured cells.

\section{b. Unstable sequences}

\section{i. $\quad$ Minisatellite repeats}

Human DNA contains tandem repeat regions of DNA which show considerable length polymorphism due to recombination (Jeffreys et al., 1985). These regions are called minisatellite DNA, and they contain a 10-15 basepair core sequence. Following digestion of human DNA with the appropriate restriction enzymes to produce short DNA fragments in the $2-20 \mathrm{~Kb}$ range, and fractionation of these fragments on acrylamide gels, characteristic fingerprints are obtained upon probing with a labeled core DNA sequence. The fingerprint obtained with DNA from a given individual is characteristic of that individual, and can thus be used to measure mutation frequency in response to any given insult such as toxic chemicals or radiation (Jeffreys $e t$ al., 1990).

By using single molecule polymerase chain reaction (PCR) amplification, Jeffreys and co-workers observed an increase in the rate of spontaneous (germline and somatic) mutation altering the length of minisatellite loci in the human and mouse genome $\left(10^{-2}-10^{-1}\right.$ rather than $\left.10^{-6}-10^{-5}\right)$ at the hprt locus (Dubrova et al., 1996). Like most of the about $97 \%$ non-coding DNA, repeat elements like mini- and microsatellites are often considered as "junk" sequences without function. However, with the discovery that many gene 
regulatory elements lie in or among repetitive sequences, this view has been reevaluated (Krontiris, 1995). Although the rate of spontaneous mutations altering minisatellite DNA length is already high, it is increased by $\gamma$ irradiation of mice with ${ }^{60} \mathrm{Co}$ (Dubrova et al., 1993). Unfortunately, the mutation frequency increase is not linear beyond $0.5 \mathrm{~Gy}$, a dose roughly double that of the spontaneous rate of mutation, but the method does provide a possible approach to detecting changes at low dose.

\section{ii. Triplet repeats}

A related form of genetic instability is triplet repeat expansion. Expansion of certain trinucleotide repeat sequences has been linked to a number of inherited diseases in humans, particularly neurological diseases (Kuhl and Caskey, 1993; Panzer et al., 1995). These sequences have been shown to be mitotically and meiotically unstable. The expanded CAG repeat length, which causes myotonic dystrophy, has been shown to progress toward larger expansion with age, with an increased size heterogeneity in blood leukocytes (Wong et al., 1995). Altered triplet repeat lengths have also been associated with cancer risk, and it has been recently reported that the risk of prostate cancer correlates with repeat length of CAG triplets in the androgen receptor gene (Holden, 1996b). Thus, radiation-induced changes in lengths of these unstable sequences could have direct implications for both cancer and neurodegenerative diseases in astronauts.

\section{iii. Telomeres}

Instability of minisatellite repeats extends to the telomeres. Telomeres are the tips of the chromosomes, containing an array of tandem repeats. They counter the effect of eukaryotic replication strategy, in which the lagging strand cannot be replicated all the way to its 5 ' terminus. Telomeric repeats can be added to the ends of chromosomes through the enzyme telomerase. Telomeres also protect the chromosome ends from factors that normally act on DNA termini (De Lange, 1994). Telomere shortening can be considered as a form of replication-dependent genetic instability (Murnane et al., 1994). Telomeric sequences are thought to discourage illegitimate recombination between the ends of chromosomes, so total loss of a telomere would not only increase the probability of incorrect joining of DSB, but could also lead to either cell senescence or death (Allsopp et al., 1992).

\section{iv. Mitochondrial DNA deletions}

One potential target, and therefore monitoring site for heavy ion-induced mutations, could be the mitochondrial genome. The circular $16.5 \mathrm{~kb}$ mitochondrial genome of mammals specifies 2 rRNAs, 22 tRNAs and genes encoding 13 mitochondrial protein subunits. These genes are necessary to produce essential enzyme complexes (part of which are encoded in the 
nuclear genome) involved in oxidative phosphorylation, the major ATPgenerating pathway in the cell. The mtDNA might be a relevant target for heavy ions for the following reasons: First, the mitochondrial genome, which is a closed circular DNA of $16,569 \mathrm{bp}$, is information-dense. Hence, random mutations generally strike a coding DNA sequence. Second, the mitochondrial genome seems less well protected by repair systems against DNA damage. Finally, the large mtDNA copy number in the cell permits otherwise lethal mutations to exist; a number of human diseases, including neuronal disorders and cancer, have been associated with mutations in mtDNA, most of which are deletions (Johns, 1995).

One of the occasional outcomes of repair following DNA damage is the generation of DNA deletions. When these occur in mitochondrial DNA, they are particularly easy to detect because not only can the mitochondria be readily separated from nuclei, but also because $P C R$ has the sensitivity to reliably amplify a single molecule of mutant DNA; this sensitivity persists even in the background of a million normal nuclear genomes (Cortopassi and Liu, 1995). The mutation frequency of any particular known mitochondrial DNA deletion in a population of mitochondrial genomes can thus be quantified by limiting dilution analysis of a known number of total mitochondrial genomes (Arnheim and Cortopassi, 1992). Such an analysis is particularly useful in non-proliferating tissue such as brain, muscle and heart, because mutant mitochondrial genomes will accumulate in such cells to a greater extent than they do in skin, spleen and lung (Cortopassi et al., 1992).

This PCR technique has been used extensively to determine the relationship between mitochondrial DNA deletion frequency and aging in response to low level but continuous oxidative stress (Wallace, 1992), a situation somewhat analogous to that which astronauts face during long term travel in outer space. For example, it was shown that such mutations greatly increase with age, i.e., by more than 10,000 fold in aging human tissues (Cortopassi and Liu, 1995; Wallace, 1995).

\section{c. Detection of genomic instability by PCR.}

\section{i. Interlocus V-I recombination}

Kirsch and his colleagues (Abdallah et al. 1995; Lipkowitz et al., 1992) have developed a sensitive assay for recombination between T-cell receptor $\gamma \mathrm{V}$ segments and T-cell receptor $\beta \mathrm{J}$ segments in peripheral blood lymphocytes, resulting in the inversion of chromosome 7 . This chromosome aberration is seen at low frequency in all individuals, but increases substantially in agriculture workers exposed to pesticides, in individuals with ataxia telangiectasia, and in patients with Hodgkin's disease undergoing chemotherapy. Thus, the increased frequency of this recombination between $\mathrm{V} \gamma$ and $\mathrm{J} \beta$ of $\mathrm{T}$ cell receptor genes appears to be directly and temporarily 
related to exposure to chemotherapeutic agents, presumably including radiation. As in chromosome painting, the assay is non-invasive and can be done longitudinally.

\section{ii. $\quad$ Chr $14-$ chr 18 translocation}

PCR has also been used to detect the frequency of oncogenic translocations. One specific example is the activation of the bcl-2 gene following a chr. 14 chr. 18 translocation, which places expression of the $b c l-2$ gene under the influence of the immunoglobulin heavy chain enhancer (Tsujimoto et al., 1984). This leads to dysregulation of the $b c l-2$ gene, inhibition of programmed cell death in lymphocytes, and lymphoma or lymphoid hyperplasia. This translocation also increases with age and exposure to cigarette smoke. Thus, amplification of $b c l-2$ expression by translocation can be used as a dosimeter for low level mutagenic events (Cortopassi and Liu, 1995).

\section{UNREPAIRED DNA DAMAGE}

As discussed previously in Section IV.B.1., DNA is subject to both base damage and strand breaks. Although base damage is usually repaired rapidly and with high fidelity, a variety of oxidized and modified bases, e.g., 8hydroxyguanine, can be detected in mammalian DNA (Fraga et al., 1990). When mice are irradiated with $\gamma$-rays, at least five pyrimidine-derived and five purine-derived lesions can be identified and quantified in liver DNA at levels significantly above control levels (Mori et al., 1993). Levels of modified bases such as these are usually determined by enzymatic digestion of the DNA followed by either high performance liquid chromatography and electrochemical detection, or gas chromatography and mass spectrometry (Halliwell and Dizdaroglu, 1992). If only one modified base is to be determined, 8-hydroxyguanine is usually chosen because of its relative prominence.

Several assays have been developed to indirectly detect the presence of DSB. One of these is referred to as the FAR method (fraction of radioactivity released), which measures the amount of radioactive DNA fragments released by electrophoresis from a gel plug in which irradiated labelled cells have been lysed (Rydberg et al., 1994); while simple, this assay does not yield very specific information about the DSBs produced. Löbrich et al. (1994) have improved this assay by using restriction enzymes to produce specific length fragments of the DNA which can be separated and sized by gel electrophoresis. Southern blotting can then be used to determine both the location of any particular genome fragment, and whether a deletion or rearrangement has occurred within that specific fragment. This assay has been used by Löbrich et al., (1995) to estimate the misjoining frequency (within about $100 \mathrm{~kb}$ resolution) between double-stranded ends following irradiation of human fibroblasts with X-rays; they found this frequency is 
about $25 \%$ and is independent of dose. Experiments with high energy $\mathrm{Ne}$ and Fe particles indicate the total joining frequency decreases with increasing LET.

Another form of damage which may be irreparable is DNA cross-linked to protein. Damaged DNA can interact with the nuclear matrix to form such cross-links. The nuclear matrix is the protein skeleton which anchors chromosomal loops and provides sites for DNA replication and transcription, and binds matrix-attachment DNA regions (MARs). When cloned MARs are irradiated with $\gamma$-rays in the presence of isolated nuclear matrices, crosslinking occurs between DNA and the proteins (Oleinick et al., 1994). The presence of histones during radiation reduces the sensitivity of the DNA with regard to formation of DSB by about 50-fold but has little effect on the formation of crosslinks (Xue et al., 1994). Cross-linking of protein to DNA can be assayed by the procedure described by Chiu et al. (1984), in which the protein-DNA complexes bind to nitrocellulose filters. The filter is then counted to determine the presence of DNA and protein (prelabelled with ${ }^{14} \mathrm{C}$ lysine and ${ }^{3} \mathrm{H}$-thymidine, respectively, or with suitable non-radioative tags).

Other assays for unrepaired or incorrectly repaired DNA damage have been described previously in Sections V.A.1. and V.A.2.

\section{PERCENTAGE OF CELLS IN S PHASE}

Cells in most adult tissues generally proliferate infrequently. Consequently only a small percentage of cells in tissue such as liver, lung, kidney, etc., are normally in S phase at any given time. However, transformation of these cells frequently increases the fraction of cells in S phase. This fraction can be determined by injecting animals with a single dose of a DNA precursor such as ${ }^{3} \mathrm{H}$-thymidine $\left({ }^{3} \mathrm{H}-\mathrm{dT}\right)$ or bromodeoxyuridine (BrdU) to label the DNA in proliferating cells. The proliferating cells are then detected by autoradiography in the tissue of choice. Typically, the \% cells in S phase in normal adult tissues such as skin, lymphocytes, and liver will be in the range of $0.1-1.0 \%$, so an increase of only a few percent of the total cells can be readily detected. In contrast, human neoplasms routinely exhibit labeling indexes in the range of 5-40\% (Fingert et al., 1993). Thus, this approach can be used invasively to detect transformation occurring in vivo in response to radiation.

\section{NUCLEAR STRUCTURE}

There are two ways to use the structure of the nucleus as a measure of damage. The first is what pathologists use routinely: staining the tissues and looking under a microscope. Any given tissue and cell type has its own characteristic nuclear morphology. Nuclear features of prognostic value are increased size, abnormal shape and a rearranged internal structure (Nickersen 
et al., 1995). It is well known that these features are perceptibly altered in malignancy and/or premalignant lesions (Kamel et al., 1990; Underwood, 1990). Nuclear morphology has been used as a powerful correlate of prognosis for breast cancer (Elston \& Ellis, 1991). Nuclear morphometry was shown to provide a better and more accurate prediction of prognosis for prostate tumors than histologic scoring (Partin et al., 1992).

The second way to use the structure of the nucleus is to analyse the nuclear matrix composition. While chromatin proteins are largely invariant from cell to cell, the protein composition of the nuclear matrix is cell- and tissue specific. Fey and Penman (1988) examined nuclear matrix proteins by twodimensional gel electrophoresis and identified two sets of proteins: those that were shared among different cell types, and those that were tissue-specific. Getzenberg and Coffey (1991) and Pienta and Coffey (1992) subsequently showed that malignancy alters this tissue-specific pattern (for a review reference, see Lelievre et al., 1996).

\section{CHANGES IN GENE EXPRESSION}

\section{a. Differential display}

Liang and Pardee (1992) have developed a method to identify and isolate genes which are differentially expressed in various cells or under altered conditions, by using the polymerase chain reaction (PCR). The key element is to use a set of oligonucleotide primers, one of which is complementary to the polyA tail of a subset of eukaryotic mRNAs, the other being short and arbitrary in sequence so that it anneals at different positions relative to the first primer. The mRNA populations defined by these primer pairs are amplified by reverse transcription and resolved on a DNA sequencing gel. When multiple primer sets are used, reproducible patterns of amplified complementary DNA fragments are obtained, depending upon the sequence specificity of the primers. This technique has been used to compare patterns of gene expression in normal human prostate tissue versus carcinoma (Wang et al., 1996b), and human mammary epithelial cells versus breast cancer (Liang et al., 1992). The most recent improvements in the method have been described by Averboukh et al. (1996).

\section{b. Microarray probes for mRNA}

To obtain information about the expression of individual genes in terms of amount of messenger RNA present, Schena et al. (1995) have developed a high capacity system to monitor the expression of many genes in parallel. Microarrays are prepared by high-speed robotic printing of complementary DNAs on glass for quantitative measurements of the corresponding mRNAs.. Because of the high density of the arrays, hybridization volumes of 2 microliters can be used for detection of rare transcripts in probe mixtures 
derived from 2 micrograms of total cellular mRNA. This procedure was used successfully by Bernard et al. (1996) to quantitate expression of 47 different genes following activation of T-cells. Such arrays could be developed using probes for expression of specific genes such as those listed in Table IV.6.

\section{c. 2-Dimensional (2-D) protein gels}

One direct assay for identifying global quantitative changes in gene expression is through the use of 2-D protein gels. To detect such changes, radioactivelylabelled proteins in a cell extract are fractionated according to size in one direction, and according to net charge in the second direction, and the dried gel is then exposed to film. Comparison of the films from the control and the experimental gels will provide information about the relative amounts of protein in a given spot. Occasionally, differences in the location of a spot will be observed which indicates that a structural change has occurred in the protein, but only rarely will the identity of any given spot be known. This technique was used by Boothman et al. (1989) to detect X-ray-induced proteins in human cells, using the procedure first described by O'Farrell (1975).

\section{d. Specific proteins}

It is unlikely that the expression of any single protein could provide a critical assay or endpoint for radiation damage. Even the products of tumor suppressor genes such as p53 and $\mathrm{Rb}$ are subject to complex changes in levels and post-translational modifications depending on the context of the cells and tissues. However, it is possible that telomerase, an enzyme activity which has been correlated with carcinogenesis in a variety of tissues (Kim et al., 1994), comes close to being such a protein. Telomerase is normally found only in germline cells, stimulated lymphocytes and thymocytes, and possibly stem cells. Pandita et al. (1996) have shown that telomerase activity also correlates with metastatic potential of human cells irradiated with $\alpha$-particles. Thus, it is possible that telomerase may provide a reasonable marker for radiationinduced carcinogenesis. However, the validity of this possibility needs to be tested in an animal model, as there is currently no evidence that telomerase is a marker of radiation-induced damage.

Telomerase is assayed by the telomere repeat amplification protocol (TRAP) assay (Kim et al., 1994) which involves adding telomere repeats onto a 32P end-labeled non-telomeric oligonucleotide, amplifying this product by PCR, fractionating this product on a non-denaturing acrylamide gel, and then detecting labeled products on film. Reagents for detecting telomerase activity are available commercially.

Because telomerase is an enzyme for which a specific assay procedure exists, it can be measured directly. However, many gene products do not have an activity which can be measured enzymatically. Such proteins can often be 
quantitatively determined by Western blot analysis (Chen et al., 1995). Such an analysis could be used to measure specific proteins such as tumor suppressors, oncoproteins, regulators of apoptosis, etc.

\section{e. Green fluorescent protein}

Another strategy for detecting changes in expression of specific genes or classes of genes is to link their promoter to the coding sequence for a marker protein such as $\beta$-galactosidase (Section V.A.1.a.), luciferase, or green fluorescent protein (GFP). The latter is particularly useful because it does not require an exogenously added substrate or cotactor. GFP can be detected intracellularly and non-invasively merely by shining near-UV or blue light on cells in culture or a transparent organism such as C. elegans or zebra fish (Chalfie et al., 1994); the protein contains an intramolecular chromophore which emits green light upon stimulation. The protein retains its fluorescence even in fixed preparations, or can be monitored by flow cytometry as a reporter of gene expression or protein localization. Clontech Laboratories has recently reported the engineering of a variant of this protein that fluoresces 35 times stronger than the wild type protein, thus making this assay much more sensitive.

\section{f. Signal transduction}

The exterior of the cell is in contact with other cells, as well as the extracellular matrix and blood vessels containing hormones, growth factors, neurotransmitters, antibodies, etc. All cells have surface receptors, with specific binding sites for hormones, growth factors, and components of the extracellular matrix. These receptors often span the membrane from outside to inside, and serve to transduce signals from extracellular molecules to the inside of the cell. Even though the receptors are specific, the molecular mechanisms of signal transduction on the inside of the cell tend to have common features (Collins et al., 1991).

\section{i. Hormones}

The typical intracellular pathway involves the activation of a $G$ protein following binding of the hormone to the receptor; this activation is accomplished by replacing bound GDP by GTP on the G protein. The activated $G$ protein then activates adenylate cyclase which catalyses the conversion of ATP to cyclic AMP (cAMP). CAMP can then activate protein kinases which in turn can phosphorylate a variety of proteins, depending on the specificity of the kinase (Hunter, 1994).

Activated $G$ proteins can also activate phospholipase $C$ which cleaves phosphatidyl inositol-4,5-bisphosphate to diacyl glycerol and inositol-4,5triphosphate $\left(\mathrm{IP}_{3}\right)$, both of which are second messengers (Berridge and Irvine, 
1989). Diacylglycerol activates protein kinase $C$, whereas $\mathbb{I P}_{3}$ causes the release of sequestered $\mathrm{Ca}^{++}$.

\section{ii. Growth factors}

Receptors for growth factors contain intracellular tyrosine kinase domains, which when activated by growth factor binding, can phosphorylate other proteins (Ullrich and Schlessinger, 1990). These growth factors are ordinarily cell-type specific, and the protein kinases activated by these growth factors play a variety of roles in phosphorylating cyclins, tumor suppressor proteins, oncoproteins, and a host of other proteins which regulate the cell cycle (Aaronson, 1991). Thus, any radiation-induced damage which upsets the delicate balance between positive and negative regulators of the cell cycle has the potential to promote carcinogenesis, and such changes could be monitored in response to irradiation.

\section{iii. Extracellular matrix (ECM)}

A dynamic and reciprocal flow of information between cells and the extracellular matrix contributes significantly to the regulation of form and function in developing systems (Roskelley et al., 1995). Signals generated by the ECM do not act in isolation. Instead, they are processed within the context of global signalling hierarchies whose constituent inputs and outputs are constantly modulated by all the factors present in the cell's surrounding microenvironment (Clark and Brugge, 1995). This is particularly evident in the mammary gland, where the construction and subsequent destruction of such a hierarchy regulates changes in tissue-specific gene expression, morphogenesis and apoptosis during each developmental cycle of pregnancy, lactation and involution.

\section{g. Serial analysis of gene expression (SAGE)}

This technique allows one to quantitatively determine the pattern of mRNAs expressed by a given cell population or tissue. It involves producing short "tagged" sequences from cDNAs, cloning these tags as linked elements, and finally sequencing the composite constructs. Both the sequences identified and the number of times they occur reveal a gene expression pattern characteristic of the tissue source of the transcripts. The effect of radiation on this pattern can be determined to assess the impact of radiation on gene expression in any given tissue. Details of this method have been described by Velculescu et al., (1995).

\section{ALTERATIONS IN ECM/TISSUE STRUCTURE}

There is no longer any doubt that interactions between cells and the ECM initiate a flow of information that acts to regulate many fundamental 
processes throughout development. These include cell migration in the early embryo, morphogenesis during organ formation, and the modulation of growth and differentiation programs of many, if not all, specialized cell types (Adams and Watt, 1993; Roskelley et al., 1995). Many interactions between ECM ligands and cell surface receptors have been well characterized, and careful molecular dissections using simplified tissue culture models have identified a number of the signals initiated by these interactions (Clark and Brugge, 1995). The task now is to understand how radiation disrupts these well integrated systems.

The most thoroughly studied interactions between the cell and the ECM are mediated by the integrins, a family of heterodimeric transmembrane receptors composed of more than 20 functional members, many of which have overlapping and competing affinities for individual ECM ligands (Hynes, 1992).

TGF- $\beta 1$ is known to induce the expression of a variety of ECM-related genes, and to participate in tissue morphogenesis and remodelling. TGF- $\beta 1$ is widely distributed in unirradiated murine mammary gland tissue, but most of this protein exists in a latent form in association with the latency-associated peptide (Barcellos-Hoff et al., 1994). Thus, the biological activity of TGF- $\beta 1$ is tightly controlled by its release from this inactive complex. It has been shown that whole body irradiation with ${ }^{60} \mathrm{Co} \gamma$-rays rapidly induces TGF- $\beta 1$ activity both intra- and extracellularly, and this activity remains elevated for up to a week (Barcellos-Hoff, 1993). This activation can be demonstrated using antibodies which specifically recognize active but not latent TGF- $\beta 1$; there is a parallel decrease in the reactivity with antibodies to latency-associated peptide. This irradiation-induced activation is accompanied by alterations in the amount and localization of collagens I and III, but not fibronectin, laminin or collagen Table IV.7. Thus, immunochemical detection of active TGF- $\beta 1$ can be used as an indicator of radiation-induced remodelling of the stromal extracellular matrix in the irradiated mammary gland.

\section{CELL DEATH BY APOPTOSIS}

Apoptosis has typically been assayed in situ by the TUNEL technique in which terminal deoxynucleotidyl-transferase is used to end-label double strand breaks in the nuclear DNA (Gavrieli et al., 1992). Biotinylated-dUTP is used as a substrate in place of dTTP and the location of the dUTP is determined by staining with streptavidin-fluorescin, followed by counterstaining with DAPI, and photography in a fluorescence microscope. A newer and more specific assay has recently been developed (Frankfurt et al., 1996), using a monoclonal antibody to single-stranded DNA, followed by staining with goat anti-mouse IgM conjugated with fluorescin, and photography in a fluorescence microscope. The advantage of this method is that necrotic cells are stained by 
the TUNEL staining procedure but not by the MAb technique. The MAb procedure is also more sensitive than the TUNEL technique.

\section{TUMOR INCIDENCE}

The following four examples describe transgenic and knockout mouse models which increase the susceptibility of the mouse to carcinogens, presumably including radiation. Whereas these mice clearly do not mimic normal carcinogenic frequency, they can be used to compress the latency period in experiments to determine the carcinogenic potential of very low doses of HZE particles.

\section{a. Mice hemizygous for tumor suppressor genes}

Tennant et al. (1995) have recently developed a semi-knockout mouse in which one allele of $p 53$ has been inactivated, and which also carries a $\mathrm{V}-\mathrm{Ha}$ ras construct. This shortens the time required for bioassays because of the animals' increased sensitivity to carcinogenic insult, and improves the accuracy of carcinogen identification. This transgenic model develops papillomas and malignant tumors in response to a number of mutagenic and non-mutagenic carcinogens and tumor promoters, but NOT in response to non-carcinogens. Thus, such a mouse while obviously not "normal", would be useful if one wants to increase the sensitivity to cancer induction at low radiation doses.

Such a sensitive model system might also provide a sensitive and economical system in which to examine RBE-LET relationships. In vivo systems are required because dose distribution is an important feature of radiation quality that cannot be assessed using cells in two-dimensional culture.

\section{b. Tissue-specific tumor induction}

The large T-antigen of SV40 binds to two tumor suppressor proteins, p53 and $\mathrm{pRb}$, thereby inactivating them and inducing transformation (Ludlow, 1993). Naik et al. (1996) have developed a strategy for inducing tissue-specific tumor induction in the pancreas by linking the rat insulin-II promoter to the gene for the SV40 large T-antigen, and generating a transgenic mouse from this construct. The expression of large T-antigen begins at about day 9 in the embryo, and persists throughout the lifetime of the mouse. One hundred percent of these mice develop pancreatic tumors by 14 weeks of life. This approach could be used to increase the sensitivity of a particular tissue to radiation-induced carcinogenesis in an attempt to estimate the carcinogenic potential of low doses of radiation in that tissue as compared to the entire animal (Section V.A.9.a.). This strategy to enhance tissue-specific radiation sensitivity can be applied to any tissue provided a tissue-specific promoter is available which will be expressed in mice. 


\section{c. Synergy between $c-m y c$ and $b c l-2$ in tumor induction}

Although expression of the $c-m y c$ transgene alone enhances lymphoid malignancy in mice (Adams et al., 1985), the latency period is reduced substantially by over-expression of the $b c l-2$ gene as well. The spectrum of tumors in this double transgenic mouse is different from that seen in the single $c-m y c$ transgenic mouse, suggesting that while the role of apoptosis in destroying pre-neoplastic cells varies among tissues, up-regulation of the $b c l-2$ gene speeds tumor induction. Thus, mice over-expressing $b c l-2$ are also expected to be more susceptible to the carcinogenic potential of ionizing radiation.

\section{d. Mice deficient in DNA repair}

The development of mice that have a particular DNA repair gene inactivated (for a representative list see Table VII.6; also see Friedberg et al., in press) allows studies to be performed which are analogous to those that have been conducted with DNA-repair deficient mammalian cell lines. These mice facilitate elucidation of the role of these genes in damage fixation, mutagenesis and carcinogenesis in different tissues. Studies conducted to date have revealed that the loss of some of these genes can lead to embryo lethality, e.g. XRCC1, ERCC1, rad51, AP endonuclease, and polymerase $\beta$, and immune function suppression, e.g. rag1, rag2, XRCC7, as well as increased rates of carcinogenesis, e.g. XPA, XPC, ERCC6, msh2. They also provide a further source of animal models which are more sensitive than the wild type animals for determining the carcinogenic potential of low levels of radiation. The susceptibility of heterozygotes also remains to be determined for many of these animals. Because the pathways for repair of ionizing radiation-induced damage have not yet been fully elucidated (Section IV.B.1.), these animals can also be a valuable tool in these determinations. For example, the role of $\mathrm{mdm} 2$ as a downstream regulator of $p 53$ transcriptional activation was identified when it was shown that the embryo lethality of $m d m 2$ knockouts could be rescued by crossing these mice with those that are homozygous for p53 inactivation (Jones et al., 1995).

\section{B. GENERAL CRITERIA RELATED TO NEUROBIOLOGICAL DEFICITS}

\section{ACTUAL LOSS OF NEURONS}

Tyrosine hydroxylase (TH) immunoreactivity is a standard technique to determine loss of dopamine (dopa) activity and cell loss, especially in the striatum. TH is an important enzyme involved in the rate limiting step in the synthesis of catecholamines. In this step $\mathrm{TH}$ catalizes the conversion of tyrosine to dopa, which is further acted upon by aromatic acid decarboxylase 
to form dopamine. The theory is that because $\mathrm{TH}$ is one of the most important enzymes in the synthesis of catecholoamines, it is involved in the rate limiting step in this biosynthetic pathway. Its location is intracellular, so decreases in its activity would be indicative of cell loss in that area. The loss of tyrosine hydroxylase-specific immunostaining in the substantia nigra of rats in response to irradiation with Fe particles was shown in Figure IV.5 (see also Section V.B.4).

\section{BRAIN IMAGING TECHNIQUES (PET, MRI, MRS)}

Positron emission tomography (PET) is a non-invasive scanning method for metabolic and blood flow imaging. PET techniques have been developed to study brain metabolic and blood flow changes using $18 \mathrm{~F}$-deoxyglucose (Brennan et al., 1993), amino acid transport across the blood brain barrier using $18 \mathrm{~F}$-phenylalanine (Ito et al., 1995), and mitochondrial mass and brain energy mechanics with 18 F-rotenone (Charalambous et al., 1995). The latter is particularly interesting because of the relationship between mitochondrial DNA damage and mitochondrial function (Wallace 1992; 1995).

Newer investigational MR techniques such as MR spectroscopy and functional $M R$ in combination with conventional $M R$ imaging have the potential to combine metabolic with anatomic imaging in one examination. A combination of both metabolic and anatomic imaging studies may ultimately offer better sensitivity and specificity for researching changes in brain function over time, and determining how these are affected by age and heavy ion irradiation. Magnetic resonance techniques for calculating both volumetric and chemistry parameters in the CNS are advancing technologically very rapidly, thereby improving accuracy. For example, changes in white matter (e.g. demyelination) can be monitored (Scheltens et al., 1995). Spectroscopic techniques allow one to follow changes in energy metabolites $(31 \mathrm{P})$, choline, creatinine and $\mathrm{N}$-acetyl aspartate with proton spectroscopy (Charles et al., 1994).

\section{CONDITIONED TASTE AVERSION (CTA) BEHAVIOR}

A simple behavioral endpoint thought to be due to neuron damage is induction of taste aversion (Rabin et al., 1989, 1994). Two experimental approaches to evaluate this possibility have been used: (1) Heavy particles as an unconditioned stimulus for CTA learning. Animals are placed on a 23.5$\mathrm{hr}$ water deprivation schedule for 5 days. On the conditioning day they are given a $10 \%$ sucrose solution to drink immediately before exposure to radiation, and their intake of this conditioning stimulus is measured. On the test day, 24 to 48 hours later, they are again presented with the sucrose solution and their intake is measured again. The acquisition of a CTA is shown as a significant reduction in test day $10 \%$ sucrose solution intake 
compared to the conditioning day intake. (2) Heavy particles as a stimulus that disrupts dopamine-mediated behaviors. In this design, the rats are placed on a water deprivation schedule several days before exposure to radiation. The conditioning day is 3 days following exposure, when they are given access to the $10 \%$ sucrose solution conditioned stimulus, followed by injection of amphetamine ( $3 \mathrm{mg} / \mathrm{kg}$, ip) or $\mathrm{LiCl}(3 \mathrm{meq} / \mathrm{kg})$. Sucrose solution intake is measured again $24-48$ hours following administration of the unconditioned stimulus.

\section{SPECIFIC ENZYME LOSS}

Loss of tyrosine hydroxylase (TH) has been used as a measure of loss of dopamine neurons, especially in the striatum (see Sections IV.D.2.b.iii and V.B.1; Figure IV.5). The amount of tyrosine hydroxylase protein present in situ is measured by avidin-biotin immunocytochemistry (Bowenkamp et al., 1996; Hudson et al., 1995). The thin section of brain tissue is first incubated with anti-TH rabbit antibody, followed by a biotinylated anti-rabbit IgG. The biotin is then incubated with avidin-biotin complex substrate which in the presence of hydrogen peroxide converts diaminobenzidine to a chromophore, which can be photographed in a microscope, and quantitated by a computerbased image analysis system.

\section{OTHER LATE EFFECTS}

\section{REPRODUCTIVE LOSS}

Approaches for studying the radiosensitivity of spermatogonial stem cells have been summarzied by Meistrich and van Beek (1990). Endpoints used include the length of the sterile period, sperm head counts, levels of activity of the $\mathrm{X}$ isozyme of lactate dehydrogenase, and direct cell counts in a variety of preparations. In general, these assays are not very sensitive and large doses must be applied before significant effects can be observed.

A functional assay for damage to the testes, and one which has been used extensively in humans, is to do sperm counts. There is a delay before the sperm count begins to drop after irradiation, and the percentage of men who become azoospermic after irradiation is dose dependent. At $\leq 20 \mathrm{cGy}$ no men become azoospermic, whereas at $\geq 1 \mathrm{~Gy}$ all men become azoospermic. Thus, such an assay would only be useful in the range $20 \mathrm{cGy}-1 \mathrm{~Gy}$. Recovery from azoospermia can also be measured and the time at which this occurs is also somewhat dose-dependent. The minimum period of time is about 6 months (after $20 \mathrm{cGy}$ ), but the time only increases to 12 months after a 4 Gy dose. Thus, it appears that much more sensitive assays such as mutations and chromosomal aberrations may be required to detect damage due to low doses of radiation. 


\section{CATARACTOGENESIS}

The classical assay is to grade opacification; such an assay has been described by Keng et al. (1982). Lenticular opacity can be graded on a 6-point scale varying from 0 (clear lens) to 5 (opaque lens). The lens is examined in situ with a slit-lamp microscope after dilation of the pupils. Anaesthesia during examination is not necessary, and longitudinal studies are possible because the procedure is not invasive. The study can also be done using a camera to record the severity and progression of the opacification.

\section{OVERALL HEALTH: SURVIVAL CURVES}

Although survival curves are a very gross measurement of overall health status of a population of individuals, they are useful in determining whether a given intervention has a significant effect on that health status. For example, they have been used to demonstrate conclusively that caloric restriction extends both median and maximum life span of rodents (Weindruch and Walford, 1988). To compare an experimental population to a control population, 60 individuals are needed per group to identify as little as a $10 \%$ difference in median life span with a probability of 0.05 and power of 0.80 (A. Richardson, personal communication). Thus, radiation-induced lifeshortening experiments using survival curves are economically feasible with short-lived animals for a limited number of dose protocols. 
TABLE V.1

\section{SUMMARY OF BIOLOGICAL ENDPOINTS FOR STUDIES IN HUMANS}

\section{BIOMARKER \\ ADVANTAGES \\ DISADVANTAGES}

\section{Endpoints related to genomic instability (and presumably carcinogenesis)}

Chromosome rearrangements by "painting"

Minisatellite repeat length

Triplet repeat length

Telomere length

Mitochondrial DNA deletion

HPRTmutation frequency

Mutations in GPA gene
Sensitive assay requiring only a few hundred cells; can be applied to lymphocytes

Can be applied to lymphocytes

Can be applied to lymphocytes

Can be applied to lymphocytes

Very sensitive--can detect as little as one deletion per sample; can be applied to lymphocytes

Can be applied to lymphocytes; easy assay; positive mutant selection

Can be applied to lymphocytes
Only non-invasive if use lymphoid cells

High background; narrow range response; low sensitivity

No evidence yet that repeat number is affected by radiation

Measurement of telomere length is imprecise; no evidence yet that radiation alters length

No direct evidence yet that radiation induces mitochondrial DNA deletions

Mutation frequency is probably underestimated 


\section{TABLE V.1 (Continued)}

\section{BIOMARKER}

Unrepaired DNA damage

Detection of translocations by PCR (e.g. V-J recombination)

\section{Endpoints related to carcinogenesis}

$\%$ cells in $\mathrm{S}$ phase

Telomerase activity

$\stackrel{N}{\infty}$

\section{Neurobiological endpoints}

Brain imaging

\section{Other}

Differential display

Microarray mRNA probes

SAGE

\section{ADVANTAGES}

Can be applied to lymphocytes

Very sensitive; can be done longitudinally in lymphocytes

Background values in most tissues are low

High correlation with cell transformation

Non-invasive techniques especially good for large animals

Doesn't require a priori assumptions of what genes to analyse; can be applied to lymphocytes

Can be applied to lymphocytes

Can analyse the expression of many genes simultaneously

\section{DISADVANTAGES}

Require biopsy for any tissue except lymphocytes; measures a transient signal

Limited to specific translocations

Invasive technique requiring biopsy samples

Assay is sensitive but hard to quantitate

Requires expensive instrumentation; not good for small animals

Require biopsy for any tissue except lymphocytes

Assay is gene-specific and limited to genes whose

sequence is known; require biopsy for any tissue except lymphocytes

Extensive DNA sequencing is required 
TABLE V.2

SUMMARY OF BIOLOGICAL ENDPOINTS FOR STUDIES IN MODEL SYSTEMS

\section{BIOMARKER}

\section{Endpoints related to genomic instability}

Mutation frequency in lacZ-plasmid transgenic mouse

Very sensitive to wide range of mutagens; can detect broad spectrum of mutations; positive selection possible

\section{Endpoints related to carcinogenesis}

Tumor induction in hemizygous $p 53$

mouse

Increased sensitivity to low doses of carcinogen

Cell death by apoptosis

Tissue-specific tumor induction

Alterations in ECM/tissue structure

\section{Neurobiological endpoints}

Loss of tyrosine hydroxylase

Taste aversion behavior

Expression of green

fluorescent protein

\section{ADVANTAGES}

Background values in most tissues are low

Good marker for
substantia nigral cells

Easy assay to do

Can be targeted to specific neurons in
DISADVANTAGES

Mutation frequency in transgene may not be typical of all genes

Rate of tumor induction is specific for only these mice, i.e. this is not a normal mouse

Invasive technique requiring

biopsy samples; signal is transient

Best sensitivity is in transgenic animals

2-D gels may be required (see below)

Loss of expression does not necessarily indicate cell loss

No unequivocal evidence that changes are due to neuron damage; animal experiments only

C. elegans; with use of appropriate promoters can be targeted to any tissue; non-invasive
Loss of expression does not necessarily indicate cell loss 
TABLE V.2 (Continued)

\section{BIOMARKER}

\section{Other}

Population survival curves

2-D protein gels

$\vec{\sigma}$

\section{ADVANTAGES}

Easy assay to do; evaluates overall health of population

Doesn't require a priori assumption of what proteins to analyse

A variety of pathways can be studied depending on endpoint of interest

\section{DISADVANTAGES}

Does not relate to any particular radiation-induced pathology; short-lived animal experiments only

To detect rare species, proteins must be labelled; identity of proteins often not known

Complexity of pathways may make interpretation difficult 


\section{CRITICAL QUESTIONS}

\section{A. CAN RESULTS WITH LOW-LET RADIATION BE EXTRAPOLATED TO HIGH-LET RADIATION?}

Because we know much less about non-DNA targets of radiation in this area, DNA will be assumed to be the biological target in this discussion. There are at least two ways to approach the question. One way is to analyze the initial damage and repair of cellular DNA and determine whether a correlation exists between low-LET and high-LET. The second way is to review experimental data on tumorigenic potential (or some other pathological endpoint) of high-LET and low-LET radiation, and analyze the possible correlation between them, if any.

From the point of view of initial damage, it is important to understand the similarities as well as the differences between mechanisms of damage. There are two ways the sugars and the bases can be damaged. One is by an indirect mechanism which involves water-derived radical attacks on those sites. Because of a considerable amount of water present inside a cell nucleus, ionizing radiation produces $\bullet \mathrm{OH}$ and $\bullet \mathrm{H}$ radicals and solvated electrons. The density with which these radicals are produced is directly dependent upon the LET. For low-LET this density is low, and therefore the chances of these radicals interacting with each other are also low. This allows the radicals to diffuse and interact with the bases and sugar-phosphate backbone of DNA. On the other hand, for high-LET tracks, many of the radicals neutralize each other due to their high density of production and thereby form molecular products such as $\mathrm{H}_{2}, \mathrm{H}_{2} \mathrm{O}_{2}, \mathrm{H}_{2} \mathrm{O}$, etc. These molecules do not interact with the bases or sugars and hence do not produce any damage. Thus, low-LET radiation is much more efficient in damaging sugars and bases through water radical mechanisms than is high-LET radiation such as HZE particles.

Much effort has been made in the past, and are underway now, to use this characteristic of low-LET particles to design radioprotectors (see Section IX.E.). An efficient radioprotector is expected to scavenge the water-derived radicals immediately after their formation so that they cannot diffuse and attack vulnerable cellular molecules. In this manner, the DNA can be protected from radiation-induced damage. However, because the biochemical reactions involve radicals, the reactions are extremely fast $\left(\sim 10^{-12}\right.$ to $\left.10^{-9} \mathrm{sec}\right)$, and the radioprotector therefore has to be present at the time the radicals are created. While no radioprotector will be able to modulate the radiation damage produced by a high-LET particle because of the high density of radical production, the radicals themselves act as radioprotectors and, thus, the presence of external radioprotectors is of little significance. However, it has been demonstrated that there is a class of radioprotectors which act not through radical scavenging mechanisms, but through activation of certain 
enzymatic processes leading to protective effect. Such protective effects have been observed in vivo for damages produced by neutrons, a moderately highLET radiation.

Another mechanism of damage involves direct deposition of energy in the DNA by particle tracks. This can lead to excitation and/or ionization of bases and sugars. For two reasons high-LET damage is much more dominant in this mode than is low-LET damage. Because the probability of ionization (or excitation) depends on the square of the charge $(Z)$ of a particle, a low-LET track is less efficient in causing such alterations than is a high-LET track. Furthermore, the frequency of ionization along the track is much greater for high-LET than it is for low-LET tracks (see Fig. IV.1). Such high frequency of ionization leads to the formation of small DNA fragments as well as clusters of damage by high LET particles (Holley and Chatterjee, 1996). It should be noted that the direct mechanism of damage, either by low- or high-LET radiation, cannot be modulated by conventional radioprotectors which are effective only for attack by diffusible radicals.

Theoretical calculations based on the above mechanisms have been carried out using a $30 \mathrm{~nm}$ solenoidal chromatin model (Holley and Chatterjee, 1996). In these calculations, it was assumed that damage of any type to sugar molecules leads to strand breaks, whereas damaged bases do not lead to strand breaks except during base excision repair. The consequences of these assumptions have been verified experimentally through measurements of the resulting fragments (Rydberg, 1996). In Fig. IV.2, damage to a $40 \mathrm{bp}$ segment of a randomly chosen region of the chromatin is shown for a lowLET as well as for a high-LET track. It is clear that for low-LET tracks there are isolated damages, in contrast to clusters of damages for high-LET tracks. In repair studies by Löbrich et al. (1994), there is evidence that clusters of damage are either unrepairable or repaired with low-fidelity. Hence, it is very likely that damage caused by high-LET radiation will not be repaired as efficiently as that induced by low-LET radiation, another example of a fundamental difference between these two types of tracks.

At present it is not clear at all how the two fundamental differences mentioned above will be manifested in the radiation-induced progression to carcinogenesis. The underlying mechanisms involving this pathway are not well known at the present time. In the absence of such knowledge, one must carefully review the existing data on carcinogenesis by low- and high-LET particles, and discuss the possibility of extrapolation.

Alpen et al. (1993) reported experimental data on tumorigenic potential of charged-particle radiation with LET values varying between $0.23 \mathrm{keV} / \mu \mathrm{m}$ (low-LET) and $464 \mathrm{keV} / \mu \mathrm{m}$ (high-LET), using the mouse Harderian gland as a target tissue (Section IV.D.2.b.ii.). In these experiments, pituitary isografts were used to enhance the expression of radiogenic tumors, and to decrease 
the latent period. From the basic data on tumor prevalence as a function of dose, risk cross sections $(\sigma)$ were derived for tumor induction, and plotted as a function of LET. In a log-log plot the risk cross sections seem to increase in a linear fashion with respect to LET. It would seem from these data that one could easily obtain the value of $\beta$ at any value of the LET using the relationship:

$$
\log \beta=-1.7+1.4(\log L)
$$

where $\mathrm{L}$ is the $\mathrm{LET}$ value in $\mathrm{keV} / \mu \mathrm{m}$.

Strictly on a theoretical basis, Curtis et al. (1995) had proposed the following relationships between quality factor, $\mathrm{Q}$, and $\mathrm{L}$ :

$$
\begin{gathered}
\mathrm{Q}(\mathrm{L})=0.32 \mathrm{~L}-2.2,10 \leq \mathrm{L} \leq 100 \mathrm{keV} / \mu \mathrm{m}, \\
\text { and } \\
Q(\mathrm{~L})=300 /(\mathrm{L})^{1 / 2}, \mathrm{~L} \geq 100 \mathrm{keV} / \mu \mathrm{m}
\end{gathered}
$$

where $Q$ is related to risk cross sections through the following equation:

$$
\sigma(\mathrm{L})=0.16 \mathrm{R} \gamma \mathrm{Q}(\mathrm{L}) \mathrm{L}
$$

where $\sigma$ again is the risk cross section and $\mathrm{L}$ is the $\mathrm{LET}$ value in $\mathrm{keV} / \mu \mathrm{m}$; the constant 0.16 is an ad hoc number for the convenience of units; $\mathrm{R} \gamma$ is the conventional risk coefficient for low-LET radiation and can be obtained from analysis of the atomic bomb survivors at Nagasaki and Hiroshima, and $Q$ is the quality factor (of radiation). In order to account for low-dose and low-dose rate, it has been suggested that the values of risk coefficient obtained from analysis of the atomic bomb survivors at Hiroshima and Nagasaki be divided by a factor of two. Atomic bomb survivors were exposed to high doses and high dose rates. Thus, according to theory which was based on several assumptions, there are three different slopes when risk cross sections and LET are plotted logarithymically. Between $0.1 \mathrm{keV} / \mu \mathrm{m}$ and $10 \mathrm{keV} / \mu \mathrm{m}$, the slope is lower than that between $10 \mathrm{keV} / \mu \mathrm{m}$ and $100 \mathrm{keV} / \mu \mathrm{m}$, but the lowest slope is obtained for values greater than $100 \mathrm{keV} / \mu \mathrm{m}$.

Thus, it seems that the theoretically-derived relationship between the risk cross section and LET and that from the Harderian gland data have the similar mathematical form. The data for cell inactivation and mutagenesis have provided support for the Q-L relationship suggested above in the theoretical formulation. However, the only data for tumorigenesis from the Harderian gland measurements at different values of LET suggest that the precipitous decrease in $Q$ at LETs in excess of $100 \mathrm{keV} / \mu \mathrm{m}$ may be a poor approximation of the actual relationship. Thus, it is evident that for a better 
understanding of the dependence of $\mathrm{Q}(\mathrm{L})$ on $\mathrm{L}$, especially above $100 \mathrm{keV} / \mu \mathrm{m}$, more animal experiments are needed involving different types of tissues.

\section{B. CAN EFFECTS WITH HIGH DOSES BE EXTRAPOLATED TO LOW DOSES?}

In order to be able to extrapolate biological effects from high doses to low doses, one needs a model for the dose response curve. With respect to carcinogenesis as the end point, there are three theoretical models which have received some consideration: (i) linear quadratic response model, (ii) quadratic response model, and (iii) linear response model. The linear response model appears to be favored by several national and international committees. The model is based on the assumption that there is no threshold dose for radiation health effects. This assumption then allows one to draw a straight line from zero dose incidence through the effects observed at high doses. If one examines the four data points on Harderian gland tumors for argon particles, it is clear that between zero dose and $0.4 \mathrm{~Gy}$, the best fit is obtained by a linear initial curve.

For HZE particles, Curtis et al. (1992, 1993 and 1995), have suggested that instead of a response curve based on dose, one should develop one based on fluence. This then allows one to use the concept of risk cross section which is the probability per unit fluence of producing a specific risk. In the case of any type of cancer, the cross section would be the initial slope of the response curve (induction of excess cancers) as a function of fluence. Because the risk cross section refers to unit fluence, this refers to the lowest possible dose.

Ideally, data would then be obtained for the risk cross section for each type of relevant cancer as a function of energy and the energy spectra in the specific organ for each type of HZE particle. The total cancer risk would then be the sum of the risks for each site. Curtis suggested that the cancer risk cross sections could be "anchored" at a point representing the risk for exposures to low-LET radiation such as those derived from the atomic bomb survivors and the relationship of the low-LET to HZE particles could be based on Quality factors. Such an approach entails the determination of the slopes of fluenceresponse curves for sufficient types of HZE particles at relevant energies so that an integral that represents the responses for other types of HZE particles and energies could be derived with confidence.

To accomplish this it will be necessary to determine: (i) the initial slopes of fluence-response curves for representative cancers such as leukemias, cancer of the breast and the lung, and (ii) the incident particle energy spectra of the selected particles and how they are transported through shielding and the astronaut's body, and how that changes the spectra when the particles reach the organ of interest. 
Regardless of whether the current method for obtaining risk estimates of cancer induction in humans by high-LET radiation, or the risk cross section approach of Curtis is selected for the task of determining the risk estimates for cancer induced by exposure to the HZE component of GCR, animal experiments will have to provide the requisite data. Of course, a method of extrapolation from animals to humans needs to be derived for estimating risks to humans in long duration space flights.

\section{IS THERE SYNERGY BETWEEN RADIATION AND MICROGRAVITY?}

It is well documented that weightlessness induces changes in a variety of physiological systems, including the cardiovascular system, the immune system, bone mass and muscle strength, fluid balance, etc. Research in these areas has recently been collectively published in the July, 1996 issue of the Journal of Applied Physiology, (Volume 81, pages 3-207). The papers in this issue describe results from some of the USA Spacelab Life Sciences (SLS) and the Russian Bion missions. In his Overview, Sulzman (1996) points out that one of the three objectives of these missions was to understand how gravity affects living systems, and the question of whether tissue changes due to microgravity could have an impact on radio sensitivity during space flight.

While these studies did not directly address radiation sensitivity, it is reasonable to ask whether physiological changes induced by microgravity could alter tissue responses to radiation. Todd (1991) has argued that the intracellular components are usually held in place by the cytoskeleton. However, the three-dimensional micro environments of both the inside and outside of the cell may be distorted from their normal configurations by microgravity. If so, it is reasonable to assume that either sensitivity to damage, or repair capacity, or both, may be altered. One factor which could affect sensitivity to DNA damaging agents is the expression of p53 in cells. Ohnishi et al. (1996) have reported that the level of p53 in skin cells in male SpragueDawley rats is increased roughly 4 -fold by space flight, but only about 2 -fold when the rats were subjected to ground physical stress comparable to that experienced by flown animals. If one were to assume that the level of p53 is inversely proportional to the rate of transformation (a questionable assumption at best), this result would suggest the possibility that sensitivity of cells to transformation might be decreased during space flight.

A recent review by Kiefer et al. (1996) summarizes the extant data on attempts to demonstrate synergistic effects between radiation and microgravity. Some evidence of synergism has been obtained in yeast and insects, but not in bacteria, fungi or rats (Gazenko, et al., 1978). Results with human lymphocytes were ambiguous (Bender et al., 1967). These results suggested that microgravity does not have a major effect on radiation sensitivity, at least not in response to low-LET radiation such as $\gamma$-rays and $\beta$-irradiation. However, 
even less is known about the possible interactions between microgravity and damage induced by HZE particles.

The difficulties in carrying out definitive experiments in this area are quite formidable. Two general approaches have been used. One is to irradiate organisms on earth, launch both the experimental and control samples, and then maintain the control samples in an onboard $1 \mathrm{xg}$ centrifuge. The other is to launch only the experimental animals, and expose them during flight to a radiation dose that is similar to that being used for the earth-bound control. Variables which are difficult to control in both approaches include flightrelated stress and temperature. A major difficulty with the second approach is the current lack of technology to generate an HZE particle beam during space flight.

If significant synergistic effects can be anticipated in any physiological system, it may be in the musculoskeletal system. Changes in muscle structure and function have been well-documented and recent studies have confirmed that these changes are significant (Caiozzo et al., 1996; Riley et al., 1996; Allen et al., 1996). Oxidative damage to mitochondrial DNA also correlates with substantial loss of muscle function in a variety of human diseases and possibly during aging (Wallace, 1992; 1995), so it is quite possible that radiation-induced oxidative stress in muscle tissue during travel in outer space could contribute to muscle atrophy. Similarly, radiation-induced damage to osteoblasts and osteoblasts could synergize with the known microgravity effects on bone modeling and remodeling (Kitajima et al., 1996). A recent report by Ducy et al. (1996) showing that osteocalcin-deficient mice have increased bone formation suggests that an antagonist of osteocalcin synthesis or function could possibly have therapeutic use during space travel. Another recent report suggests that down-regulation of expression of the cathepsin $\mathrm{K}$ gene, or inhibition of the activity of cathepsin $\mathrm{K}$ could provide a yet different strategy for preventing pathological bone loss (Gelb et al., 1996). However, the major effect of space flight on bone in rats appears to be decreased formation rather than increased resorption (Wronski and Morey, 1983; Cann and Adachi, 1983), and it is not clear that either of these counteractive measures will actually work.

Aside from the results on the musculoskeletal system, which approximates ground-based muscle atrophy when not in use, the above results do not provide strong evidence for synergism between radiation and microgravity. Because the major physiological impact of microgravity is on the musculoskeletal system, then an understanding of this space travel phenomenon is currently limited by a general lack of understanding of the molecular basis of the regulation of bone deposition, bone resorption, and muscle wasting. The Panel recommends that more earth-based research to elucidate these mechanisms should be a priority. 


\section{IS THERE SYNERGY BETWEEN DIFFERENT TYPES OF RADIATION?}

The data shown in Table IV.2 make it clear that animals and humans exposed to GCR in outer space will experience hits from a variety of particles, and it is not clear how these exposures will interact. For example, if the frequency of any cell nucleus being hit by a proton is 0.4 per day, then each HZE particle has a $40 \%$ chance of hitting a nucleus on the same day a proton hits it. Even if the repair of proton-induced damage is rapid and accurate, it remains to be determined whether continuous bombardment by protons would increase or decrease the vulnerability of cells to less frequent HZE particles.

Such effects have been observed in cultured cells. The work of McNally et al., (1988) has shown that V79 Chinese hamster cells are killed exponentially by irradiation with $\alpha$-particles from $238 \mathrm{Pu}$ at an LET of $140 \mathrm{keV} / \mu \mathrm{m}$. These cells were also killed by X-rays, but the killing curve had a substantial shoulder before exponential killing began. While an initial irradiation of the cells with 0.5 Gy $\alpha$-particles before X-irradiation had very little effect on the shape of the X-ray curve, a 2 Gy dose of $\alpha$ particles almost eliminated, and a $2.5 \mathrm{~Gy}$ completely eliminated, the shoulder. Similar results had been obtained earlier with neutrons and heavy particles (McNally et al., 1984; Ngo et al., 1981; Bird et al., 1983). Thus, $\alpha$-particles do "prime" the cell and can increase its sensitivity to subsequent $X$-irradiation at the high dose exposures used in these experiments. It should be pointed out, however, that these experiments were done on cell lines under extreme non-physiological conditions and need to reproduced in the right microenvironmental context.

These results, nevertheless, indicate that synergism between proton, $\alpha$ particle, and heavy particle irradiations is a possibility during travel in outer space. However, there are no experimental data available to address the health effects of such synergy, especially with regards to HZE particles.

To confound the matter, a few studies have given a somewhat opposite picture of possible synergistic effects between different kinds of radiation. Marples and Skov (1996) found that a protective effect can be induced in Chinese hamster V79 cells by a low exposure $(0.2 \mathrm{~Gy})$ to either neutrons or Xrays. When the cells were irradiated $4 \mathrm{hr}$. later with a $1 \mathrm{~Gy} \mathrm{X}$-ray dose, survival was $100 \%$, compared to only $73 \%$ for cells not pre-irradiated. These results, along with those reviewed by Joiner (1994), have suggested that there is an adaptive protective response which can be induced by low exposures to either X-rays or small particle irradiation. There is a recent report that lowdose $\left(0.1\right.$ - 10cGy) ${ }^{60}$ Co $\gamma$-irradiation may even decrease the frequency of transformation in C3H10T1/2 cells if the cells are held for $24 \mathrm{hr}$. at high density before dilution and re-plating (Azzam et al., 1996). Cells exposed to the 0.1 cGy dose experienced only one track per cell, indicating that one cell traversal was sufficient to induce a protective effect in these cells. Again, it is 
not known whether similar protection would be induced in human cells within tissues during travel in outer space. However, induction of DNA repair activities by a low dose of a DNA-damaging agent is a well-established response in tissues; for example, low doses of a methylating agent renders mammalian cells resistant to a subsequent challenge by an alkylating agent (Samson and Schwartz, 1980), and low dose $\gamma$-irradiation increases resistance to nitrosourea (Habrakan and Laval, 1991). The observation of Azzam et al., (1996) with regard to keeping the cultures at high density before dilution possibly is relevant to the consequences of cell-cell and cell-extracellular matrix interactions (microenvironment effect) discussed above. To conclude: the existing literature is meagre and where data are available, they have been obtained on cultured cell lines on tissue culture plastic and are indeed contradictory.

\section{E. WHAT IS THE BASIS FOR TISSUE SPECIFICITY?}

That human tissues differ greatly in their susceptibility to cancer is clear from the data on the atom bomb survivors (Section IV.D.3.b.i), and it would be extremely useful to understand the basis for these differences. One of the most obvious possibilities is a difference in DNA repair capacity. For example, terminally differentiated mammalian myoblasts exhibit strikingly reduced global DNA excision repair, although proficient repair appears to be retained in expressed genes (Ho and Hanawalt, 1991). DNA repair capacity as measured by nucleotide excision repair synthesis also varies substantially among species (Hart and Setlow, 1974), and generally correlates with maximum life span of the species, but data are needed on intra- and inter-species tissue-specific differences. However, nucleotide excision repair does not necessarily reflect the ability to deal with all radiation damage which may be experienced. Other potentially important repair pathways include base excision repair, mismatch repair, DSB repair, and transcription-coupled repair (Section IV.B.1). Whether there are tissue-specific differences in each of these repair pathways also needs to be addressed.

Another possible factor is the level of expression of genes coding for proteins that are involved in growth regulation and cancer, such as c-myc, c-fos, and ras ("onco proteins"), and proteins such as p53, p21, pRB, etc. ("tumor suppressors"). It is to be expected that the level of expression of these genes varies greatly among tissues, and that these genes are differentially expressed in different tissues in response to stress. The potential of pre-neoplastic cells to undergo apoptosis will also be a factor in both carcinogenesis and cell killing (Williams, 1991). This potential will be regulated primarily by the balance among proteins such as bcl-2 and bax, and their homologs (Reed, 1994). What in turn regulates this balance, and the activity of different oncogenes and tumor suppressor genes are important questions which are poorly understood. 
An interesting possibility to consider is the ability to express the gene(s) for components of telomerase. Considerable correlative evidence suggests that telomerase activity is a necessary, but not sufficient factor in cell immortalization. It is of possible relevance that telomerase induction occurs in human lymphocytes and thymocytes with relative ease compared to other tissues, with the exception of germline cells (Weng et al., 1996; Buchkovich and Greider, 1996), and that leukemia was the most likely outcome of exposure to atomic bomb radiation in the Japanese population in 1945.

A mechanism which only recently is being appreciated, but may be one of the fundamental aspects of tissue specificity, is how the microenvironment modulates the carcinogenic and apoptotic potential of a cell or tissue. Available data indicate that basement membrane integrity may regulate not only tissue-specific gene expression, but also act as a central switch between proliferative and differentiated states (Mooney et al., 1992; Roskelley et al., 1995). Basement membrane, which is in contact with all epithelial tissues, has been shown to repress expression of growth factors such as TGF- $\beta$ and TGF- $\alpha$ (Streuli et al. 1993; Lin et al., 1995). These growth factors are known to be involved in ECM remodelling, but also in many other aspects of growth and differentiation. Another aspect of microenvironment modulation is the fact that ECM acts as a reservoir for many latent growth factors which in turn could be activated by radiation. For example, latent TGF- $\beta 1$ levels can be anticipated to play a role in radiation-induced reorganization of the extracellular matrix (Barcellos-Hoff, 1993), as it is activated by low level radiation (Table IV.7). Finally, the extracellular matrix appears to be essential in the prevention of apoptosis in the absence of growth factors, and its integrity most probably helps maintain homeostasis (Boudreau et al., 1996). Thus, differences in the extent of damage to and remodelling of the extracellular matrix following irradiation are probably critical factors in tissue sensitivity.

The above discussion indicates that there is a large number of factors which can affect the vulnerability of a tissue to carcinogenesis and apoptosis. Unfortunately, there are few data available to provide unequivocal insights into why any particular tissue differs in radiation sensitivity from any other tissue, either within or among species. Thus, it is clear that research on the molecular basis of not only individual susceptibility (Section VI.B.4.b.), but also tissue-specific susceptibility should be included in the research agenda.

\section{F. IS ANIMAL EXPERIMENTATION NECESSARY?}

The only unambiguous information which would permit adequate risk estimation for astronauts during travel in outer space would be to have actual data on human exposure to the spectrum of radiation found in GCR. While epidemiological data on human exposure to X-rays, $\gamma$-rays, and $\alpha$-particles are available from a variety of sources, there are almost no data available on HZE 
particle irradiation. The richest source of data for the effects of low-LET radiation in humans is the still ongoing studies of Japanese survivors of the atomic bomb blasts, and these have been briefly discussed in Section IV.D.3.b. However, these data are based on exposure to low-LET radiation at a high dose rate. It is clear from the above discussion that these cannot substitute for data on HZE particle radiation in humans (Section VI.A.). Thus, the use of these data would entail the introduction of other factor(s) to account for differences in the effectiveness of the radiation qualities encountered in outer space.

Instead, the need to estimate risks has led to the development of a series of extrapolation methods (Section VI.G.). These strategies require the use of animals as an experimental surrogate for humans, as will be discussed below. The answer to the above question - Is animal experimentation necessary? - is therefore a definite and emphatic, YES.

Animals might also be used in quite a different strategy to estimate the impact of HZE particles on living systems. The daily dose of HZE particles in outer space is only in the range of 1-10 $\mu$ Gy per day. However, because of the limited facilities available for producing HZE particles in the laboratory, it has not been possible to carry out long term experiments with HZE particles at the very low dose rates found in GCR, and still expect to see measurable results in animals after short exposures. One possible strategy to overcome this difficulty is to develop sensitive model systems with very low thresholds, so that significant results could be obtained over a much shorter time frame. Some such models can be generated using transgenic and gene knockout animals (Section VII.B.2.a.ii.). If a sensitive animal model does not show any adverse effects from a radiation exposure as high as $10 \mathrm{x}$ that expected in outer space, it is probably safe to predict that such an exposure will not produce significant adverse effects in humans.

\section{G. CAN ANIMAL RESULTS BE EXTRAPOLATED TO HUMANS?}

Animal experimentation is based on the premise that the results obtained can elucidate mechanisms, that these mechanisms are similar in animals and humans, and therefore that these findings may apply qualitatively and/or quantitatively to humans. In the estimation of risks, one is concerned specifically with the quantitative extrapolation across species. The estimates of human genetic risks resulting from exposure to radiation are based on data from mice. Thus, it appears to be very much a case of expediency in accepting data from experimental animals when none exists for humans. The reluctance to use data from experimental animals is well ingrained and appears to stem from the belief that the mechanisms for cancer induction may not be the same in different species (Section IX.C), and that many of the experiments in mice involve highly inbred strains, often with a high incidence of one or another cancer, and that this and the great disparity in life spans precludes any quantitative extrapolation. The difference in life span is 
undeniable, but whether that precludes extrapolation is a very different matter.

There is ever-increasing evidence of the evolutionary conservation of the genes that are important in cell proliferation, growth, and other facets of the biology of cancer. The current evidence suggests that from the induction of DNA damage to the initial neoplastic transformation, the events in various species, even Drosophila, may be more similar than they are different. What is equally evident is that the expression, and especially the rate of expression, of the neoplastic phenotype in a given tissue, and the consequences for the whole organism are different among species. Both the similarities and the differences must therefore be kept in mind when searching for methods of extrapolation, but when used properly, both can be illuminating.

Extrapolation methods rely on either the existence of data on damage in humans for some type of radiation, or the ability to obtain such data without direct experimentation on human subjects. Then, the general approach is to relate these known data to animal data which either have been, or can be determined experimentally. For example, if

$\mathrm{X}_{\text {Human }}=$ unknown information about humans, and

$\mathrm{Y}_{\text {Human }}=$ known information about humans, then

$X_{H} / Y_{H}$ may be related to $X_{\text {Animal }} / Y_{\text {Animal, where }} X_{A}$ and $Y_{A}$ can be determined experimentally, by the following general equation (1):

$$
\frac{X_{\mathrm{H}}}{\mathrm{Y}_{\mathrm{H}}}=\mathrm{k}\left[\frac{\mathrm{X}_{\mathrm{A}}}{\mathrm{Y}_{\mathrm{A}}}\right] \text { or } \mathrm{X}_{\mathrm{H}}=\mathrm{k}\left[\frac{\mathrm{X}_{\mathrm{A}}}{\mathrm{Y}_{\mathrm{A}}}\right]\left[\mathrm{Y}_{\mathrm{H}}\right]
$$

where it is assumed that $k=1$. What is far from clear is whether $k$ will in fact equal 1 for all tissues, animals, and types of radiation. However, this can be evaluated experimentally as will be discussed below. The remainder of this section describes several ways in which this concept has been used.

One method of extrapolation used is called the relative toxicity ratio which has been proposed for predicting the effects of radionuclides, in particular plutonium ( $\mathrm{Pu}$ ) (see Evans (1966) for references). This ratio is only useful because of the human epidemiological data available due to the uninformed commercial use of radium in the early twentieth century. Thus, because the radium toxicity in humans is known from these exposures, the assumption is that if one wants to know the sensitivity of humans to another $\alpha$-particle emitter such as plutonium, the human ratio can be determined from the ratio obtained experimentally in an animal model, such as mice. Thus, equation (2) is: 


$$
\left[\frac{239 \mathrm{Pu} \text { toxicity in humans }}{226 \mathrm{Ra} \text { toxicity in humans }}\right]=\mathrm{k}\left[\frac{239_{\mathrm{Pu}} \text { toxicity in mice }}{226_{\mathrm{Ra}} \text { toxicity in mice }}\right]
$$

The unknown value ( ${ }^{239} \mathrm{Pu}$ toxicity in humans) can then be determined because the other three values are known, if $k=1$ or is also known.

The toxicity ratios for various animals have been found to vary less than risk coefficients for the radionuclides among species (see Mays et al., 1980 for a review) suggesting that between animal models, the value of $k$ is about 1 . Whether $\mathrm{k}$ is also 1 when comparing humans with different animal models is not known. Furthermore, it is questionable whether radium would be a relevant denominator for determining susceptibility to HZE irradiation

A similar approach to the estimation of the risk of cancer induced by HZE particles is to use the data from the atomic bomb survivors, who were exposed mainly to $\gamma$-rays, and to use quality factors $(Q)$ to obtain equivalent doses for the various HZE particles. These quality factors could be determined based on the rate of induction of cancer by $\gamma$-rays and representative HZE particles in relevant tissues of an experimental animal. Expressed mathematically:

HZE effect in animals $=Q \times \gamma$-ray effect in animals

Assuming $Q$ in humans $=k^{\prime} Q$ in animals, then equation (3) is:

$$
\left[\frac{\text { HZE effect in humans }}{\gamma \text {-ray effect in humans }}\right]=\mathrm{k}\left[\frac{\text { HZE effect in mice }}{\gamma \text {-ray effect in mice }}\right]
$$

a concept which is also identical to (1). The question remains whether it is valid to assume that $Q$ would be similar in humans and an animal model (so that the value of $k$ is known), and if so, how would $Q$ vary from tissue to tissue? This presents the need for a systematic attempt to determine $Q$ for a given tissue in several animal models, and for a given animal model to compare $Q$ for those tissues for which human $\gamma$-ray data are available to determine how $Q$ varies by tissue. (See also Fig. VII.3 on how to compare animal and human data). Of even more importance is again the question of whether it is reasonable to expect that HZE particle effects can be reliably related to low-LET effects in this equation.

Storer et al. (1988) have discussed whether the absolute risk or relative risk model should be used to extrapolate radiogenic cancer risks for human populations. The absolute risk method holds that the risk for radiogenic cancer is invariant and should be added to the risk for spontaneous cancer in the population. In contrast, the relative risk method assumes that the 
radiogenic risk is related to the spontaneous risk. When these authors tested data on four different mouse strains they found that the relative risks of specific solid cancers (carcinomas of lung, breast, adrenal glands, Harderian gland; liver and ovarian tumors, and myeloid leukemia) determined for one mouse strain could be used to extrapolate the risk to other mouse strains. Furthermore, relative risk estimates for lung and breast carcinoma, and leukemia in mice could be used with some success to predict the relative risk for atomic bomb survivors, while mice had a $2 x$ higher risk for liver tumors than did humans. In contrast, the risk of thymic lymphoma or reticulum cell sarcoma based on either a relative or absolute risk model could not be predicted across mouse strains and the absolute risk method did not work well for any tissue. These results suggest that while the relative risk method may be valid in general, it can not be automatically assumed to be true for alt tissues.

Curtis et al. (1992, 1995) and Curtis (1993) have suggested that a system based on fluence rather than dose should be used, where fluence is defined as the risk cross section, or the probability per unit fluence of producing a specific risk. In the case of any type of cancer, the cross section is the slope of the response curve (induction of the excess cancers) plotted as a function of fluence. Ideally, data would be obtained for the risk cross section for each type of relevant cancer as a function of energy, and the energy spectra in the specific organ for each type of HZE particle. The total cancer risk would then be the sum of the risks for each site.

Curtis (1993) suggested that the cancer risk cross sections could be "anchored" at a point representing the risk for exposures to low-LET radiation such as those derived from the atomic bomb survivors, and the relationship of the low-LET to HZE particles could be based on quality factors; presumably these quality factors would be determined by animal experimentation as discussed above. Such an approach entails the determination of the slopes of fluenceresponse curves for sufficient types of HZE particles at relevant energies so that an integral that represents the responses for other types of HZE particles and energies could be derived with confidence. To accomplish this it would be necessary to determine: 1) the initial slopes of fluence-response curves for representative cancers such as leukemias, cancer of the breast and the lung, and 2) the incident particle energy spectra of the selected particles and how they are transported through shielding and the astronaut's body and how that changes the spectra when the particles reach the organ of interest. This is no mean task.

Whether risk estimates for high-LET radiation-induced cancer in humans is obtained by using some variation of equation (1), or the risk cross section approach of Curtis is selected for the task of determining the risk estimates for cancer induced by exposure to the HZE component of GCR, animal experiments appear to be the only source of the requisite data. Similarly, if 
risk coefficients obtained for experimental animals, and a method of extrapolation is derived, animal experiments will obviously also be necessary.

\section{Review reference:}

Fry RJM. 1992. The role of animal experiments in estimates of radiation risk. Adv. Radiat. Biol. 16: 181-197. 


\section{PANEL RECOMMENDATIONS}

\section{A. THE NECESSITY OF USING ANIMALS}

After extensive documentation of the existing literature on the biological consequences of exposure to radiation in general, and to HZE particles in particular, the results summarized at the end of Sections IV.A. to D., and the questions discussed in VI.A. to G. can be encapsulated in the following statement: We simply do not have enough evidence, especially for HZE particles, to estimate risk, and to prevent pathological outcomes. Further experimentation on many fronts is necessary to achieve a rational approach to protect the astronauts, and for counteracting the results of whatever damage has been caused, and this cannot be accomplished adequately with animal alternatives (Roush, 1996). The Panel therefore concludes unanimously that animal experimentation is indeed necessary. However, the panel recognizes that the best solution is to reduce the risk and minimize the use of animals. The Panel therefore endorses:

1. the ethical use of animals - Section VII.B.1.

2. the informed choice of animal models - Section VII.B.2

3. the optimization of the use of animals - Section VII.B.3.

4. the concept that animal models such as Drosophila, nematodes, rodents and primates have proved useful for studying a wide variety of human pathologies and conditions; several examples are provided in Table VII.1 for neurodegenerative disease, cancer and aging. Thus lower species, even invertebrates, should be used to provide comparative analysis when warranted - Section VII.B.3.a. and b.

5. the use of physiologically relevant culture systems, both to lower the number of animals used, and to provide accurate cell and molecular biological markers for more sensitive assays for closing the physiological gap between animals and humans Section VII.B.3.d.

The panel also endorses:

6. thorough analysis of the possible use of radioprotectors during space flight - Section VII.B.4.a.

7. consideration given to analysing possible individual susceptibilities due to genetic diversity of the astronauts - Section VII.B.4.b.i. 


\section{TABLE VII.1}

\section{SELECTED EXAMPLES OF ANIMAL STUDIES WITH RELEVANCE TO UNDERSTANDING HUMAN BIOLOGY}

Biological insight

\section{Neurodegenerative Disease}

Parkinson's disease model

Alzheimer's disease model

Genetic basis of apoptosis

Carcinogenicity testing

Role of $B R C A 1$

gene in breast cancer

Role of $A P C$ and PTC tumor suppressor genes in signal transduction

Proteins involved

in cancer cachexia

Cancer metastasis

Role of microenvironment in breast cancer

\section{Aging and Cancer}

Retardation of aging and tumorigenesis by caloric restriction
Animal Model

rat, mouse

Fisher and Gage, 1995

Nakao et al., 1995

Microcebus murinus

(a lemurian primate)

mouse

mouse

Caenorhabditis

elegans

Bons et al., 1995

Hsaio et al., 1996

Miura et al., 1993; Yuan, 1996

Hengartner and Horvitz, 1994

rat, mouse

Gold et al., 1989

mouse

Drosophila

Peifer, 1993; 1996

Johnson et al., 1996

mouse

Todorov et al., 1996

mouse ("Metamouse")

Kuo et al., 1995

Hoffman, 1994

mouse

Sympson et al., 1994 rat, mouse

rhesus monkey
Weindruch and Walford, 1988

Kemnitz et al., 1993 


\section{B. OTHER RECOMMENDATIONS}

\section{ETHICAL USE OF ANIMALS IN SPACE RESEARCH}

Understanding that the development of knowledge necessary for the improvement of the health and well-being of humans requires in vivo experimentation with a wide variety of animal species, the U.S. Government has established principles for utilization and care of vertebrate animals used in testing, research and training. Whenever U.S. Government agencies develop requirements involving the use of vertebrate animals, these principles shall be considered. Furthermore, when these agencies either perform or sponsor such procedures, the responsible Institutional official shall ensure that these Principles are adhered to. The Principles for ethical use of animals are:

I. The transportation, care, and use of animals should be in accordance with the Animal Welfare Act (7 U.S.C. 2131 et. seq.) and other applicable Federal laws, guidelines, and policies*

II. Procedures involving animals should be designed and performed with due consideration of their relevance to human or animal health, the advancement of knowledge, or the good of society.

III. The animals selected for a procedure should be of an appropriate species and quality, and the minimum number required to obtain valid results. Methods such as mathematical models, computer simulation, and in vitro biological systems should be considered.

IV. Proper use of animals, including the avoidance or minimization of discomfort, distress, and pain when consistent with sound scientific practices, is imperative. Unless the contrary is established, investigators should consider that procedures that cause pain or distress in human beings may cause pain or distress in other animals.

V. Procedures with animals that may cause more than momentary or slight pain or distress should be performed with appropriate sedation analgesia, or anesthesia. Surgical or other painful procedures should not be performed on unanesthetized animals paralyzed by chemical agents.

VI. Animals that would otherwise suffer severe or chronic pain or distress that cannot be relieved should be painlessly killed at the end of the procedure or, if appropriate, during the procedure.

VII. The living conditions of animals should be appropriate for their species and contribute to their health and comfort. Normally, the housing, 
preventing breast and ovarian cancer (Kinzler and Vogelstein, 1996b). Examples of transgenic and knockout mice with potential to model human diseases are shown in Tables VII.2 and VII.3. Bedell et al. (1997a) have also pointed out the unique value of genetically engineered mice in modelling human disease, and have provided brief evaluaton of over 100 such mouse models (Bedell et al., 1997b).

In addition to these genetic considerations, the cost of maintaining and manipulating mice experimentally is a factor. Because of their size, and low cost per animal, mice are a relatively economical mammalian choice. Thus, the mouse has been, and should continue to be, a leading candidate for spacerelated research, especially for cancer and neurological disorders. While it is true that memory and brain function damage is more complicated to test in animals than in humans (because we do not have simple tests to examine memory in animals), there are sophisticated tests being developed which can monitor various aspects of brain function.

Nevertheless, the mouse cannot be automatically chosen for all experimental approaches. Before choosing the mouse, the investigator must make sure that the mouse best reproduces the human condition being studied. The information assembled in Table VII.1 indicates that whereas the mouse is frequently used, it is by no means the only viable animal model. Even when it can be used, the problem of extrapolating results from the mouse to the human must still be solved (see Section VII.B.3.).

\section{i. Selection of mouse strain}

There are basically three options with regard to the selection of mice. First, one or more inbred strains can be selected. A vast database on the pathology of aging mice of different strains is available (e.g., Zurcher et al., 1982; Bronson and Lipman, 1991). The main criteria in selecting one or more strains are that the study population exhibits a more or less rectangular survival curve and those animals that die should have multiple pathological changes. A strain that fulfills these criteria reasonably well is C57B1/6, which is very well defined in terms of age-related multiple pathology, and is frequently used in radiobiological and genetic toxicological studies, as well as in aging and cancer research in general. Also, two of the reporter gene mutation models have been made in a C57B1/6 background (i.e., the bacteriophage lambda lacI and the plasmid lacZ models-see Section V.A.1.a.), while several of the knockout mice (e.g., p53, XPA) are being crossed into C57B1/6 from their original 129 background. An advantage of using inbred mice is that the confounding effects of individual genetic variation are absent; hence, there is the possibility of using smaller groups of animals to obtain statistically significant results. A disadvantage is that the virtually complete homozygosity of inbred strains does not reflect the outbred situation in 
humans. Here again, comparisons between inbred and outbred strains should be done.

As an alternative, multiple strains can be crossed to generate progeny with genetic diversity. Such an approach has been used by Miller et al. (1994) to assess age-sensitive indicators of immune status in mice, and by Chrisp et al. (1996) and Miller et al. (1997) to study factors affecting longevity in mice. The second alternative is that wild mice can be collected to create populations of genetically heterogeneous animals. Finally, outbred animals can be used (Sympson et al., 1994). These three alternatives avoid the possible confounding influence of strain-specific susceptibilities, and allow one to study the influence of genetic heterozygosity.

\section{ii. $\quad$ Transgenic (TG) and knockout (KO) mice}

The mouse "is the creature we turn to to do the experiments, so important in reaching an understanding of ourselves, that are either technically impossible or morally inconceivable in human subjects" (Paigen, 1995). This statement about the use of the mouse as an experimental surrogate to understand human physiology and pathology, is even more true with the development of transgenic and knockout mouse technology during the past decade. There are now hundreds of genetically manipulated mice which are being used to unravel human diseases in a myriad of systems. The strategies being used include the introduction of mutant genes to determine the roles of their gene products in the development of pathology (e.g. Gurney et al., 1994; Ripps et al., 1995; Games et al., 1995), and inactivation of normal genes to determine the roles of their gene products in preventing pathology (e.g. Kumar et al., 1995; Sands et al., 1995a; Jacks et al., 1994). Transgenes can also be used to alter enzyme levels to determine whether that enzyme is essential or rate-limiting in a particular biochemical pathway such as DNA repair (Gu et al., 1944; Sekiguchi et al., 1996), and to increase the ability to detect perturbations in vivo due to low level environmental insults such as mutagens (Gossen et al., 1989; Kohler et al., 1991; Boerrigter et al., 1995).

Although the potential of transgenic and knockout mouse models to answer critical questions is often limited mainly by the imagination of the investigator, it is nevertheless incumbent on the investigator to understand the limits of their use in modelling human pathology and physiology. A few examples relevant to cancer and neurodegenerative disease are shown in Tables VII.2 and VII.3. Some sources of transgenic and knockout mice are listed in the Appendix (Section IX.E).

Generation of transgenic and knockout mice. Transgene technology typically involves the joining of a protein coding sequence of a gene to an appropriate promoter sequence to direct the tissue-specific expression of a heterologous gene in the recipient mouse. Lo (1996) has provided a brief and 
useful description of the steps from here. The transgene constructs are injected into fertilized mouse eggs such that they are stably integrated into the genome at random, and are passed from generation to generation. Targeted disruptions, or knockouts, are generated by insertion of an irrelevant sequence into an essential region of the targeted gene in the mouse genome, thus inactivating its expression. This is generally done using homologous sequences to help direct the specific integration of the disruptive sequence. Specific integration of the sequences is done into the genome of embryonic stem cell lines, which on injection into early-stage mouse embryos, will give rise to genetically engineered mice. The genetic alteration will be passed on as a mutation from generation to generation through the germline. The approaches actually used to generate these mice have recently been reviewed by Fässler et al., (1995) and Rossant and Nagy (1995).

\section{iii. Concerns about the use of transgenic and knockout mouse models}

There are at least two concerns associated with the use of these sophisticated animal models. The first is that the investigator must make an a priori assumption about the role of a given gene product in the process under investigation. However good these assumptions may seem, it is extremely important that the mouse model developed be thoroughly characterized to make sure it mimics what is known about the human conditions being modelled. A single gene knockout mouse which appears to recapitulate a complex human disorder remarkably well is the atm-deficient mouse which will provide an animal model for ataxia telangiectasia (Barlow et al., 1996). Other knockout mouse experiments sometimes lead to surprising results. For example, fos $\mathrm{B}$ is a component of a transcription factor complex, and is induced by environmental stimuli which trigger adaptive neuronal responses. When knockout mice deficient in fos $B$ were generated, the mice were profoundly deficient in their ability to nurture their young (Brown et al., 1996). Another example is provided by three well-known tumor suppressor genes: $p 16, p 53$ and $R b$. The $p 53$ gene is known to be mutated in about $50 \%$ of human tumors (Hollstein et al., 1991), so it is not surprising that p53-deficient mice are indeed good candidates for early carcinogenesis (Tennant $e t$ al., 1995). Similarly, $p 16$-deficient mice develop tumors readily at an early age (Serrano et al., 1996). What was unexpected is that $R b$-deficient mice develop pituitary tumors, rather than retinoblastoma, which is what humans develop (Kumar et al., 1995). Finally, the phenotype of an E2F-1 knockout mouse is opposite to what might have been expected (Yamasaki et al., 1996; Field et al., 1996). Although over-expression of E2F-1 in tissue culture cells can stimulate cell proliferation and be oncogenic, loss of E2F-1 in the knockout mouse results also in tumorigenesis, suggesting that E2F-1 also can function as a tumor suppressor. These mice also exhibit a defect in $\mathrm{T}$ lymphocyte apoptosis suggesting that E2F-1 plays a positive role in apoptosis in this cell type. 
One may not always be able to unequivocally interpret the results obtained with transgenic and knockout mice. For example, because TGF- $\beta 1$ is thought to be involved in many important processes, including regulation of immune responses, TGF- $\beta 1$ knockout mice were generated for such studies (Shull et al., 1992; Kulkarni et al., 1993). These mice suffer inflammation of many tissues and die prematurely. However, it is not clear how the loss of TGF- $\beta 1$ activity is related to this increased inflammatory activity and early death, or whether this is a valid model for studying autoimmune diseases (Lo, 1996).

A second concern is where and when the gene is expressed during development of the transgenic or knockout mouse. Our knowledge of early developmental processes are rudimentary at best, and both transgenics and knockout animals alter the embryo from its very early inception. What mechanisms nature chooses to overcome this crude manipulation of its processes may be totally unexpected. Thus, the phenotype of a given knockout mouse may not necessarily be equal to a "normal mouse minus the knockout gene." Indeed, the resulting phenotype may give an erroneous answer as the function of the gene.

The best way to deal with these problems is to make conditional knockout or conditional transgenic animals, and techniques for such manipulations are rapidly becoming available (Ewald et al., 1996). For transgenics, a form of conditional expression can be easily achieved through the use of a tissuespecific promoter linked to the transgene. For example, relevant to radiologically sensitive tissues such as the breast, milk protein promoters can be and have been used to target many genes to the breast (Sympson et al., 1994; Neuenschwander et al., 1996).

Conversely, non-specific promoters can be used if one desires to express the gene in as many tissues as possible. The regulation of when the gene is expressed may require the use of a promoter sensitive to an exogenous compound. Gossen and Bujard (1992) introduced the use of such a promoter which can be regulated by tetracycline. The gene of interest is linked to the Escherichia coli operator sequence which binds the tet transactivator protein (tTA). Tetracycline represses the function of tTA thereby preventing expression of the downstream genes. A recent modification has been to mutate the tTA protein so that tetracycline binding activates rather than represses downstream gene expression (Gossen et al., 1995b). Thus, tetracycline is only added when gene expression is desired.

The ability to control when the gene is expressed is crucial if the gene product is deleterious during fetal development, or if the absence of the gene product changes the developmental pathway. This occurs in myoD-deficient mice. MyoD is a member of a myogenic transcription factor family thought to regulate skeletal muscle differentiation. To determine the role of myoD in 
muscle development, Rudnicki et al. (1992) generated knockout mice unable to produce the myoD gene product. To their surprise, mice lacking myoD were viable, fertile, and morphologically normal. Apparently, another transcription factor, myf-5, is upregulated in these mice to make up for the absence of myoD.

The random insertion of a transgene into the mouse chromosome can also have unanticipated consequences. For example, if the transgene disrupts a tumor suppressor gene, the very act of creating the transgenic mouse would make the transgenic mouse cancer-prone. Comparable complications could result from insertion of the transgene into any critical mouse gene. Another uncertainty is how many copies of the gene are inserted; seldom is only one copy inserted. Thus, the expression of the transgene must be determined either at the protein or RNA level, or both. 
TABLE VII.2

\section{SELECTED EXAMPLES OF TRANSGENIC MOUSE MODELS USEFUL FOR MODELLING HUMAN BIOLOGY}

Gene manipulated

Transgenic models relevant to cancer

LacI

$\operatorname{LacZ}$

Stromelysin-1

TGF- $\beta 1$

$c-m y c / b c l-2$

SV40 large T-antigen in vivo mutation rates

in vivo mutation rates

breast cancer

cell cycle control, epithelial carcinogenesis

reduced latency

period for tumors

tissue-specific tumors when linked to tissuespecific promoter
References

Kohler et al., 1991

Martus et al., 1995

Sympson et al., 1994, 1995

Cui et al., 1996

Strasser et al., 1990

Naik et al., 1996

Transgenic models relevant to neurodegenerative disease

Mutant Cu/Zn-SOD1 amyotrophic lateral sclerosis

Ets2

Amyloid precursor

protein (APP gene)

$\mathrm{Cu} / \mathrm{Zn}-\mathrm{SOD} 1$

HD
Down syndrome

Alzheimer's disease cognitive loss

Parkinson's disease Down syndrome

Huntington's disease
Gurney et al., 1994

Ripps et al., 1995

Sumarsono et al., 1996

Games et al., 1995

Hsiao et al., 1996

Nakao et al., 1995

Huang et al., 1992

Mangiarini et al., 1996 
TABLE VII.3

\section{SELECTED EXAMPLES OF GENE KNOCKOUT MOUSE MODELS USEFUL FOR MODELLING HUMAN BIOLOGY}

Gene manipulated

Human condition

Reference

\section{Gene knockout models relevant to DNA repair*}

ERCC1

nucleotide excision repair

McWhir et al., 1993

XRCC5

Ku86; DSB repair;

SCID-like defect; slow growth

Zhu et al., 1996a

Nussenzweig et al., 1996

XRCC7

DNA dependent protein

kinase; DSB repair;

Sipley et al., 1995

SCID-like defect;

$X P C$

DNA repair, UV

sensitivity, cancer

DNA polymerase $B$

base excision repair

Gu et al., 1994

polyADP-ribose

DNA repair,

Wang et al., 1995

polymerase

skin disease

Sands et al., 1995a

*see also Friedberg et al. (1997) for many more examples.

\section{Gene knockout models relevant to neurodegenerative disease}

dopamine transporter schizophrenia

$A T M$

sphingomyelinase (acid)

glial derived neurotrophic factor (GDNF) ataxia telangiectasia

cell-cycle checkpoint control

Niemann-Pick disease

apoptosis

neuron survival factor
Giros et al., 1996

Barlow et al. 1996

$\mathrm{Xu}$ and Baltimore, 1996

Santana et al., 1996

Moore et al., 1996 
Gene knockout models relevant to cancer

\begin{tabular}{|c|c|c|}
\hline$p 53$ & $\begin{array}{l}\text { tumor suppression, } \\
\text { mutation rate } \\
\text { Li-Fraumeni syndrome }\end{array}$ & $\begin{array}{l}\text { Malkin et al., } 1990 \\
\text { Kumar et al., } 1995 \\
\text { Donehower et al., } 1995 \\
\text { Sands et al., 1995b }\end{array}$ \\
\hline G Alpha $i 2$ & colon adenocarcinoma & Rudolph et al., 1995 \\
\hline$\alpha$-inhibin & gonadal tumors & Matzuk et al., 1992 \\
\hline$p 16^{I N K} 4 a$ & $\begin{array}{l}\text { regulate cell cycle, } \\
\text { suppress proliferation }\end{array}$ & Serrano et al, 1996 \\
\hline p27kip1 & $\begin{array}{l}\text { regulate cell cycle, } \\
\text { suppress proliferation }\end{array}$ & $\begin{array}{l}\text { Fero et al., } 1996 \\
\text { Kiyokawa et al., } 1996 \\
\text { Nakayama et al., } 1996\end{array}$ \\
\hline$I C E$ & $\begin{array}{l}\text { IL-1 } \beta \text { converting } \\
\text { enzyme; apoptosis }\end{array}$ & Kuida et al., 1995 \\
\hline$N f 1$ & neurofibromatosis & Jacks et al., 1994 \\
\hline
\end{tabular}

Gene knockout models potentially relevant to other aspects of space travel

$\begin{array}{lll}\text { OG1, OG2 } & \begin{array}{l}\text { osteocalcin, } \\ \text { regulation of } \\ \text { bone formation }\end{array} & \text { Ducy } \text { et al., } 1996 \\ \text { Bruton's tyrosine } & \text { Uckun } \text { et al., } 1996 \\ \text { kinase, apoptosis } & & \\ \text { in lymphoma cells } & \end{array}$




\section{OPTIMIZATION OF THE USE OF ANIMALS}

A respect and sensitivity for living beings, in addition to cost and logistical difficulties, dictate that the mega-animal experimental approaches used in earlier decades should be avoided. In addition, there is little tolerance or desire to do invasive experimentation on primates and domestic animals. However, in rare instances some questions may only be asked in such species, and in such cases experimentation on higher mammals will be necessary and may be justified.

Even in the case of rodents (see Section IV.D.2.b.), where justification could be made for their use and their relevance to human risk assessment, the Panel felt it is important to optimize the number of animals, and wherever possible, use invertebrate species as long as relevance to humans is constantly checked and rechecked.

\section{a. Nematodes}

The extensive and growing knowledge about the nervous system of the nematode, $C$. elegans, suggests that the nematode may be a good model system for studying HZE-induced killing of neurons. The advantages of this model system are: 1) all neurons in the adult nematodes have been identified, 2) the functions of many of these neurons are understood and can be used in developing screening procedures for either mutations or cell deaths, and 3) the organism is short-lived, easy to maintain, and inexpensive to use experimentally, even in space. The major disadvantage is the usual problem of how to extrapolate results to humans, where the nervous system is so much more complex. The vertical 'relevance' chart (Fig. VII.1) should be kept in mind.

\section{b. Other invertebrates}

The degree of evolutionary conservation-not just of gene sequence, but also of gene function-that has emerged from the study of genes and pathways in different organisms over the last few years has surprised even the most avid proponents of model organism research. It is striking how many of the most intensively studied and important genes in mammalian development-HOX genes, engrailed, and hedgehog, to cite only a few examples-were originally identified by screening mammalian DNA with probes derived from the corresponding Drosophila gene (whose importance in Drosophila had already been revealed by genetic and molecular studies). In the study of human genetic diseases, there are numerous cases where information from model organims has been crucial. The biochemical function of the Nf1 gene was revealed by its homology to the yeast ira2 gene. Knowledge of the sequence and biochemical function of genes involved in repairing DNA damage in yeast has provided critical insights into human colon cancer genes, 
not simply by providing a way to interpret the sequence of one gene, but by also illuminating a path to rapidly isolate other genes involved in the same pathology. Similarly, knowledge of the patched and Notch receptor pathways in Drosophila has been important in understanding diseases such as skin cancer and stroke.

The recognition that fundamental developmental and physiological mechanisms are so similar among organisms is one of the most profound insights to come from all of biological science over the past several years. The intellectual excitement, interest and understanding that this revelation has generated will only increase as the genome sequencing projects of the model organisms continue. Just as the Rosetta stone gave the world the key to the long-forgotten language of ancient Egypt, so the biologically-annotated sequences of the genomes of the model organisms will provide an invaluable key to understanding the sequence of the human genome.

Among the model organisms, Drosophila is particularly well-suited for the role of determining human gene function. In terms of evolutionary conservation of sequence similarity, Drosophila is the closest of the genetically tractable model organisms (that is, bacteria, yeast, Arabidopsis, C. elegans and Drosophila) to humans. Moreover, in terms of morphological, physiological, and behavioral complexity, Drosophila is by far the closest to humans of these model organisms, yet its genome is not substantially bigger than the least complex metazoans. Finally, the large Drosophila research community has provided a wealth of information and understanding unusual in its depth and intellectual breadth. While the mouse is clearly more closely related to humans than Drosophila, one cannot do the kinds of sophisticated genetics in mice, such as a saturation genetic screen for all new mutations that affect a particular phenotype, that one can do in the other model organisms. While gene knockout by homologous recombination in mice is a very powerful method, its expense, as well as the difficulties in interpretation of phenotypes caused by the high degree of apparent gene redundancy in mammals, limit its utility on a genome-wide scale.

\section{c. Interspecies comparison: relevance to human risk}

It is abundantly clear from recent literature that studies in Drosophila and yeast, as well as mice, are contributing enormously to our discovery of genes involved in cancer and other diseases. It is not within the realm of this report to document the instances where the function of a gene or its regulation differ in different species. This should be a fairly obvious deduction. How then can we best utilize the knowledge gained from lower organisms to understand human biology? Clearly, yeast and bacteria, not being multicellular, could be used only for deciphering the existence of universal pathways and genes. What is important for our programs is that the discovered genes have to be in a correct context for us to understand both 
species- and tissue-specificity. We propose comparative analysis between invertebrates and vertebrates, between different species of vertebrates using changes in one or more of the markers we outlined in Section V in response to radiation or other insults. While a thorough comparative analysis is expensive, and usually not possible within a single research group, a sharing of experimental conditions and pooling of the data among multiple groups funded by a common mechanism and aided by computational analysis (analogous to the approach being taken for the human genome sequencing effort) should make it possible to extrapolate from one system to another. Studies analogous to those reported by Storer et al. (1988) discussed in section VI.G. would be very helpful. An analysis of why a number of tissues and diseases could be correlated and others could not, by itself, would be extremely telling. As every creative scientist knows, differences as well as similarities can reveal an important and fundamental paradigm and should thus be utilized. Because this comparative analysis cannot be accommodated for humans (except in instances where historical and accidental data already exist as has been discussed previously in this report), the final comparison with humans needs to utilize two complementary approaches: a comparison between functional, tissue-specific culture systems derived from the animal and human tissues (see next section), and non-invasive (or very mildly invasive) techniques such as imaging, tracer studies etc., comparing the animal in question and the humans before and after the flight, the given exposure, or stress, etc. The technologies developed for use in nuclear medicine such as PET, NMR, MRI should constantly be improved, and utilized in these comparative studies. There may indeed be much more data already available if investigators were encouraged to compare their data and study similarities and differences. 


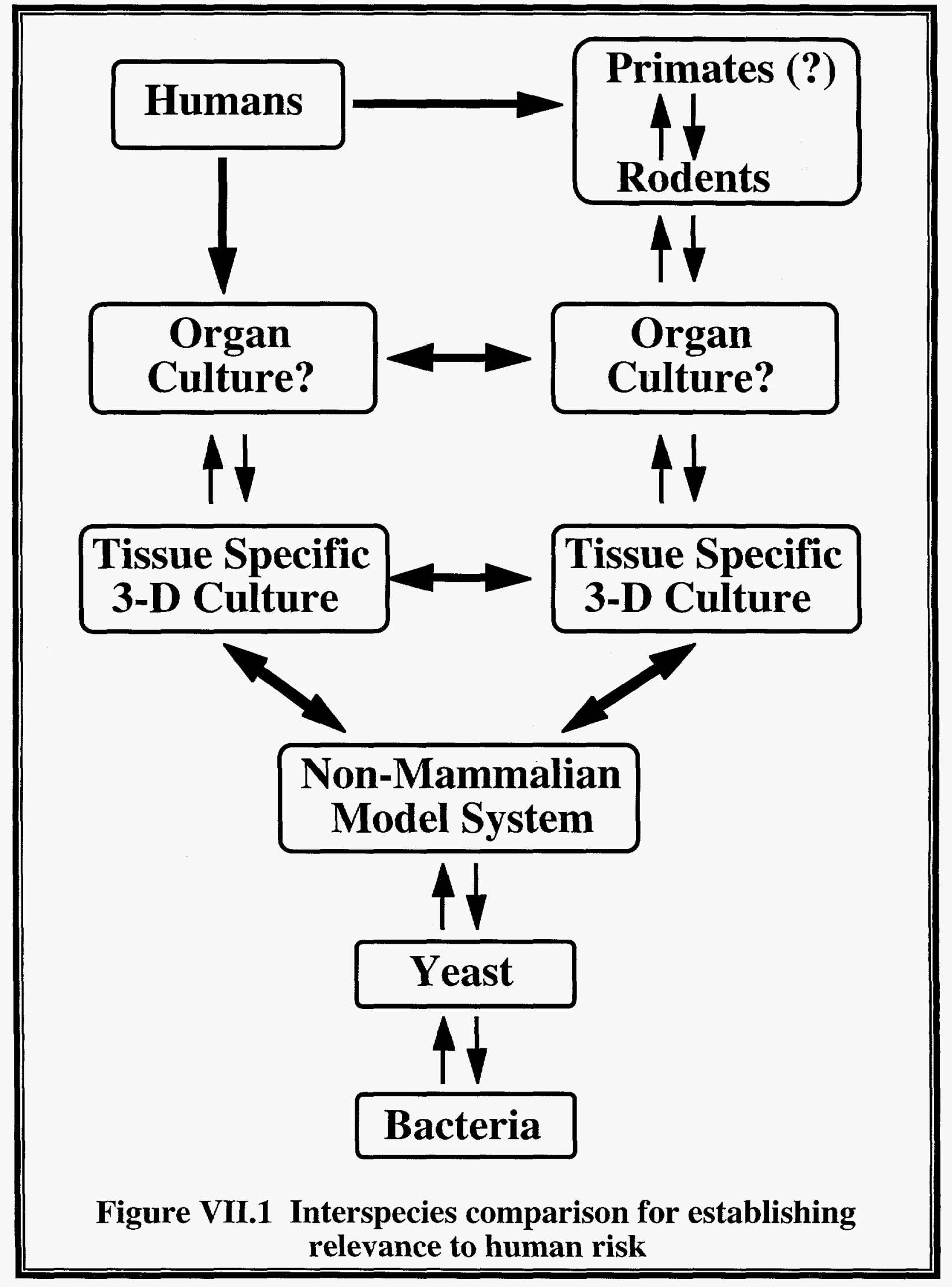




\section{d. Modeling with functional culture systems}

Cells in culture have been used to study a variety of physiological processes, including mutation frequency, carcinogenesis and programmed cell death (Table VII.4). However, existing data make it clear that traditional cell culture systems are often not adequate for this task. They also have been used to determine the molecular mechanisms of physiological processes such as signal transduction by growth factors and hormones, but it is clear that rates as well as modes of regulation determined in vitro do not provide accurate information about in vivo processes.

An example of where the rates of a given pathway are different in culture and in vivo is the repair of UV-damaged DNA using data in the existing literature (D'Ambrosio et al., 1981; Mullaart et al., 1988; Vijg et al., 1984). These papers describe experiments on the removal of UV-endonuclease sensitive sites (ESS) from DNA in human skin, rat skin, human fibroblasts, rat fibroblasts, and rat keratinocytes. The removal rates estimated are compromised because the various experiments did not use identical UV fluences, and were probably not done at the same time. Also, the removal rates in vivo (skin) and in human fibroblasts do not accurately reflect initial rates of removal. Nevertheless, they clearly indicate that rates determined in cells in 2dimensional culture systems are about an order of magnitude less than those observed in vivo. The data below indicate that whereas the absolute rates of processes determined in vitro are not reliable measurements of in vivo rates, they may retain the quantitative relationship which obtains in vivo. Thus, comparison of results in vitro with results in animal models may be predictive within a factor of 2-3 of similar phenomena in humans.

Change in ESS following UV exposure (\% removal per hr)

Experimental system

Human (Ref.)

Rat (Ref.)

Skin (in vivo)

$70^{(1)}$

$18(2)$

Fibroblasts (culture)

$10^{(3)}$

Fibroblasts (culture)

Keratinocytes (culture)

(1) D'Ambrosco et al., 1981

(2) Mullaart et al., 1988

(3) Vijg et al., 1984

The overall problems with using traditional cultures to study complex diseases such as cancer have been outlined long ago (Bissell, 1981). More recent efforts have shown that even much simpler processes such as 
regulation of specific genes are extremely context specific, and critically dependent on the local microenvironment (e.g. see Bissell and Barcellos-Hoff, 1987, Roskelly et al., 1995, Bissell and Maher, 1996, Weaver et al., 1997) (Figure VII 2).

The advent of "designer" culture systems (Stoker et al., 1990) using specific extracellular matrix molecules or a complex basement membrane have opened new opportunities to study tissue-specific gene regulation and also to distinguish normal and malignant cell behavior and regulation even for epithelial cells. (For example see Barcellos-Hoff et al., 1989, Friedman et al., 1989, Petersen et al., 1993, Mooney et al., 1992, Ronnov-Jessen et al., 1995). Most importantly, however, these studies conducted in 3-dimension with the help of a reconstituted basement membrane or basement membrane components have revealed new paradigms about how we may have to view and study tissue-specificity and cancer (Weaver et al., 1997). Specifically with regards to human breast cancer, there is now evidence that progression to malignancy -- at least with regard to tissue phenotype and function -- is not linear, but discontinuous.

The previous discussions have alluded to both the ethical impossibility of any direct approach to evaluating the effect of HZE particles on humans, and the inadequacy of 2-dimensional culture systems to model this risk. Current knowledge about these effects is very limited and is clearly inadequate for predicting with any degree of uncertainty the health risk to astronauts during a 3-year mission to Mars. This impasse suggests that animal experiments cannot be avoided. However, the uncertainty about how well human health risks can be evaluated by animal models cannot be overcome simply by doing a large number of animal experiments. Animal experiments could be combined with functional culture models to reduce the number of animal experiments as well as increase the accuracy of cross-specific comparisons.

Cancer can be used as one paradigm for this approach. Cultures of both human and animal cells irradiated by HZE particles at low doses over a period of time might be used to determine the relative (animal-human) effects of such a regime on endpoints associated with transformation. A subsequent comparison of the dose required to induce cancer in mice would then provide a factor relating cancer induction in vivo to transformation in vitro. Use of this factor to calculate the theoretical rate of cancer induction in humans at the exposure anticipated in outer space might then provide an estimated risk for humans (Figure VII.3). The validity of this concept requires that the endpoint measured in vitro has a clear relationship to the induction of cancer in vivo in both humans and the animal model chosen. Some examples of such endpoints are listed in Tables V.1 and V.2; discussions of how these endpoints can be used are briefly described under Section V, "Critical markers of physiological response to radiation-induced damage". 


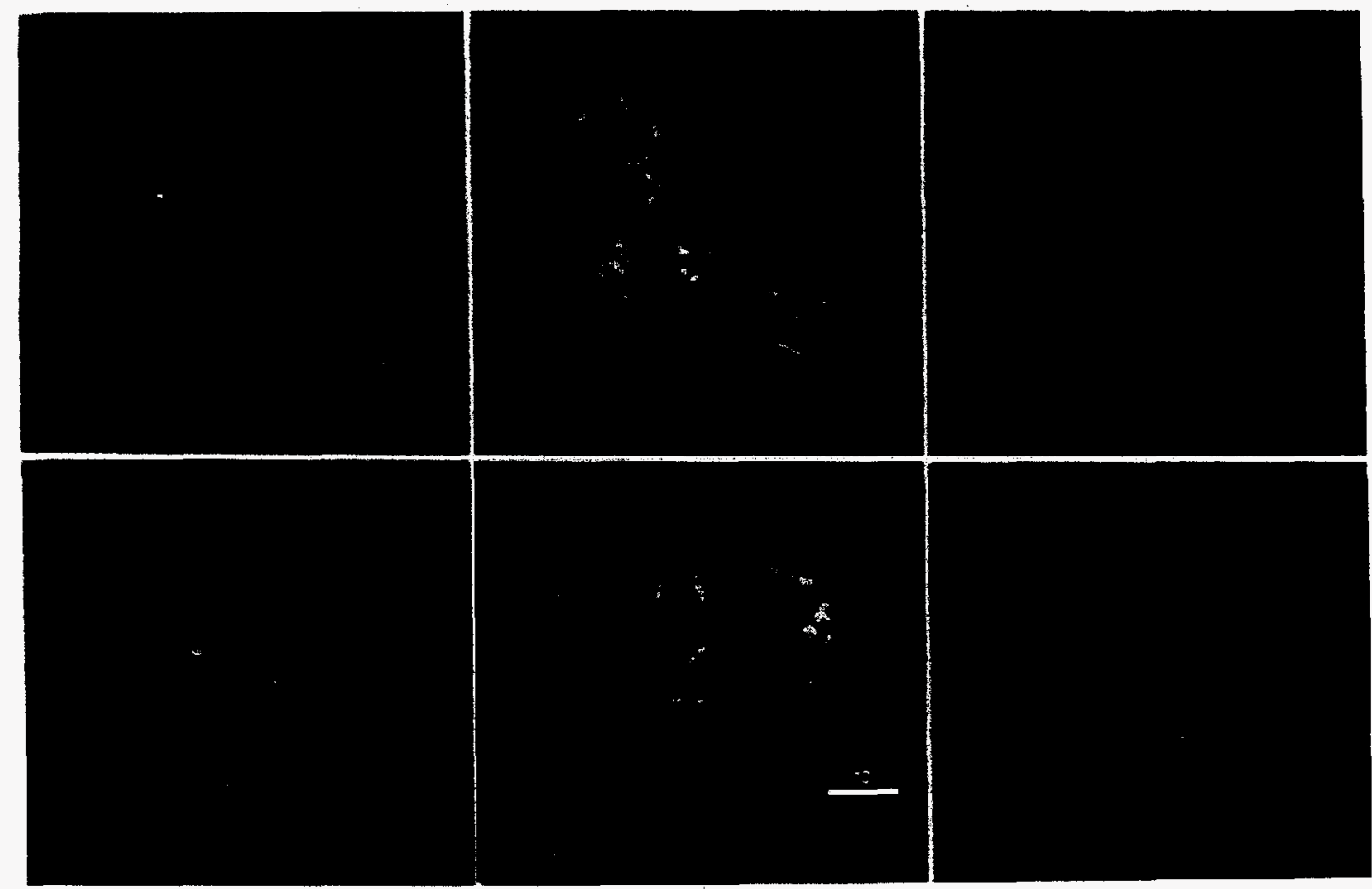

Figure VII.2: A new paradigm for cancer biology. By manipulating the microenvironment and the ECM receptors, overtly tumorigenic human breast cells are reverted to normal structures in culture and have reduced tumorigenicity in vivo. These confocal fluorescence microscopy images of frozen sections of breast cell colonies demonstrate how antibody treatment of tumor cells (middle) revert cells back to a state resembling non-malignancy. Images (top) show the cytoskeletal protein actin (green) and the labeling of cell nuclei (red) at 600X power. The bottom image shows E-cadherin (green), an adhesion protein found between two cells' surfaces, and Beta-catenin (red), a protein found on the inside of the cell surface that interacts with E-cadherin (from Weaver, et al., 1997. Reproduced with permission.) 
Calculated Value

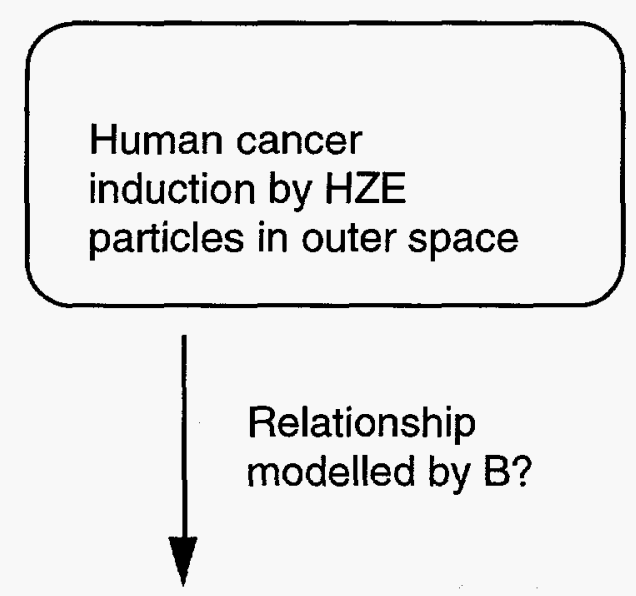

Transformation endpoints induced by HZE particles in cultured human cells

Experimental Value
Experimental Value
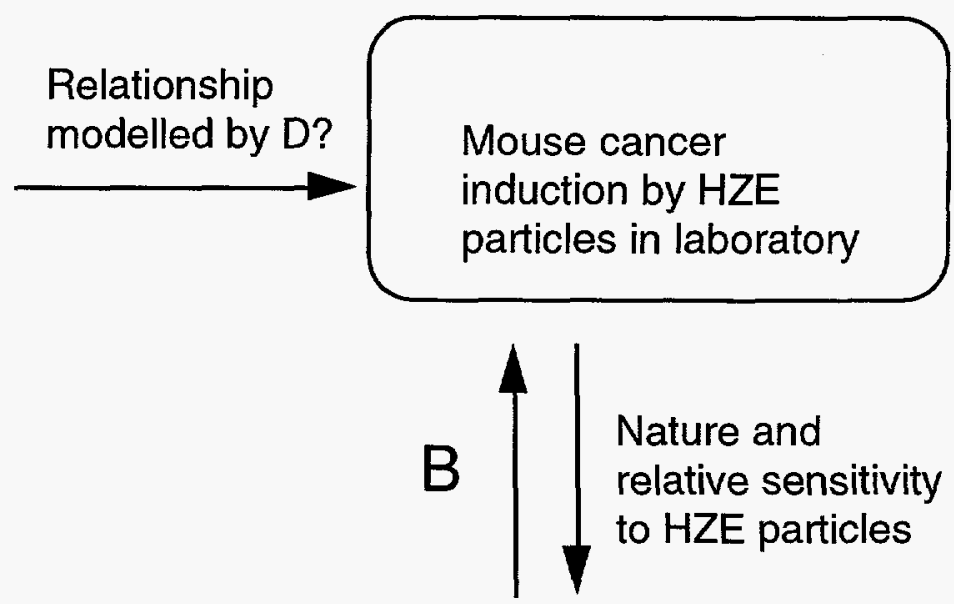

Transformation endpoints induced by HZE particles in Nature and relative sensitivity to HZE particles cultured mouse cells

Experimental Value

Examples of transformation-related endpoints in the mouse:

1) Mutation frequency

2) Chromosome translocations

3) Pattern of gene expression

4) Telomerase induction

5) Loss of tumor suppressors such as $\mathrm{p} 53, \mathrm{Rb}$

6) Nuclear structure

7) Angiogenesis, etc.

Figure VII.3. Model for estimating human risk calculated from experiments in animals and cultured cell systems. 
The validity of such an approach using HZE particles is yet to be established. The high energy deposition of HZE particles, the traversal of many cells per particle and the large amount of damage done by each particle, suggest that in vitro to in vivo, and animal to human extrapolations cannot be taken for granted, but must be assessed experimentally.

\section{e. The need for interdisciplinary research}

The exquisite complexity of mammalian systems, and the evolutionary conservation of biological systems across species, indicate both the utility of and the need for interspecies comparative studies and modeling with functional culture systems. However, such research requires a broad variety of experimental approaches and research disciplines, as well as a familiarity with several model systems. Interdisciplinary studies are needed either within a research institution, or between institutions, and means must be found to make interactions between molecular and cell biologists, physiologists, radiobiologists, pathologists and biophysicists possible. Thus, the research program initiated should encourage collaborative interdisciplinary research to take full advantage of the emerging human genome sequence information, genetically-engineered model systems, and other resources needed to develop adequate information about HZE-induced damage to humans. 
TABLE VII.4

CULTURE MODELS FOR STUDYING HUMAN BIOLOGY

Cancer

Control of Cell Proliferation

Cell senescence

Telomere shortening

Cell transformation

Mutation frequency

e.g. hprt and tk genes

Breast cancer: modelling

in three dimensions

Role of TGF- $\beta 1$ in

tumor invasiveness

Neurodegenerative disease

Programmed cell death of neurons

Alzheimer's disease

Role of mutant SOD-1 in ALS

\section{References}

Campisi, 1996

Allsop et al., 1992

NCRP, 1990

Kronenberg et al., 1995

Zhu et al., 1996b

Petersen et al., 1995

Oft et al., 1996

Martin et al., 1992

Vito et al., 1996

Rabizadeh et al., 1995

Wiedau-Pazos et al., 1996 


\section{COUNTERMEASURES}

\section{a. Radioprotectants}

The results of research on radioprotectors is summarized in the Appendix (Section IX.E). This work has focused primarily on the use of thiolamines, which are thought to reduce oxidative stress by oxidation of the sulfhydryl group. However, it is thought that these compounds are attracted specifically to DNA because of their net positive charge, thereby increasing their effectiveness in reducing DNA damage. Thus, considerable effort has gone into developing precursors which release the thiolamine moiety slowly to reduce the undersirable side effects of the thialamines which include nausea, vomiting and vasodilation.

While compounds such as these might be protective during extended flights in outer space, their use must await the outcome of appropriate clinical trials and development of a non-toxic regimen. If they act only as simple antioxidants, their effectiveness against HZE particles may be limited to reducing damage due to non-nuclear hits.. These compounds have recently been tested for effectiveness against HZE particles using cultured cells. It was found that cysteamine was effective in reducing the frequency of $h p r t$ and $t k$ mutations induced in human TK6 cells by moderately ionizing radiation such as Ne particles, but it did not reduce the mutagenic effectiveness of more clustered initial damages induced by the more densely ionizing Fe particles at either genetic locus (Amy Kronenberg, personal communication). This result casts doubt on the possibility that antioxidants may be useful against HZE particles, but further experimentation should be carried out in organ cultures and three-dimensional cell cultures, as well as in animals. Nevertheless, this difference suggests that attention should be given also to developing compounds which would be effective against high-LET radiation. Pathological endpoints should include not only those related to carcinogenesis, but also ones related to neurobiological damage and damage to the microenvironment, although the latter still needs to be examined with and without thiolamines.

If neuron loss due to HZE particle damage is in fact a significant problem during travel in outer space, it is unlikely that antioxidant intervention will protect the brain against the initial damage. However, nitrones have been shown to reduce and even reverse, protein oxidation in the brain (Carney et al., 1991), and it is likely that they and other anitoxidants could provide secondary protection against oxidative damage. This would prevent the damage spread that occurs as cells are injured and generate free radicals and peroxidation products leading to a cascade of neuronal loss as is seen after a stroke. A variety of nitrones have been shown to quench or limit this process in animal models of neurodegeneration, and at doses which are not toxic (John Carney, personal communication). 
Growth factors have also been proposed and tested as radioprotective agents. Gale and Butturini (1990) have reviewed the potential use of hematopoietic growth factors in treating radiation-induced bone marrow suppression. Neta and Oppenheim (1991) have reviewed the evidence that a variety of other cytokines such as interleukin-1 (IL-1) and tumor necrosis factor- $\alpha$ (TNF- $\alpha$ ) and interferon when administered after irradiation, promote recovery from low doses. The ability to clone and produce large amounts of these growth factors make them attractive agents as radioprotectants in humans. While it is likely that they act by preventing hematopoetic cell death, research is needed to determine whether this is indeed the case.

Finally, considerable recent evidence suggests that growth factors may even be useful in maintaining brain function under adverse conditions, possibly including radiation-induced damage. This evidence is summarized in Table VII.5. The greatest hurdle to such interventions may be delivering the growth factors, but current research on neurodegenerative diseases is focussing on this problem. Hefti (1994) has reviewed the rationale for such interventions. 
TABLE VII.5

AMELIORATION OF NEURODEGENERATIVE PROCESSES BY NERVE GROWTH FACTORS

\section{Effect}

Reduce cholinergic neuron atrophy

Improve spatial memory

Protect dopamine neurons against 6-hydroxdopamine and $\mathrm{MPP}^{+}$toxicity

Reduce rate of neuronal death in the hippocampus

Prevent apoptosis of injured central cholinergic neurons

Promote survival of dopaminergic neurons in the substantia nigra

Rescue of axotomized basal forebrain neurons

Improve cardinal symptoms of Parkinson's disease induced by MPTP
Animal

rat

rat

gerbil

rat

rat

monkey

monkey
Growth Factor

NGF

NGF

BDNF

NGF

NGF

GDNF

NGF

GDNF

\section{References}

Fischer et al., 1987

Fischer et al., 1991 Markowska et al., 1994

Spina et al., 1992

Shigeno et al., 1991

Wilcox et al., 1995

Gash et al., 1996

Hudson et al., 1995

Kordover et al., 1994

Bowenkamp et al., 1996

\section{Review reference:}

Hefti F. 1994. Neurotrophic factor therapy for nervous system degenerative diseases. J. Neurobiol. 25: 1418-1435. 


\section{b. Measuring Inter-Individual Differences In Susceptibility}

A striking feature of human populations -- and one that is very poorly understood -- is that individuals differ substantially in their susceptibility to disease. This is true whether the disease is caused by germline mutations, such as those found in the $p 53$ gene in the Li-Fraumeni syndrome, or by environmental factors, such as radiation exposure. What is the basis for this variation in individual susceptibility? It is very likely that individuals differ in their susceptibility to disease because they express different versions (i.e., polymorphic forms) of genes that influence the disease or process under study.

Polymorphisms occur in roughly one out of every three thousand base pairs in the human genome. Some polymorphisms occur in non-coding, nonregulatory regions, whereas some occur in coding regions, but do not change the encoded amino acid. These polymorphisms are presumed to be "silent", that is, without functional consequences. However, some polymorphisms cause differences in the amino acid sequence of proteins. In some cases, the difference may be a conservative change (for example, alanine versus valine), but in other instances there may be non-conservative differences (for example, alanine to glutamine). Especially in the latter cases, the difference between a polymorphism and a mutation may be semantic.

Very little is known about whether and how non-conservative polymorphisms alter protein structure and function. In a few cases -- for example, certain P450 enzymes, specific polymorphisms have been associated with increased or decreased enzymatic activity, with an accompanying difference in susceptibility to neoplasia induced by particular carcinogens. These polymorphic differences in protein function and susceptibility to neoplasia appear to be influenced by additional genetic differences among individuals. Therefore, it is very likely that an individual's susceptibility to radiation-induced disease will be dictated by that individual's complement of polymorphisms in the large number of genes that influence the response to radiation.

Clearly, understanding individual susceptibility to radiation will require not only identifying the pertinent genes, but also determining their polymorphic forms and the structural and functional consequences of the polymorphisms. This will require a concerted effort that brings together the disciplines of epidemiology, molecular and cell biology and structural biology.

The ever increasing number of genes with germline mutations that predispose humans to cancer (examples are listed in Tables IV.12 and VII.6), raises the question of whether genetic screening could be a means to identify individual risk for radiation-induced cancer, and perhaps also for other adverse effects like neurodegeneration. More specifically, the question is whether radiation could hasten cancer initiation and/or progression in 
individuals with a germline mutation in genes like $B R C A 1, p 53, A T M$, etc. The p53 gene product is one of the critical regulators of the cell cycle (Jacks and Weinberg, 1995), and experiemental manipulation of p53 levels can lead to either cell cycle arrest or apoptosis (Chen et al., 1996). The ATM gene product is an example of a protein which has roles in both cell growth control and response to radiation; atm-deficient mice fail to up-regulate p53 following $\gamma$-irradiation ( $\mathrm{Xu}$ and Baltimore, 1996). The role of BRCA1 in regulating cell proliferation is yet to be defined. Two approaches can be envisaged to test the status of these and other genes.

\section{i. $\quad$ Gene Testing}

Thus far, there is no evidence that germline mutations in cancer susceptibility genes accelerate the risk of radiation-induced cancer. For the most likely candidate in this respect, the p53 tumor suppressor gene, there is abundant evidence that mutations increase radiation sensitivity of cultured cells, although an in vivo effect has yet to be demonstrated. However, because heterozygote germline mutations of p53 cause Li-Fraumeni syndrome, in which the first cancers appear before the age of 16 in 40 percent of affected individuals (Eng et al., 1997), preventive screening for such mutations in astronauts is unnecessary.

With regard to other cancer predisposing genes there is as yet no information about additional risk of radiation. The fact that women with a mutation in $B R C A 1$ are advised to undergo mammography each 6 months already suggests that no evidence for radiation susceptibility for this gene has been apparent so far. Indeed, even for the second strongest candidate gene (after p53), ATM, where mutations cause the recessive genetic disorder, ataxia telangiectasia (AT), there is no information about whether or not there is a predisposition to cancer in heterozygote state. Cultured cells from AT individuals are hypersensitive to ionizing radiation, but it is possible that one intact copy of the gene is sufficient to perform its function in vivo. For example, transgenic knockout XPA+/- mice have the same level of unscheduled DNA synthesis (UDS; a measure for nucleotide excision repair) as do the control animals (de Vries et al., 1995).

Cancer risk could be increased by defects in many pathways which need not necessarily overlap. Extensive epidemiologic research is necessary to establish the relationship between mutations in cancer susceptibility genes and radiation sensitivity. Such research, however, is critically dependent upon the availability of cost-effective methods for accurately scanning large genes for all possible mutations. For a limited number of individuals to be tested, and in an exceptional case (like traveling to Mars), several genes can be comprehensively analyzed by direct sequencing. However, in order to establish that mutant genes that predispose individuals to cancer are also radiation-susceptibility genes, genetic epidemiologic studies on thousands of 
individuals must be performed. This is not feasible in view of the large size of many of these genes, and the current status of the technology. For this reason, alternative methods have been proposed that would allow one to scan large genes in a cost-effective manner.

One highly publicized way to scan genes of known sequence for all possible kinds of mutations is to generate so-called DNA chips, with thousands to hundreds of thousands of oligonucleotides attached to small glass surfaces in arrays (Abbott, 1996; Pennisi, 1996). Together, these oligonucleotides represent all possible combinations of complementarity to an entire gene. Mutations anywhere in the coding sequence of the gene will be detected by the failure of several oligonucleotides to hybridize. This system was pioneered by researchers in the United States, the United Kingdom, Russia and the former Yugoslavia (Beattie et al., 1995; Chee et al., 1996; Pease et al., 1994; Southern, 1996) and is presently being commercially developed by several companies. Recently, the first working chip was used to scan a small region of the HIV genome for mutations (Kozal et al., 1996). Such a technique could be used to screen for risk susceptibility gene mutations (e.g. BRCA1, $A T M)$ in astronauts, in lieu of direct sequencing of these genes, prior to embarking on a mission to outer space, or possibly prior to entering the NASA space program. It is conceivable that during the next decades this or comparable other methods will provide (a) genetic epidemiological data to firmly establish "radiation risk genes", and (b) provide a practical means to test individuals for all possible pre-disposing gene mutations. Thus, limits of radiation exposure set for large populations to protect the most sensitive members of the population, could be somewhat relaxed for astronauts who have undergone adequate genetic characterization. The ability to perform such characterization will continually improve as our understanding of the molecular basis of radiation-induced pathology improves. In this respect, a correlation of polymorphism with cancer susceptibility in experimental animals such as mice would be warranted.

\section{ii. Phenotypic Testing: DNA Repair}

An obvious way of testing individual susceptibility to radiation-induced cancer and neuronal degeneration is by measuring the level of proficiency of defense systems. There is abundant evidence that DNA repair defects increase cancer risk. The best documented examples are xeroderma pigmentosum, ataxia telangiectasia and hereditary non-polyposis colon cancer. In this respect, it seems obvious to regard a low level of DNA repair activity as a risk factor. Unfortunately, objective measures for overall DNA repair activity do not exist. DNA repair pathways are specified by a large number of genes; many of these pathways overlap with each other and with other cellular functions. One assay that became standard for measuring nucleotide excision repair, the so-called unscheduled DNA synthesis (UDS), is not very quantitative and also offers no guarantee of absolute proficiency 
(individuals with Cockayne syndrome, for example, have a normal UDS). Recently, more relevant assays for DNA repair potential such as base excision repair, the FAR method, and transcription-coupled DNA repair have been developed (Section V.A.3).

It has been argued that in humans the large individual variation in DNA repair potential would reflect the presence of heterozygous mutations in one or more DNA repair genes. Although this is not an unreasonable hypothesis, it is a thin basis for using such tests in preventive screening. For example, in individuals in which certain repair activities are very high, the accuracy of repair could be low. Thus, the cells that survive radiation may do so while accumulating many potentially cancer-causing mutations. For example, a high level of double-strand break repair, a potential measure for individual proficiency in defense against HZE particles, could be associated with an increased error frequency, thereby causing many mutations. It is easy to see how difficult it will be to interpret the results of tests that simply measure the rate of DNA repair. Based on the above, it will be necessary to await further data, especially epidemiological data, on the relationship among various measures, like DSB repair, base excision repair, and radiation sensitivity. Different strains of mice which are known toave differential susceptibilities to radiation-induced damage might be the most efficacious approach to establish such relationships.

\section{iii. Inter-species differences}

Clues about genes which are important in inter-individual differences in susceptibility could possibly come from studies about inter-species differences. While it is well known that mice are many-fold more susceptible to tumors than are humans, it is not known why this is so. Neither is it known why the burro is a particularly radiation-resistant species (Fry, 1995). Even more curious is why three species of voles differ substantially in their sensitivity to radiation as measured by mutation rates (Holden, 1996a). Whereas Microtus arvalis and Microtus rossiaemeridionalis living in the area contaminated by the Chernobyl nuclear power plant, both are highly susceptible to radiation, a third species, Microtus oeconomus, is relatively resistant. These experiments were done by comparing the rate of induction of single-base substitutions in the mitochondrial cytochrome $\beta$ gene (Baker et al., 1995); the rates in the two susceptible strains were hundreds of times greater than in the resistant vole and other vertebrate species. Thus, an important area of research is to determine the molecular basis of these inter-species differences in sensitivity to radiation. Again these animal models will provide important information for understanding the reasons behind the difference in human susceptibility. 
TABLE VII.6

\section{SELECTED EXAMPLES OF \\ GENES MUTATED IN A VARIETY OF HUMAN CANCERS}

Gene

Cancer and/or function

Reference

\section{DNA Repair Genes}

XPA, XPC

DNA repair of UV Damage;

Cleaver, 1968

xeroderma pigmentosum;

skin cancer; neuron degeneration

hMLH1, hPMS1

hereditary nonpolyposis

and $h P M S 2$

colon cancer; proteins

required for mismatch repair

Papadopoulos et al.

1994

MacPhee, 1995

\section{Cell Cycle Regulation/Transcription Factor Genes}

$\begin{array}{ll}\text { p53 } & \begin{array}{l}\text { mutated in about } 50 \% \text { of } \\ \text { human cancers; regulates } \\ \text { synthesis of p21, a proliferation } \\ \text { suppression protein; } \\ \text { genome stability; } \\ \text { Li-Fraumeni Syndrome }\end{array} \\ \text { Rb } & \begin{array}{l}\text { cell cycle regulation; } \\ \text { retinoblastoma }\end{array} \\ \text { WT1 } & \begin{array}{l}\text { Wilm's tumor; } \\ \text { transcription factor }\end{array} \\ & \\ \text { p16 } & \text { predisposition to cancer; } \\ & \text { familial melanoma }\end{array}$

Hollstein et al., 1991; Marx, 1993 Fukasawa et al., 1996

Knudson, 1971

Eng et al., 1993

Call et al., 1990

Hussussian et al., 1994

Kamb et al., 1994

Cairns et al., 1995

\section{Helicase Genes}

Bloom's

helicase; genome stability

Ellis et al., 1995

syndrome (BLM)

Werner's

helicase; genome stability;

syndrome (WRN) premature aging;

Yu et al., 1996 


\section{Cell Signaling Molecules}

$\begin{array}{lll}\text { APC } & \begin{array}{l}\text { familial adenomatous polyposis } \\ \text { and other colon cancers; binds } \\ \text { to } \beta \text {-catenin for maintenance } \\ \text { of epithelial layers. }\end{array} & \text { Su } \text { et al., } 1993 \\ \text { NF1, NF2 } & \begin{array}{l}\text { GTPase activating } \\ \text { factor; neurofibromatosis }\end{array} & \text { Jacks } \text { et al., } 1994\end{array}$

\section{Other}

$B R C A 1, B R C A 2$

breast and ovarian cancers;

Easton et al., 1993

BRCA1 required for embryonic cell Wooster et al., 1994 proliferation

Hakem et al., 1996 


\section{BIBLIOGRAPHY}

Aaronson SA. 1991. Growth factors and cancer. Science. 254: 1146-1153.

Abbott A, 1996. DNA chips intensify the sequence search. Nature. 379: 392.

Abdallah JM, Lombardi DP, Kirsch I. 1995. Genetic instability in patients with Hodgkin's disease undergoing chemotherapy. J. Clin. Invest. 96: 27442747.

Adams JC, Watt FM. 1993. Regulation of development and differentiation by the extracellular matrix. Development 117: 1183-1198.

Adams JM, Harris AW, Pinkert LM, et al. 1985. The c-myc oncogene driven by immunoglobulin enhances induces lymphoid malignancy in transgenic mice. Nature 318: 533-538.

Afzal V, Feeney L, Thomas GH, et al. 1995. Sister chromatid exchanges in cells defective in mismatch, post-replication and excision repair. Mutagenesis 10: 457-462.

Aghamohammadi SZ, Morris T, Stevans DL, Thacker J. 1992. Rapid screening for deletion mutations in the hprt gene using the polymerase chain reaction: X-ray- and alpha-particle spectra. Mutation Res., 269: 1-7.

Ainsworth EJ. 1986. Early and late mammalian responses to heavy charged particles. Adv. Space Res. 6: 153-165.

Albertini RJ, Nicklas JA, Fuscoe JC, et al. 1993. In vivo mutations in human blood cells: Biomarkers for molecular epidemiology. Environ. Health Perspect. 99: 135-141.

Albertini RJ, Sullivan LS, Berman JK, et al. 1988. Mutagenicity monitoring in humans by autoradiographic assay for mutant T-lymphocytes. Mutation Res. 204: 481-492.

Ali N, Agrawal DK. 1994. Guanine nucleotide binding regulatory proteins: their characteristics and identification J. Pharmacol. Tox. Meth. 32: 187-196.

Allen DL, Yasui W, Tanaka T, et al. 1996. Myonuclear number and myosin heavy chain expression in rat soleus single muscle fibers after spaceflight. J. Appl. Physiol. 81: 145-151. 
Allsopp RC, Vaziri H, Patterson C, et al. 1992. Telomere length predicts replicative capacity of human fibroblasts. Proc. Natl. Acad. Sci. USA 89: 1011410118.

Alpen EL, Powers-Risius P. 1981. The relative biological effect of high-Z, high-LET charged particles for spermatogonial killing. Radiat. Res. 88: 132143.

Alpen EL, Powers-Risius P, Curtis SB, DeGuzman R. 1993. Tumorigenic potential of high-Z, high-LET charged-particle radiations. Radiat. Res. 136: 382-391.

Alpen EL, Powers-Risius P, Curtis SB, et al. 1994. Fluence-based relative biological effectiveness for charged particle carcinogenesis in mouse Harderian gland. Adv. Space Res. 14: 573-581.

Ames BN, Lee FD, Durston WE. 1973. An improved bacterial test system for the detection and classification of mutagens and carcinogens. Proc. Natl. Acad. Sci. USA 70: 782-786.

Ames BN, Magaw R, Gold LS. 1987. Ranking possible carcinogenic hazards. Science 236: 271-280.

Ames BN, Gold LS. 1991. Endogenous mutagens and the causes of aging and cancer. Mutation Res. 250: 3-16.

Ames BN, Gold LS, Willett WC. 1995. The causes and prevention of cancer. Proc. Natl. Acad. Sci. USA. 92: 5258-5265.

Anderson A, Woloschak GE. 1992. Cellular pronto-oncogene expression following exposure of mice to $\gamma$ rays. Radiat. Res. 130: 340-344.

Anderson, AJ, Su JH, Cotman CW. 1996. DNA damage and apoptosis in Alzheimer's disease: co-localization with c-Jun immuno reactivity, relationship to brain area, and effect of postmortem delay. J. Neurochem. 16: 1710-1719.

Anscher MS, Kong F, Murase T, Jirtle RL. 1995. Normal tissue injury after cancer therapy is a local response exacerbated by an endocrine effect of TGF $\beta$. Brit. J. Radiat 68: 331-333.

Arends MJ, MacGregor AH, Wyllie AH. 1994. Apoptosis is inversely related to necrosis and determines net growth in tumors bearing constitutively expressed myc, ras and HPV oncogenes. Am. J. Pathol. 144: 1045-1057. 
Arnheim N, Cortopassi GA. 1992. Deleterious mitochondrial mutations accumulate in aging human tissue. Mutation Res. 275: 157-167.

Arnheim N, Boice J, Cox R, et al. 1993. Report on a workshop to examine methods to arrive at risk estimates for radiation-induced cancer in the human based on laboratory data. Radiat. Res. 135: 434-437.

Artuso M, Esteve A, Bresil H, et al., 1995. The role of the Ataxia telangiectasia gene in the p53, WAF1/CIP1 (p21) and GADD45-mediated response to DNA damage produced by ionizing radiation. Oncogene 11: 1427-1435.

Ashby J, Tennant RW. 1991. Definitive relationships among chemical structure, carcinogenicity and mutagenicity for 301 chemicals tested by the $U$. S. NTP. Mutation Res. 257: 229-306.

Ashkenas J, Muschler J, Bissell MJ. (1996). The extracellular matrix in epithelial biology: Shared molecules and common themes in distant phyla. Develop. Biol. 180: 433-444.

Averboukh L, Douglas SA, Zhao S, et al. 1996. Better gel resolution and longer $\mathrm{CDNAs}$ increase the precision of differential display. Biotechniques 20: 918-921.

Avery L, Horvitz HR. 1989. Pharyngeal pumping continues after laser killing of the pharygeal nervous system of C. elegans. Neuron 3: 473-485.

Axelrod J, Burch RM, Jelsema CL. 1988. Receptor-mediated activation of phospholipase A2 via GTP-binding proteins: arachidonic acid and its metabolites as second messengers. Trends Neurol. Sci. 11: 117-123.

Azzam EI, de Toledo SM, Raaphorst GP, Mitchell REJ. 1996. Low-dose ionizing radiation decreases the frequency of neoplastic transformation to a level below the spontaneous rate in C3H 10T 1/2 cells. Radiat. Res. 146: 369373.

Baker RJ, Van Den Bussche RA, Wright AJ, et al. 1996. High levels of genetic change in rodents of Chernobyl. Nature 380: 707-708

Balter M. 1995. Chernobyl's thyroid cancer toll. Science 270: 1758-1759.

Band V, Dalal S, Delmolino L. Androphy EJ. 1993. Enhanced degradation of p53 protein in HPV-6 and BPV-1 E6-immortalized human mammary epithelial cells. EMBO J. 12: 1847-1852. 
Bao, CY, Ma A-H, Evans HH, et al., 1995. Molecular analysis of hypoxanine phosphoribosyltransferase gene deletions induced by alpha- and X-irradiation in human lymphoblastoid cells. Mutat. Res., 326: 1-15.

Barcellos-Hoff MH. 1993. Radiation-induced transforming growth factor $\beta$ and subsequent extracellular matrix reorganization in murine mammary gland. Cancer Res. 53: 3880-3886.

Barcellos-Hoff MH. 1996. Latency and activation in the regulation of TGF- $\beta$. J. Mammary Gland Biol. and Neoplasia 1(4): 353-363.

Barcellos-Hoff MH, Derynck R, Tsang ML-S, Weatherbee JA. 1994. Transforming growth factor- $\beta$ activation in irradiated murine mammary gland. J. Clin. Invest. 93: 892-899.

Barcellos-Hoff MH, Aggeler J, Ram TG, Bissell MJ. 1989. Functional differentiation and alveolar morphogenesis of primary mammary cultures on reconstituted basement membrane. Dev. 105(2): 223-35.

Barinaga M. 1996. Forging a path to cell death. Science 273: 735-737; Life-death balance within the cell. Science 274: 724 .

Barlow C, Hirotsune S, Paylor R, et al. 1996. Atm-deficient mice: A paradigm of ataxia telangiectasia. Cell 86: 159-171.

Baverstock K, Egloff B, Pinchera A, et al. 1992. Thyroid cancer after Chernobyl. Nature 359: 21-22.

Beattie W, Meng L, Turner SL, et al. 1995. Hybridization of DNA targets to glass-tethered oligonucleotide probes. Mol. Biotechnol. 4: 213-225.

Becker D, Razskazovskii Y, Callaghan MU, Sevilla MD. 1996. Electron spin resonance of DNA irradiated with a heavy ion beam $\left({ }^{16} \mathrm{O}^{8+}\right)$ : Evidence for damage to the deoxyribose phosphate backbone. Radiat. Res. 146: 361-368.

Bedell MA, Jenkins NA, Copeland NG. 1997a. Mouse models of human disease. Part I: Techniques and resources for genetic analysis in mice. Genes \& Develop. 11:1-10.

Bedell MA, Largaespada DA, Jenkins NA, Copeland NG. 1997b. Mouse models of human disease. Part II: Recent progress and future directions. Genes \& Develop. 11:11-43.

Belyaev IY, Harms-Ringdahl M. 1996. Effects of gamma rays in the 0.5-50-cGy range on the conformation of chromatin in mammalian cells. Radiat. Res. 145: 687-693. 
Bender MA, Gooch PC, Kondo S. 1967. The Gemini 3 S4 spaceflight radiation interaction experiment. Radiat. Res. 31: 91-111.

Bernard K, Auphan N, Granjeaud S, et al. 1996. Multiplex messenger assay: simultaneous, quantitative measurement of expression of many genes in the context of T cell activation. Nucleic Acids Res. 24: 1435-1442.

Bernheimer H, Birkmayer W, Hornykiewicz O, et al. 1973. Brain dopamine and syndromes of Parkinson and Huntington: Clinical, morphological, and neurochemical correlations. J. Neurol. Sci. 20: 425-455.

Berridge MJ, Irvine RF. 1989. Inositol phosphates and cell signalling. Nature 341: 197-205.

Bird RP, Zaider M, Rossi HH, Hall EJ. 1983. The sequential irradiation of mammalian cells with $X$ rays and charged particles of high LET. Radiat. Res. 93: 444-452.

Birnbaumer L. 1991. On the origins and present state of the art of $G$ protein research. J. Recept. Res. 11: 577-585.

Bissell MJ. 1981. The differentiated state of normal and malignant cells or how to define a "normal" cell in culture. Intl. Rev. Cytol. 70: 27-100.

Bissell MJ, Barcellos-Hoff MH. 1987. The influence of extracellular matrix on gene expression: is structure the message? J. Cell Sci. Suppl. 8: 327-43.

Blakely EA. 1992. Cell inactivation by heavy charged particles. Radiat. Environ. Biophys. 31: 181-196.

Blakely EA, Ngo FQH, Curtis SB, Tobias CA. 1984. Heavy ion radiobiologycellular studies. Adv. Radiat. Biol. 11: 295-390.

Blakely EA, Fry RJM. 1995. Radiation protection in space. Radiat. Environ. Biophys. 34: 129-131.

Blakely EA, Daftari IK, Meecham WJ, et al. 1994. Helium-ion-induced human cataractogenesis. Adv. Space Res. 14: 501-505.

Blöcher D, Sigut D, Hannan MA. 1991. Fibroblasts from ataxia telangiectasia (AT) and AT heterozygates show an enhanced level of residual DNA doublestranded breaks after low dose-rate $\gamma$-irradiation as assayed by pulsed field gel electrophoresis. Int. J. Radiat. Biol. 60: 791-802. 
Boerrigter METI, Dollé MET, Martus H-J, et al. 1995 Plasmid-based transgenic mouse model for studying in vivo mutations. Nature 377: 657-659.

Boerrigter METI, Vijg, J. 1997. Sources of variability in mutant frequency determinations in different organs of lac $\mathrm{Z}$ plasmid-based transgenic mice: experimental features and statistical analysis. Environ. Molec. Mutagen (in press).

Bohr VA, Smith CA, Okumoto DS, Hanawalt PC. 1985. DNA repair in an active gene: removal of pyrimidine dimers from the DHFR gene of $\mathrm{CHO}$ cells is much more efficient than in the genome overall. Cell 40: 359-369.

Boice JD Jr. 1996. Risk estimates for radiation exposures. In: Health effects of exposure to low-level ionizing radiation, WR Hendee, FM Edwards, (Eds.), Institute of Physics Publishing, Philadelphia, pp. 237-268.

Boice JD Jr, Preston D, Davis FG, Monson RR. 1991. Frequent chest X-ray fluoroscopy and breast cancer incidence among tuberculosis patients in Massachusetts. Radiation Res. 125: 214-222.

Boice JD Jr, Miller RW. 1992. Risk of breast cancer in ataxia-telangiectasia. New Eng. J. Med. 326: 1357-1358.

Bons N, Jallageas V, Mestre-Frances N, et al. 1995. Microcebus murinus, a convenient laboratory animal model for the study of Alzheimer's disease. Alzheimer's Res. 1: 83-87.

Boothman DA, Bouvard I, Hughes EN. 1989. Identification and characterization of X-ray-induced proteins in human cells. Cancer Res. 49: 2871-2878.

Boothman DA, Wang B, Lee SW. 1991. Induction of tissue-type plasminogen activator by ionizing radiation in human malignant melanoma cells. Cancer Res. 51: 5587-5595.

Boothman DA, Meyers M, Fukunaga N, Lee SW. 1993. Isolation of X-rayinducible transcripts from radioresistant human melanoma cells. Proc. Natl. Acad. Sci. USA. 90: 7200-7204.

Borison HL. 1974. Area postrema: Chemoreceptive trigger zone for emesis - is that all? Life Sci. 14: 1807-1817.

Boudreau N, Sympson CJ, Werb Z, Bissell MJ. 1995. Suppression of ICE and apoptosis in mammary epithelial cells by extracellular matrix. Science 267: 891-893. 
Bowden GT, Jaffe D, Andrews K. 1990. Biological and molecular aspects of radiation carcinogenesis in mouse skin. Radiat. Res. 121: 235-241.

Bowenkamp KE, Hoffman AF, Gerhardt GA, et al., 1995. Glial cell linederived neurotrophic factor supports survival of injured midbrain dopaminergic neurons. J. Comparative Neurol. 355: 479-489.

Brach MA, Hass R, Sherman ML, et al. 1991. Ionizing radiation induces expression and binding activity of nuclear factor kappa B. J. Clin. Invest. 88: 691-695.

Brennan KM, Roos MS, Budinger TF, et al. 1993. A study of radiation necrosis and edema in the canine brain using positron emission tomography and magnetic resonance imaging. Radiat. Res. 134: 43-53.

Brenner DJ, Medvedovsky C, Huang Y, et al. 1991. Accelerated heavy particles and the lens. VI. RBE studies at low doses. Radiat. Res. 128: 73-81.

Bronson RT, Lipman RD. 1991. Reduction in rate of occurrence of age-related lesions in dietary restricted laboratory mice. Growth, Develop. Aging 55: 184196.

Brown JR, Ye H, Bronson RT et al. 1996. A defect in nurturing in mice lacking the immediate early gene fosB Cell 86: 297-309.

Buchkovich KJ, Greider CW. 1996. Telomerase regulation during entry into the cell cycle in normal human T cells. Molec. Biol. Cell \&: 1443-1454.

Bücker, H, Horneck G. 1975. Studies on the effects of cosmic HZE particles on different biological systems in the Biostack experiments I and II flown onboard of Apollo 16 and 17. In: Radiation Research., OF Nygaard, HI Adler, WK Sinclair, (Eds.) Academic Press, New York, pp. 1138-1151.

Burnett DM, Daniell LC, Zahniser NR. 1990. Decreased efficacy of inositol 1, 4, 5-triphosphate to elicit calcium mobilization from cerebrocortical microsomes of aged rats. Mol. Pharm. 37: 566-571.

Burns FJ, Hosselet S, Garte S. 1989. Extrapolations of rat skin tumour incidence: dose, fractionation, and linear energy transfer. In: Proceedings of the 14th LH Gray Conference, Low Dose Radiation Biological Bases of Risk Assessment. Taylor, Frances, (Eds.), London, pp. 571-584.

Burns FJ, Jin Y, Koenig KL, Hosselet S. 1993. The low carcinogenicity of electron radiation relative to argon ions in rat skin. Radiat. Res. 135: 178-188. 
Cairns P, Palascik TJ, Eby Y, et al. 1995. Frequency of homozygous deletion at p16/CDKN2 in primary human tumors. Nature Genetics 11: 210-212.

Caizzo VJ, Haddad F, Baker MJ, et al. 1996. Microgravity-induced transformations of myosin isoforms and contractile properties of skeletal muscle. J. Appl. Physiol. 81: 123-132.

Call KM, Glaser T, Ito CY, et al. 1990. Isolation and characterization of a zinc finger polypeptide gene at the human chromosome 11 Wilm's tumor locus. Cell 60: 509-520.

Campisi J. 1996. Replicative senescence: An old lives' tale? Cell 84: 497-500.

Canman CE, Kastan MB. 1995. Induction of apoptosis by tumor suppressor genes and oncogenes. Seminars Cancer Biol. 6: 17-25.

Cann CE, Adachi RR. 1983. Bone resorption and mineral excretion in rats during spaceflight. Am J. Physiol. 244: R327-R331.

Carnes BA, Fritz TE. 1993. Continuous irradiation of beagles with gamma rays. Radiat. Res. 136: 103-110.

Carney JM, Starke-Reed PE, Oliver CN, et al. 1991. Reversal of age-related increase in brain protein oxidation, decrease in enzyme activity, and loss in temporal and spatial memory by chronic administration of the spin-trapping compound N-tert-butyl- $\alpha$-phenylnitrone. Proc. Natl. Acad. Sci. USA. 88: 36333636 .

Carr AM. 1996. Checkpoints take the next step. Science 271: 314-315.

Casarett GW, Eddy HA. 1968. Fractionation of dose in radiation-induced male sterility. In: Mammalian Radiation Biology, DG Brown, RG Cragle, TR Noonan, (Eds.), CONF-680410 Biology and Medicine (TID-4500), pp. 14.1-14.10.

Chalfie M, Tu Y, Euskirchen G, et al. 1994. Green fluorescent protein as a marker for gene expression. Science 263: 802-805.

Chameaud J, Masse R, Marin M. 1985. Lung cancer induction by radon daughters in rats (present state of data on low-dose exposures). In: Occupational radiation safety in mining: Vol. 1, H Stocker, (Ed.), Heritage Publications, Petersborough, Canada, pp. 350-353.

Charalambous A, Tluczek L, Frey KA, et al. 1995. Synthesis and biological evaluation in mice of $\left(2-\left[{ }^{11} C\right]\right.$ methoxy) - 6', $7^{\prime}$ - dihydrorotenol, a second generation rotenoid for marking mitochondrial complex I activity. Nucl. Med. Biol. 22: 491-496. 
Charles HC, Lazeyras F, Krishnan KR, et al. 1994. Proton spectroscopy of human brain: effects of age and sex. Prog. Neuropsychopharmacol. Biol. Psychiatry 18: 995-1004.

Chaudhry MA, Jiang Q, Ricanati M, et al. 1996. Characterization of multilocus lesions in human cells exposed to $X$ radiation and radon. Radiat. Res. 145: 3138.

Chauser B, Morris C, Field SB. 1977. The effects of fast neutrons and X-rays on the subependymal layer of the rat brain. Radiology, Suppl 2, 122: 821-823.

Chee M, Yang R, Hubbell E, et al. 1996. Accessing genetic information with high density DNA arrays. Science 274: 610-614.

Chen DJ, Carpenter S, Hanks T. 1992. Mutagenic effects of alpha particles on normal human skin fibroblasts. In: Proceedings of the 29th Hanford Symposium on Health and the Environment - Indoor Radon and Lung Cancer: Reality or Myth? Part 2, FT Cross, (Ed.), Batelle Press, Columbus, OH, pp. 569-580.

Chen X, Bargonetti J, Prives C. 1995. p53, through p21 (WAF1/CIP1), induces cyclin D1 synthesis. Cancer Res. 55: 4257-4263.

Chen X, Ko LJ, Jayaraman L, Prives C. 1996. p53 levels, functional domains and DNA damage determine the extent of the apoptotic response of tumor cells. Genes \& Develop. 10: 2438-2451.

Cherbonnel-Lasserre C, Gauny S, Kronenberg A. 1996. Suppression of apoptosis by $b c l-2$ or $b c l-\mathrm{X}_{\mathrm{L}}$ promotes susceptibility to mutagenesis. Oncogene 13: $1489-1497$.

Chiang C-S, McBride WH. 1991. Radiation enhances tumor necrosis factor alpha production by murine brain cells. Brain Res. 566: 265-269.

Chiu S-M, Sokany NM, Friedman LR, Oleinick NL. 1984. Differential processing of ultraviolet or ionizing radiation-induced DNA-protein crosslinks in Chinese hamster cells. Int. J. Radiat. Biol. 46: 681-690.

Chrisp CE, Turke P, Luciano A, et al. 1996. Lifespan and lesions in genetically heterogeneous (four-way cross) mice: A new model for aging research. Vet. Pathol. 33: 735-743.

Chu, G. 1996. Role of the Ku autoantigen in V(D)J recombination and doublestrand break repair. In: Molecular Analysis of DNA Rearrangements in the 
Immune System. R Jesseberger, MR Lieber, (Eds.), Current Topics Microbiol. Immunol. 217: 113-132.

Clapp NK, Darden, EB Jr, Jernigan MC. 1974. Relative effects of whole body sublethal doses of $60-\mathrm{MeV}$ protons and $300 \mathrm{kVp}$ X-rays on disease incidence in RF mice. Radiat. Res. 57: 158-186.

Clark EA, Brugge JS. 1995. Integrins and signal transduction pathways: the road taken. Science 268: 233-239.

Cleaver JE. 1968. Defective repair replication of DNA in xeroderma pigmentosium. Nature 218: 652-656.

Collins S, Lohse MJ, O'Dowd B, et al. 1991. Structure and regulation of G protein-coupled receptors: the $\beta_{2}$ - adrenergic receptor as a model. Vitam. Horm. 46: 1-39.

Colotta F, Polentarutti N, Sironi M, Mantovani A. 1992. Expression and involvement of $c-f o s$ and $c-j u n$ protooncogenes in programmed cell death induced by growth factor deprivation in lymphoid cell lines. J. Biol. Chem. 267: $18278-18283$.

Columbano A. 1995. Cell death: current difficulties in discriminating apoptosis from necrosis in the context of pathological processes in vivo. J. Cell. Biochem. 58: 181-190.

Contrera JF. 1995. Control of dietary intake: Implications for drug evaluation. In: Dietary Restriction: Implications for the Design and Interpretation of Toxicity and Carcinogenicity Studies. RW Hart, DA Neumann, RT Robertson, (Eds.), ILSI Press, Washington, DC, pp. 13-17.

Cools AR, Jaspers R, Schwarz M, et al. 1984. Basal ganglia and switching and motor programs. In: Basal Ganglia Structure and Function. JS McKenzie, RE Kemm, LN Wilcock, (Eds.), Plenum Press, New York. pp. 513-544.

Cooper PK, Löbrich M, Rydberg B, Leadon SA. 1996. Induction and repair of oxidative base damage in human cells exposed to densely ionizing radiation. Radiat. Res. Soc. Abstract P10-185.

Cooper PK, Nouspikel T, Clarkson SG, Leadon SA. 1997. Defective transcription-coupled repair of oxidative base damage in Cockayne syndrome patients from xeroderma pigmentosum group G. Science 275: 990-993.

Cortopassi GA, Shibata D, Soong NW, Arnheim N. 1992. A pattern of accumulation of somatic deletion of mitochondrial DNA in aging human tissues. Proc. Natl. Acad. Sci. USA 89: 7370-7374. 
Cortopassi G, Liu Y. 1995. Genotypic selection of mitochondrial and oncogenic mutations in human tissue suggests mechanisms of age-related pathophysiology. Mutation Res. 338: 151-159.

Cox R, Thacker J, Goodhead DT, Munson RJ. 1977. Mutation and inactivation of mammalian cells by various ionizing radiations. Nature 267: 425-427.

Cox $A B$, Salmon $Y L$, Lee $A C$, et al. 1993. Progress in the extrapolation of radiation cataractogenesis data across longer-lived mammalian species. In: Biological effects and physics of solar and galactic cosmic radiation. CE Swenberg, G Horneck, EG Stassinopoulos, (Eds.), NATO ASI Series A: Life Sciences 243A. Plenum Press, New York, pp. 177-184.

Cross FT, Palmer RF, Dagle GE, et al. 1984. Influence of radon daughter exposure rate, unattached fraction and disequilibrium on occurrence of lung tumors. Radiat. Protec. Dosim., 7: 381-384.

Cui W, Fowlis DJ, Bryson S, et al. 1996. TGF $\beta 1$ inhibits the formation of benign skin tumors, but enhances progression to invasive spindle carcinomas in transgenic mice. Cell 86: 531-542.

Curtis SB. 1970. The effect of track structure on OER at high-LET. In: Charged Particle Tracks in Solids and Liquids, Physical Society, London, pp. 140-142.

Curtis SB. 1993. Relating space radiation environments to risk estimates. In: Biological Effects and Physics of Solar and Galactic Cosmic Radiation, Part B, CE Swenberg, G Hornbeck, EG Stassinopoulos, et al., (Eds.), Plenum Press, NewYork. pp. 817-829.

Curtis SB, Letaw JR. 1989. Galactic cosmic rays and cell-hit frequencies outside the magnetosphere. Adv. Space Res. 9: 293-298.

Curtis SB, Townsend LW, Wilson JW, et al. 1992. Fluence-related risk coefficients using the Harderian gland data as an example. Adv. Space Res 12: 407-416.

Curtis SB, Nealy JE, Wilson JW. 1995. Risk cross sections and their application to risk estimation in the galactic cosmic ray environment. Radiat. Res. 141: 57-65.

Curtis SB, Vasquez ME, Wilson JW, et al . 1997. Cosmic ray hit frequencies in typical sites in the central nervous system. Adv. Space Res. (in press). 
Dalal S, Gao Q, Androphy EJ, Band V. 1996. Mutational analysis of human papillomavirus type $16 \mathrm{E} 6$ demonstrates that p53 degradation is necessary for immortalization of mammary epithelial cells. J. Virol. 70: 683-688.

D'Ambrosio SM, Slazinski L, Whetstone JW, Lowney E. 1981. Excision repair of UV-induced pyrimidine dimers in human skin in vivo. J. Invest. Derm. 77: 311-313.

D'Amelio FE, Kraft LM, Benton EV, Miguel J. 1982. An electron-microscopic study of the brain of the fruit fly, Drosophila melanogaster, exposed to highLET krypton, ${ }^{84} \mathrm{Kr}$ particle radiation. Acta. Neuropathol. 57: 37-44.

D'Amelio F, Kraft LM, D'Antoni-D'Amelio et al. 1984. Ultrastructural findings in the brain of fruit flies (Drosophlia melanogaster) and mice exposed to high-energy particle radiation. Scan. Electron Microscopy 11: 801812.

Davis FG, Boice JD Jr, Hrubec Z, Monson RR. 1989. Cancer mortality in a radiation-exposed cohort of Massachusetts tuberculosis patients. Cancer Res. 49: 6130-6136.

De Lange, T. 1994. Activation of telomerase in a human tumor. Proc. Natl. Acad. Sci. USA 91: 2882-2885.

DeBry RW, Seldin MF. 1996. Human/mouse homology relationships. Genomics 33: 337-351.

de Vries A, Van Oostrom CT, Hofhuis FM, et al. 1995. Increased susceptibility to ultraviolet- $\mathrm{B}$ and carcinogens of mice lacking the DNA excision repair gene XPA. Nature 377: 169-173.

DiChiro G, Oldfield E, Wright DC, et al. 1988. Cerebral necrosis after radiotherapy and/or intra-arterial chemotherapy for brain tumors: PET and neuropathologic studies. Am. J. Roentgenol. 150: 189-197.

Dimri GP, Campisi J. 1994. Molecular and cell biology of replicative senescence. Cold Spring Harbor Symposia on Quantitative Biology 59: 67-73.

Dollé MET, Martus H-J, Gossen JA, et al. 1996. Evaluation of a plasmid-based transgenic mouse model for detecting in vivo mutations. Mutagenesis 11: 111-118.

Donehower LA, Harvey M, Vogel H, et al. 1995. Effects of genetic background on tumorigenesis in p53-deficient mice. Molec. Carcinogenesis 14: 16-22. 
Dooms GC, Hecht S, Brant-Zawadzki M, et al. 1986. Brain radiation lesions. MR Imaging. Radiology 158: 149-155.

Douglas GR, Gingerich JD, Gossen JA, Bartlett SA. 1994. Sequence spectra of spontaneous lacZ gene mutations in transgenic mouse somatic and germline tissues. Mutagenesis 9: 451-458.

Doyle WK, Budinger TF, Valk PE, et al. 1987. Differentiation of cerebral radiation necrosis from tumor recurrence by $18 \mathrm{FDG}$ and $82 \mathrm{Rb}$ positron emission tomography. J. Comput. Assist. Tomagr. 11: 563-567.

Dubrova YE, Jeffreys AJ, Malashenko AM. 1993. Mouse minisatellite mutations induced by ionizing radiation. Nature Genetics 5: 92-94.

Dubrova YE, Nesterov VN, Krouchinsky NG, et al. 1996. Human minisatellite mutation rate after the Chernobyl accident. Nature 380: 683-686.

Ducy P, Desbois C, Boyce B, et al. 1996. Increased bone formation in osteocalcin-deficient mice. Nature 382: 448-452.

Easton DF, Bishop DT, Ford D, Crockford. The Breast Cancer Linkage Consortium. 1993. Genetic linkage analysis in familial breast and ovarian cancer. Results from 214 families. Am. J. Hum. Genet. 52: 678-701.

Ehrhart EJ, Gillette EL, Barcellos-Hoff MH. 1996. Immunohistochemical evidence of rapid extracellular matrix remodeling after iron-particle irradiation of mouse mammary gland. Radiat. Res 145: 157-162.

Ehrhart EJ, Segarini P, Tsang ML-S Barcellos-Hoff MH. Quantitative and functional in situ evidence of radiation-induced latent transforming growth factor-beta activation (Submitted).

Elkind MM, Han A, Hill CK. 1984. Error-free and error-prone repair in radiation-induced neoplastic cell transformation. In: Radiation carcinogenesis: Epidemiology and biological significance. JD Boice, JF Fraumeni , (Eds.), Raven Press, New York, pp. 303-318.

Elkind MM, Gotchy RL, Bedford J, et al. 1990. Cellular and molecular research to reduce uncertainties in estimates of health effects from low level radiation: A feasibility study. U.S. Nuclear Regulatory Comm., Report No. NUREG/CR5635.

Ellis NA, Groden J, Ye T-Z, et al. 1995. The Bloom's syndrome gene product is homologous to recQ helicases. Cell 83: 655-666. 
Ellis RE, Yuan J, Horvitz HR. 1991. Mechanisms and functions of cell death. Ann. Rev. Cell Biol. 7: 663-698.

Elston CW, Ellis IO. 1991. Pathological prognostic factors in breast cancer. I. The value of histological grade in breast cancer. Experience from a large study with term follow-up. Histopathol. 19: 403-410.

Eng, C, Li FP, Abramson DH, et al. 1993. Mortality from second tumors among long-term survivors of retinoblastoma. J. Natl. Cancer Inst. 85: 11211128 .

Eng C, Fraumeni JF, Li FP. 1997. Meeting report -- Third International Workshop on collaborative interdisciplinary studies of p53 and other predisposing genes in Li-Fraumeni Syndrome. Cancer Epidem. Biomark. Prevent. (In press).

Erickson BH. 1976. Effect of ${ }^{60} \mathrm{Co}$ radiation on stem and differentiating spermatogonia of the post puberal rat. Radiat. Res. 68: 433-448.

Estus S, Zaks WJ, Freeman RS, et al. 1994. Altered gene expression in neurons during programmed cell death: identification c-jun as necessary for neuronal apoptosis. J. Cell Biol. 127: 1717-1727.

Evans RD. 1966. The effect of skeletally deposited alpha-ray emitters in man. Brit. J. Radiol. 39: 881-895.

Evans VG. 1993. Multiple pathways to apoptosis. Cell Biol. Int. 17: 461-476.

Evans HH. 1994. The prevelance of multilocus lesions in radiation-induced mutants. Radiat. Res. 137: 131-144.

Ewald D, Li M, Efrat S, et al. 1996. Time-sensitive reversal of hyperplasia in transgenic mice expressing SV40 T antigen. Science 273: 1384-1386.

Fanton JW, Golden JG. 1991. Radiation-induced endometriosis in Macaca mulatta. Radiat. Res. 126: 141-146.

Fässler R, Martin K, Forsberg E, et al. 1995. Knockout mice: How to make them and why. The immunological approach. Int. Arch. Allergy Immunol. 106: 323-334.

Fearon ER, Vogelstein B. 1990. A genetic model for colorectal tumorigenesis. Cell 61: 759-767. 
Felber M, Burns FJ, Garte SJ. 1992. Amplification of the c-myc oncogene in radiation-induced rat skin tumors as a function of linear energy transfer and dose. Radiat. Res. 131: 297-301.

Fero ML, Rivkin M, Tasch M, et al. 1996. A syndrome of multiorgan hyperplasia with features of gigantism, tumorigenesis, and female sterility in p27kip1-deficient mice. Cell 85: 733-744.

Fey EG, Penman S. 1988. Nuclear matrix proteins reflect cell type of origin in cultured human cells. Proc. Natl. Acad. Sci. USA. 85: 121-125.

Field SJ, Tsai F-Y, Kuo F, et al. 1996. E2F-1 functions in mice to promote apoptosis and suppress proliferation. Cell 85: 549-561.

Fike JR, Cann CE, Davis RL, et al., 1984. Computed tomography analysis of the canine brain: effects of hemibrain X irradiation. Radiat. Res. 99: 294-310.

Fike JR, Cann CE, Turowski K, et al. 1988. Radiation dose response of normal brain. Int. J. Radiat. Oncol. Biol. Physics. 14: 63-70.

Fingert HJ, Campisi J, Pardee AB. 1993. Cell proliferation and cancer. In: Cancer Medicine, 3rd edition, JF Holland, E Frei III, RC Bast, Jr., DW Kuje, DL Morton, RR Weichselbaum, (Eds.), Lea and Febiger, Philadelphia, Vol 1, pp. 114 .

Finkelstein JN, Johnston CJ, Baggs R, Rubin P. 1994. Early alterations in extracellular matrix and transforming growth factor beta gene expression in mouse lung indicative of late radiation fibrosis. Int. J. Radiat. Oncol. Biol. Phys. 28: 621-631.

Fischer W, Wictorin K, Bjorklund A, et al. 1987. Amelioration of cholinergic neurons atrophy and spatial memory impairment in aged rats by nerve growth factor. Nature 329: 65-67.

Fischer W, Bjorklund A, Chen K, Gage FH. 1991. NGF improves spatial memory in aged rodents as a function of age. J. Neurosci. 11: 1889-1906.

Fishel R, Lescoe, MK, Rao MRS, et al. 1994. The human mutator gene homolog MSH2 and its association with hereditary nonpolyposis colon cancer. Cell 75: 1027-1038.

Fisher SK, Agranoff BW. 1987. Receptor activation and inositol lipid hydrolysis in neural tissues. J. Neurochem. 258: 7358-7363.

Fisher LJ, Gage FH. 1995. Radical directions in Parkinson's disease. Nature Medicine. 1: 201-203. 
Ford JM, Hanawalt PC. 1995. Li-Fraumeni syndrome fibroblasts homozygous for p53 mutations are deficient in global DNA repair but exhibit normal transcription-coupled repair and enhanced UV resistance. Proc. Natl. Acad. Sci. USA 92: 8876-8880.

Fraga CG, Shigenaga MK, Park JW, et al. 1990. Oxidative damage to DNA during aging: 8-hydroxy-2'-deoxyguanosine in rat organ DNA and urine. Proc. Natl. Acad. Sci. USA 87: 4533-4537.

Frankfurt OS, Robb JA, Sugarbaker EV, Villa L. 1996. Monoclonal antibody to single-stranded DNA is a specific and sensitive cellular marker of apoptosis. Exp. Cell Res. 226: 387-397.

Fraser A, Evan G. 1996. A licence to kill. Cell 85: 781-784.

Frejter WL, McDaniel LD, Johns D, et al. 1992. Correction of xeroderma pigmentosum complementation group $\mathrm{D}$ mutant cell phenotypes by chromosome and gene transfer: Involvement of the human ERCC2 DNA repair Gene. Proc. Natl. Acad. Sci. USA 89: 261-265.

Friedberg EC, Meira LB, Cheo DL. 1997. Database of mouse strains carrying targeted mutations in genes affecting cellular responses to DNA damage. Mutat. Res. 383 N2: 183-188.

Friedman SL, Roll FJ, Boyles J, Arenson DM, Bissell DM. 1989. Maintenance of differentiated phenotyope of cultured rat hepatic lipocytes by basement membrane matrix. J. Biol. Chem. 264(18): 10756-62.

Friguet B, Szweda LI, Stadtman ER. 1994. Susceptibility of glucose-6phosphate dehydrogenase modified by 4-hydroxy-2-nonenal and metalcatalysed oxidation to proteolysis by the multicatalytic protease. Archives Biochem. Biophys. 311: 168-173.

Fry RJM. 1992. The role of animal experiments in estimates of radiation risks. Adv. Radiat. Biol. 16: 181-197.

Fry RJM. 1995. Mice, myths and men. L.S. Taylor Lectures in radiation protection and measurements. No. 18. National Council on Radiation Protection and Measurement.

Fry RJM, Powers-Risius P, Alpen EL, Ainsworth EJ. 1985. High-LET radiation carcinogenesis. Radiat. Res. 104: S188-S195.

Fukasawa K, Choi T, Kuriyama R, et al. 1996. Abnormal centromere amplification in the absence of p53. Science 271: 1744-1747. 
Fuks, Z, Persaud RS, Alfieri A, et al. 1994. Basic fibroblast growth factor protects endothelial cells against radiation-induced programmed cell death in vitro and in vivo. Cancer Res. 54: 2582-2590.

Fukunaga N, Burrows HL, Meyers M, et al. 1992. Enhanced induction of tissue-type plasminogen activator in normal human cells compared to cancer-prone cells following ionizing radiation. Int. J. Radiat. Oncol. Biol. Phys. 24: 949-957

Gale RP, Butturini A. 1990. Use of hematopoietic growth factors in radiation accidents. Int. J. Radiat. Oncol. Biol. Phys. 19: 1291-1295.

Game JC. 1993. DNA double-strand breaks and the rad50 and rad57 genes in Saccharomyces. Seminar Cancer Biol. 4: 73-83.

Games D, Adams D, Alessandrini R, et al. 1995. Alzheimer-type neuropathology in transgenic mice overexpressing V717F $\beta$-amyloid precursor protein. Nature 373: 523-527.

Gash DM, Zhang Z, Ovadia A, et al. 1996. Functional recovery in parkinsonian monkeys treated with GDNF. Nature 380: 252-255.

Garte SJ, Burns FJ, Ashkenazi-Kimmel T, et al. 1990. Amplification of the c$m y c$ oncogene during progression of radiation-induced rat skin tumors. Cancer Res. 50: 3073-3077.

Gavrieli Y, Sherman Y, Ben-sasson SA. 1992. Identification of programmed cell death in situ via specific labelling of nuclear DNA fragmentation. J. Cell Biol. 119: 493-501.

Gazenko OG, Adamovich BA, Grigoriev YG, et al. 1978. Radiobiological experiment aboard the biosatellite COSMOS 690. Aviat. Space Environ. Med. 49: 42-46.

Gelb BD, Shi G-P, Chapman HA, Desnick RJ. 1996. Pycnodysostosis, a lysosomal disease caused by cathepsin K deficiency. Science 273: 1236-1238.

Getzenberg RH, Coffey DS. 1991. Identification of nuclear matrix proteins in the cancerous and normal rat prostate. Cancer Res. 51: 6514-6520.

Giros B, Jaber M, Jones SR, et al. 1996. Hyperlocomotion and indifference to cocaine and amphetamine in mice lacking the dopamine transporter. Nature 379: 606-612. 
Gold LS, Bernstein L, Magaw R, Slone TH. 1989. Interspecies extrapolation in carcinogenesis: Prediction between rats and mice. Environ. Health Perspect. 81: 211-219.

Gold LS, Manley NB, Slone TH, et al. 1993. The fifth plot of the Carcinogenic Potency Database: results of animal bioassays published in the general literature through 1988 and by the National Toxicology Program through 1989. Environ. Health Perspect. 100: 65-168.

Gossen JA, de Leeuw WJF, Tan CHT, et al. 1989. Efficient rescue of integrated shuttle vectors from transgenic mice: a model for studying gene mutations in vivo. Proc. Natl. Acad. Sci. USA 86: 7971-7975.

Gossen JA, de Leeuw WJF, Verwest A, et al. 1991. High somatic mutation frequencies in a $\mathrm{LacZ}$ transgene integrated on the mouse $\mathrm{X}$-chromosome. Mutation Res. 250: 423-429.

Gossen M, Bujard H. 1992. Tight control of gene expression in mammalian cells by tetracyline-responsive promotors. Proc. Natl. Acad. Sci. USA 89: 55475551.

Gossen JA, Martus H-J, Wei JY, Vijg J. 1995a. Spontaneous and X-ray-induced deletion mutations in a lac Z plasmid-based transgenic mouse model. Mutation Res. 331: 89-97.

Gossen M, Friendlieb S, Bender G, et al. 1995b. Transcriptional activation by tetracylines in mammalian cells. Science 268: 1766-1769.

Grdina DJ, Kataoka Y, Basic I, Perrin J. 1992. The radioprotector WR-2721 reduces neutron-induced mutations at the hypoxanthine-guanine phosphoribosyl transferase locus in mouse splenocytes when administered prior to or following irradiation. Carcinogenesis 13: 811-814.

Grdina DJ, Shigematsu N, Dale P, et al. 1995. Thiol and disulfide metabolites of the radiation protector and potential chemopreventive agent WR-2721 are linked to both its anti-cytotoxic and anti-mutagenic mechanisms of action. Carcinogenesis 16: 767-774.

$\mathrm{Gu} \mathrm{H}$, Marth JD, Orban PC, et al. 1994. Deletion of a DNA polymerase $\beta$ segment in T cells using cell type-specific gene targeting. Science 265: 103-106.

Gurney ME, Pu H, Chiu AY, et al. 1994. Motor neuron degeneration in mice that express a human $\mathrm{Cu}, \mathrm{Zn}$ superoxide dismutase mutation. Science 264: $1772-1775$. 
Haag JD, Gould MN. 1994. Mammary carcinoma regression induced by perillyl alcohol, a hydroxylated analog of limonene. Cancer Chemother. Pharmacol. 34: 477-483.

Habrakan Y, Laval F. 1991. Enhancement of 1,3 bis (2-chloroethyl)-1nitrosourea resistance by gamma-irradiation or drug pretreatment in rat hepatoma cells. Cancer Res. 51: 1217-1220.

Haimovitz-Friedman A, Vlodavsky I, Chaudhuri A, et al. 1991. Autocrine effects of fibroblast growth factor in repair of radiation damage in endothelial cells. Cancer Res. 51: 2552-2558.

Haimovitz-Friedman A, Balaban N, McLoughlin M, et al. 1994a. Protein kinase $C$ mediates basic fibroblast growth factor protection of endothelial cells against radiation-induced apoptosis. Cancer Res. 54: 2591-2597.

Haimovitz-Friedman A, Kan C-C, Ehleiter D, et al. 1994b. Ionizing radiation acts on cellular membranes to generate ceramide and initiate apoptosis. J. Expt. Med. 180: 525-535.

Hainaut P, Milner J. 1993. Redox modulation of p53 conformation and sequence-specific DNA binding in vitro. Cancer Res. 53: 4469-4473.

Hakem R, de la Pompa JL, Sirard C, et al. 1996. The tumor suppressor gene Brca1 is required for embryonic cellular proliferation in the mouse. Cell 85: 1009-1023.

Hakoda M, Akiyama M, Kyoizumi S, et al. 1988. Increased somatic cell frequency in atomic bomb survivors. Mutation Res. 201: 29-48.

Hall EJ, Rossi HH, Zaider M, et al. 1982. The role of neutrons in cell transformation research. II. Experimental. In: Neutron Carcinogenesis. JJ Broerse, GB Gerber, (Eds.), Commission of the European Communities, Luxemborg, pp. 381-?

Hallahan DE, Gius D, Kuchibhotla J, et al. 1993a. Radiation signaling mediated by jun activation following dissociation from a cell type-specific repressor. J. Biol. Chem. 268: 4903-4907.

Hallahan DE, Haimovitz-Friedman A, Kufe DW, et al. 1993b. The role of cytokines in radiation oncology. In: Important Advances in Oncology. VT DeVita, S Hellman, SA Rosenberg, (Eds.), JB Lippincott Co., Philadelphia, pp. $71-80$. 
Halliwell B, Dizdaroglu M. 1992. The measurement of oxidative damage to DNA by HPLC and GC/MS techniques. Free Radical Research Commun. 16: 75-87.

Han A, Elkind MM. 1979. Transformation of mouse C3H/10T $1 / 2$ cells by single and fractionated doses of $\mathrm{X}$-rays and fission-spectrum neutrons. Cancer Res. 39: 123-130.

Hanawalt PC. 1994. Transcription-coupled repair and human disease. Science 266: 1957-1958.

Hart R, Setlow RB. 1974. Correlation between deoxyribonucleic acid excision repair and life-span in a number of mammalian species. Proc. Natl. Acad. Sci. USA 71: 2169-2173.

Hart RW, Neumann DA, Robertson RT. 1995. Preface In: Dietary Restriction: Implications for the Design and Interpretation of Toxicity and Carcinogenicity Studies. RW Hart, DA Neumann, RT Robertson, (Eds.), ILSI Press, Washington, DC. pp. xxi-xxiv.

Hartley KO, Gell D, Smith GC, et al. 1995. DNA-dependent protein kinase catalytic subunit: A relative of phosphatidylinositol 3-kinase and the ataxia telangiectasia gene product. Cell 82: 1-4.

Hartman PS, Herman RK. 1982. Radiation-sensitive mutants of Caenorhabditis elegans. Genetics 102: 159-178.

Hartwell, LH, Kastan MB. 1994. Cell cycle control and cancer. Science 266: 1821-1827.

Hefti F, 1994. Neurotrophic factor therapy for nervous system degenerative diseases. J. Neurobiol. 25: 1418-1435.

Hei TK, Komatsu K, Hall EJ, Zaider M. 1988a. Oncogenic transformation by charged particles of defined LET. Carcinogenesis. 9: 747-750.

Hei TK, Chen DJ, Hall EJ. 1988b. Mutation induction by charged particles of defined linear energy transfer. Carcinogenesis 9: 1233-1236.

Hei TK, Piao CQ, Willey JC, et al. 1994. Malignant transformation of human bronchial epithelial cells by radon-simulated alpha particles. Carcinogenesis, 15: 431-437.

Hengartner MO, Horvitz HR. 1994. C. elegans cell survival gene ced-9 encodes a functional homolog of the mammalian proto-oncogene $b c l-2$. Cell 76: 665-676. 
Hickman AW, Jaramillo RJ, Lechner JF, Johnson NF. 1994. Alpha-particleinduced p53 protein expression in a rat lung epithelial cell strain. Cancer Res. 54: $5797-5800$.

Ho L, Hanawalt PC. 1992. Gene-specific DNA repair in terminally differentiating rat myoblasts. Mutat. Res., DNA Repair 255: 123-141.

Hoffman RM. 1994. Orthotopic is orthodox: Why are orthotopic-transplant metastatic models different from other models. J. Cell. Biochem. 56: 1-3.

Holden C. 1996a. Invulnerable vole found at Chernobyl. Science: 273: 313.

Holden C. 1996b. Gene modulates prostate cancer risk. Science 272: 1271.

Holley WR, Chatterjee A. 1996. Clusters of DNA damage induced by ionizing radiation: Formation of short DNA fragments. I. Theoretical modelling. Radiat. Res. 145: 188-199.

Hollstein M, Sidransky D, Vogelstein B, Harris CC. 1991. p53 mutations in human cancers. Science 253: 49-53.

Holt JT, Thompson ME, Szabo C, et al. 1996. Growth retardation and tumor inhibition by BRCA1. Nature Genetics 12: 298-302.

Hong J, Chiang C, Campbell IL, et al. 1995. Induction of acute phase gene expression by brain irradiation. Int. J. Radiat. Oncol. Biol. Phys. 33: 619-626.

Hornsey, S, Myers R, Warren P. 1977. RBE for the two components of weight loss in the mouse testis for fast neutrons relative to X-rays. Int. J. Radiat. Biol. 32: 297-301.

Hsiao K, Chapman P, Nilsens S, et al. 1996. Correlative memory deficits, A $\beta$ elevation and amyloid plaques in transgenic mice. Science 274: 99-102.

Huang TT, Carlson EJ, Leadon SA, Epstein CJ. 1992. Relationship of resistance to oxygen free radicals to $\mathrm{CuZn}$-superoxide dismutase activity in transgenic, transfected and trisomic cells. FASEB J. 6: 903-910.

Huang J-C, Hsu DS, Kazantsev A, Sancar A. 1994. Substrate spectrum of human excinuclease: repair of abasic sites, methylated bases, mismatches, and bulky adducts. Proc. Natl. Acad. Sci. USA 91: 12213-12217.

Hudson J, Granholm A-C, Gerhardt GA, et al. 1995. Glial cell line-derived neurotrophic factor augments midbrain dopaminergic circuits in vivo. Brain Res. Bull. 36: 425-432. 
Huguet F, Drieu K, Piriou A. 1994. Decreased cerebral 5-HT1A receptors during aging: reversal by Ginkgo biloba extract (Egb 761). J. Pharm. Pharmacol. 46: 316-318.

Hui TE, Poston JW, Fisher DR. 1990. The microdosimetry of radon decay products in the respiratory tract. Radiat. Protein Dosim. 31: 405-411.

Hunter T. 1994. 1001 protein kinases redux -- towards 2000. Seminars Cell Biol. 5: 367-376.

Hussussian CJ, Struewing JP, Goldstein AM, et al. 1994. Germline p16 mutations in familial melanoma. Nature Genetics 8: 15-21.

Hynes RO. 1992. Integrins: versatility, modulation and signalling in cell adhesion. Cell 69: 11-25.

Ikpeme S, Löbrich M, Akpa T, et al. 1995. Heavy ion-induced DNA doublestrand breaks with yeast as a model system. Radiat. Environ. Biophys. 34: 9599.

ICRP (International Commission on Radiological Protection). 1991. 1990 recommendations of the ICRP, Publication No. 60, Pergamon Press, Elmsford, NY.

Ito H, Hatazawa J, Murikami M, et al. 1995. Aging effect on neutral amino acid transport at the blood-brain barrier measured with L-[2-18 F] fluorophenylalanine and PET. J. Nucl. Med. 36: 1232-1237.

Jacks T, Weinberg RA. 1995. Cell-cycle control and its watchman. Nature 381: 643-644.

Jacks T, Shih TS, Schmitt EM, et al. 1994. Tumour predisposition in mice heterozygous for a targeted mutation in Nf1. Nature Genetics 7: 353-361.

Jain RK. 1996. Delivery of molecular medicine to solid tumors. Science 271: 1079-1080.

James AC. 1995. Dosimetry of inhaled radon and thoron progeny, Government Reports, Announcements, and Index, 2, DOE, Washington, DC.

Jeffreys AJ, Wilson V, Thein SL. 1985. Individual-specific "fingerprints" of human DNA. Nature 316: 76-79. 
Jeffreys AJ, Neumann R, Wilson V. 1990. Repeat unit sequence variation in minisatellites: A novel source of DNA polymorphism for studying variation and mutation by single molecule analysis. Cell 60: 473-485.

Jeggo PA, Taccioli GE, Jackson SP. 1995. Menage a trois: double strand break repair, V(D)J recombination and DNA-PK. Bioessays 17: 949-957.

Jensen RA, Thompson ME, Jetton TL, et al. 1996. BRCA1 is secreted and exhibits properties of a granin. Nature Genetics 12: 303-308.

Jiang T-N, Lord BI, Hendry JH. 1994. Alpha particles are extremely damaging to developing hemopoiesis compared to gamma irradiation. Radiat. Res. 137: 380-384.

Jin Y, Burns FJ, Garte SJ. 1992. Oncogene amplication detected by in situ hybridization in radiation-induced skin cancers in rats. Radiat. Res. 132: 193199.

Johns DR. 1995. Mitochondrial DNA and disease. New Eng. J. Med. 333: 638644.

Johnson RL, Rothman AL, Xie J, et al. 1996. Human homolog of patched, a candidate gene for the basal cell nevus syndrome. Science 272: 1668-1671.

Johnson TE, Nelson GA. 1991. Caenorhabditis elegans: A model system for space biology studies. Experiment. Gerontol. 26: 299-309.

Joiner MC. 1994. Induced radioresistance: an overview and historical perspective. Int. J. Radiat. Biol. 65: 79-84.

Jones SN, Roe AE, Donehower LA, Bradley A. 1995. Rescue of embryonic lethality in $m d m 2$-deficient mice by absence of p53. Nature 378: 206-208.

Joseph JA, Dalton TK, Hunt WA. 1988a. Age-related decrements in the muscarinic enhancement of $\mathrm{K}^{+}$-evoked release of endogenous striatal dopamine: An indicator of altered cholinergic-dopaminergic reciprocal inhibitory control in senescence. Brain Res. 454: 140-148.

Joseph JA, Dalton TK, Roth GS, Hunt WA. 1988b. Alterations in muscarinic control of striatal dopamine autoreceptors in senescence: a deficit at the ligand-muscarinic receptor interface. Brain Res. 454: 149-155.

Joseph JA, Roth GS. 1991. Loss of agonist receptor efficacy in senescence: Possible decrements in second messenger function and calcium mobilization. In: Challenges in Aging: The 1980 Sandoz Lectures in Gerontology, M 
Bergener, M Ermini, HB Stahelin, (Eds.), Academic Press, New York, pp. 167185.

Joseph JA, Hunt WA, Rabin BM, Dalton TK. 1992. Possible "accelerated aging" induced by ${ }^{56} \mathrm{Fe}$ heavy particle irradiation: Implications for manned space flights. Radiat. Res. 130: 88-93.

Joseph JA, Hunt WA, Rabin BM, Dalton TK. 1993. Deficits in the sensitivity of striatal muscarinic receptors induced by ${ }^{56} \mathrm{Fe}$ heavy particle irradiation: Further "age-radiation parallels". Radiat. Res. 135: 257-261.

Joseph JA, Villalobos-Molina R, Denisova N, et al. 1996. Age differences in sensitivity to $\mathrm{H}_{2} \mathrm{O}_{2}$ - or $\mathrm{NO}$-induced reductions in $\mathrm{K}^{+}$-evoked dopamine release from superfused striatal slices: Reversals by PBN or Trolox. Free Rad. Biol. Med. 20: 821-830.

Jostes RF. 1996. Genetic, cytogenetic, and carcinogenic effects of radon: a review. Mutation Res. 340: 125-139.

Jostes RF, Fleck EW, Morgan TL, et al. 1994. Southern blot and polymerase chain reaction exon analyses of HPRT-mutations induced by radon and radon progeny. Radiat. Res. 137: 371-379.

Juràskovà V; Kozubek S. 1996. The response of mouse lymphosarcoma cells to continuous gamma radiation. Radiat. Res. 146: 88-92.

Kadhim MA, Macdonald DA, Goodhead DT, et al. 1992. Transmission of chromosomal instability after plutonium alpha-particle irradiation. Nature 355: $738-740$.

Kadhim MA, Lorimore SA, Hepburn MD, et al. 1994. Alpha-particle-induced chromosomal instability in human bone marrow cells. Lancet 344: 987-988.

Kahn P. 1996. Coming to grips with genes and risk. Science 274: 496-498.

Kamb A, Gruis NA, Weaver-Feldhaus J, et al. 1994. A cell cycle regulator potentially involved in genesis of many tumor types. Science 264: 436-440.

Kamel HM, Kirk J, Toner PG. 1990. Ultrastructural pathology of the nucleus. Curr. Top. Pathol. 82: 17-89.

Kato H, Schull WJ. 1982. Studies of the mortality of A-bomb survivors, Report 7, Mortality, 1950-1978: Part I, Cancer Mortality, Radiat. Res. 90: 395-432. 
Kato H, Brown CC, Hoel DG, Schull WJ. 1982. Studies of the mortality of Abomb survivors, Report 7, Mortality, 1950-1978: Part II, Mortality from causes other than cancer and mortality in early entrants. Radiat. Res. 91: 243-264.

Katoh M, Inomata T, Horiya N, et al. 1994. Studies on mutations in male germ cells of transgenic mice following exposure to isopropyl methanesulfonate, ethylnitrosourea or X-ray. Mutation Res. 341: 17-28.

Kayalar C, Ord T, Anton R, Bredesen DE. 1996. Cleavage of actin by interleukin $1 \beta$-converting enzyme to reverse DNase I inhibition. Proc. Natl. Acad. Sci. USA 93: 2234-2238.

Kazakov VS, Demidchik EP, Astakhova LN. 1992. Thyroid cancer after Chernobyl. Nature 359: 21.

Keith CT, Schreiber SL, 1995. PIK-related kinases: DNA repair, recombination, and cell cycle checkpoints. Science 270: 50-51.

Kemnitz JW, Weindruch R, Roecker EB, et al. 1993. Dietary restriction of adult male rhesus monkeys: design, methodology and preliminary findings from the first year of study. J. Gerontology 48: B17-B26.

Kemp CJ; Wheldon T, Balmain A. 1994. p53-deficient mice are extremely susceptible to radiation-induced tumorigenesis. Nature Genetics 8: 66-69.

Keng PC, Lee AC, Cos AB. 1982. Effects of heavy ions on rabbit tissues: cataractogenesis. Int. J. Radiat. Biol. 41: 127-137.

Kennedy AR. 1994. Prevention of carcinogenesis by protease inhibitors. Cancer Res. (Suppl.) 54: 1999S-2005S.

Kennedy AR, Little JB. 1978. Protease inhibitors suppress radiation-induced malignant transformation in vitro. Nature 276: 825-826.

Kennedy AR and Little JB. 1981. Effects of protease inhibitors on radiation transformation in vitro. Cancer Res. 41: 2103-2108.

Kennedy AR, Manzone H. 1995. Effects of protease inhibitors on levels of proteolytic activity in normal and premalignant cells and tissues. J. Cell. Biochem. Suppl. 22: 188-194.

Kerr JFR, Wyllie AH, Currie AR. 1972. Apoptosis: a basic biological phenomenon with wide-ranging implications in tissue kinetics. Brit. J. Cancer 26: 239-257. 
Khaidakov M, Young D, Erfle $H$, et al.. 1997. The molecular analysis of mutations of T-lymphocytes from experienced Soviet Cosmonauts. Environ. Molec. Mutagen (in press).

Khan MA, Cross FT, Buschborn L, Brooks AL. 1995. Inhaled radon-induced genotoxicity in Wistar rat, Syrian hamster, and Chinese hamster deep lung fibroblasts in vivo. Mutation Res. 334: 131-137.

Kiefer J, Schenk-Meuser K, Kost M. 1996. Radiation biology. In: Biological and Medical Research in Space. D Moore, P Bie, H Oser, (Eds.), SpringerVerlag, New York, pp. 300-367.

Kim CY, Giaccia AJ, Strulovici B, Brown JM. 1992. Differential expression of protein kinase $C$ protein in lung cancer cell lines by ionizing radiation. Brit. J. Cancer 66: 844-849.

Kim NW, Piatyszek MA, Prowse KR, et al. 1994. Specific association of human telomerase activity with immortal cells and cancer. Science 266: 20112015.

Kinsella TJ. 1989. Effects of radiation therapy and chemotherapy on testicular function. Prog. Clin. Biol. Res. 302: 157-171.

Kinzler KW, Vogelstein B. 1996a. Lessons from hereditary colorectal cancer. Cell 87: 159-170.

Kinzler KW, Vogelstein B. 1996b. What's mice got to do with it? Nature 382: 672 .

Kirchgessner CU, Patil CK, Evans JW, et al. 1995. DNA dependent kinase (p350) as a candidate gene for the murine SCID defect. Science 267: 1178-1182.

Kiser GL, Weinert TA. 1996. Distinct roles of yeast $M E C$ and $R A D$ checkpoint genes in transcriptional inducton after DNA damage and implications for function. Molec. Biol. Cell 7: 703-718.

Kitajima I, Semba I, Noikura T, et al. 1996. Vertebral growth disturbance in rapidly growing rats during 14 days of spaceflight. J. Appl. Physiol. 81: 156-163.

Kiyokawa H, Kineman RD, Manova-Todorova KO, et al. 1996. Enhanced growth of mice lacking the cyclin-dependent kinase inhibitor function of p27kip1. Cell 85: 721-732.

Knudson AG Jr. 1971. Mutation and cancer: Statistical study of retinoblastoma. Proc. Natl. Acad. Sci. USA 68: 820-823. 
Kohler SW, Provost GS, Fieck A, et al. 1991. Spectra of spontaneous and mutagen-induced mutations in the LacI gene in transgenic mice. Proc. Natl. Acad. Sci. USA 88: 7958-7962.

Kordower JH, Winn SR, Liu YT, et al. 1994. The aged monkey basal forebrain: Rescue and sprouting of axotomized basal forebrain neurons after grafts of encapsulated cells secreting human growth factor. Proc. Natl. Acad. Sci. USA 91: 10898-10902.

Kostyuk VA, Potapovich AI, Speransky SD, Maslova GT. 1996. Protective effect of natural flavonoids on rat peritoneal macrophages injury caused by asbestos fibers. Free Rad. Biol. Med. 21: 487-493.

Kozal MJ, Shah N, Shen N, et al. 1996. Extensive polymorphisms observed in HIV-1 clade B protease gene using high density oligonucleotide arrays. Nature Medicine 2: 753-759.

Kramer S, Southard ME, Mansfield CM. 1972. Radiation effects and tolerance of the central nervous system. Front. Radiat. Ther. Oncol. 6: 332-345.

Kramer S, Hendrickson F, Zelen M, Schotz W. 1977. Therapeutic trials in the management of metastatic brain tumors by different time/dose fraction schemes of radiation therapy. Nat. Cancer Inst. Monographs. 46: 213-221.

Krebs W, Krebs I and Worgul BV. 1990. Effects of accelerated iron ions on the retina. Radiat. Res. 123: 213-219.

Kronenberg A, Gauny S, Criddle K, et al. 1995. Heavy ion mutagenesis - linear energy transfer effects and genetic linkage. Radiat. Environ. Biophys. 34: 73-78.

Krontiris TG. 1995. Minisatellites and human disease. Science 269: 1682-1683.

Kuerbitz SJ, Plunkett BS, Walsh WV, Kastan MB. 1992. Wild-type p53 is a cell cycle checkpoint determinant following radiation. Proc. Natl. Acad. Sci. USA 89: 7491-7495.

Kuhl DP, Caskey CT. 1993. Trinucleotide repeats and genome variation. Curr. Opinion Genet. Develop. 3: 404-407.

Kuida K, Lippke JA, Ku G, et al. 1995. Altered cytokine export and apoptosis in mice deficient in interleukin-1 $\beta$ converting enzyme. Science 267: 2000-2003.

Kulkarni AB, Huh CG, Becker D. 1993. Transforming growth factor beta 1 null mutation in mice causes excessive inflammatory response and early death. Proc. Natl. Acad. Sci. USA 90: 770-774. 
Kumar TR, Donehower LA, Bradley A, Matzuk MM. 1995. Transgenic mouse models for tumor-suppressor genes. J. Int. Medicine 238: 233-238.

Kuo T-H, Kubota T, Watanabe M, et al. 1995. Liver colonization competence governs colon cancer metastasis. Proc. Natl. Acad. Sci. USA 92: 12085-12089.

Kyoizumi S, Akigama M, Cologne JB, et al. 1996. Somatic cell mutations at the glycophorin A locus in erythrocytes of atomic bomb survivors: implications for radiation carcinogenesis. Radiat. Res. 146: 43-52.

Land CE. 1995. Studies of cancer and radiation dose among atomic bomb survivors. The example of breast cancer. J. Am. Med. Assoc. 274: 402-407.

Langberg CW, Hauer-Jensen M, Sung C-C, et al. 1994. Expression of fibrogenic cytokines in rat small intestine after fractionated irradiation. Radiother. Oncol. 32: 29-36.

Laramore GE. 1991. Injury to central nervous system after high LET radiation. In: Radiation Injury to the Nervous System. PH Gutin, SA Leibel, GE Sheline, (Eds.), Raven Press, NY, pp. 341-360.

Leach EG, Gunther EJ, Yeasky TM, et al. 1996. Frequent spontaneous deletions at a shuttle vector locus in transgenic mice. Mutagenesis 11: 49-56.

Lee AT, DeSimone C, Cerami A, Bucala R. 1994. Comparative analysis of DNA mutations in lacI transgenic mice with age. FASEB J. 8: 545-550.

Lehmann AR, Bootsma D, Clarkson SG, et al. 1994. Nomenclature of human DNA repair genes. Mutation Res. 315: 41-42.

Lelievre S, Weaver VM, Bissell MJ. 1996. Extracellular matrix signalling from the cellular membrane skeleton to the nuclear skeleton: A model of gene regulation. Recent Prog. Hormone Res. 51: 417-432.

Lett JT, Keng PC, Bergtold DS, Howard J. 1987. Effects of heavy ions on rabbit tissues: induction of DNA strand breaks in retinal photoreceptor cells by high doses of radiation. Radiat. Environ. Biophys. 26: 23-26.

Lett JT, Lee AC, Cox AB. 1991. Late cataractogenesis in Rhesus monkeys irradiated with protons and radiogenic cataract in other species. Radiat. Res. 126: $147-156$.

Lewko W, Liotta LA, Wicha MS, et al. 1981. Sensitivity of Nnitrosomethylurea-induced rat mammary tumors to cis-hydroxyproline, an inhibitor of collagen production. Cancer Res. 41: 2855-2862. 
Li FP, Fraumeni JF Jr., Mulvihill JJ, et al. 1988. A cancer family syndrome in twenty four kindreds. Cancer Res. 48: 5358-5362.

Liang P, Averboukh L, Keyomarsi K, et al. 1992. Differential display and cloning of messenger RNAs from human breast cancer versus mammary epithelial cells. Cancer Res. 52: 6966-6968.

Liang P, Pardee AB. 1992. Differential display of eukaryotic messenger RNA by means of polymerase chain reaction. Science 257: 967-971.

Likhtarev IA, Sobolev BG, Kairo IA et al. 1995. Thyroid cancer in the Ukraine. Nature 375: 365.

Lin CQ, Dempsey PJ, Coffey RJ, Bissell MJ. 1995. Extracellular matrix regulates whey acidic protein gene expression by suppression of TGF-alpha in mouse mammary epithelial cells: studies in culture and in transgenic mice. J. Cell Biol. 129: 1115-1126.

Lindholm D, Castren E, Kiefer R, et al. 1992. Transforming growth factor- $\beta 1$ in the rat brain: Increase after injury and inhibition of astrocyte proliferation. J. Cell Biol. 117: 395-400.

Liotta LA, Rao CN, Barsky SH. 1983. Tumor invasion and the extracellular matrix. Lab Invest. 49: 636-649.

Lipkowitz S, Garry VF, Kirsch IR. 1992. Interlocus V-J recombination measures genomic instability in agriculture workers at risk for lymphoid malignancies. Proc. Natl. Acad. Sci. USA. 89: 5301-5305.

Liu Y, Hernandez AM, Shibata D, Cortopassi GA. 1994. BCL2 translocation frequency rises with age in humans. Proc. Natl. Acad. Sci. USA 91: 8910-8914.

Lo D. 1996. Animal models of human disease. Transgenic and knockout models of autoimmunity: Building a better disease. Clinical Immunol. Immunopath. 79: 96-104.

Löbrich M, Rydberg B, and Cooper PK 1994. DNA double-strand breaks induced by high-energy neon and iron ions in human fibroblasts. II. Probing individual NotI fragments by hybridization. Radiat. Res. 139: 133-141.

Löbrich M, Rydberg B, Cooper PK. 1995. Repair of X-ray-induced DNA doublestrand breaks in specific NotI restriction fragments in human fibroblasts: Joining of correct and incorrect ends. Proc. Natl. Acad. Sci. USA 92: 1205012054. 
Lochter A, Srebrow A, Sympson CJ, et al. 1997. Misregulation of stromelysin1 expression in mouse mammary tumor cells accompanies acquisition of stromelysin-1-dependent invasive properties. J. Biol. Chem. 272: 5007-5015.

Loeb LA. 1994. Microsatellite instability: marker of a mutator phenotype in cancer. Cancer Res. 54: 5059-5063.

Lowe SW, Schmitt SW, Smith SW, et al. 1993. p53 is required for radiationinduced apoptosis in mouse thymocytes. Nature 362: 847-849.

Ludlow JW. 1993. Interactions between SV40 large-tumor antigen and the growth suppresser proteins pRB and p53. FASEB J. 7: 866-971.

Lushbaugh CC, Casarett GW. 1976. Effects of gonadal irradiation in clinical radiation therapy: A review. Cancer 37: 1111-1125.

Lutze LH, Winegar RA, Jostes RF, et al. 1992. Radon-induced deletions in human cells: Role of nonhomologous strand rejoining. Cancer Res. 52: 51265129.

MacGregor JT, Farr S, Tucker JD, et al. 1995. New molecular endpoints and methods for routine toxicity testing. Fundamental Appl. Toxicol. 26: 156-173.

MacPhee DG. 1995. Mismatch repair, somatic mutations, and the origin of cancer. Cancer Res. 55: 5489-5492.

Maher JJ, Bissell DM. 1993. Cell-matrix interactions in liver. Semin Cell Biol. 4: 189-201.

Malkin D, Li FP, Strong LC, et al. 1990. Germ line p53 mutations in a familial syndrome of breast cancer, sarcomas, and other neoplasms. Science 250: 12331238.

Mangiarini L, Sathasivam K, Seller M, et al. 1996. Exon 1 of the HD gene with an expanded CAG repeat is sufficient to cause a progressive neurological phenotype in transgenic mice. Cell 87: 493-506.

Markowska AL, Koliatsos VE, Breckler SJ, et al. 1994. Human nerve growth factor improves spatial memory in aged but not young rats. J. Neurosci. 14: 4815-4824.

Marples B, Skov KA. 1996. Small doses of high-linear energy transfer radiation increase the radioresistance of Chinese hamster V79 cells to subsequent $X$ irradiation. Radiat. Res. 146: 382-387. 
Martin DP, Ito A, Horigome K, et al. 1992. Biochemical characterization of programmed cell death in NGF-deprived sympathetic neurons. J. Neurobiol. 23: $1205-1220$.

Martin M, Lefaix J-L, Pinton P, et al. 1993. Temporal modulation of TGF- $\beta 1$ and $\beta$-actin gene expression in pig skin and muscular fibrosis after ionizing radiation. Radiat. Res. 134: 63-70.

Martus H-J, Dollé MET, Gossen JA, et al. 1995. Use of transgenic mouse models for studying somatic mutations in aging. Mutation Res. 338: 203-213.

Marx J. 1993. How p53 suppresses cell growth. Science 262: 1644-1645.

Massaque' J. 1996. TGF $\beta$ signalling: receptors, transducers, and Mad proteins. Cell 85: 947-950.

Matzuk MM, Finegold MJ, Su JG, et al. 1992. Alpha-inhibin is a tumorsuppressor gene with gonadal specificity in mice. Nature 360: 313-319.

Mays CW. 1988. Alpha-particle-induced cancer in humans. Health Physics. 55: 637-652.

Mays CW, Taylor GN, Lloyd RD. 1980. Toxicity ratios: Their use and abuse in predicting risk from induced cancer. In: Life-Span Radiation Effects Studies in Animals: What Can They Tell Us? Conf. 830951 (DE87000490) Office of Scientific and Technical Information, US, DOE.

McKinnon RD, Peiras G, Ida JA Jr, Dalcq-Dubois M. 1993. A role for TGF- $\beta$ in oligodendrocyte differentiation. J. Cell Biol. 121: 1397-1407.

McNally NJ, deRonde J, Hinchliffe M. 1984. The effect of sequential irradiation with $\mathrm{X}$-rays and fast neutrons on the survival of V79 Chinese hamster cells. Int. J. Radiat. Biol. 45: 301-310.

McNally NJ, de Ronde J, Folkard M. 1988. Interaction between X-ray and $\alpha$ particle damage in V79 cells. Int. J. Radiat. Biol. 53: 917-920.

McWhir J, Selfridge J, Harrison DJ, et al. 1993. Mice with DNA repair gene (ERCC-1) deficiency have elevated levels of p53, liver nuclear abnormalities and die before weaning. Nature Genetics 5: 217-224.

Meistrich ML, van Beek ME. 1990. Radiation sensitivity of the human testis. Adv. Radiat. Biol. 14: 227-268. 
Mellon I, Rajpal DK, Koi M, et al. 1996. Transcription-coupled repair deficiency and mutations in human mismatch repair genes. Science 272: 557560.

Mertz PM, Fox PC, Pluta A, et al. 1992. Effects of ionizing radiation and $\beta$ adrenergic stimulation on the expression of early response genes in rat parotid glands. Radiat. Res. 130: 104-112.

Metting NF, Rossi HH, Braby LA, et al. 1988. Microdosimetry near the trajectory of high-energy heavy ions. Radiat. Res. 116: 183-195.

Metting NF, Palayool ST, Macklis RM, et al. 1992. Induction of mutations by bismuth-212 alpha particles at two genetic loci in human B-lymphoblasts. Radiat. Res. 132: 339-345.

Meyn MS. 1995. Ataxia-telangiectasia and cellular responses to DNA damage. Cancer Res. 55: 5991-6001.

Meyn MS, Strasfeld L, Allen C. 1994. Testing the role of p53 in the expression of genetic instability and apoptosis in ataxia-telangiectasia. Int. J. Radiat. Biol. 66: S141-149.

Miller RC, Brenner DJ, Geard CR, et al. 1988. Oncogenic transformation by fractionated doses of neutrons. Radiat. Res. 114: 589-598.

Miller RC, Randers-Pherson G, Lieber H, et al. 1993. The inverse dose-rate effect for oncogenic transformation by charged particles is dependent on linear energy transfer. Radiat. Res. 133: 360-364.

Miller RA, Turke P, Chrisp C, et al. 1994. Age-sensitive phenotypes covary in genetically heterogeneous mice and predict early death from lymphoma. J. Gerontol. 49: B255-262.

Miller RC, Marino SA, Brenner DJ, et al. 1995. The biological effectiveness of radon-progeny alpha particles. II. Oncogenic transformation as a function of linear energy transfer. Radiat. Res. 142: 54-60.

Miller RA, Bookstein F, Van der Meulen J, et al. 1997. Candidate biomarkers of aging: Age-sensitive indices of immune and muscle function covary in genetically heterogeneous mice. J. Gerontol. 52: B39-B47.

Mills JJ, Chari RS, Boyer IJ, et al. 1995. Induction of apoptosis in liver tumors by the monoterpene perillyl alcohol. Cancer Res. 55: 979-983.

Milner JA. 1994. Reducing the risk of cancer. In: Functional Foods. I. Goldberg, (Ed.), Chapman and Hall, NY, pp. 39-70. 
Missiaen L, Taylor CW, Berridge MJ. 1991. Spontaneous calcium release from inositol triphosphate-sensitive calcium stores Nature 352: 241-244.

Miura M, Zhu H, Rotello R, et al. 1993. Induction of apoptosis in fibroblasts by IL-1ß-converting enzyme, a mammalian homolog of the $C$. elegans cell death gene ced-3. Cell 75: 653-660.

Modrich P. 1994. Mismatch repair, genetic stability, and cancer. Science 266: 1959-1960.

Mooney D, Hansen L, Vacanti J, et al. 1992. Switching from differentiation to growth in hepatocytes: control by extracellular matrix. J. Cell Physiol. 151: 497505 .

Moore MW, Klein RD, Fariñas I, et al. 1996. Renal and neuronal abnormalities in mice lacking GDNF. Nature 382: 76-79.

Moran MF, Ebisuzaki K. 1987. Base excision repair in $\gamma$-irradiated human cells. Carcingenesis 8: 607-609.

Morgan WF, Day JP, Kaplan MI, et al. 1996. Genomic instability induced by ionizing radiation. Radiat. Res. 146: 247-258.

Mori T, Hori Y, Dizdaroglu M. 1993. DNA base damage generated in vivo in hepatic chromatin of mice upon whole body gamma-irradiation. Int. J. Radiat. Biol. 64: 645-650.

Morrison V. Ashby J. 1994. A preliminary evaluation of the performance of the MutaTM Mouse (lacZ) and Big Blue TM (lacI) transgenic mouse mutation assays. Mutagenesis 9: 367-375.

Muggenberg BA, Hahn FF, Griffith WC Jr, et al. 1996. The biological effects of radium-224 injected into dogs. Radiat. Res. 146: 171-186.

Mullaart E, Lohman PH, Vijg J. 1988. Differences in pyrimidine dimer removal between rat cells in vitro and in vivo. J. Invest. Derm. 90: 346-349.

Murnane JP, Sabatier L, Marder BA, Morgan WF. 1994. Telomere dynamics in an immortal human cell line. EMBO J. 13: 4953-4962.

Murray D, Milas L, Meyn RE. 1988. Radioprotection of mouse jejunem by WR-2721 and WR-1065: Effects on DNA double strand-break induction and rejoining. Radiat. Res. 114: 268-280. 
Nagasawa H, Little JB. 1981. Induction of chromosome aberrations and sister chromatid exchanges by X-rays in density-inhibited cultures of mouse 10T $1 / 2$ cells. Radiat. Res. 87:538-551.

Nagasawa H, Little JB. 1992. Induction of sister chromatid exchanges by extremely low doses of $\alpha$-particles. Cancer Res. 52: 6394-6396.

Nagata S, Golstein P. 1995. The Fas death factor. Science 267: 1449-1456.

Naik P, Karrim J, Hanahan D. 1996. The rise and fall of apoptosis during multistage tumorigenesis: down-modulation contributes to tumor progression from angiogenic progenitors. Genes Develop. 10: 2105-2116.

Nakao N, Frodl EM, Widner $\mathrm{H}$, et al. 1995. Overexpressing $\mathrm{Cu} / \mathrm{Zn}$ superoxide dismutase enhances survival of transplanted neurons in a rat model of Parkinson's disease. Nature Medicine. 1: 226-231.

Nakayama K, Ishida N, Shirane M, et al. 1996. Mice lacking p27kip1 display increased body size, multiple organ hyperplasia, retinal dysplasia, and pituitary tumors. Cell 85: 707-720.

NASA Life Sciences Strategic Planning Study Committee. 1988. Exploring the Living Universe: A Strategy for Space Life Sciences. Washington, DC.

NCRP. 1989. Guidance on Radiation Received in Space Activities, NCRP Report No. 98. National Council on Radiation Protection and Measurements, Bethesda, MD, pp. 15-26; 105-122.

NCRP 1990. The Relative Biological Effectiveness of Radiations of Different Quality, NCRP Report No. 104. National Council on Radiation Protection and Measurements, Bethesda, MD, pp. 49-74.

Neel JV. 1990. Toward an explanation of the human sex ratio. In: Gender, Health and Longevity: Multidisciplinary Perspectives, MG Ory, HR Warner, (Eds.), Springer Publish. Co., New York, pp. 57-72.

Nelson GA, Schubert WW, Marshall TM, et al. 1989. Radiation effects in Caenorhabditis elegans by high and low LET ionizing radiation. Mutat. Res. 212: 181-192.

Nelson GA, Schubert WW, Marshall TM. 1992. Radiobiological studies with the nematode Caenorhabditis elegans. Genetic and developmental effects of high LET radiation. Nucl. Tracks Radiat. Meas. 20: 227-232.

Nelson GA, Schubert WW, Kazarians GA, et al. 1994. Radiations effects in nematodes: Results from IML-1 experiments. Adv. Space Res. 14: 87-91. 
Nelson SL, Jones IM, Fuscoe JC, et al. 1995. Mapping the endpoints of large deletions affecting the hprt locus in human peripheral blood cells and cell lines. Radiat. Res. 141: 2-10.

Nelson S, Grosovsky A, Gauny S. et al. 1996. Molecular characterization of 304 HPRT-deficient mutants of human lymphoid cells arising after low fluence exposures to high energy heavy ions. Proceed. Seventh Annual Space Radiation Health Investigators' Workshop (Riverside, CA).

Neta R, Oppenheim JJ. 1991. Radioprotection with cytokines -- learning from nature to cope with radiation damage. Cancer Cells 3: 391-396.

Neuenschwander S, Schwartz A, Wood TL, et al. 1996. Involution of the lactating mammary gland is inhibited by the IGF system in a transgenic mouse model. J. Clin. Invest. 97: 2225-2232.

Newton GL, Aguilera JA, Ward JF, Fahey RC. 1996. Binding of radioprotective thiols and disulfides in Chinese hamster V79 cell nuclei. Radiat. Res. 146: 298-305.

Ngo FH, Blakely EA, Tobias CA. 1981. Sequential irradiation of mammalian cells with low and high 1.e.t. radiation. Radiat. Res. 87: 59-78.

Nickerson JA, Blencowe BJ, Penman S. 1995. The architectural organization of nuclear metabolism. Int. Rev. Cytol. 162A: 67-123.

Nussenzweig A, Chen C, da Costa Soares V, et al. 1996. Requirement for Ku80 in growth and immunoglobulin V(D)J recombination. Nature 382: 551-555.

Oakberg EF. 1956. A description of spermiogenesis in the mouse and its use in analysis of the cell cycle of the seminiferous epithelium and germ cell renewal. Am. J. Anat. 99: 391-414.

Oakberg EF. 1971. Spermatogonial stem cell renewal in the mouse. Anat. Rec. 169: 515-532.

O'Farrell PH. 1975. High resolution two-dimensional electrophoresis of proteins. J. Biol. Chem. 250: 4007-4021.

Oft M, Peli J, Rudaz C, et al. 1996. TGF- $\beta 1$ and Ha-Ras collaborate in modulating the phenotypic plasticity and invasiveness of epithelial tumor cells. Genes Develop. 10: 2462-2477. 
Ohnishi T, Inoue N, Matsumoto $\mathrm{H}$, et al. 1996. Cellular content of p53 protein in rat skin after exposure to the space environment. J. Appl. Physiol 81: 183185.

Ohta M, Inoue H. Cotticelli MG, et al. 1996. The FHIT gene, spanning the chromosome 3 p14.2 fragile site and renal carcinoma-associated $t(3 ; 8)$ breakpoint, is abnormal in digestive tract cancer. Cell 84: 587-597.

Oleinicki NL, Balasubramaniam U, Xue L, Chiu S. 1994. Nuclear structure and the microdistribution of radiation damage in DNA. Int. J. Radiat. Biol. 66: 523-529.

Olinski R, Nackerdien Z, Disadaroglu M. 1992. DNA-protein cross-linking between thymine and tyrosine in chromatin of gamma-irradiated or $\mathrm{H}_{2} \mathrm{O}_{2}$ treated cultured human cells. Arch. Biochem. Biophys. 297: 139-143.

Ootsuyama A, Tanooka H. 1993. Zero tumor incidence in mice after repeated lifetime exposures to 0.5 Gy of beta radiation. Radiat. Res. 134: 244-246.

Oyama Y, Hayashi A, Ueha T. 1993. $\mathrm{Ca}^{++}$-induced increase in oxidative metabolism of dissociated mammalian brain neurons: efects of extract of Ginkgo biloba leaves. Jap. J. Pharm. 61: 367-370.

Paigen K. 1995. A miracle enough: the power of mice. Nature Medicine 1: 215220.

Pandita TK, Hittelman WN. 1992. The contribution of DNA and chromosome repair deficiencies to the radiosensitivity of ataxia-telangiectasia. Radiat. Res. 131: 214-223.

Pandita TK, Hall EJ, Hei TK, et al. 1996. Chromosome end-to-end associations and telomerase activity during cancer progression in human cells after treatment with alpha-particles simulating radon progeny. Oncogene 13: 14231430.

Panzer S, Kuhl DP, Caskey CT. 1995. Unstable triplet repeat sequences: a source of cancer mutations? Stem Cells 13: 146-157.

Papadopoulos N, Nicolaides NC, Wei Y-F, et al. 1994. Mutation of a mutL homolog in hereditary colon cancer. Science 263: 1625-1629.

Partin AW, Steinberg GD, Pitcock RV, et al. 1992. Use of nuclear morphometry, Gleason histologic scoring, clinical stage, and age to predict disease-free survival among patients with prostate cancer. Cancer 70: 161-168. 
Pease AC, Solas D, Sullivan EJ, et al. 1994. Light generated oligonucleotide arrays for rapid DNA sequence analysis. Proc. Natl. Acad. Sci. USA 91: 50225026

Peifer M. 1993. Cancer, catenins and cuticle pattern: A complex connection. Science 262: 1667-1668.

Peifer M. 1996. Regulating cell proliferation: As easy as APC. Science 272: 974975.

Pennisi E. 1996. Chipping away at the human genome. Science 272: 1737.

Pereira-Smith O, Smith JR. 1988. Genetic analysis of indefinite division in human cells: identification of four complementation groups. Proc. Natl. Acad. Sci. USA 85: 6042-6046.

Petersen OW, Rønnov-Jessen L, Howlett AR, Bissell MJ. 1992. Interaction with basement membrane serves to rapidly distinguish growth and differentiation pattern of normal and malignant human breast epithelial cells. Proc. Natl. Acad. Sci. USA 89: 9064-9068.

Petersen OW, Rønnov-Jessen L, Bissell MJ. 1995. The microenvironment of the breast: three-dimensional models to study the roles of the stroma and the extracellular matrix in function and dysfunction. The Breast J. 1: 22-35.

Petridou E, Trichopoulos D, Dessypris N, et al. 1996. Infant leukaemia after in utero exposure to radiation from Chernobyl. Nature 382: 352-353.

Philpott DE, Sapp W, Miguel J, et al. 1985. The effect of high energy particle (HZE) radiation $(40 \mathrm{Ar})$ on aging parameters of mouse hippocampus and retina. Scanning Electron Microscopy III: 1177-1182.

Pienta KJ, Coffey DS. 1992. Nuclear-cytoskeletal interactions: Evidence for physical connections between nucleus and cell periphery and their alteration by transformation. J. Cell Biochem. 49: 357-365.

Pierce DA, Shimuzu Y, Preston DL, et al. 1996. Studies of the mortality of atom bomb survivors. Report 12, Part I. Cancer 1950-1990. Radiat. Res. 146: 127.

Prehn J, Peruche B, Unsicker K, Krieglstein J. 1993a. Isoform-specific effects of transforming growth factors-beta on degeneration of primary neuronal cultures induced by cytotoxic hypoxia or glutamate. J. Neurochem. 60: 16551672 . 
Prehn JHM, Backhauss C, Krieglstein J. 1993b. Transforming growth factor -beta 1 prevents glutamate neurotoxicity in rat neocortical cultures and protects mouse neocortex from ischemic injury in vivo. J. Cerebral Blood Flow Metab. 13: 521-525.

Preston DL, Kusumi S, Tomonaga M, et al, 1994. Cancer incidence in atomic bomb survivors. Part III: Leukemia, lymphoma, and multiple myeloma, 19501987. Radiat Res. 137: S68-S97.

Price A. Lindahl T. 1991. Enzymatic release of 5'-terminal deoxyribose phosphate residues from damaged DNA in human cells. Biochemistry 30: 8631-8637.

Pronk GJ, Ramer K, Amiri P, Williams LT. 1996. Requirement for an ICE-like protease for induction of apoptosis and ceramide generation by REAPER. Science 271: 808-810.

Rabin BM, Hunt WA, Lee J. 1983. Attenuation of radiation- and druginduced conditional taste aversions following area postrema lesions in the rat. Radiat. Res. 93: 388-394.

Rabin BM, Hunt WH, Joseph JA. 1989. An assessment of the behavioral toxicity of high-energy iron particles compared to other qualities of radiation. Radiat. Res. 119: 113-122.

Rabin BM, Hunt WH, Joseph JA, et al. 1991. Relationship between linear energy transfer and behavioral toxicity in rats following exposure to protons and heavy particles. Radiat. Res. 128: 216-221.

Rabin BM, Hunt WA, Wilson ME, Joseph JA. 1992. Emesis in ferrets following exposure to different types of radiation: A dose-response study. Aviat. Space Environ. Med. 63: 702-705.

Rabin BM, Joseph JA, Hunt WA, et al. 1994. Behavioral endpoints for radiation injury. Adv. Space Res. 14: 457-466.

Rabizadeh S, Gralla EB, Borchelt DR, et al. 1995. Mutations associated with amyotrophic lateral sclerosis convert superoxide dismutase from an antiapoptotic gene to a proapoptotic gene: Studies in yeast and neural cells. Proc. Natl. Acad. Sci. USA 92: 3024-3028.

Rai SS, Shovlin C, Wesnes KA. 1991. A double-blind placebo controlled study of Ginkgo biloba extract ("tanakan") in elderly outpatients with mild to moderate memory impairment. Curr. Med. Res. Opin. 12: 350-355. 
Rall JF, Beebe GW, Hoel DG, et al. 1985. Report of the National Institutes of Health Ad Hoc Working Group to Develop Radioepidemiological Tables, DHHS Publication No. (NIH) 85-2748 (U.S. Government Printing Office, Washington).

Ramsey MJ, Moore DH, Briner JF, et al. 1995. The effects of age and lifestyle factors on the accumulation of cytogenetic damage as measured by chromosome painting. Mutation Res 338: 95-106.

Ramsey MJ, Tucker JD, Senft JR, et al. 1996. Cytogenetic analaysis of Chernobyl clean-up workers as measured by chromosome painting. Environ. Molec. Mutagen. 27 (S27): 56.

Rana B, Mischoulon D, Xie Y, et al. 1994. Cell-extracellular matrix interactions can regulate the switch between growth and differentiation in rat hepatocytes: reciprocal expression of $\mathrm{C} / \mathrm{EBP} \alpha$ and immediate-early growth response transcription factors. Molec. Cell. Biol. 14: 5858-5869.

Raymond JR. 1995. Multiple mechanisms of receptor-G protein signalling specificity. Am. J. Physiol. 269: 141-158.

Reed JC. 1994. Bcl-2 and the regulation of programmed cell death. J. Cell Biol. 124: $1-6$.

Reinhold MS. 1980. Late changes in the architecture of blood vessels of the rat brain after irradiation. Biol. J. Radiol. 53, 693-696.

Rens-Domiano S, Hamm HE. 1995. Structural and functional relationships of heterotrimeric G-proteins. FASEB J. 9: 1059-1066.

Riley AL, Tuck DL. 1985. Conditioned taste aversions: A behavioral index of toxicity. Ann N.Y. Acad. Sci. 443: 272-292.

Riley DA, Ellis S, Slocum GR, et al., 1996. In-flight and postflight changes in skeletal muscles of SLS-1 and SLS-2 spaceflown rats. J. Appl. Physiol. 81: 133144.

Ripps ME, Huntley GW, Hof PR, et al. 1995. Transgenic mice expressing an altered murine superoxide dismutase gene provide an animal model of amyotrophic lateral sclerosis. Proc. Natl. Acad. Sci. USA 92: 689-693.

Roberts JC, Koch KE, Detrick SR, et al. 1995. Thiazolidine prodrugs of cysteamine and cysteine as radioprotective agents. Radiat. Res. 143: 203-213.

Robbins D. (In press). The space radiation environment. NCRP Symposium on Acceptability of Risk from Radiation-Application to Human Space Flight. 
Ronnov-Jessen L, Petersen OW, Koteliansky VE, Bissell MJ. 1995. The origin of the myofibroblasts in breast cancer. Recapitulation of tumor environment in culture unravels diversity and implicates converted fibroblasts and recruited smooth muscle cells. J. Clin. Investig. 95(2): 859-73.

Roscoe RJ, Steenland K, Halperin WE, et al. 1989. Lung cancer mortality among nonsmoking uranium miners exposed to radon daughters. J. Am. Med. Assoc. 262: 629-633.

Rossant J, Nagy A. 1995. Genome engineering: the new mouse genetics. Nature Medicine 1: 592-594.

Roskelley CD, Srebrow A, Bissell MJ. 1995. A hierarchy of ECM-mediated signalling regulates tissue-specific gene expression. Curr. Opin. Cell Biol. 7: 736-747.

Roth GS, Joseph JA, Mason P. 1995. Membrane alterations as causes of impaired signal transduction in Alzheimer's disease and aging. Trends Neurol. Sci. 18: 203-206.

Roush W. 1996. Hunting for animal alternatives. Science 274: 168-171.

Rowley MJ, Leach DR, Warner GA, Heller CG. 1974. Effects of graded doses of ionizing radiation on the human testes. Radiat. Res. 59: 665-678.

Rubin DB, Drab EA, Kang HJ, et al. 1996. WR-1065 and radioprotection of vascular endothelial cells. I. Cell proliferation, DNA synthesis and damage Radiat. Res. 145: 210-216.

Rudnicki MA, Braun T, Hinuma S, Jaenisch R. 1992. Inactivation of myoD in mice leads to up-regulation of the myogenic HLH gene myf-5 and results in apparently normal muscle development. Cell 71: 383-390.

Rudolph U, Finegold MJ, Rick SS, et al. 1995. Ulcerative colitis and adenocarcinoma of the colon in $\mathrm{G}$ alpha i2-deficient mice. Nature Genetics. 10: $143-150$.

Rugh R, Wolff J. 1957. Threshold X-irradiation sterilization of the ovary. Fertil. Steril 8: 428-437.

Russell WL. 1951. X-ray induced mutations in mice. Cold Spring Harbor Symp. Quant. Biol. 16: 327-336.

Russell LB, Russell WL. 1954. An analysis of the changing radiation response of the developing mouse embryo. J. Cell Comp. Physiol. 43: 103-149. 
Rydberg B, Löbrich M. and Cooper PK. 1994. DNA double-strand breaks induced by high-energy neon and iron ions in human fibroblasts. I. Pulsedfield gel electrophoresis method. Radiat. Res. 139: 133-141.

Rydberg B. 1996. Clusters of DNA damage induced by ionizing radiation: Formation of short DNA fragments. II. Experimental detection. Radiat. Res. 145: 200-209.

Samson L, Schwartz JL. 1980. Evidence for an adaptive DNA repair pathway in CHO and human skin fibroblast cell lines. Nature 287: 861-863.

Sancar A. 1994. Mechanisms of DNA excision repair. Science 266: 1954-1956.

Sancar A. 1995. Excision repair in mammalian cells. J. Biol. Chem. 270: 15951598.

Sands AT, Abuin A, Sanchez A, et al. 1995a. High susceptibility to ultravioletinduced carcinogenesis in mice lacking XPC. Nature 377: 162-165.

Sands AT, Suraokar MB, Sanchez A, et al. 1995b. p53 deficiency does not affect the accumulation of point mutations in a transgene target. Proc. Natl. Acad. Sci. USA 92: 8517-8521.

Santana P, Pena LA, Haimovitz-Friedman A, et al. 1996. Acid sphingomyelinase-deficient human lymphoblasts and mice are defective in radiation-induced apoptosis. Cell 86: 189-199.

Savitsky K, Bar-Shira A, Gilad S, et al. 1995a. A single ataxia telangiectasia gene with a product similar to PI-3 kinase. Science 268: 1749-1753.

Savitsky K, Sfez S, Tagle DA, et al. 1995b. The complete sequence of the coding region of the ATM gene reveals similarity to cell cycle regulators in different species. Human Molecular Genetics 4: 2025-2032.

Schaeffer L, Roy R, Humbert S, et al. 1993. DNA repair helicase: a component of BTF2 (TFIIH) basic transcription factor. Science 260: 58-63.

Schaeffer L, Moncollin V, Roy R, et al. 1994. The ERCC2/DNA repair protein is associated with the class II BTF2/TFIIH transcription factor. EMBO J. 13: 2388-2392.

Scheltens P, Barkhop F, Leys D, et al. 1995. Histopathologic correlates of white matter changes on MRI in Alzheimer's disease and normal aging. Neurology 45: 883-888. 
Schena M, Shalon D, Davis RW, Brown PO. 1995. Quantitative monitoring of gene expression patterns with a complementary DNA microarray. Science 270: $467-470$.

Schimmerling W. 1992. Radiobiological problems in space. An overview. Radiat. Environ. Biophys. 31: 197-203.

Schmidt-Ullrich RK, Valerie K, Fogleman PB, Walters J. 1996. Radiationinduced autophosphorylation of epidermal growth factor receptor in human malignant mammary and squamous epithelial cells. Radiat. Res. 145: 81-85.

Schröck E, du Manoir S, Veldman T, et al. 1996. Multicolor spectral karyotyping of human chromosomes. Science 273: 494-497.

Schroeder F. 1984. Role of membrane lipid asymmetry in aging. Neurobiol. Aging 5: 323-333.

Schull WJ, Weiss KM. 1992. Radiation carcinogenesis in humans. Adv. Radiat. Biol. 16: 215-258.

Schull WJ, Otake M, Funamoto S. 1994. Radiation cataracts among Hiroshima Atomic-bomb survivors. Radiation Effects Research Foundation Technical Report 11-92.

Schwartz JL, Rotmensch J, Sun J, et al. 1994. Multiplex polymerase chain reaction-based deletion analysis of spontaneous, gamma ray-, and alphainduced hprt mutants of CHO-K1 cells. Mutagenesis 9: 537-540.

Sekiguchi M, Nakabeppu Y, Sakumi, Tuzuki T. 1996. DNA repair methyltransferase as a molecular device for preventing mutation and cancer. J. Cancer Res. Clin. Oncol. 122: 199-206.

Serrano M, Lee HW, Chin L, et al. 1996. Role of the INK4a locus in tumor suppression and cell Mortality. Cell 85: 27-37.

Shaver SL. 1953. X-irradiation injury and repair in the germinal epithelium of male rats. I. Injury and repair in adult rats. Am. J. Anat. 92: 391-432.

Sherman ML, Datta R, Hallahan DE, et al. 1990. Ionizing radiation regulates expression of the c-jun protooncogene. Proc. Natl. Acad. Sci. USA 87: 56635666.

Shigeno T, Mima T, Takakura K, et al. 1991. Amelioration of delayed neuronal death in the hippocampus by NGF growth factor. J. Neurosci. 11: 2914-2919. 
Shinohara A, Ogawa T. 1995. Homologous recombination and the roles of double-strand breaks. Trends Biochem. Sci. 20: 387-391.

Shull MM, Ormsby I, Kier AB, et al. 1992. Targeted disruption of the mouse transforming growth factor-beta 1 results in multifocal inflammatory disease. Nature 359: 693-699.

Sijbers AM, de Laat WL, Ariza RR, et al. 1996. Xeroderma pigmentosum Group F caused by a defect in a structure-specific DNA repair endonuclease. Cell 86: 811-822.

Singh SP, Lavin MF. 1990. DNA-binding protein activated by gamma radiation in human cells. Mol. Cell. Biol. 10: 5279-5285.

Sipley JD, Menninger JC, Hartley KO, et al. 1995. Proc. Natl. Acad. Sci. USA. 92: 7515-7519.

Skopek TR, Kort C, Marino DR. 1995. Relative sensitivity of the endogenous hprt gene and lacI transgene in ENU-treated Big Blue $\mathrm{B}_{6} \mathrm{C}_{3} \mathrm{~F}_{1}$ mice. Environ. Molec. Mutagen. 26: 9-15.

Southern EM. 1996. DNA chips: analyzing sequence by hybridization to oligonucleotides on a large scale. Trends Genet. 12: 110-115.

Space Studies Board, National Research Council. 1996. Radiation Hazards to Crews of Interplanetary Missions. Biological Issues and Research Strategies. National Academy Press, Washington D.C.

Speicher MR, Ballard SG, Ward DC. 1996. Karotyping human chromosomes by combinatorial multi-fluor FISH. Nature Genetics 12: 368-375.

Spina MB, Squinto SP, Miller J, et al. 1992. BDNF protects dopamine neurons against 6-OHDA and N-methyl-4-phenylpyridinium ion toxicity: involvement of the glutathione system. J. Neurochem. 59: 99-106.

Stadler J, Gowen JW. 1964. Observations on the effects of continuous irradiation over ten generations on reproductivities of different strains of mice. In: Effects of Ionizing Radiation on the Reproductive System, WD Carlson, EX Gassner, (Eds.), Pergamon Press, New York, pp. 111-122.

Stadtman ER. 1992. Protein oxidation and aging. Science 257: 1220-1224.

Stark G. 1991. The effect of ionizing radiation on lipid membranes. Biochim. Biophys. Acta 1071: 103-122. 
St. Clair WH. 1991. Suppression of 3-methylcholanthrene-induced cellular transformation by timed administration of the Bowman-Birk protease inhibitor. Carcinogenesis 12: 935-937.

Stoker AW, Streuli CH, Martins-Green M, and Bissell MJ. 1990. Designer microenvironments for the analysis of cell and tissue function. Current Opinion in Cell Biology Vol. 2: 864-874.

Storer JB, Mitchell TJ, Fry RJM. 1988. Extrapolation of the relative risk of radiogenic neoplasms across mouse strains and to man. Radiat. Res. 114, 331353.

Strasser A, Harris AW, Bath ML, Cory S. 1990. Novel primitive lymphoid tumors induced in transgenic mice by cooperation between $m y c$ and $b c l-2$. Nature 348: 331-333.

Streuli $\mathrm{CH}$, Schmidhauser C, Kobrin M, et al. 1993. Extracellular matrix regulates expression of the TGF- $\beta 1$ gene. J. Cell Biol. 120: 253-260.

Su L-K, Vogelstein B, Kinzler KW. 1993. Association of the APC tumor suppressor protein with catenins. Science 262: 1734-1737.

Sulston JE, Schievenberg E, White JG, Thomson JN. 1983. The embryonic cell lineage of the nematode Caenorhabditis elegans. Develop. Biol. 100: 64-119.

Sulzman FM. 1996. Overview. J. Appl. Physiol. 81: 3-6.

Sumarsono SH, Wilson TJ, Tymms MJ, et al. 1996. Down's syndrome-like skeletal abnormalities in Ets2 transgenic mice. Nature 379: 534-537.

Sutherland BM, Bennett PV, Sutherland JC. 1996. Double-strand breaks induced by low doses of gamma rays or heavy ions: Quantitation in nonradioactive human DNA. Analytical Biochem. 239: 53-60.

Swift M, Morrell D, Massey RB, Chase CL. 1991. Incidence of cancer in 161 families affected by ataxia-telangiectasia. New Eng. J. Med. 325: 1831-1836.

Sympson CJ, Talhouk RS, Alexander CM, et al. 1994. Targeted expression of stromelysin-1 in mammary gland provides evidence for a role of proteinases in branching morphogenesis and the requirement for an intact basement membrane for tissue-specific gene expression. J. Cell Biol. 125: 681-693.

Sympson CJ, Bissell MJ, Werb Z. 1995. Mammary gland tumor formation in transgenic mice overexpressing stromelysin-1. Seminars Cancer Biol. 6: 159163. 
Taccioli GE, Alt FW. 1995. Potential targets for autosomal SCID mutations. Curr. Opinions Immunol. 7: 436-440.

Tao F, Medvedovsky C, David J, et al. 1993a. Accelerated heavy ions and the lens. IX. Late effects of LET and dose on cellular parameters in the murine lens. Int. J. Radiat. Biol. 64: 103-111.

Tao KS, Urlando C, Heddle JA. 1993b. Comparison of somatic mutation in a transgenic versus host locus. Proc. Natl. Acad. Sci. USA 90: 10681-10685.

Taucher-Scholz G, Heilmann J, Schneider M, Kraft G. 1995. Detection of heavy-ion-induced DNA double-strand breaks using static-field gel electrophoesis. Radiat. Environ. Biophy. 34: 101-106.

Taylor JA, Watson MA, Devereaux TR, et al. 1994. P53 mutation hotspot in radon-associated lung cancer. Lancet 343: 86-87.

Teale B, Singh S, Khanna KK, et al. 1992. Purification and characterization of a DNA binding protein activated by ionizing radiation. J. Biol. Chem. 267: 10295-10301.

Tennant RW. 1993. Stratification of rodent carcinogenicity bioassay results to reflect relative human hazard. Mutation Res. 286: 111-118.

Tennant RW, French JE, Spalding JW. 1995. Identifying chemical carcinogens and assessing potential risk in short-term bioassays using transgenic mouse models. Environ. Health Perspect. 103: 942-950.

Tewari M, Quan LT, O'Rourke K, et al. 1995. Yama/CPP32B, a mammalian homolog of CED-3, is a CrmA-inhibitable protease that cleaves the death substrate poly (ADP-ribose) polymerase. Cell 81: 801-809.

Thompson CB. 1995. Apoptosis in the pathogenesis and treatment of disease. Science 267: 1456-1462.

Thompson DE, Mabuchi K, Ron E, et al. 1994. Cancer incidence in atomic bomb survivors. Part II: Solid tumors, 1958-1987. Radiation Res. 137: S17-S67.

Thompson LH, Jeggo PA. 1995. Nomenclature of human genes involved in ionizing radiation sensitivity. Mutation Res. 337: 131-134.

Tlsty TD, Briot A, Gualberto A, et al. 1995. Genomic instability and cancer. Mutat. Res. 337: 1-7.

Todd P. 1991. Gravity dependent processes and intracellular motion. ASGSB Bulletin. 4: 35-39. 
Todorov P, Cariuk P, McDevitt T, et al. 1996. Characterization of a cancer cachectic factor. Nature 379: 739-742.

Tokunaga M, Land CE, Tokuoka S, et al. 1994. Incidence of female breast cancer among atomic bomb survivors, Hiroshima and Nagasaki, 1950-1985. Radiation Res. 138: 209-223.

Tsuboi K, Yang TC, Chen DJ. 1992. Charged particle mutagenesis. I. Cytoxic and mutagenic effects of high-LET charged iron particles on human skin fibroblasts. Radiat. Res. 129: 171-176.

Tsujimoto Y, Finger LR, Tunis J, et al. 1984. Cloning of the chromosome breakpoint of neoplastic B cells with the $t(14 ; 18)$ chromosome translocation. Science 226: 1097-1099.

Tucker JD, Ramsey MJ, Lee DA, Minkler JL. 1993. Validation of chromosome painting as a biodosimeter in human peripheral lymphocytes following acute expsoure to ionizing radiation in vitro. Int. J. Radiat. Biol. 64: 27-37.

Uckun FM, Waddick KG, Mahajan S, et al. 1996. BTK as a mediator of radiation-induced apoptosis in DT-40 lymphoma B cells. Science 273: 10961100.

Ullrich A, Schlessinger J. 1990. Signal transduction by receptors with tyrosine kinase activity. Cell 61: 203-212.

Underwood JC. 1990. Nuclear morphology and grading of tumors. Curr. Top. Pathol. 82: 1-15.

UNSCEAR. 1982. United Nations Scientific Committee on the Effects of Atomic Radiation. Ionizing Radiation: Sources and Biological Effects. 1982 Report to the General Assembly (United Nations Publications, New York).

UNSCEAR, Annex F. 1993. Influence of dose and dose rate on stochastic effects of radiation. In: Sources and effects of ionizing radiation. No. E.94.IX.2, New York: United Nations, pp. 619-728.

Vahakangas KH, Samet JM, Metcalf RA, et al. 1992. Mutations of p53 and ras genes in radon-associated lung cancer from uranium miners. Lancet, N. Am. Ed. 339: 576-580.

Vainio H, Cardis E. 1992. Estimating human cancer risk from the results of animal experiments: relationship between mechanism and dose-rate and dose. Am. J. Indust. Med. 21: 5-14. 
Velculescu VE, Zhang L, Vogelstein B, Kinzler KW. 1995. Serial analysis of gene expression. Science 270: 484-487.

Venitt S, Biggs PJ. 1994. Radon, mycotoxins, p53 and uranium mining. Lancet 343: 795.

Verheij M, Bose $\mathrm{R}$, Lin $\mathrm{XH}$, et al. 1996. Requirement for ceramide-initiated SAPK/JNK-mediated signalling in stress-induced apoptosis. Nature 380: 7579.

Vijayalaxmi, Reiter RJ, Meltz ML. 1995. Melatonin protects human blood lymphocytes from radiation-induced chromosome damage. Mutat. Res. 346: 23-31.

Vijg J, Mullaart E, van der Schans GP, et al. 1984. Kinetics of ultraviolet induced DNA excision repair in rat and human fibroblasts. Mutat. Res. 132: 129-138.

Vijg J, Douglas GR 1996. Bacteriophage lambda and plasmid lacZ transgenic mice for studying mutations in vivo. In: Technologies for Detection of DNA Damage and Mutations, GP Pfeifer, (Ed.), Plenum Press, New York, pp. 391410.

Villalobos-Molina R, Joseph JA, Rabin B, et al. $1994 .{ }^{56} \mathrm{Fe}$ irradiation diminishes muscarinic but not alpha-1 adrenergic-stimulated low $\mathrm{K}_{\mathrm{m}}$ GTPase activity in rat brain. Radiat. Res. 140: 382-386.

Vito P, Lacana E, D'Adamio L. 1996. Interfering with apoptosis: $\mathrm{Ca}^{2+-}$ binding protein ALG-2 and Alzheimer's gene ALG-3. Science 271: 521-524.

Vrdoljak E, Bill CA, Stephens LC, et al. 1992. Radiation-induced apoptosis of oligodendrocytes in vitro. Int. J. Radiat. Biol. 62: 475-480.

Wallace DC. 1992. Mitochondrial genetics: A paradigm for aging and degenerative diseases. Science 256: 628-632.

Wallace DC. 1995. Mitochondrial DNA variation in human evolution, degenerative disease, and aging. Am. J. Hum. Genet. 57: 201-223.

Wallace SS. 1988. AP endonucleases and DNA glycosylases that recognize oxidative DNA damage. Environ. Molec. Mutagen. 12: 431-477.

Wallace SS. 1994. DNA damages processed by base excision repair: biological consequences. Int. J. Radiat. Biol. 66: 579-589. 
Wang Z-Q, Auer B, Stingl L, et al. 1995. Mice lacking ADPRT and poly (ADPribosyl)ation develop normally but are susceptible to skin disease. Genes Dev. 9: 509-520.

Wang C-Y, Mayo MW, Baldwin AS Jr. 1996a. TNF- and cancer therapyinduced apoptosis: Potentiation of inhibition by NF-KB. Science 274: 784-787.

Wang FL, Wang Y, Wong WK, et al. 1996b. Two differentially expressed genes in normal human prostate tissue and carcinoma. Cancer Res. 56: 36343637.

Ward JF. 1985. Biochemistry of DNA lesions. Radiat. Res. 104: S103-S111.

Ward JF. 1988. DNA damage produced by ionizing radiation in mammalian cells: Identities, mechanisms of formation and repairability. Prog. Nucleic Acid Res. Mol. Biol. 35: 95-125.

Ward JF. 1995. Radiation mutagenesis: The initial DNA lesions responsible. Radiat. Res. 142: 362-368.

Warner HR. 1983. Prokaryotic DNA repair enzymes. In: Enzymes of Nucleic Acid Synthesis and Modification, Vol. I, DNA enzymes. ST Jacob, (Ed.), CRC Press, Boca Raton, FL, pp. 145-177.

Warner HR, Starke-Reed P. 1997. Oxidative stress and aging. In: Oxygen, Gene Expression, and Cellular Function, D Massaro, LB Clerch, (Eds.), Marcel Dekker, Inc., NY, pp. 139-167.

Wazer DE, Chu Q, Liu XL, et al.. 1994. Loss of p53 protein during radiation transformation of primary human mammary epithelial cells. Molec. Cell Biol. 14: 2468-2478.

Weaver VM, Petersen OW, Wang F, Larabell CA, Briand P, Damsky C, Bissell MJ. 1997. Reversion of the malignant phenotype of human breast cells in 3dimensional culture and in vivo by integrin blocking antibodies. J. Cell. Biol. 137: 231-246.

Weichselbaum RR, Hallhan DE, Sukhatame V, et al. 1991. Biological consequences of gene regulation after ionizing radiation exposure. J. Natl. Cancer Inst. 83: 480-484.

Weindruch R, Walford R. The Retardation of Aging and Disease by Dietary Restriction, Charles C. Thomas, Springfield, IL, 1988. 
Weindruch R, Warner HR, Starke-Reed PE. 1993. Future directions of free radical research in aging. In: Free Radicals in Aging. BP Yu, (Ed.), CRC Press, Boca Raton, FL, pp. 269-295.

Weng NP, Levine BL, June CH, Hodes RJ. 1996. Regulated expression of telomerase activity in human $\mathrm{T}$ lymphocyte development and activation. J. Expt. Med. 183: 2471-2479.

White JG, Southgate E, Thomson JN, Brenner S. 1986. The structure of the nervous system of the nematode Caenorhabditis elegans. Phil. Trans. Royal Soc. London Ser. B, 314: 1-340.

Wiedau-Pazos M, Goto JJ, Rabizadeh S, et al. 1996. Altered reactivity of superoxide dismutase in amyotrophic lateral sclerosis. Science 217: 515-518.

Wilcox BJ, Applegate MD, Prteracailbiau C, Koliatsos VE. 1995. Nerve growth factor prevents apoptotic cell death in injured central cholinergic neurons. J. Comp. Neurol. 359: 573-585.

Williams GR, Lett JT. 1994. Effects of $40 \mathrm{Ar}$ and $56 \mathrm{Fe}$ ions on retinal photoreceptor cells of the rabbit: Implications for manned missions to Mars. Adv. Space Res. 14: 217-220.

Williams GT. 1991. Programmed cell death: apoptosis and oncogenesis. Cell 65: 1097-1098.

Winegar RA, Lutze LH, Hamer JD, et al. 1994. Radiation-induced point mutations, deletions and micronuclei in lacI transgenic mice. Mutation Res. 307: 479-487.

Woloshak GE, Chang-Liu C-M, Shearin-Jones P. 1990. Regulation of protein kinase $C$ by ionizing radiation. Cancer Res. 50: 3963-3967.

Wong L-J C, Ashizawa T, Monckton DG, et al. 1995. Somatic heterogeneity of the CTG repeat in myotonic dystrophy is age and size dependent. Am. J. Hum. Genet. 56: 114-122.

Wood DH. 1991. Long-term mortality and cancer risk in irradiated Rhesus monkeys. Radiat. Res. 126: 132-140.

Wooster R, Neuhausen SL, Mangion J, et al. 1994. Localization of a breast cancer susceptibility gene, BRCA2, to chromosome 13q12-13. Science 265: 2088-2090. 
Worgul BV, Medvedovsky C, Huang V, et al. 1996. Quantitative assessment of the cataractogenic potential of very low doses of neutrons. Radiat. Res. 145: 343-349.

Wronski TJ, Morey ER. 1983. Effect of spaceflight on periosteal bone formation in rats. Am. J. Physiol. 244: R305-R309.

Wyllie AH. 1995. The genetic regulation of apoptosis. Curr. Opin. Genetics Develop. 5: 97-104.

Xia F, Wang X, Wang Y-H, et al. 1995. Altered p53 status correlates with differences in sensitivity to radiation-induced mutation and apoptosis in two closely related human lymphoblast lines. Cancer Res. 55: 12-15.

Xu Y, Baltimore D. 1996. Dual roles of ATM in the cellular response to radiation and in cell growth control. Genes Develop. 10: 2401-2410.

Xue LY, Friedman LR, Oleinick NL, Chiu SM. 1994. Induction of DNA damage in $\gamma$-irradiated nuclei stripped of nuclear protein classes: differential modulation of double-strand break and DNA-protein crosslink formation. Int. J. Radiat. Biol. 66: 11-21.

Yamagami K, Joseph JA, Roth GS. 1992. Decrement of muscarinic receptorstimulated low $\mathrm{K}_{\mathrm{m}}$ GTPase activity in striata and hippocampus from aged rat. Brain Res. 576: 327-331.

Yamasaki L, Jacks T, Bronson $\mathrm{R}$, et al. 1996. Tumor induction and tissue atrophy in mice lacking E2F-1. Cell 85: 837-848.

Yang F-T, Lord BI, Hendry JH. 1995. Gamma irradiation of the fetus damages the developing hemopoietic microenvironment rather than the hemopoietic progenitor cells. Radiat. Res. 141: 309-313.

Yochmowitz MG, Wood DH, Salmon YL. 1985. Seventeen-year mortality experience of proton radiation in Macaca mulatta. Radiat. Res. 102: 14-34.

Young HK, Floyd RA, Maidt ML, Dynlacht JR. 1996. Evaluation of nitrone spin-trapping agents as radioprotectors. Radiat. Res. 146: 227-231.

Yu C-E, Oshima J, Fu Y-H, et al. 1996. Positional cloning of the Werner's syndrome gene. Science 272: 258-262.

Yuan J. 1996. Evolutionary conservation of a genetic pathway of programmed cell death. J. Cell. Biochem. 60: 4-11. 
Yuhas JM. 1972. Improvement of lung tumor radiotherapy through differential chemoprotection of normal and tumor tissues. J. Nat. Cancer Inst. 48: 1255-1257.

Yuhas JM, Storer JB. 1969. Chemoprotection against three modes of radiation death in the mouse. Int. J. Radiat. Biol. Related Studies Phys. Chem. Med. 15: 233-237.

Zeman W. 1961. Radiosensitivities of nervous tissue. In: Fundamental Aspects of Radiosensitivity, Report of Symposium, BNL 675 (c-31) Biology and Medicine, TID 4500, pp. 176-199.

Zhan Q, Carrier F, Fomace AJ Jr. 1993. Induction of cellular p53 activity by DNA-damaging agents and growth arrest. Mol. Cell. Biol. 13: 4242-4250.

Zhang Y, Proenca R, Maffi M, et al. 1994. Positional cloning of the mouse obese gene and its human homologue. Nature 372: 425-431.

Zhu C, Bogue MA, Lim D-S, et al. 1996a. Ku86-deficient mice exhibit severecombined immunodeficiency and defective processing of $V(D) J$ recombination intermediates. Cell 86: 379-389.

Zhu LX, Waldren CA, Vannais D, Hei TK. 1996b. Cellular and molecular analysis of mutagenesis induced by charged particles of defined linear energy transfer. Radiat. Res. 145: 251-259.

Zurcher C, vanZwieten MJ, Solleveld HA, et al. 1982. Aging research. In: The Mouse in Biomedical Research. Vol IV, Experimental Biology and Oncology. HL Foster, JD Small, JG Fox, (Eds.), Academic Press, Inc., New York, pp. 1-35. 
IX. APPENDIX 


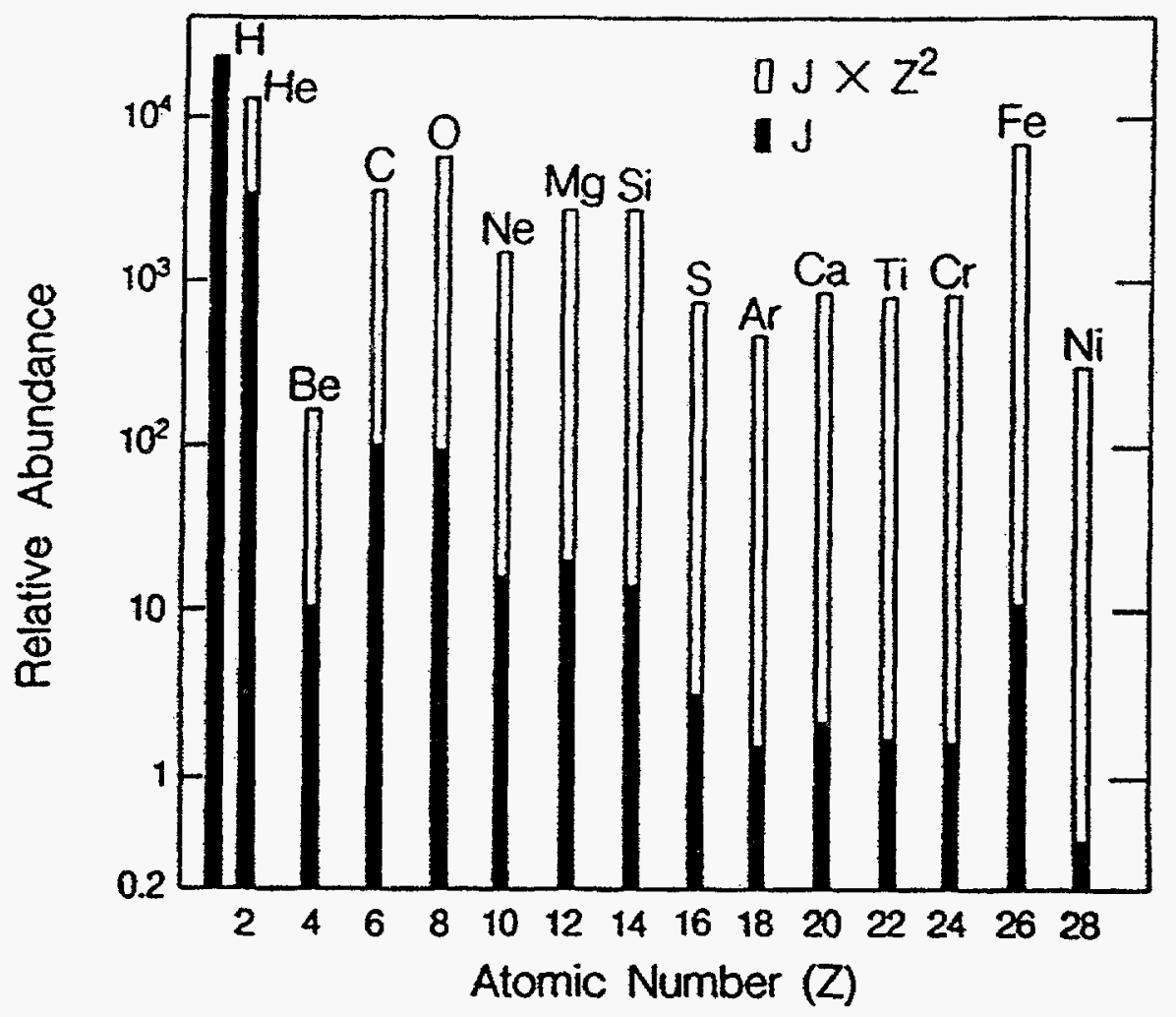

Figure IX.1. Relative abundance $(J)$ and ionizing power $\left(\mathrm{J} \times \mathrm{Z}^{2}\right)$ of protons and the even-numbered particles in GCR. Taken from NCRP (1989). 


\section{A. BIOLOGICAL TISSUES AVAILABLE FROM PREVIOUS SPACE FLIGHTS}

Previous US space flights have yielded a variety of animal and human tissues, some of which are available to non-NASA scientists for research purposes. Animal tissues currently available from previous flights are listed in Tables IX.1. Additional animal tissues will become available after future flights, and these are summarized in Table IX.2.

\section{BIOLOGICAL TISSUES AVAILABLE FROM SPACE-FLOWN ANIMALS}

The animal samples discussed below are stored at $-70^{\circ} \mathrm{C}$ if unfixed, and at $+2^{\circ} \mathrm{C}$ if fixed, and information can be obtained by contacting Dr. Paul X. Callahan, NASA/Ames Research Center (415-604-6046). Samples can be obtained by submitting a proposal for peer review to Dr. Ronald J. White, NASA Headquarters (202-358-2530).

1. The Spacelab 3 (SL-3) mission which was launched on 4/29/85 aboard Challenger remained in space for 7 days, and carried 30 experiments to act as verification tests for a rodent and primate Research Animal Holding Facility. From these experiments, 13 male rat carcasses (whole-powdered) are available.

2. The Spacelab Life Sciences 1 (SLS1) mission was launched on 6/5/91, remained in space for 9 days aboard Columbia, and carried 7 experiments using laboratory rats. Neuroscience, musculoskeletal, and hematology experiments were conducted on these rats, and a large number of tissue samples were preserved and are available to interested investigators. These samples are listed in Table IX.1a.

3. The Spacelab Life Sciences 2 (SLS2) mission was launched on 10/18/93, remained in space for 14 days aboard Columbia, and carried 4 experiments using laboratory rats. Tissue samples remaining from these experiments and available to interested investigators are listed in Table IX.1b. Urine samples are also available from this flight

4. The STS-56 mission was launched on $4 / 8 / 93$, remained in space for 10 days aboard Discovery, and carried experiments focused primarily on musculoskeletal changes during exposure to microgravity using laboratory rats. Tissue samples remaining from these experiments and available to interested investigators are listed in Table IX.1c. 
TABLE IX.1a

SLS-1 Unassigned Blospecimens

\begin{tabular}{|c|c|c|c|c|c|c|c|c|c|c|c|}
\hline & $\begin{array}{c}L+0 \\
\text { Basal }\end{array}$ & $\frac{2+0}{D F T}$ & $\begin{array}{l}\mathrm{R}+0 \\
\mathrm{a} F \mathrm{r}\end{array}$ & $\begin{array}{c}\text { R+o } \\
\text { DFPI } \\
\text { Control }\end{array}$ & $\begin{array}{c}\text { R+0 } \\
\text { Fllght }\end{array}$ & $\begin{array}{l}R+0 \\
\text { Cround } \\
\text { Control }\end{array}$ & $\begin{array}{l}\mathrm{R}+10 \\
\mathrm{DFPT}\end{array}$ & $\begin{array}{l}\text { R+ML } \\
\text { CFPT }\end{array}$ & $\begin{array}{l}\text { R+ul } \\
\text { Dept } \\
\text { Control }\end{array}$ & $\begin{array}{l}\text { R+kil } \\
\text { Flfght }\end{array}$ & $\begin{array}{l}\text { Btul } \\
\text { Cround } \\
\text { Control }\end{array}$ \\
\hline Aorta & & 5 & 5 & 5 & 5 & 5 & & 5 & 5 & 5 & 5 \\
\hline BloodABC-RBC-1 & & 6 & 5 & 5 & & & & 4 & 5 & & \\
\hline Elood RBC-RBO-2 & & 5 & 5 & 5 & & & & 5 & 5 & & \\
\hline Blood RBC-RBCO & 10 & 10 & 10 & 10 & 10 & 10 & & 8 & 10 & 8 & 10 \\
\hline Blood RBC-RBC-4 & 2 & 8 & 10 & 10 & 10 & 10 & & 8 & 10 & $\theta$ & 10 \\
\hline Duodenum- & & 5 & 5 & 5 & & & & 5 & 5 & & \\
\hline Duodenum-rt & & 5 & 5 & 5 & & & & 5 & 5 & & \\
\hline Heart auricle & 5 & 5 & 5 & 5 & 5 & 5 & & 5 & 5 & 5 & 5 \\
\hline Heart-z & & & 5 & 5 & & & & 5 & 5 & & \\
\hline Houmf & & 5 & 5 & 5 & & & & 5 & 5 & & \\
\hline Iloum-th & & 5 & 5 & 5 & & & & 5 & 8 & & \\
\hline Selunum- & & 5 & 6 & 5 & & & & 5 & 5 & & \\
\hline Jelunum-t & & 5 & 5 & 5 & & & & 5 & 5 & & \\
\hline Kldnoy-t & & & & & & & 15 & & & & \\
\hline Kldney-t & 15 & 15 & 15 & 15 & 15 & 15 & 15 & 14 & 15 & 14 & 10 \\
\hline Kdney-z & 10 & 10 & 15 & 75 & 10 & 10 & & 14 & 15 & 14 & 10 \\
\hline Luer-l lobe & 15 & 15 & 15 & 75 & 15 & 5 & & 14 & 15 & 14 & 15 \\
\hline Luer-z & & & 5 & 6 & & & & 6 & 6 & & \\
\hline Lunges & 5 & 5 & 5 & 5 & & & & 5 & E & 5 & 5 \\
\hline Pencreas dower $1 / 2$ & 15 & 15 & 15 & 15 & 16 & 15 & & 14 & 15 & 14 & 15 \\
\hline Pancreas-ujper $1 / 2$ & 10 & 16 & 15 & 15 & 10 & 10 & & 14 & 15 & 9 & 10 \\
\hline Plasma-PLS-1 & 5 & 5 & 5 & 8 & & 5 & & 5 & 6 & 5 & 5 \\
\hline Platina- PLS-2 & & 5 & 5 & 5 & & & & 5 & & & \\
\hline Plaems-PLSA & & & & 5 & & & & 5 & 5 & & \\
\hline Plasma-PLS-4 & & 5 & 5 & 5 & & & & 5 & 5 & & \\
\hline Plasma-PLS-5 & & 5 & 5 & E & & & & 5 & 5 & & \\
\hline Plasma-PLS-6 & 10 & 10 & 10 & 10 & 10 & 10 & & 9 & 10 & 9 & 9 \\
\hline Plasma- PLS7 & 10 & 10 & 10 & 10 & 10 & 10 & & 9 & 10 & 9 & 10 \\
\hline Plasma-PLS-8 & 10 & 10 & 10 & 10 & 10 & 10 & & 8 & 10 & 9 & 10 \\
\hline Plasma-PLSe & 10 & 10 & 10 & 10 & 10 & 10 & & $\theta$ & 10 & $\theta$ & 10 \\
\hline Spinal cord- lower $1 / 2$ & 5 & & & & 5 & 5 & & & & 5 & 5 \\
\hline Solnal cord-upoer & 5 & & & & 5 & 5 & & & & 5 & 5 \\
\hline Stomach & 10 & 15 & 15 & 16 & 10 & 10 & & 14 & 15 & $\theta$ & 10 \\
\hline Testis-ft & 15 & 10 & 15 & 15 & 16 & 15 & & 14 & 10 & 14 & 15 \\
\hline Tostls-it & 15 & 15 & 15 & 15 & 15 & 15 & & 14 & 15 & 14 & 15 \\
\hline Thymus & 15 & 15 & 15 & 15 & 15 & 15 & 16 & 14 & 15 & 14 & 15 \\
\hline
\end{tabular}

$L+0=$ Launch day

$R+0=$ Day of recovery

$A+10$. Recovery date +10 days

R+MLx Recovery date + mission length

Numbars indleate number of samples collected. 
SLS-2 Unassigned Biospecimens

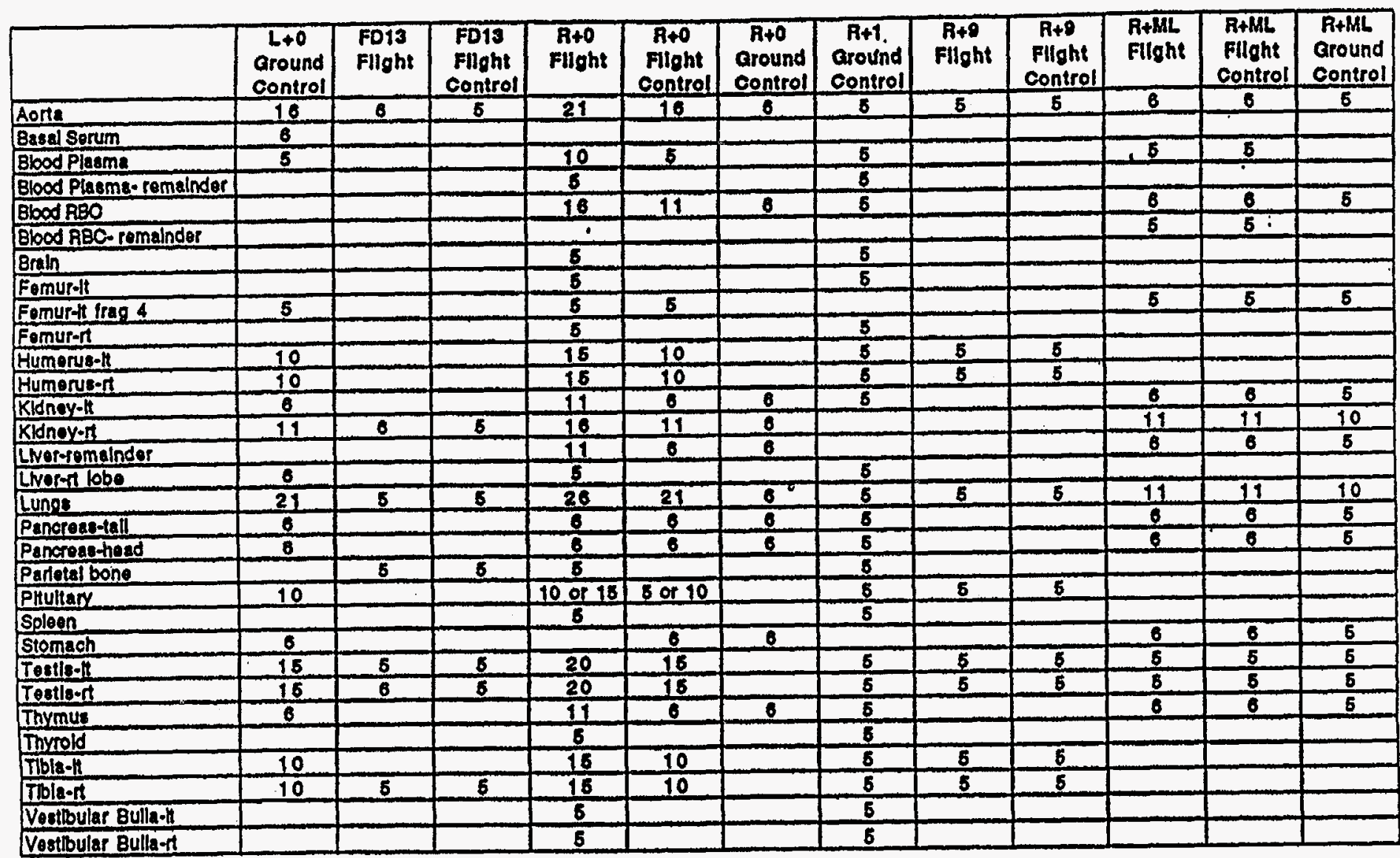

Vom taun day

FOrs Flloht day 13

8+0u Oay of racovery

$R+1=R$ ecovery dato +1 day

$R+9=$ Reoovery date +9 days

$R+M L=$ Recovery date + mission length

Numbers Indicate number of samples collected. 
Pare.03 Unassigned Blospecimens

\begin{tabular}{|c|c|c|c|c|c|c|c|c|c|c|}
\hline & $\begin{array}{c}L+0 \\
\text { Basal }\end{array}$ & $\begin{array}{c}\text { R+o } \\
\text { Fllght } \\
\text { Control }\end{array}$ & $\begin{array}{c}\text { R+o } \\
\text { Fllght }\end{array}$ & $\begin{array}{c}B+0 \\
\text { Ground } \\
\text { Control }\end{array}$ & $\begin{array}{l}\text { R+24 } \\
\text { Fllght } \\
\text { Control }\end{array}$ & $\begin{array}{l}\text { f+24 } \\
\text { Flight }\end{array}$ & $\begin{array}{l}R+24 \\
\text { Cround } \\
\text { Control }\end{array}$ & $\begin{array}{l}\text { R+72 } \\
\text { Fllght } \\
\text { Control }\end{array}$ & $\begin{array}{l}\text { R+72 } \\
\text { Fllght }\end{array}$ & $\begin{array}{l}\mathrm{R}+72 \\
\text { Ground } \\
\text { Control }\end{array}$ \\
\hline Bladder & 6 & 6 & 6 & 17 & 5 & 5 & 10 & 5 & 5 & 10 \\
\hline Blood RBC & 8 & 6 & 6 & 17 & 6 & 5 & 10 & 5 & 5 & 10 \\
\hline Colon & 8 & 6 & 6 & 17 & 5 & 5 & 10 & 5 & 5 & 10 \\
\hline Colon-plece & 6 & 6 & 6 & 17 & 5 & 5 & 10 & 5 & 5 & 10 \\
\hline Dlaphragm & 8 & 6 & 6 & 17 & 5 & 5 & 10 & 5 & 5 & 10 \\
\hline Eyes & 6 & 6 & 6 & 17 & 5 & 5 & 10 & 6 & 5 & 10 \\
\hline Hypolhalamus & 3 & 6 & 6 & 17 & 5 & 5 & 10 & 5 & 5 & 10 \\
\hline Ileum & $\overline{8}$ & 6 & 6 & 17 & 5 & 5 & 10 & 5 & 5 & 10 \\
\hline lleum-plece & 6 & 8 & 6 & 17 & 5 & 5 & 10 & 5 & 5 & 10 \\
\hline Jolunum & 6 & 6 & 6 & 17 & 5 & 5 & 10 & 5 & 5 & 10 \\
\hline Jolunum-plece & 6 & 8 & 6 & 17 & 5 & 5 & 10 & 5 & 5 & 10 \\
\hline Liverth lobe seo. 1 & $B$ & 6 & 6 & 17 & 6 & 5 & 10 & 5 & 5 & 10 \\
\hline Llver-tt. lobo 800.2 & 6 & 6 & 6 & 17 & 5 & 5 & 10 & 5 & 5 & 10 \\
\hline Llver-th lobe & $B$ & 6 & 6 & 17 & 5 & 5 & 10 & 5 & 5 & 10 \\
\hline Liverort. lobe & 8 & B & 6 & 17 & E & 5 & 10 & 5 & 5 & 10 \\
\hline Lung-Jt, & 6 & 6 & 8 & 17 & 5 & 5 & 10 & 5 & 5 & 10 \\
\hline Luno-rt. & 6 & 6 & 6 & 17 & 5 & 5 & 10 & 5 & 5 & 10 \\
\hline Pltultery & 8 & 6 & 6 & 17 & 5 & 5 & 10 & 5 & 5 & 10 \\
\hline Skin & 8 & 8 & 6 & 17 & 5 & 5 & 10 & 5 & 5 & 10 \\
\hline Slomech & 6 & 6 & 6 & 17 & 6 & 5 & 10 & 5 & 5 & 10 \\
\hline Testlo-tt & 6 & 6 & 6 & 17 & 5 & 5 & 10 & 5 & 5 & 10 \\
\hline Testls-rt & 5 & 6 & 6 & 17 & 5 & 5 & 10 & 5 & 5 & 10 \\
\hline Thyrold & 0 & 6 & 6 & 17 & 5 & 5 & 10 & 5 & 5 & 10 \\
\hline Trachea & 6 & 6 & 6 & 17 & 5 & 5 & 10 & $\frac{5}{5}$ & 5 & 10 \\
\hline
\end{tabular}

$L+O=$ Launch day

$R+0=$ Day of recovery

$R+24=$ Recovery time +24 hours

$R+72=$ Recovery time +72 hours

Numbers Indicale number of samples collected. 


\section{POTENTIAL ANIMALS FLOWN PRIOR TO A HYPOTHETICAL 2016 MANNED MARS MISSION}

Current plans for flights carrying animals are summarized in Table IX.2. These plans are based on the following assumptions:

1. The date 2016 was chosen for this exercise as it was the frequent date-of choice for a study recently performed at NASA/Ames to identify technology drivers required for the mission.

2. Prior to 2001, flights supporting Space Station development will not also support whole animal experiments. Beginning in 2001, there will be 4 increments ( $90 \mathrm{~d}$ each) per year. Of those, 2 will support animal experiments (4 Advanced Animal Habitats [AAH] per increment), 1 will support cell cultures (incubator $/ 2$ cell culture chamber system [CCU] per increment) and the fourth will be used by non-life sciences disciplines. An AAH will house 6 rats or 24 mice, and it is assumed that the AAHs will be split evenly between rats and mice, and that half of each will be at $0-\mathrm{g}$ and half at 1-g. A CCU will hold $24 \times 3 \mathrm{ml}, 16 \times 7-10 \mathrm{ml}$ or $6 \times 30 \mathrm{ml}$ culture chambers, and it is assumed that the average volume per CCU will be $150 \mathrm{ml}$.

Beginning in 2002, the Biotechnology Facility (BTF) will be available and will support up to 4 batch cultures per year ( 1 batch per increment). Of those, 2 increments per year are assumed to be for research purposes. A batch is assumed to be 30 liters.

\section{BIOLOGICAL TISSUES AVAILABLE FROM ASTRONAUTS}

Samples (primarily urine and blood) have been obtained from human subjects participating in spaceflight missions. However, primarily due to privacy issues, no catalog of available samples currently exists for public distribution. Further information can be obtained by contacting Dr. Joel Leonard, Life Sciences Data Archive Program Scientist, (301) 295-3520. 
TABLE IX.2

Potential Specimens Available from Future Flights

\begin{tabular}{|c|c|c|c|c|c|c|}
\hline Year & Vehicle & Mice & Rats & Primates & CCUVol & Batch Vol \\
\hline 1997 & $\operatorname{AEM}(15 \mathrm{~d})$ & & 6 & & & \\
\hline 1998 & Neurolab & 18 & $\begin{array}{l}38 \text { adults } \\
140 \text { pups }\end{array}$ & & & \\
\hline & BION & & & 3 rhesus & & \\
\hline 1999 & & & & & TBD & \\
\hline 2000 & Nika $B(45 d)$ & 75 & 30 & & & \\
\hline 2001 & Space Station & 192 & 48 & & 300 & \\
\hline 2002 & $\begin{array}{l}\text { Space Station } \\
\text { BTF }\end{array}$ & 192 & 48 & & 300 & 60000 \\
\hline 2003 & $\begin{array}{l}\text { Space Station } \\
\text { BTF }\end{array}$ & 192 & 48 & & 300 & 60000 \\
\hline 2004 & $\begin{array}{l}\text { Space Station } \\
\text { BTF }\end{array}$ & 192 & 48 & & 300 & 60000 \\
\hline 2005 & $\begin{array}{l}\text { Space Station } \\
\text { BTF }\end{array}$ & 192 & 48 & & 300 & 60000 \\
\hline 2006 & $\begin{array}{l}\text { Space Station } \\
\text { BTF }\end{array}$ & 192 & 48 & & 300 & 60000 \\
\hline 2007 & $\begin{array}{l}\text { Space Station } \\
\text { BTF }\end{array}$ & 192 & 48 & & 300 & 60000 \\
\hline 2008 & $\begin{array}{l}\text { Space Station } \\
\text { BTF }\end{array}$ & 192 & 48 & & 300 & 60000 \\
\hline 2009 & $\begin{array}{l}\text { Space Station } \\
\text { BTF }\end{array}$ & 192 & 48 & & 300 & 60000 \\
\hline 2010 & $\begin{array}{l}\text { Space Station } \\
\text { BTF }\end{array}$ & 192 & 48 & & 300 & 60000 \\
\hline 2011 & $\begin{array}{l}\text { Space Station } \\
\text { BTF }\end{array}$ & 192 & 48 & & 300 & 60000 \\
\hline 2012 & $\begin{array}{l}\text { Space Station } \\
\text { BTF }\end{array}$ & 192 & 48 & & 300 & 60000 \\
\hline 2013 & $\begin{array}{l}\text { Space Station } \\
\text { BTF }\end{array}$ & 192 & 48 & & 300 & 60000 \\
\hline 2014 & $\begin{array}{l}\text { Space Station } \\
\text { BTF }\end{array}$ & 192 & 48 & & 300 & 60000 \\
\hline 2015 & $\begin{array}{l}\text { Space Station } \\
\text { BTF }\end{array}$ & 192 & 48 & & 300 & 60000 \\
\hline & & 3,073 & 934 & 3 & $4,500^{*}$ & $840,000^{* *}$ \\
\hline
\end{tabular}




\section{B. CELL SIGNALLING THROUGH G PROTEINS}

The striatum is one of the basic central processing areas involved in mediating specific second messengers that further convey the signals to other neurons, and subsequent targets. Neurotransmitters and other ligands relay transfer messages through receptors such as the muscarinic receptors. These receptors are linked to signal-transducing guanine regulatory binding proteins, the G proteins (see reviews by Ali and Agrawal, 1994; Axelrod et al., 1988; Birnbaumer, 1991; Raymond, 1995; Rens-Domiano and Hamm, 1995). The $G$ proteins are heterotrimers composed of $\alpha, \beta, \gamma$ subunits. Upon stimulation, guanine diphosphate (GDP) is replaced with guanine triphosphate (GTP), and the G protein becomes dissociated from the receptor (specifically, the $\alpha$ subunit becomes dissociated from the $\beta \gamma$ subunits). It is the $\alpha$ subunits which activate specific second messengers that further convey the signals to other neurons or subsequent targets. Following stimulation, the receptor G-protein complex reassociates when an enzyme, GTPase, hydrolyzes GTP to GDP, which causes the $\alpha$ subunit to reassociate with the $\beta \gamma$ subunits. During stimulation, there are a great number of second messengers that can be activated, depending upon the particular receptor G-protein complex that is stimulated. In the case of muscarinic subtype 1 receptor $(\mathrm{m} 1 \mathrm{AChR})$ stimulation, phosphatidylinositol (PI) is phosphorylated to form phosphatidylinositol 4-phosphate (PIP) which is further phosphorylated to form phosphatidylinositol 4,5 diphosphate (PIP2) which is further broken down under the actions of phospholipase $C$ to 1,4,5-inositol trisphosphate (IP3) and diacylglycerol (DAG), two of the second messengers in this system. (Berridge and Irvine, 1989; Fisher and Agranoff, 1987). IP3 acts to evoke the quantal release of $\mathrm{Ca}^{2}+$ (Missiaen et al., 1991).

\section{CHEMICAL CARCINOGENICITY STUDIES IN RODENTS}

For a variety of reasons, rodents have usually been chosen for testing longterm toxicity and carcinogenicity of chemicals, and in the 1960s standard protocols were established for performing these studies (summarized by Hart et al., 1995). The standard procedure used in testing drugs, environmental agents, and other possible carcinogens is to study two species, using both sexes at two dose levels (Contrera, 1995). Ordinarily rats and mice are the species chosen because of their reasonable life span, ease of breeding and general similarity to humans in metabolism and pathology. The environmental conditions, diet composition, and animal care conditions are carefully regulated in such studies, and these studies have identified hundreds of potential human carcinogens based on their ability to induce cancers in at least one of the species. 
There are a number of difficulties with this approach. The most important one is whether rodent carcinogens can automatically be considered to be human carcinogens, and the answer is clearly "no". Ames et al. (1987) concluded that "quantitative extrapolation from rodents to humans...is guesswork", and that the "sources of uncertainty are so numerous, and so substantial, that only empirical data will resolve them, and little of this is available. While arguing that these data do not provide a basis for absolute human risk assessment, they do acknowledge that the data can be used as a guide for setting priorities. Thus, large databases of rodent carcinogens have been established (Ashby and Tennant 1991; Tennant, 1993; Gold et al., 1993), and are used by the Food and Drug Administration (FDA) to regulate human intake of such chemicals.

A second question is whether human susceptibility at low dose is adequately modelled by animal tests done at high dose. To assume that it is also assumes a linear dose response, but this is usually not known because only a limited number of doses have been utilized (usually two). Quite often when sufficient data are available, a quadratic model is more consistent with the dose-response relationship than is a linear model.

A third difficulty is that, because of the high cost of doing so, the dietary intake of each test animal is not controlled even though it is now well known that both maximum life span and development of pathology are highly sensitive to caloric intake and body weight (Weindruch and Walford, 1988). Because of this confounding factor the FDA has recently established the policy that weight control must now be included in future testing. Such a condition should be included in all future assays in which cancer rates are being determined, if possible.

Thus, while there is little evidence that extrapolation from the results of rodent cancer tests done at high doses to effects on humans exposed to low doses is justified, Ames et al. (1987) do state that "some reliance on animal cancer tests is unavoidable". This is frequently because of the virtual absence of good human data, a situation which certainly parallels our knowledge of radiation effects on humans in outer space. Often the best human data available are epidemiological, and it is difficult to establish causal relationships from such data alone.

An additional complication is that results with rats and mice, which are closely related, also show some discordance. Of 226 compounds tested which were carcinogenic in either rats or mice, 96 of these were positive in only one of the two species (Ames et al., 1987). In a later paper, Gold et al. (1989) reported that of 392 tested in both species, $76 \%$ of rat carcinogens are positive in the mouse, and that $70 \%$ of mouse carcinogens are positive in the rat. In general, predictions are better for mutagens than for non-mutagens, and for substances that are active at low doses. The predictive ability is also organ- 
specific. These results suggest that the predictability of carcinogenesis results from rodents to humans will be less than $70 \%$ until more is known about species differences in mechanisms of DNA damage due to carcinogens and its repair, metabolism and pharmacokinetics of carcinogens, and the role of anticarcinogenic mechanisms. This is due to insufficient experimental information available about six major areas:

(1) the basic mechanisms of carcinogenicity

(2) the relation of cancer, age and life span

(3) the timing and order of the steps in the carcinogenic process that are being accelerated

(4) species differences in metabolism and pharmacokinetics

(5) species differences in anticarcinogens and other defenses

(6) human heterogeneity

In response to this challenge, one can ask whether the lack of knowledge is as extensive in 1996 as it was in 1987, and the answer is no, particularly with regard to items (1) - (3). Item (1) has been addressed by numerous investigators, with the result that many oncogenes and tumor suppressor genes have now been discovered and characterized. For example, Kumar et al. (1995) have recently summarized our knowledge for several tumor suppressor genes (p53, RB, $\propto$-inhibin) obtained from mutant mice, and other tumor suppressor genes are constantly being identified and characterized. Table VII.6 lists several of the many genes that may be mutated and/or inactivated in various human tumors. Knowledge about item (2) has benefited from the impressive advances which have been made since 1987 in understanding the genetic basis for cell senescence (Pereira-Smith and Smith, 1988), the role of replicative senescence in controlling carcinogenesis (Dimri and Campisi, 1994), and the role of oxidative damage in both aging and carcinogenesis (Ames and Gold, 1991). Finally, the pioneering work of Fearon and Vogelstein (1990) has provided exciting new information about the steps in the carcinogenic process which may be accelerated in colon cancer.

Jain (1996) has recently and briefly reviewed the hopes for treatment of solid human tumors with molecular medicine. He concludes that "Despite the limitations inherent in animal tumor models, they have provided valuable information for the delivery of therapeutic agents. Molecular genetics will certainly help in the development of more realistic animal models of the human disease." Examples of some of these are listed in TablesVII.1, VII.2, and VII.3. 


\section{SOURCES OF TRANSGENIC AND KNOCKOUT MICE}

Most genetically altered mice are obtained by contacting the investigator(s) who produced the mouse. However, some mice can now be obtained from commercial suppliers, and this trend is expected to continue as these genetically altered mice become increasingly regarded as "reagents". One of these suppliers is The Jackson Laboratory. A catalog can be obtained from The Jackson Laboratory, Animal Resources, 600 Main Street, Bar Harbor, Maine, 04609-1500; TEL: 207-288-6414. The 1996 catalog lists 64 transgenic mouse strains, which can be purchased for $\$ 43.40$ (and up) per breeder pair. Most of these strains do not appear to be relevant for studies on radiation-induced damage and repair, with the possible exception of mice carrying extra copies of genes for $b c l$-2 (an anti-apoptotic gene) and superoxide dismutase-1, an antioxidant gene. The Jackson Laboratory will soon carry the lacZ-plasmid mouse described in Section V.A.1.a. The Jackson Laboratory also maintains hundreds of mutant mouse strains useful for a wide variety of purposes.

Other transgenic (TG) and knockout (KO) mice commercially available include:

p53 knockout mouse OncoMouse ( $V$-Ha-ras TG) 12526; TEL: 518-537-6208

p53 (KO)/Big Blue

pim-1(TG) (sensitive to chemically-induced lymphoma)

MPF outbred mice

Big Blue mouse and rat

Muta Mouse

Production of transgenic mice

Production of knockout mice
Stratagene; 11011 N. Torrey Pines Rd., LaJolla, CA, 92037; TEL: 800-424-5444

HRP Inc.; Box 7200, Denver, PA, 17517; TEL: 800-345-4114,

DNX Transgenics; 303 B College Rd., East Princeton, NJ, 08540; TEL: 609-520-0300

Genome Systems Inc.; 8620 Pennel Drive St. Louis, MO, 63114; TEL: 800-430-0030 


\section{E. MODULATION OF RADIATION-INDUCED DAMAGE WITH RADIOPROTECTORS}

Because the radiation environment in space cannot be eliminated, consideration has been given to strategies to reduce the risks associated with exposure to radiation. In this regard there are two scenarios and two types of risks which must be considered during travel in outer space. Each requires a somewhat different approach. Astronauts are at risk for acute effects of radiation only under conditions where exposure occurs outside the spacecraft during a solar particle event. Under these conditions it is possible that doses received may be sufficiently high to result in acute hematological effects which could be debilitating or life threatening. In contrast, day to day exposures inside the space craft are substantially lower and will not result in the astronauts being at risk for acute radiation effects. It is thus important to consider strategies which would address each of these two distinct scenarios.

\section{THIOL-TYPE RADIOPROTECTORS}

The use of radioprotective drugs is one possible approach to reducing the risks associated with acute high dose exposures that might be encountered during a solar particle event while outside the spacecraft. It has long been known that thiol-containing compounds can protect cells both in vivo and in vitro from the toxic effects of radiation, presumably by functioning in an antioxidant role. The earliest thiol compounds tried included such compounds as cysteine and cysteamine, which are effective but have undesirable side effects. A large battery of compounds has been developed as part of a program at Walter Reed Army Institute of Research, the most well known of which is WR-2721 (Yuhas and Storer, 1969). Experimental studies have demonstrated that this compound can be effective in reducing a number of deterministic effects associated with radiation exposure, including effects on the hematopoietic system and the skin (Yuhas and Storer, 1969; Yuhas, 1972). Such experimental results have been the basis for clinical trials examining the efficacy of this compound as a radioprotective agent during treatment of cancer with radiation. Unfortunately, the protective effects of WR-2721 require the administration of an oral dose which produces side effects not desirable for space flight. These include vomiting and vasodilation, the latter resulting in hypotension. Other compounds need to be examined to determine their efficacy as radioprotective agents with fewer side effects.

A series of studies by Grdina and co-workers (Grdina et al., 1992; 1995) have suggested that low doses of WR-2721 and its active metabolite WR-1065, N-(2mercaptoethyl)-1,3-diaminopropane, given up to three hours after neutron radiation or ${ }^{60} \mathrm{Co} \gamma$-ray exposure can reduce the mutagenic and carcinogenic effects of radiation, possibly by means of a mechanism independent of its protective effects against acute (cytotoxic/oxidative) effects. One possibility is 
that WR-1065 induces apoptosis of radiation-damaged cells. Some recent studies suggest that the disulfide of WR-1065 may even act like a polyamine, competing with spermine, and thereby influencing gene expression and chromatin stabilization (Newton et al., 1996). It is not known at present whether this approach would also be effective in reducing effects produced by protons and heavy ions. However, the use of this compound on a daily basis is not possible because multiple low doses eventually result in similar toxic effects as higher single doses. This makes use of this particular compound inappropriate as a daily supplement.

Additional mechanistic studies are needed to allow the opportunity for the development of agents which are effective, but also have fewer and less toxic side effects which would allow them to be taken on a daily basis. One approach to avoid this problem is to develop pro-drugs which release the free sulfhydryl groups nonenzymatically and slowly once inside the cells. Roberts et al. (1995) have synthesized thiazolidine derivatives of ribocysteamine and glucocysteamine which liberate the corresponding thiolamines endogenously. These compounds were not toxic at concentrations as high as $25 \mathrm{mM}$, when added to cultures of hamster cells, and reduced cellular damage due to ${ }^{137} \mathrm{Cs} \gamma$-rays at a dose of up to $6 \mathrm{~Gy}$. These two pro-drugs were compared with WR-1065, which provides protection against $\gamma$-rays in animals (Murray et al., 1988) and cultured cells (Rubin et al., 1996). In an experiment where WR-1065 and the sugar-cysteamine compounds were compared at $4 \mathrm{mM}$, the former was only slightly more effective at reducing radiosensitivity (Roberts et al., 1995).

\section{NITRONES AS SPIN-TRAPPING COMPOUNDS}

Recent work on $\alpha$-phenyl-tert-butyl nitrone (PBN) has indicated that chronic administration either intraperitoneally or in the diet not only can protect the gerbil brain against death due to artificially-induced ischemia, but also reduces oxidation of proteins in the brain (Carney et al., 1991). They also obtained evidence that PBN can reverse age-related protein oxidation, and decrease error frequency in a radial arm maze designed to test spatial and short term memory. Even though nitrones are spin-trapping compounds which can neutralize free radicals, it is doubtful whether the amount of PBN used was sufficient to serve as a stoichiometric antioxidant. The actual mechanism of action of nitrones in reducing protein oxidation in the brain is unknown, as are the possible side effects of chronic administration in human. The development of these compounds for biomedical purposes is currently being carried out by a biotechnology company called Centaur Pharmaceuticals in Sunnyvale, CA.

The results of experiments using PBN and other nitrones as radioprotectants are equivocal so far. Young et al. (1996) found that while several nitrones, 
including PBN, were very effective at preventing DNA oxidation in cultured CHO cells by ${ }^{137}$ CS $\gamma$-rays, they only marginally increased cell survival at doses up to $10 \mathrm{~Gy}$. Similar experiments should be done using HZE particle irradiation.

\section{PROTEASE INHIBITORS}

Kennedy (1994) has recently summarized her work on the possible role of protease inhibitors in preventing carcinogenesis. She has shown that the Bowman-Birk inhibitor (BBI) is particularly effective at suppressing carcinogenesis in rodents (mice, rats, hamsters) in a variety of tissues, such as colon, liver, lung, esophagus. BBI can be administered intraperitoneally, intravenously, topically or in the diet. BBI is effective in preventing both radiation-induced (Kennedy and Little, 1978) and chemical-induced (St. Clair, 1991) transformation of cultured cells, but has no effect on cells which are already transformed (Kennedy and Little, 1981). These properties suggest it could be useful as a secondary radioprotectant during a space flight to prevent or reduce post-flight carcinogenesis. Clinical trials in humans to establish both safety and efficacy have begun (Ann Kennedy, personal communication).

The mechanistic basis of the protective action of BBI is not known, but it is clear that certain proteolytic activities increase during transformation, and that these activities are inhibited by BBI (Kennedy and Manzone, 1995). It is also clear that the protease inhibitor is acting early in the transformation process. One possibility is that BBI prevents the recently reported degradation of p53 (and other tumor suppressor activities?) which occurs during transformation of primary cultures of mammary epithelial cells (Band et al, 1993; Dalal et al. 1996); radiation-induced transformation induces a similar loss of p53 (Wazer et al., 1994).

\section{DIETARY SUPPLEMENTS}

Diet is also known to have an important influence on cancer development because natural foods contain both carcinogens and anti-carcinogens (Ames et al., 1991; 1995; Milner, 1994). Anti-carcinogens are particularly abundant in fruits and vegetables. Plants contain flavonoid glycosides which are thought to have antioxidant properties which could account for their apparently beneficial effects on human cognitive junction (Rai et al., 1991), their ability to reduce $\mathrm{Ca}^{++}$-induced increase in oxidative metabolism of brain neurons (Oyama et al., 1993) and slow down age-related structural changes in hippocampi (Barkats et al., 1994) and cerebral cortex in mice (Huguet et al., 1994). Kostyuk et al. (1996) have shown that natural flavonoids such as quercetin and rutin can reduce asbestos fiber-induced oxidative damage as well as a spectrum of physiological damage caused by oxidative stress. These 
observations suggest the possibility that such compounds might also be useful in reducing oxidative damage due to radiation, but the idea is as yet untested.

Another natural compound which can be added to the diet and which has been tested in vitro is melatonin (Vijayalaxmi et al., 1995). Melatonin has been shown to have antioxidant properties in vitro, and to protect lymphocytes against induction of chromosome aberrations by ${ }^{137} \mathrm{Cs} \gamma$-rays. Melatonin at $1 \mathrm{mM}$ reduces the induction of acentric chromosome fragments, ring chromosomes, and other chromosomal aberrations by $150 \mathrm{cGy} \gamma$-rays by about $50 \%$. In contrast to thiol radioprotectants, melatonin is a naturally circulating compound in rodents and humans, and has not yet been found to be toxic.

None of these compounds has yet been tested against the effects of HZE particles, so it is not known whether any of these putative antioxidants may be effective as radioprotectants against particle radiation.

Compounds of some therapeutic promise against carcinogenesis are limonene, and its hydroxylated analog, perillyl alcohol (Haag and Gould, 1994). When added to the diet, perillyl alcohol is five times more efficient at inducing regression of chemically-induced mammary carcinomas in rats than is limonene. Perillyl alcohol has also been shown to increase apoptosis in chemically-induced liver tumors, suggesting this could be the mechanism for tumor regression (Mills et al., 1995), although other mechanisms remain possible. Thus, while perillyl alcohol would not prevent the initial HZE particle-induced damage, it might be quite effective in preventing the subsequent formation of a tumor. 


\section{BIOSKETCHES of PANEL MEMBERS}

Susan M. Berget, Ph.D.

Current Position

Professor, Department of Biochemistry

Baylor College of Medicine

Houston, TX 77030

Professional Experience

1974: Ph.D. in Biochemistry, University of Minnesota

1974 - 1978: Postdoctoral work at MIT (Sharp)

1979 - 1985: Faculty member, Department of Biochemistry, Rice University, Houston, TX

1985 - present : Faculty member, Department of Biochemistry, Baylor College of Medicine

Recent Related Professional Activities

NIH Molecular Biology Review Committee (1985-1989)

NIH Genome Research Review Committee (1985-1998)

Editorial Board, Molecular and Cellular Biology (1988-1995);

Gene Expression (1990-1994)

Recent Relevant Publications

1. Berget SM. 1995. Exon recognition in vertebrate splicing. J. Biol. Chem 270: 2411-2414.

2. Humphrey MB, Bryan J, Cooper TA, Berget SM. 1995. A 32-nucleotide exon-splicing enhancer regulates usage of competing 5 ' splice sites in a differential internal exon. Mol. Cell. Biol. 15: 3979-3988.

3. Lou H, Yang Y, Cote GJ, Berget SM, Gagel RF. 1995. An intron enhancer containing a $5^{\prime}$ splice site sequence in the human calcitonin/calcitonin gene-related peptide gene. Mol. Cell. Biol. 15: 7135-7142.

4. Lou H, Gagel RF, Berget SM. 1996. An intron enhancer recognized by splicing factors activates polyadenylation. Genes Develop. 10: 208-219.

Current Research Funding American Cancer Society research grant; NIH research grants, Robert Welch Foundation grant

Current Use of Animals in Research - none 
Mina J. Bissell, Ph.D.

Current Position

Director, Life Sciences Division

Lawrence Berkeley National Laboratory (LBNL)

Berkeley, CA 94720

Professional Experience

1969: Ph.D. in Microbiology and Molecular Genetics, Harvard University 1969-1970: Milton Fellow, Harvard University

1970-1972: American Cancer Society Postdoctoral Fellow, University of

California, Berkeley (Rubin)

1972- Present: Scientific Staff, Senior Scientist, LBNL

1989-1992: Director, Cell and Molecular Biology Division, LBNL

1992-Present: Director, Life Sciences Division, LBNL

Recent Related Professional Activities

President Elect, American Society of Cell Biology (1995-1997)

Associate Editor - (current only) - Cancer Res.; Molec. Cell. Diff.; In vitro Cell.

Develop. Biol.; Molec. Carcinogen.; Breast J.

NIH study Sections - Molecular Cytology (1981-1985); Pathology B (1988-1992)

Health \& Environment Advisory Board, (HERAC), DOE - Member and

Subcommittee Chair, 1996-97

Integration Panel on Breast Cancer - Member and Subcommittee Chair, 1996

Conference Chair-Gordon Research Conference on Biological Structure and

Gene Expression, 1992; Keystone Symposium on Breast and Prostate

Cancer, 1996.

Recent Relevant Publications

1. Bissell MJ, Werb Z. (1995). Eds.: Basic science aspects of breast cancer.

Seminars in Cancer Biology. 6: 117-118.

2. Streuli CH, Schmidhauser C, Bailey N, Yurchenco P, Skubitz A, Bissell MJ. 1995. A domain within laminin that mediates tissue-specific gene expression in mammary epithelia. J. Cell Biol. 120: 253-260.

3. Ronnov-Jessen L, Petersen OW, and Bissell MJ. (1996) Cellular changes involved in conversion of normal to malignant breast: The importance of the stromal reaction. Physiological Reviews. 76: 69-125.

4. Boudreau N, Sympson CJ, Werb Z, and Bissell MJ. (1995) Suppression of ICE and apoptosis in mammary epithelial cells by extracellular matrix. Science 267: 891-893.

Current Research Funding

NIH research grants, DOE research grant, industrial, BARD cooperative grants, Israel. 
Current Use of Animals in Research - mice, mice and human cells in culture (from both primary and cell lines) 


\section{Aloke Chatterjee, Ph.D.}

\section{Current Position}

Deputy Head, Life Sciences Division

Lawrence Berkeley National Laboratory

Berkeley, CA 94720

\section{Professional Experience}

1970: Ph.D. in Chemical Physics, University of Notre Dame 1970 - present: Biophysicist, Lawrence Berkeley National Laboratory 1988 - present: Head, Department of Radiation Biology and DNA Repair 1989 - present: Deputy Head, Life Sciences Division

\section{Recent Related Professional Activities}

Associate Editor, Radiation Research since July 1995

Director, LBNL-CSU NSCORT Program since January 1992

\section{Recent Relevant Publications}

1. Chatterjee A, Schmidt JB, Holley WR. 1994. Monte Carlo approach in assessing damage in higher order structures of DNA, in "Computational approaches in molecular radiation biology: Monte Carlo methods", M. N. Varma and A. Chatterjee, Eds. Plenum Press NY, NY pg. 225-241.

2. Holley WR, Chatterjee A. 1994. A computational approach to the relationship between radiation-induced double strand breaks and translocations, in "Computational approaches in molecular radiation biology: Monte Carlo methods", M. N. Varma and A. Chatterjee, Plenum Press NY, pg. 251-259.

3. Henle ES, Roots R, Holley WR, Chatterjee A. 1995. DNA strand breakage is correlated with unaltered base release after gamma irradiation. Radiation Res. 143: 144-150.

4. Holley WR, Chatterjee A. 1996. Clusters of DNA damage induced by ionizing radiation: Formation of short DNA fragments. I. Theoretical modelling. Radiation Res. 145: 188-199.

\section{Current Research Funding}

NASA research and training grant, DOE research grant

Current Use of Animals in Research None 


\section{R. J. Michael Fry, MD}

Current Position

Consultant, Biology Division

P. O. Box 2009

Oak Ridge National Laboratory

Oak Ridge, TN 37831-8080

\section{Professional Experience}

1962: $\quad$ MD, University of Dublin, Ireland

1949-1970: Clinical appointments, Asst. Professor of Physiology

University of Dublin, Ireland and

Physiologist, Argonne National Laboratory

1970-1977: Professor, Department of Radiology, University of Chicago

1977-1992: Head, Cancer Biology Section, Biology Division

Oak Ridge National Laboratory

1991-present: Consultant, Oak Ridge National Laboratory

Recent Related Professional Activities

Editor, Radiation Research (since 1988);

Member, NCRP Committee (since 1988) and ICRP Committee (1985-1992)

Member, IOM Committee to study Military Personnel Present at Atmospheric

Tests of Nuclear Weapons (since 1993).

BNL Scientific Advisory Committee for Radiobiology (1995-1997)

Chairman, Advisory Committee for LBNL-CSU NSCORT Program (since 1992)

Chairman, NASA Radiation and Environmental Health Discipline Working Group (since 1988)

\section{Recent Relevant Publications}

1. Fry RJM. 1992. The role of animal experiments in estimates of radiation risk Adv. Radiat. Biol. 16: 181-197.

2. Money K, Winishoerffer F, Gorshretz V, Uri J, Cheung B, Case C, Smith J, Fry RJM. 1993. Human factors and physiological aspects of the Mars mission. ACTA Astronautica. 31: 72-78 .

3. Alpen EL, Powers-Risius P, Curtis SB, DeGuzman R, Fry RJM. 1994. Fluencebased relative biological efectiveness for charged particle carcinogenesis in mouse Haderian gland. Adv. Space Res. 14: 573-581.

4. Fry RJM. 1996. Effects of low doses of radiation. Health Physics 70: 823-827.

\section{Current Research Funding - None}

Current Use of Anmials in Research - None 


\section{Philip Hanawalt, Ph.D}

\section{Current Position}

Professor, Department of Biological Sciences

Stanford University

Stanford, CA 9433055020

Professional Experience

1959: Ph.D. in Biophysics, Yale University

1958-1961: Postdoctoral work at University of Copenhagen (Maaløe) and Cal Tech

(Sinsheimer)

1961-present: Faculty Member, Department of Biological Sciences, Stanford University

1982-1989: Chair, Department of Biological Sciences, Stanford University

Recent Related Professional Activities

External Advisory Board, Environmental Health Sciences Center, UTMB, Galveston (since 1994)

Scientific Advisory Board, Office of Environmental Health Hazard Assessment, California EPA (since 1994)

Board on Radiation Effects Research, NAS/NRC Commission on Life Sciences (since 1995)

Fogarty International Center Scientific Advisory Board, NIH (since 1995)

Toxicology Advisory Committee, The Burroughs-Wellcome Fund (since 1995)

Outside Review Committee for LBNL-NSCORT Program (since 1991)

Managing Editor, Mutation Research DNA Repair (1982-1993)

Associate Editor - Cancer Research (since 1984), Environmental Health Perspect. (since 1993), Molecular Carcinogensis (1988)

Recent Relevant Publications

1. Donahue BA, Yin S, Taylor J-S, Reines D, Hanawalt PC. 1994. Transcript cleavage by RNA polymerase II arested by a cyclobutane pyrimidine dimer in the DNA template. Proc. Natl. Acad. Sci. USA. 91: 8502-8506.

2. Hanawalt PC. 1994. Transcription-coupled repair and human disease. Science 266: 1957-1958.

3. Islas AL, Hanawalt PC. 1995. DNA repair in the MYC and FMS proto-oncogenes in ultraviolet light-irradiated human HL60 promyelocytic cells during differentiation. Cancer Res. 54: 336-341.

4. Ford JM, Hanawalt PC. 1995 Li-Fraumeni syndrome fibroblasts homozygous for p53 mutations are deficient in global DNA repair but exhibit normal transcription-coupled repair and enhanced UV-resistance. Proc. Natl. Acad. Sci. USA 92: 8876-8880.

Current Research Funding

$\mathrm{NIH}$ research grants

Current Use of Animals in Research - none 
Michael B. Kastan, M.D., Ph.D.

Current Position

Associate Professor of Oncology

Associate Professor of Pediatrics

Joint appointment, Molecular Biology and Genetics

Johns Hopkins University School of Medicine

Baltimore, MD 21205

Professional Experience

1984: M.D., Ph.D. at Washington University School of Medicine 1984-1989: Intern, resident, clinical fellow in Pediatrics at JHU

1986-1989: Clinical fellow in Oncology at JHU

1989-1993: Assistant Professor of Oncology and Pediatrics at JHU

1993-Present: Associate Professor of Oncology and Pediatrics at JHU

Recent Related Professional Activities

Associate Editor-Molecular Carcinogenesis, Clinical Cancer Research

Editorial Board-Apoptosis, Intl. J. Oncology

NIH Radiation Study Section (1995-present)

Board of Advisors - Grace Cancer Drug Center

Recent Relevant Publications

1. Hartwell LH, Kastan MB. 1994. Cell cycle control and cancer. Science 266: 18211828.

2. Canman CE, Gilmer T, Coutts S, Kastan MB. 1995. Growth factor modulation of p53-mediated growth arrest vs. apoptosis. Genes \& Development. 9: 600-611.

3. Chen C-Y, Hall I, Lansing TJ, Gilmer TM, Tlsty TD, Kastan MB. 1996. Separate pathways for p53 induction by ionizing radiation and PALA. Cancer Res. 56: 36593662.

4. Kastan MB, (Ed.). 1997. Genetic Instability and Tumorigenesis. In: Current Topics in Microbiology and Immunology. Springer-Verlag, Berlin/Heidelberg.

Current research funding

NIH research grants; grants from Glaxo, Leukemia Society of America

Current use of animals in research

none 


\section{Louise Lutze-Mann, Ph.D.}

\section{Current Position}

Assistant Research Biologist

Laboratory of Radiobiology and Environmental Health

University of California (UCSF)

San Francisco, CA 94143-0750

\section{Professional Experience}

1981: Ph.D. in Biochemistry, University of New South Wales, Australia 1982-1985: Senior Research Officer, School of Microbiology, UNSW

1986-1987: Postdoctoral work at UCSF (Cleaver)

1987-1988: Visiting Research Fellow, Prince of Wales Hospital, Australia

1988-1992: Visiting Postgraduate Research Biologist, Laboratory of Radiobiology and Environmental Health, UCSF

1992-Present: Assistant Research Biologist, LREH, UCSF

\section{Recent Related Professional Activities}

Reviewer for radiation biology journals such as Radiation Research, Mutagenesis, International Journal of Radiation Research, Mutation Research, etc., and invited speaker at national and international meetings on radiation biology.

\section{Recent Relevant Publications}

1. Lutze LH, Cleaver JE, Morgan WF, Winegar RA. 1993. Mechanisms involved in rejoining DNA double-strand breaks induced by ionizing radiation and restriction enzymes. Mutation Res. 299: 225-232.

2. Winegar RA, Lutze LH, Hamer JD, O'Loughlin KG, Mirsalis JC. 1994. Radiation-induced point mutations, deletions, and micronuclei in lacI transgenic mice. Mutation Res. 307: 479-487.

3. Mitchell DL, Cleaver JE, Lutze LH. 1994. Excision of cyclobutane dimers in genomic and episomal DNA in human cells. Photochem. Photobiol. 60: 221224.

4. Lutze LH, Cleaver JE, Winegar RA. 1994. Factors affecting the frequency, size, and location of ionizing radiation-induced deletions in human cells. In: "Molecular Mechanisms in Radiation Mutagenesis, and Carcinogenesis," KH Chadwick, R Cox, H Leenhauts, J Thacker, (Eds.), European Commission, Luxembourg, pp. 41-46.

Current Research Funding

Electric Power Research Institute Contract, NASA research grant

Current Use of Animals in Research - Mice 


\section{Kenneth A. Souza, MS}

Current Position

Associate Director for Life Sciences

Ames Research Center, NASA

Moffett Field, CA 94035-1000

\section{Professional Experience}

1971: MS in Microbiology, California State University, San Jose

1966-1975: Microbiologist, Planetary Biology Div., Ames Reserach Center (NASA)

1975-1976: Technical Assistant to Chief, Planetary Biology and Quarantine

Programs, NASA Headquarters

1976-1981: Manager, US/USSR Biological Satellite (COSMOS) Project;

Ames Research Center

1981-1985: Assistant Chief, Biomedical Research Division

Ames Research Center

1986-1993: Chief, Space Life Sciences Payloads Office, Ames Research Center 1994-present: Associate Director for Life Sciences, Ames Research Center

Recent Related Professional Activities

Spacelab-J Investigators Working Group (since 1985)

US/Japan (NASDA) Life Sciences Joint Work Group (since 1985)

US/France (CNES) Life Sciences Joint Working Group (since 1987)

US/ESA Life Sciences Joint Working Group (since 1985)

US/Russia Joint Working Group (since 1977)

Intl. Space Life Sciences Working Group (since 1991)

US/Canada (CSA) Life Sciences Joint Working Group (since 1994)

US/Germany (DARA) Life Sciences Joint Working Group (since 1994)

Amer. Soc. for Gravitation Space Biol.; Board of Governor's since 1994,

Secretary/Treasurer since 1996

\section{Recent Relevant Publications}

1. Miguel J, Souza KA. 1991. Gravity effects on reproduction, development and aging. Adv. Space Biol. Med. 1: 71-97.

2. Souza KA, Black S, Wassersug R. 1995. Amphibian development in the virtual absence of gravity. Proc. Natl. Acad. Sci., USA. 92: 1975-1978.

3. Black SK, Larkin N, Jacqmotte R, Wassersug R, Souza K. 1996. Regulative development of Xenopus laevis in microgravity. Adv. Space Res. 17: 209-217.

Current Research Funding - No longer engaged in independent research; manages NASA grant program

Current Use of Research Animals - Manages Ames Life Sciences Division which is responsible for conduct of internal research and oversight of external use of animals while flying on NASA spacecraft 


\section{Robert Ullrich, Ph.D.}

\section{Current Position}

Professor and Director, Biology Division

Department of Radiation Therapy

University of Texas Medical Branch

Galveston, TX 77555-0656

\section{Professional experience}

1974-1988: Research Associate, Staff Scientist, Senior Scientist, Biology Division, Oak Ridge National Laboratory

1988-present: Professor and Director, Biology Division, Department of Radiation Therapy, University of Texas Medical Branch

1992-present: Vice-Chairman, Department of Radiation Therapy, University of Texas Medical Branch

Recent Related Professional Activities

Associate Editor, Radiation Research (1983-1990)

NCRP, Council Member (1988-2000); Scientific Committee 1-3 on Collective Dose (1990-1992)

NAS/NRC, Panel on Space Radiation Effects Committee on Space Biology and Medicine, Space Studies Board (since 1995)

$\mathrm{NIH}$, Cancer Center and Research Programs, Subcommittee C-Basic Sciences (since 1994)

Recent Relevant Publications

1. Ullrich RL, Alien B, Lee W, Satterfield LC, Jernigan MC. 1992. Induction of phenotypically altered mammary epithelial cells by neutrons and gamma rays. Radiation Res. 129: 102-106.

2. Hanania EG, Au WA, Ullrich RL, Papaconstantinou J. 1994. Involvement of the retinoblastoma gene in a mouse mammary tumor model. Cancer Res. Ther. Control 4: 67-76.

3. Selvanayagam CS, Davis CM, Cornforth MN, Ullrich RL. 1995. Latent expression of p53 mutations and radiation-induced mammary cancer. Cancer Res. 55: 3310-3317.

4. Hanania EG, Au WW, Ullrich RL, Papaconstantinou J. 1995. Regulation of retinoblastoma gene expression in a mouse mammary tumor model. Cancer Gene Ther. 2: 251-261.

Current Reserach Funding

NIH research grant

Current Use of Animals in Research - mice 
Jan Vijg, Ph.D.

Current Position

Director, Molecular Genetics Section

Gerontology Division

Department of Medicine

Beth Israel Hospital

Harvard University

Boston, MA 02215

Professional Experience

1987: Ph.D, University of Leiden, The Netherlands

1987-1990: Research Associate, TNO Institute for Experimental Gerontology Head, Department of Molecular Biology

1990-1993: Lecturer in Medicine, Harvard University Medical School, Division on Aging

1993-present: Associate Professor of Medicine, Harvard Medical School

Recent Related Professional Activities

Scientific Director, Ingeny, Leiden, The Netherlands (1990-1993)

Scientific Advisor (since 1993)

Founder, Chairman of Board, Biomedical Study Group on Etiology of Aging, the Dutch Organization MEDIGON (1985-1990)

Founder, Project Manager of the EC "EURAGE Molecular Biology Research Group (1987-1990)

Managing Editor, "Mutation Research, DNAging" (since 1988)

Recent Relevant Publications

1. Gossen JA, Martus H-J, Wei JY, Vijg J. 1995 Spontaneous and X-ray-induced deletion mutations in a lac $\mathrm{Z}$ plasmid-based transgenic mouse model. Mutation Res. 331:89-97.

2. Boerrigter METI, Dolle' MET, Martus H-J, Gossen JA, Vijg J. 1995. Plasmidbased transgenic mouse model for studying in vivo mutations. Nature 377:657-659.

3. Mullaart E, Verwest AM, Borglum AD, Uitterlinden AG, te Meerman GJ, Kruse TA, Vijg J. 1995. Two-dimensional DNA typing of human pedigrees: spot pattern characterization and segregation. Genomics 29: 641-646.

4. Dolle' M, Martus H-J, Gossen JA, Boerrigter METI, Vijg J. 1996. Evaluation of a plasmid-based transgenic mouse model for detecting in vivo mutations. Mutagenesis 11:111-118.

Current Research Funding

NIH research grant, Massachusetts Department of Public Health research grant, Cystic Fibrosis Foundation research grant; industry

Current Use of Animals in Research - mice, rats 
Huber R. Warner, Ph.D.

Current Positon

Assistant Deputy Head

Life Sciences Division

Lawrence Berkeley National Laboratory

Berkeley, CA 94720

\section{Professional Experience}

1962: Ph.D. in Biochemistry, University of Michigan

1962-1964: Postdoctoral work at MIT (Buchanan)

1964-1984: Member of faculty, Department of Biochemistry, University of Minnesota

1984-1995: Extramural Program Manager, Branch Chief, Deputy Associate

Director, Biology of Aging Program, National Institute on Aging, NIH 1995-present: Assistant Deputy Head, LSD, LBNL

Recent Related Professional Activities

Program manager of extramural research program on molecular biology of aging (since 1984).

Recent Relevant Publications

1. Warner HR. 1994. Superoxide dismutase, aging and degenerative disease. Free Radical Biol. Med. 17: 249-258.

2. Warner HR, Fernandes G, Wang E. 1995. A unifying hypothesis to explain the retardation of aging and tumorigenesis by caloric restriction. J. Gerontol. 50A B107-B109.

3. Warner HR, Starke-Reed PE. 1996. Oxidative stress and aging, in "Oxygen, Gene Expression and Cellular Function". LB Clerch, D Massoro, Eds, Marcel Dekker, Inc. NY, NY (in press).

4. Warner HR. 1996. Aging and regulation of apoptosis, in "Current Topics in Cellular Regulation", ER Stadman, Ed. 35 (in press).

Current Research Funding- none

Current Use of Animals in Research - none 
